*als Fiew/Print Document Cover Sheet tow

This document was retrieved from the Documentation and Records Management (DRM) ISEARCH System. It is intended for Information only and may not be the most recent or updated version. Contact a Document Service Center (see Hanford Info for locations) if you need additional retrieval information.

Accession \#: D196025248

Document \#: SD-GN-HC-20002

Title/Desc:

CATEGORY 3 THRESHOLD QUANTITIES FOR HAZARD CATEGORIZATION OF NONREATOR FACILITIES

Pages: 172 


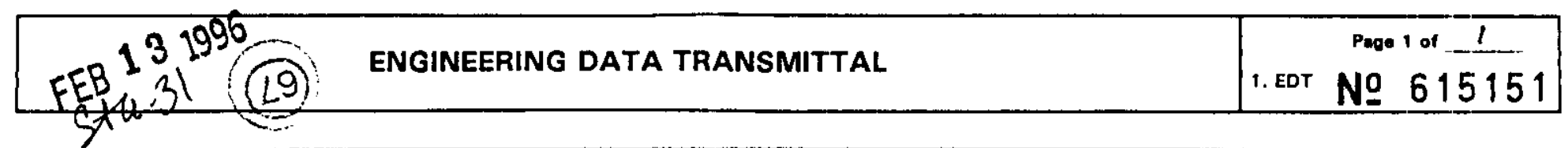

2. To: (Receiving Organization)

Distribution

5. Proj./Prog./Dept./Div.:

31E00, M3E4A

8. Originator Remarks:

This document will allow the determination of Hazard Category 3 Threshold Quantities of isotopes not listed in WHC-CM-4-46, Section 4. Table 1.
3. From: (originating Organization) Nuclear Safety Programs and Projects

6. Cog. Engr.:

C. Brad Evans
4. Related EDT No.:

$\mathrm{N} / \mathrm{A}$

7. Purchase Order No.: $\mathrm{N} / \mathrm{A}$

9. Equip./Component No.: $N / A$

10. System/Bldg./Facility: $\mathrm{N} / \mathrm{A}$

12. Major Assm. Dwg "No.: $N / A$

13. Permit/Permit Application No.: $\mathrm{N} / \mathrm{A}$

14. Required Response Date: $1 / 26 / 96$

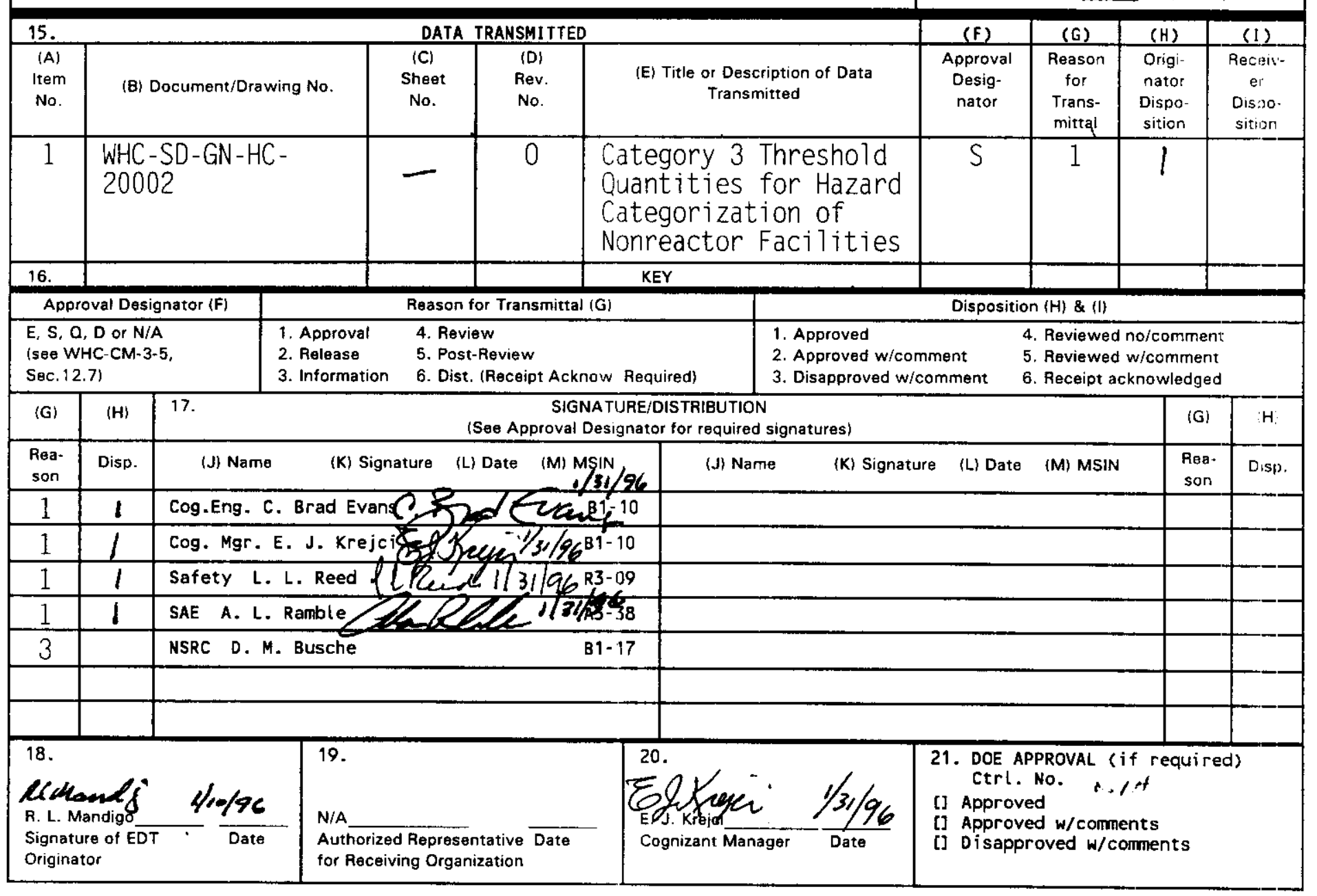

BD-7400-172-2 (04/94) GEF097 


\title{
Category 3 Threshold Quantities for Hazard Categorization of Nonreactor Facilities
}

\author{
R. L. Mandigo / C. Brad Evans
}

Westinghouse Hanford Company. Richland. WA 99352

U.S. Department of Energy Contract DE-AC06-87RL10930

$\begin{array}{ll}\text { EDT: } 615151 & \text { UC: } 500 \\ \text { Org Code: } 31 E 00 & \text { Charge Code: M3E1A } \\ \text { B\&R Code: YN0100000 } & \text { TotaT Pages: } 162\end{array}$

Key Words: Hazard, Category 3. Threshold Quantities

Abstract: This document provides the information necessary to determine Hazard Category 3 threshold quantities for those isotopes of interest not listed in WHC-CM-4-46. Section 4. Table 1. "Threshold Quantities".

TRADEMARK DISCLAIMER. Reference herein to any specific comercial product, process, or service by trade name, trademark, manufacturer, or otherwise, does not necessarily constitute or imply its endorsement, recommendation, or favoring by the United States Government or any agency thereof or its contractors or subcontractors.

Printed in the United States of America. To obtain copies of this document contact: WHC/RCS Document Control Services, P.O. Box 1970, Mailstop H6-08, Rightand WA 99352, Phone (509) 372-2420; Fax (509) 376-4989.
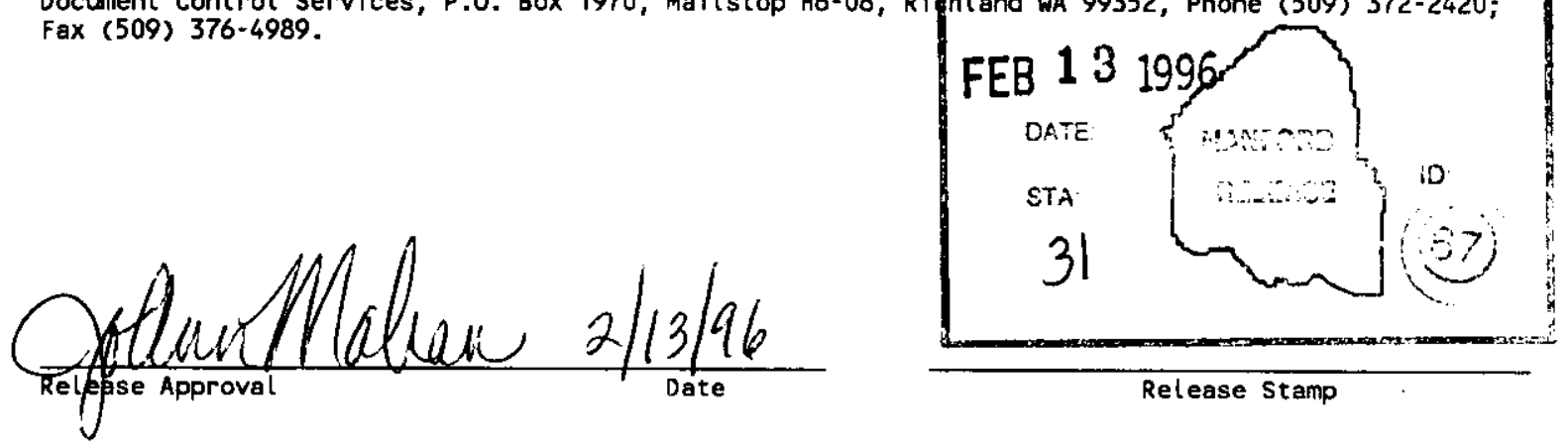

Approved for Public Release 
EDT 615151

WHC-SD-GN-HC-20002, REV. 0

ATTACHMENT

TECHNICAL BACXGROUND DOCUNENT TO SUPPORT FIRAL RULDARENG PURSUART TO SECTION 102 OF THE COAPREHTASIVE ENVIRONRENTAL RESPONSE, COAPENSATION, AND LIABILITY ACT: RADIONOCLIDES

\author{
A Report to the \\ BIRGENCY RESPOASE DIVISION \\ Office of Eergency and Rewedial Response \\ U.S. Enviromental Protection Agency
}

February 1989

Prepared by:

ICF INCORPORATED and

C-I Eavirotidaital

EPA Contract 68-03-3452 
WHC-SD-GN-HC-20002, REV. 0

This Page Left Blank 


\section{Category 3 Threshold Quantities for Hazard Categorization of Nonreactor Facilities}

\subsection{Introduction}

The purpose of this document is to provide the category 3 threshold quantities for radionuclides that are not listed in DOE-STD-1027-92, Hazard Categorization and Accident Analysis Techniques for Compliance with DOE Order 5480.23, Nuclear Safety Analysis Reports, as provided by WHC-CM-4-46, Safety Analysis Manual, Chapter 4.0, "Determining and Documenting Facility Hazard Category."

For unlisted radionuclides, DOE-STD-1027-92 directs the user to consult the U.S. Department of Energy (DOE), NE-70, for category 3 threshold quantities (TQs). The Attachment of this document provides the complete set of category $3 \mathrm{TQs}$ available from DOE.

\subsection{Methodology}

DOE-STD-1027-92 states that the basis for the category 3 TQs is a modification of the U.S. Environmental Protection Agency (EPA) definition of reportable quantities (RQs) for radionuclides contained in 40 CFR 302.4, Appendix B. As discussed in the Attachment, the RQ values are based on the radionuclide activity which, if subjected to release mechanisms, would produce less than 500 mrem dose-equivalent at a receptor distance of 30 meters based on a 24-hour exposure using the most limiting of four dose pathways. The calculated activity is then rounded down into one of seven RQ categories (from $0.001 \mathrm{Ci}$ to $1000 \mathrm{Ci}$ ).

For the purpose of category 3 TQs, DOE uses a limiting dose of 10 rem dose-equivalent but retains the other EPA parameters ( 30 meters, 24 hours, dose-limiting pathway). DOE does not round down this calculated value, and does not provide the option of selecting other dose pathways, release fractions, or other parameters specific to the hazards analysis. Such manipulation of the category 3 TQs is inappropriate; the methods used to determine hazard category thresholds are not intended to duplicate hazards and accident analysis techniques except as provided by WHC-CM-4-46, Chapter 4.0 for the final hazard categorization.

\subsection{Procedure}

For selecting category 3 TQs for radionuclides not listed in DOE-STD-1027-92 as provided by WHC-CM-4-46, Chapter 4.0:

a. Find the radionuclide of interest in Appendix E of the Attachment.

b. Select the most limiting threshold value (lowest value) from those provided under Ingestion (food), Ingestion (water), Inhalation, and Direct Exposure. This limiting value is indicated by a superscript star $\left(^{\star}\right)$ adjacent to that value.

c. Multiply the limiting value by twenty (20) to determine the category $3 \mathrm{TQ}$.

d. Repeat for all applicable radionuclides. 
This Side Left Blank

$$
i-a
$$




\section{TABLE OF CONTENTS}

CHAPTER 1: BACKGROUND AND INTRODUCTION $\ldots \ldots \ldots \ldots \ldots \ldots \ldots \ldots \ldots \ldots$

1.1 Background on CERCLA and RQ Notification Requirements ...... $1-1$

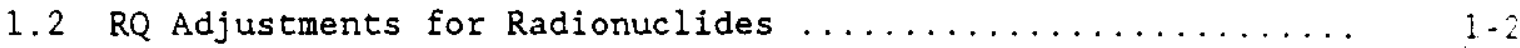

1.3 The Scope of the Radionuclide Release Problem ........... 1.5

1.3.1 The Affected Community .................. $1-6$

1.3.2 Radionuclide Release History $\ldots \ldots \ldots \ldots \ldots \ldots \ldots \ldots \ldots$

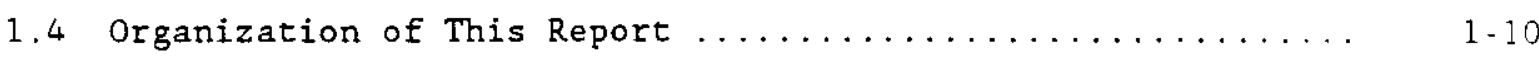

CHAPTER 2: OPTIONS FOR THE ADJUSTMENT OF RADIONUCLIDE RQS $\ldots \ldots \ldots 2-1$

2.1 Option 1: Allowing the Radionuclide RQ to Remain at

One Pound ............................. 2.1

2.2 Option 2: Considering Radionuclides as a Generic Class of Substances, Without an RQ and Not Subject to CERCLA

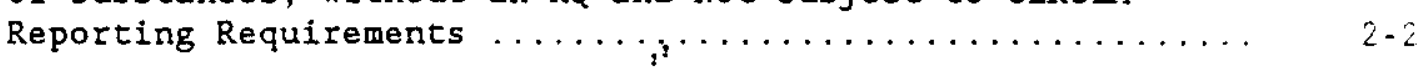

2.3 Option 3: Establishing a Dose-Equivalent Level as the

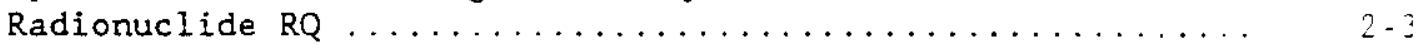

2.4 Option 4: Considering Radionuclides as a Class with a

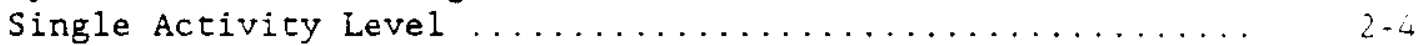

2.5 Option 5: Grouping Radionuclides into Categories with an Activity Level Assigned to Each of the Separate



2.6 Option 6: Establishing an Activity Level RQ for Individual Radionuclides .................... 2 . $t$

CHAPTER 3: MAJOR ISSUES ASSOCIATED WITH THE SELECTED RQ

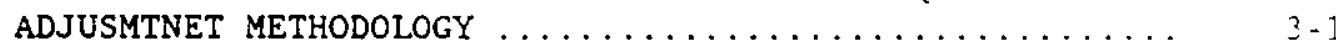

3.1 Departure from the Methodology for Adjusting RQs of Potential Carcinogens .................... 3.2

3.2 Incorporation of Radioactive Decay $\ldots \ldots \ldots \ldots \ldots \ldots \ldots \ldots \ldots$ 3-2

3.3 Assumed Distance Between the Point of Release and Point of Exposure ......................... 3-3

3.4 Assumed Configuration of Radionuclide Release .......... 3-4 


\section{TABLE OP CONTENTS}

\section{(continued)}

3.5 Modeling of Potential Exposures Through the Ingestion of Contaminated Vegetables .................... 3.5

3.6 Additional Exposure Pathway Models .............. 3.6

CHAPTER 4: METHODOLOGY FOR RQ ADJUSTMENTS $\ldots \ldots \ldots \ldots \ldots \ldots \ldots \ldots \ldots$

4.1 Overview of the Methodology $\ldots \ldots \ldots \ldots \ldots \ldots \ldots \ldots \ldots \ldots \ldots \ldots \ldots \ldots$

4.2 Release Values for the Inhalation Pathway ............ 4.2

4.3 Release Values for the Ingestion of Water ............ $4-j$

4.4 Release Values for the Ingestion of Food ............. 4.9

4.5 Release Values for the Direct Exposure Pathway ......... 4.12

4.5.1 Direct Exposure from a Point Source ............. 4-12

4.5.2 Submersion in a Radioactive Cloud of Noble Gas ..... 4.16

4.6 Assignment of Radionuclides to RQ Groups $\ldots \ldots \ldots \ldots \ldots \ldots \ldots$

4.7 Reporting Requirements for Mixtures of Radionuclides ...... 4.19

4.7.1 Mixtures of known Composition .............. 4.19

4.7 .2 Mixtures of Unknown Composition ............... 4.20

4.7 .3 Common Radionuclide Mixtures ................. 4.20

4.8 Reporting Requirements for Compounds and Mixtures of

Radionuclides and Other Hazardous Substances ........... 4-21

APPENDIX A: Modeling the Airborne Release and Inhalation of

Radionuclides .......................... A

APPENDIX B: Modeling the Ingestion of Contaminated Drinking

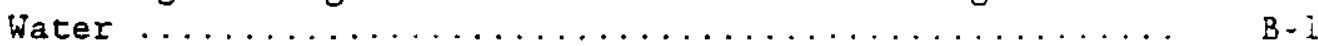

APPENDIX C: Modeling the Ingestion of Contaminated Foodstuffs $\because \ldots \ldots \quad C-1$

APPENDIX D: Modeling of Direct Exposure to Radionuclides ......... D-1

APPENDIX E: Release Values and Final RQs $\ldots \ldots \ldots \ldots \ldots \ldots \ldots \ldots \ldots \ldots$ 


\section{BACRGROUND AND INIRODUCTION}

This report discusses the options that were considered by the U.S. Environmental Protection Agency (EPA) for adjusting the one-pound statutory reportable quantity (RQ) for radionuclides, and presents in detail the option and method the Agency has selected.

This chapter outlines the general reporting requirements under sections 103(a) and (b) of the Comprehensive Environmental Response, Compensation, and Liability Act (CERCLA) and the specific reporting requirements for radionuclides. Section 1.1 describes CERCLA reporting requirements and the types of potential response activities triggered by CERCLA reporting; Section 1.2 describes the statutory authority for and the intended purpose of the RQ adjustment for radionuclides; Section 1.3 explains the scope of the radionuclide release problem; and Section 1.4 introduces the remaining chapters of this report.

\subsection{BACKGROUND ON CERCLA AND RQ NOTIFICATION REQUIREMFNTS}

CERCLA, as amended by the Superfund Amendments and Reauthorization Act of 1986 (SARA), establishes broad federal authority to respond to releases or threats of releases of hazardous substances from vessels and facilities. Th.e Act requires immediate notification to the National Response Center when a hazardous substance designated under CERCLA is released into the environment. in an amount equal to or greater than the $R Q$ for that substance.

Section 101(14) of CERCLA defines as a CERCLA hazardous substance any substance designated under:

- Sections 307 and 311 of the Clean Water Act;

- Section 3001 of the Resource Conservation and Recovery Act;

- Section 112 of the Clean Air Act; and

- Section 7 of the Toxic Substances Control Act.

In addition, EPA has the authority under section 102(a) of CERCLA to designate additional hazardous substances. Currently, there are 721 CERCLA hazardous substances, excluding radionuclides. Radionuclides are hazardous substances under CERCLA because they were designated generically as a hazardous air pollutant pursuant to section 112 of the Clean Air Act. Section 102(b) of CERCLA establishes a one-pound RQ for radionuclides, but section 102(a) authorizes EPA to adjust this statutory RQ by regulation. RQ adjustments for radionuclides were proposed in a Notice of Proposed Rulemaking on March 16 , 1987 (52 FR 8172).

Under regulations implementing the general reporting requirements of sections 103(a) and (b) of CERCLA, a person in charge of a vessel or facility is required to notify the National Response Center immediately when there is a release of a designated hazardous substance in an amount that equals or 
exceeds the RQ for that substance ( 40 CFR 302.6(a)). In addition, SARA section 304 requires facility owners or operators to immediately notify state and local officials after the release of an $R Q$ or more. SARA section 304 notification requirements apply only to releases that have potential for off. site exposure and that are from facilities that produce, use, or store a "hazardous chemical," as defined by regulations under the Occupational Safety and Health Act of 1970 (29 CFR 1910.1200(c)) and section 311 of SARA. Those persons required to notify but who knowingly fail to report immediately the release of an $R Q$ are subject to criminal penalties under CERCLA section 103(b). Releases that are federally permitted, as defined by section 101(10), are exempt from the Section 103 notification requirements.

It is important to clarify that the immediate reporting requirements of CERCLA section 103 apply to releases of an RQ or more within a 24-hour period. Persons who frequently release an $R Q$ or more in 24 hours may qualify for reduced reporting. Specifically, section $103(f)(2)$ of CERCLA provides a reduced reporting provision for releases of an $R Q$ or more that are "continuous" and "stable in quantity and rate." Such releases only need to be: reported annually and when there is a statistically significant increase in the quantity of the hazardous substance released. Persons who do not release an $R Q$ in 24 hours do not have to report at all.

The purpose of RQ notification is to alert appropriate government agencies to releases of hazardous substances that may require rapid response to protect public health or welfare or the environment. For example, under section 104 of CERCLA, the federal government may take response action whenever there is a release or a substantial threat of a release of a hazardous substance or of any pollutant or contaminant that may present an imminent and substantial danger to public health or welfare. 1 Notification based on RQs serves to inform the government of a release, thereby enabling ar. evaluation of the situation and a timely field response should one be deemed necessary. The release of an $R Q$ does not necessarily mean that there will be a hazard. Similarly, notification does not necessarily mean that a federal field response will occur, nor does it eliminate liability or responsibility for response costs or natural resource damages associated with the release.

\subsection{RQ ADJUSTMENTS FOR RADIONUCLIDES}

There are approximately 1,500 known radionuclides. A radionuclide is an isotope with an unstable combination of protons and neutrons in its nucleus. Instability is the result of an imbalance in repulsive and attractive forces between these two types of nuclear particles. To achieve a more stable configuration, the nucleus releases energy in the form of particles or rays by a process of decay called radioactivity. Each radionuclide decays by a specific mechanism and at a specific rate and, as a result, a pound of two different radionuclides could represent significantly different types and levels of radioactivity.

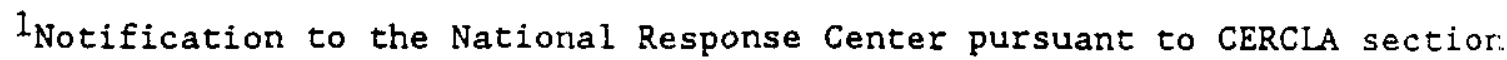
103 is limited to releases of designated hazardous substances in amounts that equal or exceed the applicable RQ. Releases consisting solely of pollutants or contaminants that are not designated as hazardous substances under CERCLA need not be reported to the National Response Center. 
There are four types of emissions from radionuclides during the decay process that may have a significant impact on human health or welfare or the environment: alpha particles, beta particles, gamma rays, and neutrons (which are also particles). The particles and rays differ in their mass, charge, energy content, and range of penetration and potential damage in surrounding media.

Alpha particles consist of two protons and two neutrons and have a positive charge of 2 . Alpha particles possess energies in the range of 2 to 12 million electron volts ( $\mathrm{MeV}$ ), with typical values falling between 4 and? $\mathrm{MeV}$. Alpha particles travel only short distances in matter and are highly disruptive in tissue because of their large mass, relatively high speed, and large charge. In general, alpha particles present no external hazard because of their short range, but do present a significant internal hazard when taken into the body.

Beta particles are either electrons or positrons (positively charged electrons). The energy range of beta particles is $0.02 \mathrm{MeV}$ to $14 \mathrm{MeV}$, with typical values falling between 0.04 and $6 \mathrm{MeV}$. Beta particles are more penetrating (i.e., have a longer range in matter) than alpha particles, and are more easily scattered and are less disruptive than alpha particles. Beta particles are primarily internal hazards, although certain high energy beta particles also may present an external hazard at relatively close range.

Gamma rays are photons that have no mass and no charge, and possess energies in the range of 0.01 to $10 \mathrm{MeV}$. Gamma rays are not scattered easily, can be very penetrating, and are of most concern as potential external hazards.

Neutrons have no net charge and a mass that is slightly larger than that of a proton. They are emitted from a variety of sources, most of which are man-made (e.g., mixtures of certain radioactive sources and target substances, collisions of high-speed particles in accelerators, and fissions in a nuclear reactor). However, neutrons also may be emitted naturally from a handful of transuranic elements and uranium isotopes that undergo spontaneous fission. Along with gamma rays, neutrons are of most concern as potential external hazards.

As noted previously, radionuclides were designated generically as hazardous air pollutants under section 112 of the Clean Air Act and are, therefore, designated CERCLA hazardous substances. Section 102 of CERCLA establishes a one-pound reportable quantity for radionuclides, as a generic class of substances, but authorizes EPA to adjust this RQ by regulation. EPA recognizes that an $R Q$ of one pound for radionuclides is not an appropriate level in most cases because releases of less than one pound of a radionuclide may present a substantial danger to public health or welfare or to the environment. In addition, "pound" units are not commonly used for measuring quantities of radionuclides.

CERCLA hazardous substances other than radionuclides have reportable quantities ranging from one pound to 5000 pounds. For these substances, the principal health concerns are chemical toxicity, ignitability, reactivity, or potential carcinogenicity. These criteria may be related to a specific number: of pounds of the hazardous substance released. Radionuclides are very 


\section{$1 \cdot 4$}

different from other CERCLA hazardous substances because the principal health hazard associated with most radionuclides is the potential for cancer caused by exposure to radioactivity. Although the level of radioactivity for a given radionuclide is directly proportional to its mass, equal masses of different radionuclides will not produce equal adverse health and environmental effects. For this reason, activity levels are used most generally as indicators of radiation intensity and potential hazard. The quantity of radioactivity is measured in units of curies ${ }^{2}$ (Ci) and, for different radionuclides, the same number of pounds translates into a different number of curies. Thus, the statutory one-pound RQ translates into a wide range of curies for different radionuclides, covering at least twenty orders of magnitude.

In addition to curies, another widely used unit for measurement of radiation hazard is the rem (originally Roentgen Equivalent Man). The rem is a unit of measure for radiation dose-equivalent and is often expressed as some number of rem delivered to a specific organ such as the lungs, thyroid, or whole body. Whereas the curie is a measure of the quantity of radiation emitted, the dose-equivalent directly reflects the level of tissue damage. Curies can be converted into rem by considering an exposure scenario defined by such factors as the radionuclide identity, route and duration of exposure, quantity of intake, tissues most affected, type of radiation, and other factors that determine the hazardous effects of the radiation.

The nuclear industry in the United States generally uses units of curies and rem and, in fact, most existing reporting triggers for radionuclide releases are expressed in terms of one ox the other, or both, of these two units. ${ }^{3}$ In addition, essentially all existing regulations and controls established by the Nuclear Regulatory Commission and the Department of Energy. which govern a major portion of the nuclear industry, are based on units of curies or rem. Therefore, for the RQ under CERCLA to be consistent and meaningful, and to ensure that the radionuclide RQ allows for timely reporting and rimely field response, if necessary, the statutory one-pound $R Q$ is being adjusted by regulation. The $R Q$ adjustments are in units of curies.

The Agency is adjusting the RQ for 757 specific radionuclides for which the International Commission on Radiological Protection (ICRP) has provided metabolic data and recommended intake limits in ICRP Publication 30.4 All radionuclides not listed by the ICRP are grouped into a generic class of "radionuclides," with one RQ for the entire class. Chapters 3 and 4 of this report discuss the $\mathrm{RQ}$ adjustment process in more detail.

2 The curie is a measure of the rate of radioactive decay, with one curie equal to $3.7 \times 10^{10}$ disintegrations per second.

${ }^{3}$ Radiation measurements can also be expressed in international metric units of becquerels or sieverts; however, these terms are less common in the United States.

4 International Commission on Radiological Protection, Annals of the ICRP: Limits for Intakes of Radionuclides by Workers, ICRP Publication 30 , Part 2, 1980. 
The harmful effects of radiation on humans has been the focus of most $c f$ the research efforts concerning radiation exposure in the past. EPA's mandate under CERCLA is, of course, concerned with the broader problem of potentially deleterious effects to the environment as well as to humans. In adjusting the radionuclide RQ, the Agency's goal is to ensure, to the extent possible, ample protection for the most sensitive species of flora and fauna. The Agency reviewed the existing literature and determined that present information indicates that protection of human health would be sufficiently protective of the environment as well. The National Academy of Science states:

The principal potential impact of radioactive effluents on the biosphere is the induction of deleterious health effects in man. Comparable levels of impact undoubtedly exist in other biota, but there is no present evidence that there is any biological species whose sensitivity is sufficiently high to warrant a greater level of protection than that adequate for man. 5

In addition, the ICRP has stated as part of its recommended objectives that:
Although the principal objective of radiation protection is the achievement and maintenance of appropriately safe conditions for activities involving human exposure, the level of safety required for the protection of all human individuals is thought likely to be adequate to protect other species, although not nęcessarily individual members of those species. The Commis'sion therefore believes that if man is adequately protected then other living things are also likely to be sufficiently protected. ${ }^{6}$

The Agency has determined, therefore, that RQ adjustments for radionuclides developed with the goal of protecting public health will protect: the environment as well.

\subsection{THE SCOPE OF THE RADIONUCLIDE RETEASE PROBLEA}

Radionuclide emissions are most closely identified with the nuclear power industry, but are commonly released from other activities as well. The

${ }^{5}$ National Academy of Sciences, The Effects on Population of Exposure to Low Levels of Ionizing Radiation, Report of the Advisory Committee on the Biological Effects of Ionizing Radiation, National Research Council, Novembe: 1972 , P.11.

${ }^{6}$ International Commission on Radiological Protection, Recommendations of the International Commission on Radiological Protection (ICRP), Publication 26, January 1977, p. 3. 
Nuclear Regulatory Commission, Agreement States, ${ }^{7}$ and the Department of Energy (DOE) all license or oversee a variety of industrial facilities and non-industrial operations that emit radionuclides. In addition, several industrial categories not licensed by the Commission or an Agreement State potentially could release radionuclides. Coal-fired utilities and industrial boilers, and mineral extraction industries such as uranium, aluminum, $z$ inc, copper, lead, and phosphorous mining all release certain amounts of naturally occurring radionuclides during their operations. This section sumnarizes the types of facilities most likely to be affected by the RQ adjustments and reviews briefly the available data on past radionuclide releases.

\title{
1.3.1 The Affected Conmity
}

The Nuclear Regulatory Commission has authority under the Atomic Energy Act of 1954 to license source, byproduct, and special nuclear materials. 8 Agreement States also have authority under the Atomic Energy Act to license source, byproduct, and special nuclear materials at facilities within their boundaries. As of 1984, there were approximately 8,900 Comnission licensees

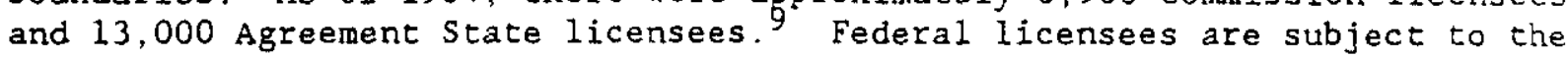
radioactive material release limits specified in $10 \mathrm{CFR}$ Part 20 , as well as other controls specified by the license and other regulations. Agreement State licensees are subject to release limits and reporting requirements specified in relevant state regulations, which generally are at least as restrictive as those in 10 CFR Part 20. Source, byproduct, and special nuclear material licensees can be divided into the following six general categories:

\author{
- power reactors: \\ - research and test reactors; \\ - nuclear fuel cyole facilities (other than reactors);
}

${ }^{7}$ Agreement States are states that have entered into an agreement with the Atomic Energy Commission or the Nuclear Regulatory Commission pursuant to section 274 of the Atomic Energy Act of 1954, as amended, under which the Commission has relinquished to such states the majority of its regulatory authority over source, byproduct, and special nuclear material in quantities not sufficient to form a critical mass.

${ }^{8}$ These terms are defined in Section 11 of the Atomic Energy Act. Source material is defined as (1) natural uranium (comprised of 99.27 percent $\mathrm{U}^{238}$, 0.72 percent $\mathrm{U}^{235}$, and 0.0057 percent $\mathrm{U}^{234}$ ), natural thorium ( $\mathrm{Th}^{232}$ ), or any combination thereof; or (2) ores that contain 0.05 percent (by weight) of uranium or thorium. Special nuclear material is defined as plutonium or uranium enriched in the $U^{235}$ or $U^{23}$ isotope (i.e., $U^{235}$ makes up more than 0.72 percent by weight). Byproduct material is defined as (1) any material made radioactive by exposure to radiation incident to the process of producing or utilizing special nuclear material; or (2) the wastes produced by the extraction or concentration of uranium or thorium from ore (e.g., Uranium Mill. Tailings).

${ }^{9}$ U.S. Nuclear Regulatory Commission, 1984 Annual Report, p. 73. 
- radiation source manufacturers; and

- other licensees, including laboratories, low-level waste disposal sites, certain mineral and metal processing facilities, and certain Department of Defense facilities, including the Armed Forces Radiobiology Research Institute and nine naval shipyards.

Agreement States may also license and/or regulate a fourth class of radioactive material called naturally occurring or accelerator-produced radioactive material (NARM). The States' authority to control NARM, however, is not federally derived because the only authority that can be relinquished to states by the Nuclear Regulatory Commission is the authority under the Atomic Energy Act to license source, byproduct, and special nuclear material One large category of NARM users 1icensed by Agreement States is low energy accelerators. Such accelerators are used for a wide variety of applications including radiography, activation analysis, food sterilization and preservation, radiation therapy, and research. As of 1984 , there were an estimated 1,500 low energy, accelerators in use in the U.S., not including accelerators owned by DOE. 10

The Atomic Energy Act authorizes DQE "to protect the public health and safety" with respect to the operation ot so-called "Goco" facilities -facilities that are "government owned, contractor operated." This authority applies to activities involving NARM, as well as activities involving source byproduct, and special nuclear material. As of 1980, 78 Goco facilities in 24 states were subject to DOE health and safety requirements. Currently, there are approximately 47 DOE facilities that actively use radionuclides; 11 some cf these facilities, such as the Hanford Installation, actually are comprised of numerous separate facilities that carry out different operations. Major DOE facilities include national laboratories, uranium enrichment faciliites, and facilities associated with: nuclear weapons research, development, and production; medical and biological research; and industrial applications and development. DOE also is responsible for managing several sites that are not active but contain radioactive contamination, such as sites associated with the Formerly Utilized Sites Remedial Action Program (FUSRAP), the Uranium Mill Tailings Remedial Action Program (UMTRAP), the Grand Junction Remedial Action Program (GJRAP), and the Surplus Facilities Management Program (SFMP). Radionuclide release limits and reporting requirements applicable to DOE facilities are set forth in a series of internal DoE orders issued under the authority of the Atomic Energy Act.

${ }^{10}$ U.S. Environmental Protection Agency, Radionuclides Background Information Document for Final Rules, Volume II, October 1984, p. 3.2-6.

$11_{\text {ICF }}$ estimate. 
Over 70 percent of the facilities that use materials containing radionuclides are not licensed by the Nuclear Regulatory Commission, an Agreement State, or by DOE. These facilities are discussed briefly below.

Large coal-fired boilers are used to generate electricity for public and industrial use and to provide process steam, process hot water, and space heat. More than 600 million tons of coal are burned each year in utility and industrial boilers. Coal contains mineral matter including trace quantities of naturally occurring radionuclides. Uranium-238 and thorium-232 and their decay products are found in coal, 12 however, based on sample results for five utility boilers, 13 less than three percent of the total quantity of radionuclides input from coal is usually released to the air. Solid wastes from coal-fired boilers (e.g., fly ash, bottom ash, slag, and scrubber sludges) are stockpiled commonly in large quantities on-site, and these wastes may contain low concentrations of naturally occurring radionuclides.

In early 1985, there were 1,281 coal-fired units operating in the utility industry, with a total generating capacity of 281 gigawatts. 14 Major users of coal-fired industrial boilers (producing process steam and hot water, generating electricity for the producers' own use, and providing space heat) include the steel, aluminum, chemical, and paper industries. There are an estimated 51,187 coal-fired industrial boilers operating in the United States. Radionuclide emission levels from large utility boilers are generally in the range of 0.01 curies per day; radionuclide emission levels from the smaller industrial boilers are generally in the range of 0.001 curies per day. 15

Almost all mineral extraction industries that involve the removal and processing of ores to recover metal release some radionuclides. The Agency has identified the following mineral extraction industries as having the greatest potential to release radionuclides to the air: the uranium mining industry, the aluminum industry, the copper industry, the zinc industry, the lead industry, and the phosphate industry. These industries were identified because of the large quantity of ore mined domestically and because the mining and processing operations conducted create a likelihood of radionuclide emissions. Except for the uranium mining industry, individual radionuclide emission levels to the air are generally in the range of 0.001 curies to 0.000001 curies per day from these facilities; uranium mines may emit more

12U.S. Environmental Protection Agency, Radionuclides Background Information Document for Final Rules, Volume II, October 1984, p.4.0.1.

13U.S. Environmental Protection Agency, Survey of Five Utility Boilers for. Radionuclide Emissions, Final Report, Office of Radiation Programs, Washington, D.C., December 1983, p. 3 .

14 ICF Energy Service, Summer/Fall 1985 Coal and Electric Utilities Market Assessment, p. $1+2$ (1985).

15U.S. Environmental Protection Agency, Radionuclides Background Information Document for Final Rules, Volume II, October 1984, p. 4.1-11 and p. $4.2-7$. 
than 30 -curies of radon per day. 16 similar to coal-fired boilers, facilities in these industries may stockpile large quantities of solid waste containing, generally low concentrations of naturally occurring radionuclides. There are numerous mines, mills, smelters, and other processing plants in each of these industries.

\subsubsection{Radionuclide Release History}

As part of this regulatory development process, release data were collected from the major federal agencies licensing, regulating, and controlling radionuclide releases: the Nuclear Regulatory Commission, the Department of Transportation, DOE, and EPA. The data were examined to understand the scope of the radionuclide release problem. The following release data were collected:

- Reports maintained by the Nuclear Regulatory Commission's Office for Analysis and Evaluation of Operational Data (AEOD), for the years 1981 through 1985 ;

- Reports maintained by the Transportation Technology Cencer (TTC) of Sandia National Laboratory in Albuquerque, New Mexico, for 1971 through 1985;

- Data provided by the Department of Energy's Office of Environment and Health, Bmergency Operations Center (EOC), for March 1983 through April 1986;

- Reports to the National Response Center, for 1982 through 1985;

- Reports to the EPA's Office of Radiation Programs (ORP), for October 1981 through September 1983; and

- Reports to the Nuclear Regulatory Commission's Operations Center, for January 1983 through January 1986.

The availability and quality of data varied from source to source, but duplication among the six sources appeared to be relatively limited.

The AEOD data include some 300 reports annually, although about two thirds of the reports are incidents involving monitoring compliance or some other technical infraction that does not involve radionuclide releases. The ITC data include between 1 and 12 reports annually of transportation inciderts involving radionuclide releases. These events already are required to be reported to the National Response Center under Department of Transportation regulations ( $49 \mathrm{CFR}$ Parts 171-177). The Department of Energy EOC data include 52 release events over a 3-1/2 year period (between 11 and 22 events annually)

16U.S. Environmental Protection Agency, Radionuclide Background Information Document for Final Rules, Volume II, October 1984, p. 7.1-8, $7.2-6,7.3-4,7.4-4,6.1-11,5-15$. 
and include releases that are reportable under DOE Order 5484.1. The National Response Center data include approximately 80 reports (about 30 reports annually) and the ORP data include approximately 60 reports (about 30 reports annually). The National Response Center data include little detail on the radionuclide identity and the quantity released. The ORP data reflect mosty releases from power reactors. The final data source, the Nuclear Regulatory Commission Operations Center, include data on 26 events (about 8 events annually).

Although the six data sources include a total of about 400 events annualiy, at least 200 of these annual events are not releases to the environment. Data are available, therefore, on approximately 200 release events annually. These data sources, however, do not cover releases from all. facilities that handle and that are, therefore, likely to release radionuclides. For example, releases from unlicensed facilities and releases from facilities in Agreement States would not be expected to be well represented in the data sets. In addition, not all types of radioactive material is well represented. One particular type of radioactive material that is not well represented in the data sets is NARM. Although Agreement States and DOE control NARM uses at facilities under their jurisdiction, there are no uniform regulatory or reporting requirements for NARM. Virtually all states, both agreement and non-agreement, have some type of NARM regulatory. program; 17 however, the data collected under these programs have not been gathered as part of this analysis because they were too diffuse. The available data, therefore, do not represent fully NARM releases.

\subsection{ORGANIZATION OF THIS REPORT}

This report discusses the various options considered for adjusting the one-pound $R Q$ for radionuclides and examines in detail the selected option. The remainder of this report is organized as follows:

Chapter 2: Options for the Adjustment of Radionuclide RQs - a review of the regulatory approaches considered and the one selected;

Chapter 3: Major Issues Associated with the Selected RO Adjustment Methodology -- a discussion of major technical issues raised in comments on the proposed $R Q$ rulemaking and changes made to the adjustment methodology in response to comments;

Chapter 4: Methodology for RQ Development - the technical analysis and establishment of $R Q$ values;

Appendix A: Modeling the Airborne Release and Inhalation of Radionuclides;

17U.S. Nuclear Regulatory Commission, Regulation of Naturally Occurring and Accelerator-Produced Radioactive Materials-An Update, NUREG-0976, October 1984, p. 3 . 


\section{$1-11$}

Appendix B: Modeling the Ingestion of Contaminated. Drinking Water;

Appendix C: Modeling the Ingestion of Contaminated Foodstuffs;

Appendix D: Modeling of Direct Exposure to Radionuclides; and

Appendix E: Release Values and Final RQs. 
This Side Left Blank 
Several options for adjusting radionuclide RQs were carefully examined during the development of the final regulation. Each option presented certain advantages and disadvantages but each of the rejected options was determined to be inferior to the selected approach. This chapter discusses the following regulatory options and explains the Agency's position and rationale for selecting option 6 , the approach used to develop the final RQs:

- Option 1: Allowing the radionuclide $R Q$ to remain at one pound;

- Option 2: Considering radionuclides as a generic class of substances, without an $R Q$ and not subject to CERCLA reporting requirements;

- Option 3: Establishing a dose-equivalent level as the radionuclide $R Q$;

- Option 4: Considering radionuclides as a class with a single activity level;

- Option 5: Grouping radionuclides into categories with an activity level assigned to each of the separate categories; and

- Option 6: Establishing an activity level RQ for individual radionuclides.

\subsection{OPTION 1: ALIOWING THE RADIONUCLIDE RQ TO REMAIN AT ONE POUND}

Section 102 (b) of CERCLA establishes the RQ for radionuclides at one pound. While a one-pound $R Q$ might be useful to ensure reporting of very large radionuclide releases, the Agency does not believe that this RQ level is appropriate to trigger timely reporting or timely field responses, if necessary, for releases of many radionuclides because releases of radionuclides that are several orders of magnitude smaller than one pound may represent a serious health and environmental threat. In addition, a one-pound $R Q$ does not conform to commonly accepted units of measurement for radionuclides. Most radiation measurements in the United States are in terms of curies or rem, 1 not pounds. A one-pound RQ level would, therefore, differ markedly from reporting requirements under other radionuclide regulations developed by EPA and other agencies.

$A$ one-pound RQ for the entire class of radionuclides would also not take into account the variety of hazards posed by different radionuclides. Because each radionuclide has a unique specific activity (i.e., a certain number of

$1_{\text {Radiation measurements can also be expressed in international units }}$ of becquerels or sieverts; however, these terms are less common in the United states. 
curies for one pound), a single one-pound RQ would relate to different numbers of curies .. and different radiation levels . - for each radionuclide. The Agency, therefore, concluded that a one-pound $R Q$ was not sufficiently protective of public health and welfare and the enviroment.

\subsection{OPTION 2: CONSIDERING RADIONUCLIDES AS A GENERIC CLASS OF SUBSTANCES, WITHOUT AN RQ AND NOT SUBJECT TO CERCLA REPORTING REQUIRERENTS}

In the April 4, 1985 final rule establishing notification requirements and adjusting RQs for certain hazardous substances (50 FR 13456), EPA decicied not to establish RQs for broad generic classes of organic and metallic compounds even though they are designated as toxic pollutants under section 307 (a) of the Clean Water Act and thus included in CERCLA's hazardous substance list. The reasoning for this decision, as stated in the preamble to that rule, was:

Many of the generic classes of compounds encompass hundreds or even thousands of specific compounds. It would be virtually impossible for the Agency to develop a reportable quantity that would take into account the varying characteristics of all the specific compounds in the class ( 50 FR 13461).

Because there are over 1,500 known radionuclides, the Agency considered using a similar approach for radionuclides; that is, not establishing an RQ for radionuclides and not requiring radionuclide releases to be reported to the National Response Center. In considering this approach, however, the Agency determined that the same technical argument could not be used to support a decision not to establish an $R Q$ for radionuclides. Although the term "radionuclides" encompasses hundreds of radioactive isotopes and countless chemical compounds involving these isotopes, it is possible to set a single $R O$ in terms of dose-equivalent ( $\mathrm{rem}$ ) for the generic class of radionuclides and still take into account some of the unique characteristics of individual radionuclides. Using a set of conservative exposure assumptions, it is also possible to set an $R Q$ in terms of activity levels (curies) for radionuclides based on a predetermined acceptable exposure level. The argument used for the generic classes of organic and metallic compounds, therefore, is not applicable entirely to radionuclides.

The Agency also considered establishing no RQ for radionuclides based on the finding that existing reporting mechanisms for radionuclide releases were adequate and that any additional reporting pursuant to CERCLA would provide no additional benefit. Under this approach, even without an RQ and therefore without a requirement to report releases of radionuclides under.CERCLA, radionuclides would remain listed as a hazardous substance and would be subject to CERCLA response and liability provisions. Elimination of an RQ for radionuclides would rely on existing reporting requirements of other agencies. This approach would minimize duplication of and conflicts with other federal and state reporting requirements

The Agency determined, however, that this option would not be sufficiently protective of public health and welfare and the environment. Less than one third of facilities that handle or produce radionuclides are 
licensed by the Nuclear Regulatory Commission, an Agreement State, or the Department of Energy. The regulation of NARM is fragmented, non-uniform, and incomplete. Releases of NARM generally are not subject to federal control and licensing, and state controls over NARM range from complete licensing programs to initial registration requirements. ${ }^{2}$ Releases from these facilities could go unreported if no RQ were to be established. The Agency concluded, therefore, that it would not be fulfilling its mandate under CERCLA if no RQ was established for radionuclides.

\subsection{OPTION 3: ESTABLISHING A DOSE-EQUIVAIEATT LEVEL AS THE RADIONUCLIDE RQ}

A dose-equivalent level is a direct measurement of the amount of biological damage resulting from exposure to ionizing radiation. Dose-equivalent is measured in terms of rem or sieverts and is equal to the product of the absorbed dose, in units of rads or grays, and a quality factor assigned to the type of radiation being emitted. ${ }^{3}$

Dose-equivalent, unlike activity, is not a measure of the emitted radiation, but is a method of normalizing the effectiveness of an absorbed dose of radiation in damaging tissue, regardless of the type of radiation. It also must be understood that activity is a physical phenomenon, whereas dose. equivalent is a description of the biological e. Eectiveness of a given exposure circumstance. Nevertheless, using standard assumptions regarding such factors as route and duration of exposure, quantity of intake, and determination of the tissues most affected, a dose-equivalent level may be related directly to a level of activity'for particular radionuclides.

The Agency considered establishing an $R Q$ for radionuclides in terms of dose-equivalent (rem) because rem is an acceptable unit of measurement for radionuclide releases and, in fact, most existing reporting requirements are in units of rem. The principal advantage to this option is that different exposure scenarios (e.g., different radionuclide forms, routes of exposure, and age and locations of receptors) will yield a different number of rem. Therefore, an $R Q$ in terms of a rem level that is deemed to be acceptable could be independent of the exposure scenario -- it would apply to any release which, under existing circumstances (whatever they may be), could result in the specified number of rem.

2U.S. Nuclear Regulatory Commission, Regulation of Naturally: Occurring and Accelerator-Produced Radioactive Materials-An Update, NUREG-0976, October 1984, p. 1-3.

${ }^{3}$ The gray is a unit of absorbed dose. One gray is equal to an absorbed dose of 1 joule/kilogram or $100 \mathrm{rads}$. The rad is a unit of absorbed dose. One $\mathrm{rad}$ is equal to an absorbed dose of $100 \mathrm{ergs} / \mathrm{gram}$ or 0.01 joule/kilogram. The sievert is a unit of dose-equivalent. One sievert is equal to a doseequivalent of $100 \mathrm{rem}$. Originally "Roentgen Equivalent Man," the rem is also a unit of dose-equivalent. The dose-equivalent in rem is numerically equal to the absorbed dose in rads multiplied by the quality factor ( $Q$ ). $Q$ is equal to 1 for $X$-rays, gamma rays, and beta particles; $Q$ is equal to 10 for fast neutrons from fission, for example, and for protons; and $Q$ is equal to 20 for alpha particles and fission fragments. 
There are several important disadvantages to this option, however. First, an RQ in terms of dose-equivalent ( $\mathrm{rem}$ ) would leave a significant amount of judgment to the person in charge of the facility or vessel. This person would have been required to estimate or judge the quantity released, the potential routes of exposure, the period of exposure, and the most vulnerable organ of the body potentially affected by the release. In essence, if the $R Q$ were to be established in units of rem, the person in charge of the vessel or facility would be placed in a position of determining whether the release posed a threat to public health or welfare or the environment. CERCLA establishes that role for the federal government, not for the person in charge of the vessel or facility.

In addition, the calculation (or estimation) of dose-equivalent is not straightforward. It could preclude a timely report and, therefore, a timely response should one be deemed appropriate. Finally, because of all the judgments and assumptions required to estimate dose-equivalent, the estimated dose-equivalent for two different releases with the same level of activity of the same radionuclide may vary drastically under different assumptions. This potential variability, even with a standardized calculation methodology, makes it difficult to ( 1 ) assure that the government will be notified of all radionuclide releases that it deems necessary; and (2) enforce an $R Q$ in doseequivalent units.

\subsection{OPTION 4: CONSIDERING RADIONOCLIDES AS A CLASS UITH A SINGLE ACTIVITY LEVEL}

Because activity levels are relatively easy (compared to the estimation: of dose-equivalents) to estimate or measure quickly during a release event through the use of available survey instruments, the Agency considered establishing an $R Q$ for radionuclides, as a generic class, in units of curies. A level of activity, in units of curies (or becquerels), is a measure of the rate of radioactive decay and thus the amount of radiation given off by a substance. However, a single RQ in units of curies applicable to all radionuclides would not account for varying degrees of hazard posed by different radionuclides. Exhibit 2.1 shows the range of different dose-equivalent levels (reflecting relative levels of damage to the body) which may result from the inhalation of one microcurie of different radionuclides.

While simplicity in reporting must be sought, the Agency does not believe that it should be accomplished by ignoring substantial differences among individual radionuclides. It would be extremely difficult to derive an RQ in terms of a single level of activity that would. provide timely reporting of the most hazardous radionuclides while not being overly protective for others.

\subsection{OPTION 5: GROUPING RADIONOCLIDES INTO CATEGORIES UITH AN ACTIVITY LEVEL ASSIGNED TO EAGH OF THE SEPARATE CATEGORIES}

Radionuclides may be segregated into various groups in such a way that a single level of activity may be an appropriate $R Q$ for all the radionuclides within a given group. One RQ, which would assure timely reporting for releases of the most hazardous radionuclides, could be assigned to each group. For example, the Agency considered grouping radionuclides into "half-life 
EXHIBIT 2-1

EFFECTIVE DOSE-EQUTVALENTSa/ RESULTING FROM THE INHAIATION OF ONE MICROCURIE OF DIFFERENT RADIONUCLIDES

Radionuclide

Effective dose-equivalent

if one microcurie

is inhaled (rem)

$\begin{array}{ll}\text { Tritium }\left(\mathrm{H}_{3}\right) & .0001 \\ \text { Technetium-99 } & .07 \\ \text { Radium-226 } & 8 \\ \text { Uranium-238 } & 6 \\ \text { Plutonium-238 } & 500\end{array}$

a/ The effective dose-equivalent is a wieighted average of committed doseequivalents for specific organs. It provides a measure of the overall (i.e., whole body) carcinogenic and genetic effects resulting from a radionuclide exposure.

b/ The number of rem to the whole body resulting from the intake of a radionuclide depends on, among other factors, the particle size and solubility of the radionuciide involved. To facilitate comparison of the hazard levels associated with each of the above radionuclides, the dose-equivalent levels are based on each radionuclide having roughly the same solubility (a "W" compound or, in the case of tritium, highly soluble) and particle size (an activity median aerodynamic diameter of $1 \mu \mathrm{m}$ ).

Source: Dunning, et.al., Estimates of Internal Dose-Equivalents to 22 Target Organs for Radionuclides Occurring in Routine Releases From Nuclear Fuel-Cycle Facilities, Vol. III, NUREG-0150, 1981. 
categories" with progressively higher RQs for those categories having shorter half lives. Another option considered was to separate radionuclides into groups of alpha, beta, and gamna emitters with progressively higher RQs for each of these categories. The RQs for non-radioactive substances have been established in this fashion, with different RQs for different groups of chemicals having similar chemical and toxicological properties.

The Agency chose not to adopt the two methods of categorizing radionuclides mentioned above. The Agency believes that radionuclides grouped. into half-life categories with progressively higher RQs for those categorjes having shorter half lives may not be protective of public health and the environment because radionuclides with relatively short half lives (e.g., ten days) could emit high energy radiation at a high rate for which the federal government may wish to receive notification to determine whether a response action is necessary. With regard to categorizing radionuclides on the basis of whether they are primarily alpha, beta, or gamma emitters, the actual threat to public health or welfare or the environment is often less dependent on the type of emission than on the energy of the radiation (i.e., a high energy beta particle might be more harmful than a low energy alpha particle).

The Agency did not select this option because it could not determine appropriate groups or categories for radionuclides prior to examining each individual radionuclide and estimating the potential effect of a release of each.

\subsection{OPTION 6: ESTABLISHING AN ACTIVIT' LEVEL RQ FOR INDIVIDUAL RADIONUCLIDES}

The Agency ultimately decided to issue RQ adjustments for individual radionuclides based on levels of activity. There are several advantages to basing radionuclide RQs on activity levels. For example, a level of radioactivity is much easier to estimate than a dose-equivalent. The Agency believes that setting $R Q s$ in terms of activity, therefore, would provide more timely reporting than an $R Q$ expressed in terms of dose-equivalent.

A second advantage of using activity levels is that establishing RQs for radionuclides individually would allow consideration of individual radionuclide characteristics including the type and strength of ionizing radiation produced during a release. An $R Q$ in terms of dose-equivalent (rem) also would (by definition) have considered type and strength of ionizing radiation; but would have left much greater judgment to the persion in charge of the vessel or facility. Activity level RQs (curies) also consider each radionuclide individually, but minimize judgments by the person in charge of the vessel or facility. The option to establish RQs in terms of curies, therefore, was considered advantageous.

The Agency recognizes that the nuclide-specific RQ approach also has disadvantages. Primarily, unlike a dose-equivalent value, a level of activity by itself does not necessarily reflect a level of danger to human health. A release of an $R Q$, therefore, does not necessarily mean that there has been or will be any harm. As is presently the case for RQs for non-radioactive substances, a case-by-case evaluation will be necessary to estimate the human health and welfare and environmental hazards associated with a radionuclide release, and to determine if a federal response is warranted. 


\section{CHAPTER 3}

\section{MAJOR ISSUES ASSOCIATED UITH THE SETECTED RQ ADJUSTMEMTT METHODOLOGY}

Based on the advantages and disadvantages of the various RQ adjustment. options discussed in Chapter 2 of this report, EPA chose to establish a specific curie level for individual radionuclides as the adjusted radionuclide RQs. To determine the appropriate $R Q$ for each radionuclide, EPA estimated the quantity of radionuclides that, if released under a conservative set of exposure conditions, could result in an individual receiving an effective dose-equivalent ${ }^{1}$ of 500 millirem. The specific methodology used to estimate this quantity for each radionuclide is described in detail in Chapter 4 of this report.

EPA published a Notice of Proposed Rulemaking (NPRM) to adjust the statutory RQ for radionuclides on March 16, 1987 (52 FR 8172). The methodology used to determine the RQ adjustments proposed in the NPRM was documented in detail in a supporting Technical Background Document (TBD) ${ }^{2}$ EPA received numerous comments on the NPRM concerning the technical approach used to calculate the proposed RQs. Many of the comments questioned specific assumptions made in the exposure scenarios used to calculate RQs and, in response to these comments, the Agency analyzed how the proposed RQs would change under varying sets of assumptions. The methods and results of this additional analysis are documented in a Supple. ntary Technical Background. Document. 3 Based on the comments received and further analysis, several changes in the proposed RQ adjustment methodology were made in order to calculate final RQs.

This chapter summarizes the major technical issues raised in comments on the NPRM and TBD, and highlights changes made in the RQ adjustment methodolog, in response to these comments. Where applicable, the Agency's rationale for not changing the methodology in response to comments also is summarized. The chapter is divided into six sections, with each section describing a separate issue and what, if any, changes have been made in the RQ adjustment methodology in order to resolve the issue.

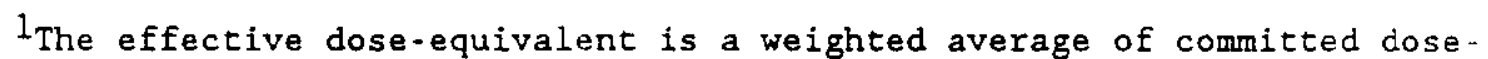
equivalents for specific organs, with the weights determined from risk factors associated with the respective organs. It provides a measure of the overall (i.e., total body) carcinogenic and genetic risk resulting from a radionuclide exposure.

2U.S. Environmental Protection Agency, Technical Background. Document to Support Proposed Rulemaking Pursuant to Section 102 of the Comprehensive Environmental Response. Compensation and Liability Act: Radionuclides office of Emergency and Remedial Response, Emergency Response Division, December 1986.

3U.S. Environmental Protection Agency, Methods and Results for Calculations of Radionuclide Reportable Quantities Under Varying Sets of Conditions, Office of Emergency and Remedial Response, Emergency Response Division, June 18, 1987. 


\subsection{DEPARTURE FROM THE METHODOLOGY FOR ADJUSTING RQS OF POTENTIAL CARCINOGENS}

Although radionuclides are recognized as potential carcinogens, EPA chose not to use the existing RQ adjustment methodology for potential carcinogens to determine proposed $\mathrm{RQs}$ for radionuclides. This choice has been affirmed in the determination of final radionuclides RQs. The reasons for this departure are outlined below, following a brief description of the potential carcinogen me thodology.

EPA's methodology for adjusting the RQs of potential carcinogens was: published in the Federal Register on March 16, 1987 (52 ER 8140). Briefly, this methodology consists of two general steps. Fisst, potential carcinogens are assigned to "high," "medium," or "low" hazard categories based on their carcinogenic potency and the weight-of-evidence indicating that they are in fact human carcinogens. In the next step, RQs are assigned to each potential carcinogen based on their relative ranking. Potential carcinogens in the high category are assigned an $R Q$ of one pound, those in the medium category are assigned a 10 -pound $R Q$, and those in the low category are assigned an $R Q$ of 100 pounds.

Direct application of the potential carcinogen methodology for the adjustment of radionuclide RQs would not be appropriate for several reasons. First, because all radionuclides produce ionizing radiation and ionizing radiation is known to be carcinogenic to humans, radionuclides would be assigned either a one- or 10-pound RQ based on the potential carcinogen ranking system. Neither of these levels are appropriate for radionuclide RQs because as little as one-billionth of a pound of certain radionuclides might pose a hazard worthy of a report. Second, the RQs that would be established if the potential carcinogen methodology was used (i.e., one or 10 pounds) would vary by only one order of magnitude, while the hazards associated with radionuclides can differ by many orders of magnitude. Finally, establishing $\mathrm{RQs}$ in mass units such as pounds is inappropriate because most radiation measurements and standards in the U.S. are established in terms of curies or rem, not pounds.

Even modification of the potential carcinogen methodology would not address the crucial question of the appropriate scales for radionuclide RQs The potential carcinogen methodology would be useful to rank radionuclides relative to each other, but not to assign a specific $R Q$ to each radionuclide. Therefore; EPA has developed an entirely different methodology for adjusting radionuclide RQs, one that models a series of exposure scenarios that link a quantity of radionuclide released with an internationally accepted doseequivalent limit of 500 millirem for the general public.

\subsection{INCORPORATION OF RADIOACTIVE DECAY}

In the exposure pathway modeling done to calculate proposed radionuclide $R Q s$, EPA purposefully ignored the effects of radioactive decay for the sake of conservatism and simplicity. Many commenters expressed concern that this approach led to RQs for certain short-lived radionuclides that were unnecessarily low. Based on these comments and recognizing that radioactive decay is an intrinsic property of all radionuclides, EPA has decided to incorporate the effects of radioactive decay in the exposure pathway models 
used to develop final RQs. As would be expected, this change resulted in a general shift toward higher $R Q S$.

For the purpose of this analysis, the total period of time in the hypothetical release and exposure scenarios can be divided into three segments: (1) the time period over which the release occurs; (2) the time it takes for the radionuclide to travel from the point of release to the point $0:$ exposure; and (3) the period of exposure. Radioactive decay over these time periods is taken into account differently in the different exposure pathway models, as described in Chapter 4 and Appendices A through $D$ of this report.

\subsection{ASSUMED DISTANCE BETUEEN THE POINT OF RELEASE AND THE POINT OF EXPOSURE}

As described in detail in Chapter 4, the radionuclide RQs were determined by examining a hypothetical release and exposure scenario in which a radionuclide is released into the environment and migrates to an exposure point. In determining proposed RQs, the assumed distance between the point of: release and point of exposure in all scenarios was 30 meterst. EPA received conflicting comments on this assumed distance; some arguing that it is too close because the distance to unrestricted areas at many facilities that handle radionuclides is far greater than 30 meters, and others arguing that it: is too far because it is possible for individuals to come within closer distances (e.g., 1 meter) of a radionuclide release.

EPA has retained the assumed distance of 30 meters in all exposure scenarios analyzed for the development of final $R Q s$. It is recognized that no one, single distance would be representative of all possible release scenarios involving radionuclides; however, EPA also believes that it would be unnecessarily. complicated (thus jeopordizing timely reporting) to have multiple RQs for different distances, especially when it is realized that the actual circumstances of a release (including the distance to exposure points will be evaluated in deciding whether to take a field response once a report is made. Therefore, recognizing its inherent limitations, EPA has decided to base all the radionuclide RQ calculations on just one distance.

There are several compelling reasons to use 30 meters in the calculation of RQs. First, this distance is in the range of, and generally is consistent with, recommended isolation distances in the event of hazardous substance spills. The Department of Transportation (DOT) Emergency Response Guidebook recommends that unnecessary people be kept at least 45 meters upwind from releases of three categories of nuclear material. For 11 other categories of nuclear material, however, the Guidebook does not specify a single evacuatior: or isolation distance; it simply recommends that unnecessary people be kept "away," that the hazard area be isolated, and that entry to the area be denied. Furthermore, for small leaks of hazardous chemicals (not radionuclides), the recommended initial isolation distances range from 9 to 180 meters, and for large spills, the recommended isolation distances range from 20 to 380 meters. Approximately 44 percent of the initial isolation distances recommended for releases of hazardous chemicals is in the 0.30 meter

${ }^{4} U . S$. Department of Transportation, 1984 Emergency Response Guidebook. Guidebook for Hazardous Materials Incidents, DOT P 5800-3, 1984. 
range. Therefore, 30 meters appears to be an isolation distance that generally would be familiar based on published recommendations, and one that might actually be used in the event of a radioactive material release.

Second, although many facilities are separated from unrestricted areas by more than 30 meters, certain categories of facilities that can release radionuclides often do not have such a large buffer area surrounding them. For example, medical facilities and research laboratories may allow members of the general public within 30 meters of possible release points.

Finally, EPA believes that a distance of 30 meters is reasonably conservative and that using this distance to determine RQs would assure timely reporting for most conceivable release situations. Using a shorter distance, such as 1 meter, would result in RQs that are unreasonably low for most release situations, leading to unnecessary reports and burdens. Long-term exposures at less than 30 meters are believed mostly to be representative of occupational exposures within the workplace, which RQs are not intended to address. Moreover, it is recognized that exposure distances of less than 30 meters could occur in scenarios involving a lost radioactive source, but reports of lost sources generally would not initiate a response action regardless of the $R Q$ because the location of the source would be unknown.

\subsection{ASSUMED CONFIGURATION OF RADIONUCLIDE; RELEASE}

As part of the release and exposure scenarios examined for the determination of proposed RQs, EPA assumed that radionuclides are released into the environment from a point source. Many commenters pointed out that radionuclides frequently are released from areal sources (e.g., radon releases from coal ash piles or open pit mines) and that the proposed RQs were unnecessarily low for this type of release.

Although EPA recognizes that a point source release model is not applicable for areal sources, the point source release configuration has been retained in all exposure scenarios used to determine final RQs. The rationaie for this decision is basicaliy the same as that presented above for the selection of the 30 -meter distance in the exposure scenario. Namely, EPA believes that it would be best to use a single release configuration to determine RQs (multiple RQs for different release configurations could cause confusion and untimely reporting), and the single best release configuration to assume is a point source because it is conservative (i.e.. it is more likely to yield RQs that will assure timely reporting than an areal source).

By assuming a point source to determine RQs, however, EPA recognizes that there may be many areal sources that release more than an RQ of radionuclides each day. It is possible that the government would never respond to a report of some of these releases. Therefore, in response to requests from the public. EPA plans to evaluate available release data to determine if certain releases can be administratively exempted from the RQ reporting requirements to help eliminate unnecessary reporting burdens. In response to public comments on the NPRM, EPA already has examined and prepared a separate 
report ${ }^{5}$ on the radiological hazards associated with coal and ash at coal-fired boiler sites. The purpose of this analysis was to investigate whether a sufficient technical basis exists for administratively exempting releases of radionuclides in coal and coal ash from the $R Q$ reporting requirements.

\subsection{MODELING OF POTENTIAL EXPOSURES THROUGH THE INGESTION OF CONTAMINATED VEGETABLES}

In determining the proposed RQs, EPA considered an exposure scenario in which an individual ingests vegetables contaminated by the airborne deposition of radionuclides. This scenario was not used as a basis for the proposed RQs. however, because it was found to be generally a less critical exposure pathway than the ingestion of contaminated water under the set of conditions assumed (i.e., for the majority of radionuclides, lower RQs were calculated for scenarios involving the consumption of contaminated water than for scenarios involving the consumption of contaminated vegetables). The ingestion of contaminated vegetables, however, was considered more fully in the development of final RQs for the reasons stated below.

Decisions to include the effects of radioactive decay in the exposure pathway models and to use a different, more conservative model for calculating the factor representing the transfer of radionuclides from air to vegetation tend to exaggerate the importance of the vegetable ingestion pathway relative to other pathways. Appendix $C$ of the Techinical Background Document supporting the NPRM describes the two models considered for estimating deposition of radionuclides. One of the models is presented by the Nuclear Regulatory Commission in Regulatory Guide $1.109^{6}$ and the other is a model presented by the National Council on Radiation Protection and Measurements (NCRP).' The proposed RQs were based on the Nuclear Regulatory Commission model, which was subsequently determined to be inappropriate for the release configurations and distances considered for the development of RQs. The NCRP model, which is very conservative when coupled with the atmospheric dispersion factor considered, was determined to be the most straightforward method for determining $R Q$ s for the vegetable ingestion pathway. See Section 4.4 and Appendix $C$ of this report for more detail on these two models and the reasons for ultimately selecting the NCRP model.

5 U.S. Environmental Protection Agency, Technical Background Supplement in Support of Rulemaking Adjustment Activities for Reportable Quantities (RQs) of Radionuclides, Office of Radiation Programs, February 1989.

${ }^{6}$ U.S. Nuclear Regulatory Commission, Calculation of Annual Doses to Man from Routine Releases of Reactor Effluents for the Purpose of Evaluating Compliance with 10 CFR Part 50. Appendix I, Regulatory Guide 1.109, Revisior. 1, October 1987.

'National Council on Radiation Protection and Measurements, Screening Techniques for Determining Compliance with Environmental Standards: Releases of Radionuclides to the Atmosphere, NCRP Commentary No. 3, 1986. 


\subsection{ADDITIONAL EXPOSURE PATHWAY MODELS}

In the development of final RQs, the Agency considered four potential exposure pathways more fully than it did in the development of proposed RQs. These pathways are the ingestion of contaminated surface water, the ingestion of vegetables contaminated by radionuclide-bearing irrigation water, the ingestion of contaminated milk, and direct exposure to neutrons.

As described in the TBD supporting the NPRM, potential exposures through the ingestion of contaminated surface water were considered qualitatively, but an equation for the calculation of $R Q$ s based on this pathway was not developed. It was recognized that, as long as radioactive decay was not taken into account (as was the case for the proposed RQs), the ingestion of surface water generally would be a less critical exposure pathway than the ingestion of ground water because surface water generally would provide for much greater dilution. By incorporating radioactive decay into the calculation of final $R Q s$, however, the relative importance of the surface water pathway was increased significantly because of the decay that can occur over the long transport times in ground water. Accordingly, the potential ingestion of contaminated surface water was considered more rigorously in the development of final RQs (see Section 4.3 and Appendix $B$ of this report).

Similarly, to determine the proposed RQs, EPA considered potential exposures via other ingestion pathways (e.' meat and milk) qualitatively, suggesting that, under the set of exposure conditions assumed, these other ingestion pathways would be less critical than either the ingestion of water or the ingestion of vegetables. EPA recognizes that these other ingestion routes actually could be more critical depending on the conditions of a release and, based on comments received on the NPRM, the ingestion of vegetables contaminated by irrigation and the ingestion of meat and milk was analyzed more fully in the development of final RQs. See Section 4.4 and Appendix $C$ of this report for a discussion of the methods and results of this analysis.

Twenty-four radionuclides decay, at least part of the time, by spontaneous fission and emit neutrons. Neutrons can present a significant external hazard and, therefore, direct exposure to neutrons was taken into account in the determination of final RQs (see Section 4.5 and Appendix $D$ of this report for a discussion of the methods and result of this analysis of neutrons). 
This chapter describes the Agency's methodology for adjusting the RQ for radionuclides. The chapter is divided into seven main sections. Section 4.1 provides an overview of the methodology, outlining the basic rationale and general steps taken. The sections that follow describe the steps outlined in Section 4.1 in more detail. Sections $4.2,4.3,4.4$, and 4.5 describe the methods used to determine $R Q s$ based on inhalation, ingestion of water, ingestion of food, and direct exposure, respectively. In Section 4.6, the assignment of radionuclides to $R Q$ groups is described and, finally, Section 4.7 outlines the basis for reporting requirements for mixtures.

\subsection{OVERVIEH OF THE METHODOLOGY}

In simplest terms, the $R Q s$ were determined by estimating the quantity of a radionuclide that, if released into the environment under an assumed set of conditions, could result in an individual receiving a specified effective dose-equivalent. To estimate this quantity for each radionuclide, a series of hypothetical (but conservative) exposure scenarios were analyzed to link a quantity released with an accepted dose level.

This process begins with the Annual Limits of Intake (ALIs) published for 757 radionuclides in ICRP's Publication 30.1 ALIs are the quantity of radionuclides (in becquerels) that, if taken in by "Refegence Man," 2 would result in either (1) a committed effective dose-equivalent ${ }^{3}$ of 5 rem to the whole body (stochastic ALI), or (2) a committed dose-equivalent ${ }^{4}$ of 50 rem to any organ or tissue (non-stochastic ALI). In the proposed revision to $10 \mathrm{CFR}$ Part 20, the Nuclear Regulatory Commission proposes the adoption of ALIs because: "the revision improves radiation protection standards by reflecting developments in the principles that underlie radiation protection and advances in related sciences that have occurred since the promulgation of 10 CFR Part

International Commission on Radiological Protection, Annals of the ICRP:Limits for Intakes of Radionuclides by Workers, ICRP Publication 30, Part 2, 1980 .

2 Reference man is a hypothetical individual possessing "average" characteristics of humans (such as body weight, dietary intake, and inhalation rate) to serve as a common biological basis for calculating ALI and other values.

${ }^{3}$ An effective dose-equivalent is a weighted average of committed dose. equivalents for specific organs, with the weights determined from risk factor: associated with the respective organs. It provides a measure of the overall (i.e., total body) carcinogenic and genetic risk resulting from a radionuclide exposure. The term "committed dose-equivalent" means that this is the dose that will accrue from one year of intake of radionuclides during the remaining lifetime ( 50 years) of the individual.

${ }^{4}$ The dose-equivalent referred to here is the same as that described in footnote 3 above, except that it is the dose to a single organ or tissue rather than an "effective" dose to the total body. 
20 nearly 30 years ago" (50 FR 1092, January 9, 1986). In short, the proposec ALIs are intake limits designed to limit the risk of health damage.

EPA used the ALIs from ICRP 30 to determine RQs by estimating the quantity of radionuclides that, if released, could result in the intake of one-tenth of an ALI. The ALIs were divided by 10 to adjust the dose that they are based on (an effective dose-equivalent of 5 rem for most radionuclides and, for a minority of radionuclides, a dose-equivalent of $50 \mathrm{rem}$ to the critical organ) to an effective dose-equivalent of $0.5 \mathrm{rem}$ ( 500 millirem). A whole-body dose-equivalent of 500 millirem is recommended by the Federal Radiation Protection Guidance as an upper bound on exposure to individual members of the general public. EPA believes that this dose-equivalent level is appropriate for the purpose of calculating RQs; RQs based on 500 millirem should be sufficiently low to assure timely reporting in most circumstances but not so low as to create unnecessary reporting. As discussed below, numerous conservative assumptions were made in the calculation of RQs so that the release of an $R Q$ will probably result in whole body doses less than 500 millirem.

Hypothetical releases and exposures were analyzed for four different routes of exposure: inhalation, ingestion of water, ingestion of vegetables, and direct exposure. For each exposure pathway, a "release value" was calculated for the 757 radionuclides for which ALIs have been published. The release values represent a quantity of radionuclides (in curies) that, if released under the conditions assumed, could result in a whole-body doseequivalent of 500 millirem via each of the exposure pathways. These release values were calculated using simple and conservative models that define a hypothetical scenario in which: (1) a radionuclide is assumed to be released into an environmental medium; (2) the radionuclide is transported from the point of release to the point of exposure and diluted along the way; and (3) a person is exposed to (i.e., inhales, ingests, or is exposed to direct: radiation from) the released radionuclide over a certain length of time. In these scenarios, many properties intrinsic to the radionuclides and many environmental variables are considered, leading to different release values for the different exposure pathways.

For each radionuclide, the release values calculated for the different exposure pathways were compared to one another and the lowest was selected. Th: :s lowest release value was then rounded down to the nearest decade to determine the $R Q$ for that radionuclide. For all radionuclides that do not have published ALI values, a single RQ was selected for all of them based on the distribution of RQs calculated as outlined above for the 757 radionuclides that do have ALIs.

\subsection{RELEASE VALUES FOR THE INHALATION PATHUAY}

Inhalation release values are in units of curies and represent the activity level of each radionuclide that, if released under a set of conservative circumstances, could result in an exposed individual inhaling 
one-terith of an ALI. 5 The Agency developed the following mathematical expression to derive release values based on exposure through inhalation:

(1) Inhalation Release Value $=\operatorname{ALI} /\left((10) *(\mathrm{R}) *(\mathrm{X} / \mathrm{Q}) *(\mathrm{BR}) *\left(1 \times 10^{6}\right)\right)$

where:

$$
\begin{aligned}
& \text { ALI - Annual Limit of Intake for inhalation (microcuries); } \\
& 10 \text { - Factor to adjust the dose-equivalent on which the ALI is } \\
& \text { based (dimensionless); } \\
& \text { R - Airborne release fraction (dimensionless); } \\
& \mathrm{X} / \mathrm{Q} \text { - Atmospheric relative concentration value }\left(8.4 \times 10^{-13}\right. \\
& \text { day/cubic cm); } \\
& \mathrm{BR} \text { - Breathing rate }\left(2.3 \times 10^{7}\right. \text { cubic cm/day); and } \\
& 1 \times 10^{6} \text { - Conversion factor between microcuries and curies. }
\end{aligned}
$$

The inhalation ALIs used in the calculations are taken from the ICRP's' Publication 30 (after conversion from becquerels to curies). Where more than one inhalation ALI was available for a particular radionuclide, the lowest value was used for the calculations. This approach assures that release of the radionuclide in its most hazardous themical form is taken into consideration. The inhalation ALIs are derived for workers in nuclear facilities and are 10 times those recommended for adult members of the genera! public. To adjust the Commission's ALIs to reflect the more protective level of exposure to the general public, the ALIs are divided by 10 .

The release fraction, $R$, reflects the fraction of the radionuclide release that could become airborne and be of respirable size ( 10 microns in diameter or less). The Nuclear Regulatory Commission has developed methods for estimating release fractions for radionuclides under accident conditions. ${ }^{6}$ A summary of these methods and a table of release fractions for those individual radionuclides with specific RQs can be found in Appendix $A$ of this report.

The atmospheric relative concentration value $(X / Q)$ used in the calculations, $8.4 \times 10^{-13}$ day/cubic $\mathrm{cm}$, corresponds to the relative concentration, at ground level, 30 meters downwind from a ground-level point. source release under neutral (Class D) meteorological conditions. A

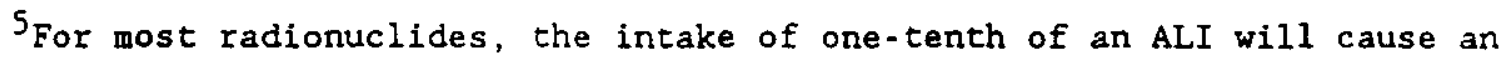
effective dose-equivalent of 500 millirem. For a few radionuclides, the intake of one-tenth of an ALI will result in a dose-equivalent of 5 rem to the most exposed organ.

6McGuire, S.A., A Regulatory Analysis on Emergency Preparedness for FueI Cycle and Other Radioactive Materials Licenses, NUREG-1140, U.S. Nuclear Regulatory Commission. 
ground-level release under Class $D$ meteorological conditions leads to higher ground-level concentrations than would be the case for a release under rore turbulent conditions. By using the ground-level concentration, the derived release values are lower than would be the case if the Agency had used an above-ground concentration. Similarly, release values based on a pointsource release at ground level are lower than would be calculatec if an areal source had been assumed or if an above-ground source (e.g., a smokestack) had been assumed. Thus, the proposed RQs are based on a more protective release scenario.

The Agency has chosen 30 meters as a reasonably conservative distance between the point of release and point of exposure (see Section 3.3 of this report). At fixed facilities, the distance to unrestricted areas is likely to be greater than 30 meters; therefore, 30 meters will result in a conservative estimate for exposure. The Agency derived the value of $X / Q$ for distances less than 100 meters based on the dispersivity data presented in The Workbook of Atmospheric Dispersion Estimates. 7 The X/Q values presented in the Workbook do not include data for distances less than 100 meters; therefore extrapolation is necessary. Although the extrapolation from 100 meters to $3 C$ meters may not be totally accurate, a more preferred method of determining a value for $X / Q$ at this distance could not be identified. The Agency believes its evaluation of exposure via inhalation is conservative, and that the error introduced by the extrapolation to 30 meters is not detrimental given the purpose of RQs. A further explanation of atmospheric relative concentration values and their derivation can be found in Appendix $A$ of this report and in the Workbook on Atmospheric Dispersion Estimates.

The inhalation of toxic substances depends in an obvious manner on the breathing rate of individuals. For purposes of the release value calculations, the breathing rate of "Reference Man" is assumed to be $2.3 \times 1 C^{7}$ cubic centimeters per day.

The expression shown in Equation (1) for determining the release value for the inhalation pathway can be simplified by substituting the following values into the equation:

$$
\begin{aligned}
& \circ \quad(X / Q)-8.4 \times 10^{-13} ; \text { and } \\
& \circ \quad B R=2.3 \times 10^{7} .
\end{aligned}
$$

By multipling the numbers in the denominator, Equation (1) simplifies to:

$$
\text { (2) Inhalation Release Value - ALI (inhalation)/((193.2)*(R)) }
$$

For each of the individual radionuclides for which an ALI is available, the release values calculated for the inhalation pathway are presented in Appendix

${ }^{7}$ Turner, D. Bruce, Workbook of Atmospheric Dispersion Estimates, EPA Office of Air Programs, 1970.

${ }^{8}$ Till, J.E., Meyer, H.R. (Editors), Radiological Assessment. A Textbook on Environmental Analysis, NUREG/CR-3332, U.S. Nuclear Regulatory Commission, 1983. 
$E$ of this report. As noted in the appendix, the inhalation model was rot used for noble gases other than radon (e.g., argon, krypton, and xenon). According, to ICRP Publication 30, the effects of inhaling a noble gas are negligible compared to the effects of external irradiation from a person being submerged in a cloud of these radionuclides. Thus, a separate model described in Section 4.5 was used to determine the direct exposure release value for noble gases. Inhalation of radon was considered because the critical health effec: associated with exposure to radon is caused by inhalation of radon's shortlived decay products.

It is important to clarify that Equations (1) and (2) ignore the effects of radioactive decay. This is because the inhalation pathway model considers exposure to an airborne plume of radionuclides. In this situation, a shortlived radionuclide could undergo significant decay if the release and exposule? periods were a full day, but decay would be much less if a time period of several minutes was considered. Because it was not possible to establish exact bounds on the range of release and exposure periods, the Agency assumed conservatively that no decay occurs over these periods. EPA also ignored decay over the period of radionuclide transport to the point of inhalation. This approach was adopted because decay during airborne transport to a receptor just 30 meters away would be negligible for most radionuclides.

\subsection{RELSASE VAUUES FOR THE INGESTION OF UATER}

EPA calculated release values for the ingestion of contaminated ground water and the ingestion of contaminated surface water. The models used to calculate these release values are summarized in this section and documented in detail in Appendix $B$ of this report.

For the ingestion of contaminated surface water, EPA calculated release values for a scenario in which: (1) a radionuclide is released from a point source into a small river; (2) the radionuclide mixes completely and instantaneously in the water column but does not settle to the botcom or decay; and (3) a person draws water from a point 30 meters downstream and drinks the water directly over the period of time that it takes the contamination to pass. Radioactive decay over the time it takes for the radionuclide to travel to the point of exposure was ignored because this time period would be short (probably around a minute or less), and decay over this period would be negligible for most radionuclides. Decay over the periods of release and exposure also was ignored because these periods could not be defined; they could be very short, such that insignificant decay would occur or they could be very long, as would be the case if an individual stored a large quantity of water withdrawn from the river and consumed the water over an extended period.

Although the release values calculated for the surface water ingestion pathway were sometimes lower than those calculated for the ingestion of grourd water, the surface water release values were never the lowest when compared to the release values calculated for the other exposure pathways. As a result, none of the RQs calculated for the 757 specific radionuclides are based on the surface water ingestion pathway By comparison, however, the release values calculated for the ground-water ingestion pathway were the lowest ones (and hence serve as the basis for RQs) for several radionuclides. Therefore, 
because the ground-water ingestion pathway affects some of the RQs while the surface water ingestion pathway does not, the Agency chose to use only the ground-water ingestion pathway in the development of final RQs.

The method that the Agency has adopted for the calculation of release values based on consumption of contaminated ground water is presented in Equation (3) below:

$$
\text { Drinking Water Release Value }=\operatorname{ALI} /\left((10) *(D F) *(C T) *(W C) *\left(1 \times 10^{6}\right)\right)
$$

where:

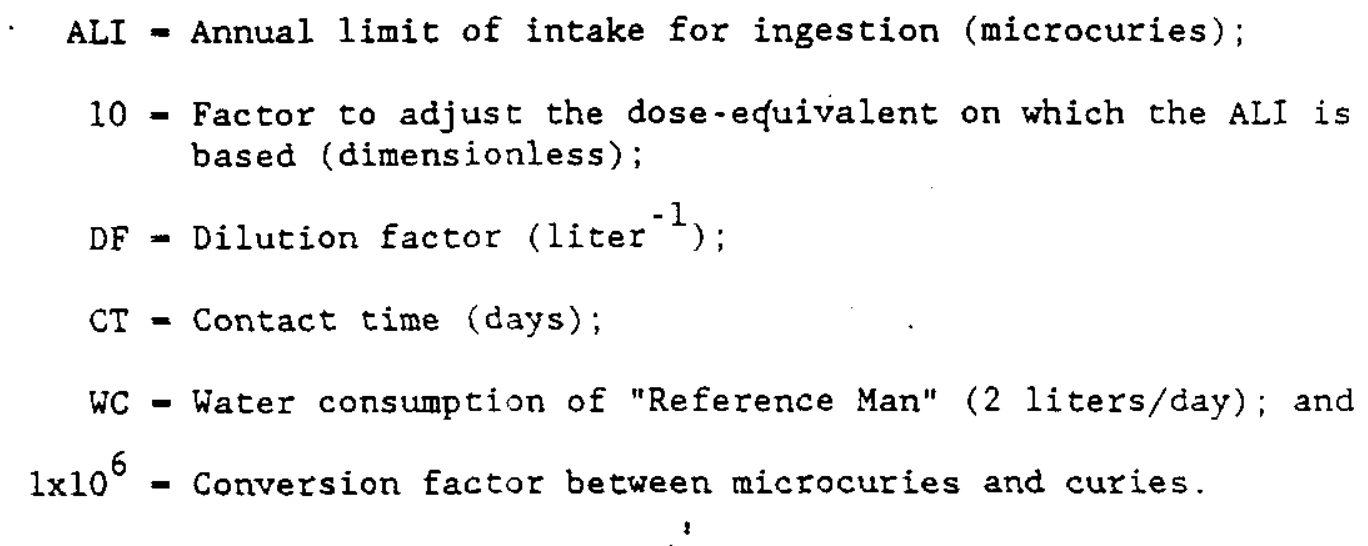

The ingestion ALIs used in the calculations are taken from ICRP's Publication 30 (after conversion from becquerels to curies). Where more than one ingestion ALI was available for a particular radionuclide, the lowest ALI was used for the calculations. The factor 10 converts the 5 rem annual occupational dose limit to the 500 millirem $(0.5 \mathrm{rem})$ annual limit for membersi of the general public, as discussed for the inhalation pathway.

The dilution factor (DF) is derived by considering the maximum concentration in a contaminant plume 30 meters downgradient from a point source release, as calculated by use of standard equations modeling ground-water transport. The maximum concentration is assumed to be uniform $1 y$ distributed throughout the plume. ${ }^{9}$ Thirty meters is chosen for consistency with the atmospheric model and leads to higher concentrations and lower release values than would be the case for a greater distance.

The Agency considered two dilution models during the RQ development process: a simple dilution model and an advection-dispersion model. The simple dilution model relies on the estimate that the practical need for water

${ }^{9}$ This is a conservative approximation because concentrations are ususal:-y' distributed in a gaussian fashion within a plume, with smaller concentrations toward the edges of the plume and higher concentrations near the plume's center line. 
of a single person living in a rural area is 7,700 cubic meters per year. 10 This represents a dilution factor of $1.3 \times 10^{-7}$ per liter. The model assumes the flow rate of the aquifer is sufficiently slow that the contact time is an entire year ( 365 days) and the entire quantity released is pumped from the well over a period of one year.

Use of the advection-dispersion model for determination of radionuclide concentration in drinking water relies on estimates of longitudinal and transverse coefficients of dispersion, bulk density of the aquifer, sorption coefficients for individual radionuclides, and aquifer flow rate. The Agency believes that, for the purpose of developing RQs, the advection-dispersion model is more appropriate than the simple dilution model. The simple dilutior. model assumes that all of the release will be pumped from the well and all of the contaminated water will be consumed by an individual. Although the simple dilution model appears appropriate for determining concentration levels for: purposes of risk assessment, the advection-dispersion model is based on the somewhat less conservative but nore likely assumption that only a fraction of the release will be pumped from the well and consumed by an individual. The Agency, therefore, based its drinking water exposure calculations on the advection-dispersion model.

The Agency also considered use of several other ground-water models used by EPA's Office of Solid Waste to support analyses under the Resource Conservation and Recovery Act (RCRA). The equations used in the RCRA models are similar to the equations used in the advection-dispersion model; however, certain parameters used in the equation's in the RCRA models are much more conservative than those used for purposes of $R Q$ adjustment in the advection-dispersion model. The Agency believes that the values used as inputs to the advection-dispersion model are reasonably conservative and appropriate for the calculation of RQs. Further discussion of the advection-dispersion model, the simple dilution model, and the four RCRA models can be found in Appendix $B$ of this report.

The ground-water advection-dispersion modeling equations utilize a retardation factor, which accounts for the extent to which a radionuclide is retarded relative to the transporting water mass. Retardation factors for each radionuclide differ because different radionuclides are adsorbed differently onto the sand or soil in an aquifer. Because of their chemical nature, some radionuclides are adsorbed only weakly or not at all (e.g., technetium), while others are adsorbed strongly (e.g., cesium)... The retardation factor used in the model takes into account the soil bulk density,

${ }^{10}$ The Nuclear Regulatory Commission uses the simple dilution model for the purposes of determining allowable onsite disposal concentrations for radioactive waste. Oztunali, O.I., Roles, G.W., De Minimis Waste Impacts Analys is Methodology, NUREG/CR-3585, February 1984. While water supplies in suburban or urban areas may be from ground water, the ground water is likely to be pumped through several high-capacity wells and then distributed through several interconnecting pipes to individual homes. This type of system will result in much greater dilution than a simple rural system where water is obtained from a backyard well and taken directly to a tap. 
porosity, and the sorption coefficient, $K_{d}$. A table of sorption coefficients used in the model can be found in Appendix $B$. When the sorption coefficient is equal to zero, the retardation factor, $R_{\text {, }}$ is equal to one; that is, there is no retardation. When the sorption coefficient is greater than zero, the retardation factor is greater than one and nuclide retardation has occurred. The dilution factor used in Equation (3) is related directly to the sorption coefficient. The greater the sorption coefficient, the greater is the nuclide retardation in the aquifer, and the greater is the dilution factor.

The retardation factor also affects the estimation of the contact time, the total time a contaminant plume will be in contact with an affected well. If the retardation factor is equal to one, the advection-dispersion model assumes that the contamination is moving at the same velocity as the water in the aquifer (i.e., no retardation occurs), and the well is in contact with the contamination for nine days. If the retardation factor is greater than one, the contamination is being retarded and is moving at a slower rate than the water in the aquifer. The contact time, therefore, will be longer than nine days. Appendix $B$ describes further the relationship between the retardation factors, dilution factors, and contact times for different radionuclides.

In calculating the drinking water release values, when the sorption coefficient is greater than or equal to 4 for a particular radionuclide, the contact time is assumed to be 365 days. In reality, it could take significantly longe: than 365 days for the contaminant plume to pass the well head, but because ALIs reflect annual iptake levels, the contact time in the advection-dispersion model is constrained not to exceed 365 days. The dilution factor, however, also will reflect the sorption coefficient; the dilution factor is very large when the sorption coefficient is significantly above 4 .

In the model used to calculate release values for the ingestion of grounc. water, the release is assumed conservatively to be instantaneous to the saturated zone such that no decay over the period of release could occur. Equation (3), however, does consider decay over the period of transport and period of ingestion. For the period of transport, an exponential decay term is incorporated in the calculation of the dilution factor (see Appendix $B$ ) To consider decay over the period of ingestion, it is recognized that an individual would ingest smaller quantities of radioactivity over time.

Accordingly, decay over the period of exposure is taken into account using the following integrated exponential equation involving the contact time:

where:

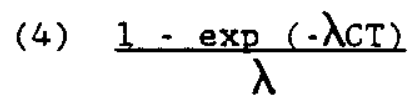

$$
\begin{aligned}
\lambda= & 0.693 / t_{1 / 2} \text {, where } t_{1 / 2}-\text { radionuclide half-life in days; and } \\
\mathrm{CT}= & \text { contact time, ranging anywhere from } 9 \text { days when } \mathrm{Rd}-1 \text { to up to } \\
& 365 \text { days when } \mathrm{Rd}>1 .
\end{aligned}
$$

Release Values calculated for the ingestion of water are presented in Appendix E. Again, all of the water ingestion release values in the exhibit are for the ingestion of ground water, because the surface water release 
values are never the most limiting (i.e., never affect the RQs) for any radionuclide. The release values noted in Appendix $E$ as being "very large" are for radionuclides that have a large retardation factor and relatively short half-life. For these nuclides, the time of travel to a well 30 meters away is sufficiently long that much of the nuclide is lost due to radioactive decay. While release values were not calculated in these cases, it is recognized that they would be "very large" relative to the release values for the other pathways and, therefore, would not serve as the basis for RQs.

\subsection{REILASE VALUES FOR THE INGESTION OF FOOD}

EPA considered a variety of exposure scenarios involving the ingestion of contaminated food. The scenarios analyzed were for:

- the ingestion of vegetables contaminated by the airborne deposition of radionuclides;

- the ingestion of vegetables irrigated with radionuclide-bearing ground water; and

- the ingestion of animal products (meat and milk) from livestock that ingested contaminated forage.

Although it is recognized that any of these exposure scenarios could be the most critical (i.e., result in the greatest human exposures) depending $0: 2$ the actual circumstances surrounding a telease, EPA decided to base release values for the ingestion of food solely on the scenario involving the ingestion of vegetables contaminated by airborne deposition. The irrigation pathway was rejected because, based on the defined exposure scenarios, the direct consumption of contaminated ground water would result in greater exposures than the ingestion of vegetables irrigated with contaminated grounc: water. In other words, release values calculated for the ingestion of ground water would always be lower (under the conditions assumed) than release values for the ingestion of vegetables contaminated through irrigation. Ingestion of contaminated milk and/or meat was rejected because radionuclide concentratiors found in milk or meat are highly dependent upon element-specific transfer factors between forage and animal products. Transfer factors are available for only a few elements and, as such, an acceptable model could not be applied to most radionuclides. The models used to evaluate each of these pathways ard the reasons for choosing the vegetable ingestion pathway are described in detail in Appendix $C$ of this report. The method for calculating release values for the ingestion of vegetables contaminated by airborne deposition is summarized below.

Conceptually, release values for the ingestion of vegetables contaminated by airborne deposition are calculated for a scenario defined by the following assumptions: (1) radionuclides are released to the air over a 24-hour period from a point source at ground level; (2) the radionuclide disperses in air in a gaussian plume; (3) a portion of the airborne radionuclides deposits on a vegetable crop located 30 meters downwind on the first day of the growing season; (4) an individual ingests one day's worth of vegetables from the contaminated crop for a period of 60 days, the entire length of the growing season; and (5) the vegetables are not washed or stored after harvest, but 
rather are ingested directly. EPA recognizes that this scenario is very conservative, particularly with respect to the assumption of a vegetable crop being located just 30 meters downwind from the point of release. These conservative assumptions, as well as the equations used to model this pathway. tend to exaggerate the importance of the vegetable ingestion pathway relative to the other pathways. Basing the release values on these conservative assumptions, however, assures that there will be timely reporting for most conceivable release situations.

The vegerable ingestion release values represent the quantity of radionuclides that, if released under the set of assumptions outlined above, could result in an exposed individual receiving an effective dose-equivalent of 500 millirem. The basic equation used to calculate these release values is:

(5) Vegetable Ingestion Release Value (in curies)

$$
=\operatorname{ALI} /\left((10) *(D F) *(F C) *(C T) *(R) *\left(1 \times 10^{6}\right)\right)
$$

where:

\author{
ALI - Annual Limit of Intake for ingestion (microcuries); \\ 10 - Factor to adjust the dose-equivalent limit built into the \\ ALI, 5 rem, to a linit of 0.5 rem (dimensionless); \\ DF - Dilution factor accounting for the transfer of \\ radionuclides from air to vegetation (curies $/ \mathrm{kg}$ of \\ vegetables at the point of exposure per curie released to \\ the atmosphere); \\ FC = Food (i.e., leafy vegetable) consumption rate of reference \\ $\operatorname{man}(0.175 \mathrm{~kg} /$ day); \\ CT - Contact time, or the number of days over which \\ contaminated vegetables are ingested; \\ $\mathrm{R}=$ Airborne release fraction (dimensionless); and \\ $1 \times 10^{6}$ - Conversion factor between microcuries and curies.
}

The ALIs used in Equation (5) were taken from ICRP Publication 30 . When more than one ingestion ALI was reported for a single radionuclide, the lowest one was used. Selecting the lowest ALI assures that the release values are based on the most hazardous chemical form of a radionuclide.

As described in detail in Appendix $C$, the dilution factor is based on the concentration of radionuclides in air over a vegetable crop and the extent to which the radionuclides deposit on and in the vegetables. The atmospheric relative concentration ( $X / Q$ ) value used in the inhalation pathway equation was used to estimate the concentration in air at a point 30 meters downwind from the point of release. A model presented by the NCRP in NCRP Commentary No. 
311 was used to determine the transfer of radionuclides from air to vegetation. This model accounts for the radionuclide deposition velocity, radionuclide loss due to weathering, uptake from soil, time period that the crops are exposed to contamination, and several other factors.

The value used for the food consumption rate is the rate that leafy vegetables are consumed by reference man. The selected value, $0.175 \mathrm{~kg} /$ day, is used commonly in radiological assessments. 12 The airborne release fraction, $R$, represents the portion of a released radionuclide that actually becomes airborne. The values used for $R$ in Equation (5) are the same ones that are used in the calculation of inhalation release values (see Section 4.2), and are based on the values presented in the Nuclear Regulatory Commission's NUREG-1140 for severe accident situations. The values used are shown in Exhibit A-1 in Appendix. A.

Although it was assumed that the exposed individual ingests contaminated vegetables for 60 days, this time period was adjusted for radioactive decay and weathering loss to derive ar equivalent contact time (CT) for use in Equation (5). The dilution factor outlined above, when applied to the quantity of radionuclide released in one day, yields the concentration of radionuclide in and on vegetation after one day. Over the next 60 days that a person is assumed to ingest the vegetables, the radionuclide concentration will progressively decrease as more and more of the contamination is lost due to radioactive decay and weathering. Therefore, the value used for CT in Equation (5) is derived using an exponential decay expression that accounts for the amount of radionuclide lost over the 60 day ingestion period. A different CT value is calculated for each radionuclide as a function of the radionuclide's half-life. The expression used to calculate CT is presented in Appendix $C$.

Finally, no radioactive decay is considered during the period of release and deposition. This approach is taken because decay during airborne transport to and deposition on vegetation located 30 meters away would be negligible for most radionuclides.

The release values calculated using Equation (5) are presented in Appendix E under the heading "Ingestion (Food)."

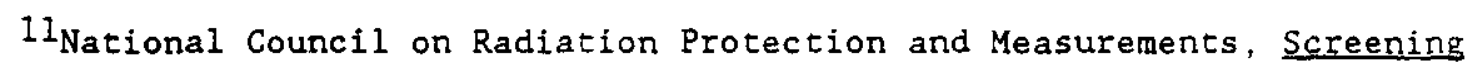
Iechniques for Determining Compliance with Environmental Standards: Releases of Radionuclides to the Atmosphere, NCRP Commentary No. 3, 1986 :

12U.S. Nuclear Regulatory Commission, Calculation of Annual Doses to Man from Routine Releases of Reactor Effluents for the Purpose of Evaluating Compliance with 10 CFR Part 50, Appendix I, Regulatory Guide 1.109, Revision 1, October 1977. Table E-5 (page 1.109-40) of this Guide recommends, in lieu of site-specific data, use of a leafy vegetable consumption rate of $64 \mathrm{~kg} /$ yea: to assess the doses to maximally exposed adults. For the purposes of this analysis, $64 \mathrm{~kg} /$ year was divided by 365 to obtain $0.175 \mathrm{~kg} / \mathrm{day}$. 


\subsection{REIEASE VALUES FOR THE DIRECT EXPOSURE PATHWAY}

The methodology for determining release values for direct exposure to radiation depends on the form of the radionuclide released. For certain noble gas isotopes, the release values are based on exposure due to total body submersion in a radioactive gas cloud. For all other radionuclides, release values are based on the quantity of radioactivity received by an individual exposed to a point source of radiation. The calculation of release values fo: point source and noble gas releases are summarized below and described in. greater detail in Appendix $D$ of this report. The release values calculated for direct exposures are presented in Appendix $E$.

\subsubsection{Direct Exposure Fron a Point Source}

As is the case for the other exposure pathway analyses, the calculation of direct exposure release values assumes that a person 30 meters from the point of a radionuclide release receives an effective dose-equivalent of 500 millirem. Assuming that a person is 30 meters from the point of release, direct exposure hazards are associated almost entirely with neutrons and gamma. rays; the range in air of all alpha particles and most beta particles is far less than 30 meters. ${ }^{13}$ Therefore, to determine release values for direct exposures to a point source, EPA considered both the exposure to neutrons and the exposure to gamma rays.

of the 757 radionuclides listed in ICRP Publication 30, 24 decay at leas: part of the time by spontaneous fission and emit neutrons. As described in Section D.1.2 of Appendix D, the Agency calculated release values for these nuclides based on direct exposure to neutrons. The exposure scenario assumed in the calculation of these release values is similar to that assumed for the other exposure pathways, i.e., a person stands 30 meters from a point source for 24 hours and receives a whole body dose-equivalent of 500 millirem. In all cases, the direct epxosure release values for the neutron-emitting isotopes were less than the corresponding release values calculated for the inhalation pathway. The usual mode of decay for the 24 isotopes (certain uranium isotopes and isotopes of some transuranic elements) is the emission of: alpha particles, which can cause significant biological damage when emitted inside the body. Under the exposure conditons assumed, therefore, the RQs for these isotopes would not be based on the direct exposure to neutrons and this exposure pathway was dropped from further consideration.

${ }^{13}$ For example, a $10 \mathrm{MeV}$ alpha or beta particle would be an extremely energetic particle. The mean range of a $10 \mathrm{MeV}$ alpha particle in air is less than 15 centimeters. Beta particles typically range in energy between 0.04 and $6 \mathrm{MeV}$, although there are a few radionuclides which emit beta particles with higher energies (e.g., the maximum beta particle energy for carbon-15 and bromine- 87 is about 10 and $8 \mathrm{MeV}$, respectively). The mean range of a $6 \mathrm{MeV}$ beta particle in air is only about 20 meters and these high energy beta particles are very rare. Therefore, although there are a few nuclides for which beta particles can conceivably travel approximately 30 meters in air, exposures at this distance are for the most part only a concern for gamma rays and neutrons. 
The method used by the Agency for calculating direct exposure release values from a fixed point source of gamma rays is adapted from the Health Physics and Radiological Health Handbook ${ }^{14}$ and includes gamma ray attenuation in air between the source and the receptor. It reflects the effects of gamma radiation and can be simplified, as shown in Appendix $D$, to yield the following equation:

$$
\text { Direct Exposure Release Value = }
$$

where:

$$
\left(\left(6.41 \times 10^{-5}\right) *(D n) *\left(S^{2}\right)\right) /\left(\left(E_{1}\right) *\left(u_{a}\right) *(T) *\left(\exp \left(-100 u_{a} S\right)\right)\right)
$$

$$
\begin{aligned}
\mathrm{Dn}_{\mathrm{n}}= & \text { Dose-equivalent in rem }(0.5 \text { rem or } 500 \mathrm{millirem}) ; \\
\mathrm{S}= & \text { Distance from the release }(30 \mathrm{~m}) ; \\
\mathrm{E}_{1}= & \text { The sum of the products of the gamma ray energies and the } \\
& \text { gamma ray fractions }(\mathrm{MeV}) ; \\
\mathrm{u}_{\mathrm{a}}= & \text { Linear energy absorption coefficient for gamma rays in air } \\
& \left(\mathrm{cm}^{-1)}\right) \\
\mathrm{T}= & \text { Duration of exposure (in hours); and } \\
\exp \left(-100 \mathrm{u}_{\mathrm{a}} \mathrm{S}\right)= & \text { Attenuation factor (dimensionless). }
\end{aligned}
$$

The direct exposure release value was calculated using Equation (6) for every radionuclide of interest that emits a gamma ray. For many of these radionuclides, gamma rays are not emitted every time that the nuclide decays (i.e., disintegrates). In addition, a gamma ray that is emitted from a given radionuclide does not necessarily always have the same energy level. This phenomenon is illustrated in Exhibit 4-1. As shown in this exhibit, every time argon-4l disintegrates, it emits a gamma ray with an energy level of 1.3 MeV. Krypton-85 emits a gamma ray for only a small fraction of its disintegrations ( 0.4 percent), while several different gammas with different energies are emitted at different frequencies by molybdenum- 99 .

To account for these various gamma ray energies and fractions when using Equation ( 6 ), the energy level $\left(E_{1}\right.$ ) for a given radionuclide was derived by taking the sum of the products of the gamma ray energies and the gamma ray fractions. For example, the $E_{1}$ value used for argon-4l was $1.3 \mathrm{MeV}$ and the $E_{1}$ value used for molybdenum-99 was 0.14 . This approach considers all of the gamma rays for a given radionuclide and accounts for the fraction of time that: such a gamma ray is actually emitted.

The linear energy absorption coefficient for gamma rays in air ( $u_{a}$ ) varies with the gamma ray energy. When the gamma ray energy is $1 \mathrm{MeV}$, the

14 Nucleon Lectern Associates, The Health Physics and Radiological Health Handbook, 1984, p. 41 . 
EXHIBIT 4-1

GAYRA RAY ENERGIES, GAYIYA RAY

FRACTIONS, AND ENERGY LEVEIS FOR SELECTED RADIONUCLIDES

\begin{tabular}{|c|c|c|c|c|}
\hline Radionuclide & $\begin{array}{c}\text { Gamma Ray } \\
\text { Energy, E } \\
\text { (MeV) }\end{array}$ & $\begin{array}{l}\text { Gamma Ray } \\
\text { Fraction } \\
\text { (percent) }\end{array}$ & $\begin{array}{l}\text { Gamma Ray } \\
\text { Fraction } \\
\text { Times E } \\
(\mathrm{MeV})\end{array}$ & $\begin{array}{c}\text { Radionuclide } \\
\text { Energy Level, } \\
E_{1} \\
(\mathrm{MeV})\end{array}$ \\
\hline Argon -41 & 1.3 & 100 & 1.3 & 1.3 \\
\hline Krypton- 85 & 0.513 & 0.43 & $2.2 \times 10^{-3}$ & $2.2 \times 10^{-3}$ \\
\hline Molybdenum - 99 & $\begin{array}{l}0.041 \\
0.141 \\
0.181 \\
0.366 \\
0.740 \\
0.777 \\
0.822\end{array}$ & $\begin{array}{c}1 \\
5 \\
6 \\
1 \\
12 \\
4 \\
0.1\end{array}$ & $\begin{array}{r}4.1 \times 10^{-4} \\
70.5 \times 10^{-4} \\
108.6 \times 10^{-4} \\
36.6 \times 10^{-4} \\
88.8 \times 10^{-3} \\
310.8 \times 10^{-4} \\
8.2 \times 10^{-4}\end{array}$ & $\mid \begin{array}{l}1 \\
1 \\
1 \\
1\end{array}$ \\
\hline
\end{tabular}

Source: National Council on Radiation Protection and Measurements, A Handbook of Radioactivity Measurement Procedures. NCRP Report No. 58. Washington, D.C. November 1978. 
linear energy absorption coefficient is $3.7 \times 10^{-5} / \mathrm{cm} .15$ For gamma rays witt. energies between $0.07 \mathrm{MeV}$ and $2 \mathrm{MeV}$, the absorption coefficient will vary frcm $3.7 \times 10^{-5}$ by plus or minus 15 percent. Because the variation is so slight for purposes of calculating the direct exposure release values, EPA assumed that the absorption coefficient is $3.7 \times 10^{-5} / \mathrm{cm}$ for all radionuclides of concern.

The duration of exposure, $T$, is assumed to be 24 hours. Because of radioactive decay, however, it is recognized that a person would be exposed to successively smaller quantities of radioactivity over this period of exposure. To determine an individual's cumulative exposure over the 24-hour period, therefore, a different exposure duration is calculated for each radionuclide using an integrated decay expression that accounts for the extent of radioactive decay that would occur over 24 hours. This expression is as follows:

where:

(7) $T=\frac{1-\exp (-\lambda t)}{\lambda}$

$$
\begin{aligned}
& \lambda=0.693 / t_{1 / 2}, \text { where } t_{1 / 2} \text { is the radionuclide half-life in days: " } \\
& \text { and } \\
& t=1 \text { day. }
\end{aligned}
$$

Multiplying the $T$ derived from Equation'(7) by 24 (i.e., 24 hours/day) yields a duration of exposure in units of hours, which can be plugged into Equation ( 6 ).

While decay over the period of exposure is taken into account through Equation ( 7 ), the Agency decided to ignore the effects of radioactive decay over the period of release and the period of transport to a receptor. The release is assumed conservatively to be instantaneous, such that no decay over the release period would occur. It is impossible to put bounds on the length of time necessary for a person to come into contact with direct radiation from a released point source. The Agency conservatively assumed, therefore, that no decay occurs over this "transport time."

Substituting all of the values outlined above into Equation (6), the equation simplifies to:

(8) Direct Exposure Release Value

25. 1

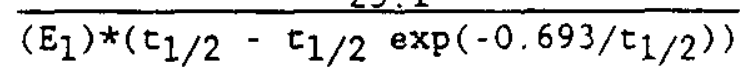

Direct exposure release values calculated for the radionuclides that emit gamma rays are presented in Appendix $E$ of this report.

15 Nucleon Lectern Associates, The Health Physics and Radiological Health Handbook, 1984, p. 41 . 


\subsubsection{Subnersion in a Radioactive Cloud of Noble Gas}

Because the noble gases argon, krypton, and xenon are chemically very stable, they are not likely to form solid or liquid compounds that can be ingested. Also, because they are relatively insoluble in blood and are displaced easily by gases more common in air such as oxygen and nitrogen, these noble gases are not incorporated readily into the body after inhalation. As a result, ingestion and inhalation are not significant exposure pathways and ALIs for ingestion and inhalation were not developed by the ICRP for most noble gases. However, submersion in a radioactive cloud can cause a significant whole body dose due to direct exposure. Therefore, direct exposure release values for argon, krypton, and xenon were derived assuming that an exposed individual is submerged in a cloud of the gas 30 meters from the release point.

Argon, krypton, and xenon are the only noble gases whose release values are calculated based on total submersion in a cloud. The noble gases helium and neon do not form isotopes with half lives longer than a few seconds. ALI:s for these isotopes have not been developed and, therefore, no release values have been calculated. The noble gas radon has two isotopes (radon-220 and radon-222) with inhalation ALIs. Inhalation of radon, rather than submersion in a cloud, was considered because the critical health effect associated with exposure to radon is caused by inhalation of its short-lived decay products. EPA recognizes that a cloud of non-noble gases can also contribute to a dose through the submersion-in-a-cloud pathway, in the same manner as noble gases. However, it is generally recognized that, in this situation, the inhalation pathway is controlling. Therefore, direct exposure by submersion in a cloud was analyzed for only argon, krypton, and xenon.

A different equation for the calculation of direct exposure release values is appropriate for radioactive noble gases because submersion in a cloud results in an integrated dose from all directions at varying distances from the body. The direct exposure release values for submersion in a radioactive cloud of a noble gas are derived through the following equation. 16

$$
\begin{aligned}
& \text { Direct Exposure } \\
& \text { Release Value }
\end{aligned}=((83) *(\mathrm{DAC}) *(\mathrm{~T})) /\left((10) *(\mathrm{X} / \mathrm{Q}) *\left(1 \times 10^{6}\right)\right)
$$

where:

$$
\begin{aligned}
\text { DAC } & =\text { Derived Airborne Concentration (microcuries } / \mathrm{cm}^{3} \text { ); } \\
T & =\text { Duration of Exposure ( } 1 \text { day); }
\end{aligned}
$$

${ }^{16}$ This equation is derived from an equation found in the Annals of the ICRP, Publication No. 30, Part 1, Volume 2, No. 3/4, 1979, PP. 10 and 47 . See Appendix $D$ for more detials. 


\author{
$X / Q$ - Atmosphefic Relative Concentration Value at 30 meters \\ $\left(8.4 \times 10^{-13} \mathrm{day} / \mathrm{cm}^{3}\right) ;$ and \\ $1 \times 10^{6}$ - Conversion factor between microcuries and curies.
}

The DAC value specifies the airborne concentration that would result in a 5 rem whole body dose-equivalent for a 2000 hour exposure period. To adjust the airborne concentration from a 2000 hour to a 24 hour exposure period, the DAC value in Equation (9) is multipled by 83 (i.e., 2000 hours/24 hours). 17 The factor of 10 in the denominator of Equation (9) converts the 5 rem whole bocy limit for occupational exposure to the $0.5 \mathrm{rem}$ ( $500 \mathrm{millirem}$ ) limit for exposure to the general public. $X / Q$ is the ground-level concentration value 30 meters from the release point (see Section 4.2 above and Appendix A for further discussion of $X / Q$ ).

The effects of radioactive deay are ignored in Equation (9). This pathway model considers exposure to an airborne plume of radionuclides just 30 meters from the point of release. The time of transport to the exposure point is short ( 30 seconds assuming a 1 meter/second wind), and decay over this period would be negligible for most radionuclides. Although the period of exposure is assumed to be one day, an individual would not be exposed to the same radionuclides over this period. As the plume passes the point of exposure, "new" radionuclides just released would approach the individual while "old" ones would move farther downwind. Again, because the time of travel to a point 30 meters from the point of release is short, the "new" radionuclides that the person is repeatedly exposed to would not have decayed significantly. For this reason, decay over the period of exposure was ignored.

The expression for determining the release value for the direct exposure pathway due to submersion in a cloud of radioactive noble gas can be simplified by multiplying the rumbers in the numerator and denominator. Equation (9) simplifies to:

$$
\text { Direct Exposure Release Value }=\operatorname{DAC} /\left(1 \times 10^{-7}\right)
$$

The direct exposure release values for argon, krypton, and xenon can be fourd at the end of this report in Appendix E.

${ }^{17}$ If a different exposure period was assumed, the DAC value in Equation (9) would have to be multiplied by a number different than 83 . For example, if an exposure period of 12 hours was assumed, the DAC would have to be multiplied by $166(2000 / 12)$. This change would have to be accompanied with a corresponding change in $T$; the value for $T$ would be 0.5 day rather than 1 day. For this reason, the direct exposure release value would not increase with longer exposure periods as is implied by Equation ( 9 ) (one would expect intuitively that the release value and exposure duration would be inversely related). 


\subsection{ASSIGILEANT OF RADIONUCLIDES TO RQ GROUPS}

Appendix $E$ at the end of this report displays the four release values calculated for each radionuclide. The lowest release value for each radionuclide has an asterisk beside it. The lowest release values range from over 100,000 curies to approximately 0.001 curie. For administrative feasibility and simplicity, the Agency decided to assign the radionuclides to one of seven distinct groups identified by specific final RQs. Each radionuclide is assigned a final RQ of 0.001 curie, 0.01 curie, 0.1 curie, 1 curie, 10 curies, 100 curies, or 1000 curies. Assignment of an adjusted $\dot{R} Q$ to a particular radionuclide was made by examining the lowest release value for each radionuclide and rounding that value down to the nearest RQ group.

The 757 radionuclides with RQs are represented as follows:

- 7 radionuclides (18) have lowest release values less than 0.01 curie and, therefore, have an adjusted RQ of 0.001 curie;

- 29 radionuclides (48) have lowest release values greater than or equal to 0.01 curie but less than 0.1 curie and, therefore, have an adjusted RQ of 0.01 curie;

- 29 radionuclides (48) have lowest release values greater than or equal to 0.1 curie but less than 1 curie and, therefore, have an $R Q$ of 0.1 curie;

32 radionuclides ( 48 ) have lowest release values. greater than or equal to 1 curie but less than 10 curies and, therefore, have an RQ of 1 curie;

- 220 radionuclides (298) have lowest release values greater than or equal to 10 curies but less than 100 curies and, therefore have an $R Q$ of 10 curies;

- 235 radionuclides (31\%) have lowest release values greater than or equal to 100 curies but less than 1000 curies and, therefore, have an adjusted RQ of 100 curies; and

- 205 radionuclides (278) have lowest release values greater than or equal to 1000 curies and, therefore, have an RQ of 1000 curies.

An RQ of $I$ curie also is assigned to all radionuclides not listed in ICRP's Publication 30. The Agency believes, for three reasons, that by establishing an $R Q$ for the broad generic class "radionuclides," it is fulfilling the CERCLA mandate to protect public health, welfare, and the environment. First, as seen above, the 1 -curie RQ is the middle RQ level and the majority (918) of the radionuclides with proposed RQs have minimum release values greater than or equal to 1 curie. Therefore, the generic RQ of 1 curie for all other radionuclides (i.e., those not included in the 1 ist of 757 
radionuclides with specific $R Q$ s) is probably a conservative value. Second, most of the radionuclides that fall into this category are rare, both in terns of frequency of use and quantities used. Many of these nuclides have been produced in only a few isolated research projects and the world's total quantity of many is less than 1 curie. Therefore, releases of radionuclides not 'isted by ICRP Publication 30 are expected to be infrequent and, if they occur, are expected to be released within any 24 -hour period in quantities smaller than 1 curie. Finally, many of the remaining radionuclides have short: half-lives and do not decay into other radioactive isotopes. Under most. realistic release situations, these radionuclides would be expected to dęcay and virtually disappear before they could reach receptor locations.

Two or more radionuclides with the same RQ do not reflect a determination that a release of one will be as hazardous as the release of another, or even that the release of one will be hazardous at the proposed RQ level and not hazardous below that level. The Agency has found that the actual hazard wil:vary with the unique circumstances of the release, and extensive scientific data and analysis would be necessary to determine the hazard presented by each substance under a number of possible circumstances. Instead, the RQs are. designed to be a trigger for notification and reflect the Agency's judgment that the federal government should be notified of certain releases to which a federal response might be necessary. The reportable quantities represent a determination only of possible or potential harm, not that releases of a particular amount of a hazardous substance necessarily will be harmful to public health or welfare or the environment.

\subsection{REPORTING REQUIREYIXNTS FOR MIXTURES OF RADIONOCLIDES}

Some releases of radioactive substances are likely to consist of mixtures. of radionuclides. These releases will be one of two general types: mixtures of known composition or mixtures of unknown composition. The conventions adopted by the Agency in establishing reporting requirements for mixtures and the $\mathrm{RQs}$ for four common radionuclide mixtures are presented below.

\subsubsection{Mixtures of Known Conposition}

Reporting requirements for releases involving mixtures of known composition can be obtained directly from the RQs for individual constituents of the mixture. If the identity and quantity of each radionuclide involved in a release event is known, the decision to report a release must be made in the following manner: for each radionuclide in the mixture, the ratio between the: quantity released (in curies) and the $R Q$ for the radionuclide must be determined. If the sum of the ratios for all radionuclides is less than 1 , the release need not be reported. If the sum is equal to or greater than 1 , the release must be reported to the National Response Center.

For example, if radionuclides " $a, "$ "b," and "c" are released in quantities of $Q \mathrm{a}, \mathrm{Qb}$, and $\mathrm{Qc}$ curies in a mixture, and if the $R Q s$ are $R Q a, R Q b$, and RQc, respectively, then the quantity released for the mixture does not exceed the $R Q$ and the release need not be reported to the National Response Center if $(Q a / R Q a+Q b / R Q b+Q c / R Q c)$ is less than 1 . This convention for handling releases of rajionuclide mixtures is recommended by the ICRP. 


\subsubsection{Mixtures of Unknown Composition}

Reporting requirements for mixtures of unknown composition cannot be based on the determination of quantities released. For mixtures of unknown composition, there are three possibilities: (1) the identity of the radionuclides involved is known, but the amounts released of each are unknown, (2) the identity of the radionuclides (or one of the radionuclides) in the mixture is unknown, but the amount released is known in total curies per unit volume or weight, or (3) the identity of the radionuclides involved is unknown and the amount of individual radionuclides released in the mixture is unknown (but the total quantity is known). For these cases, the decision to report a release is made as follows:

\section{(1) Identity known, but amount unknown.}

If the identity of each radionuclide in the mixture is known but the concentration of one or more of the radionuclides is unknown, the $R Q$ for the mixture shall be the lowest RQ of any radionuclide in the mixture.

This method for determining the $R Q$ of a mixture assures a report to the National Response Center if the total number of curies involved in a release is equal to or greater than the $R Q$ in curies of the substance with the lowest $\mathrm{RQ}$ in the mixture.

$:^{2}$

(2) and (3) Identity of radionuclide(s) in the release is unknown.

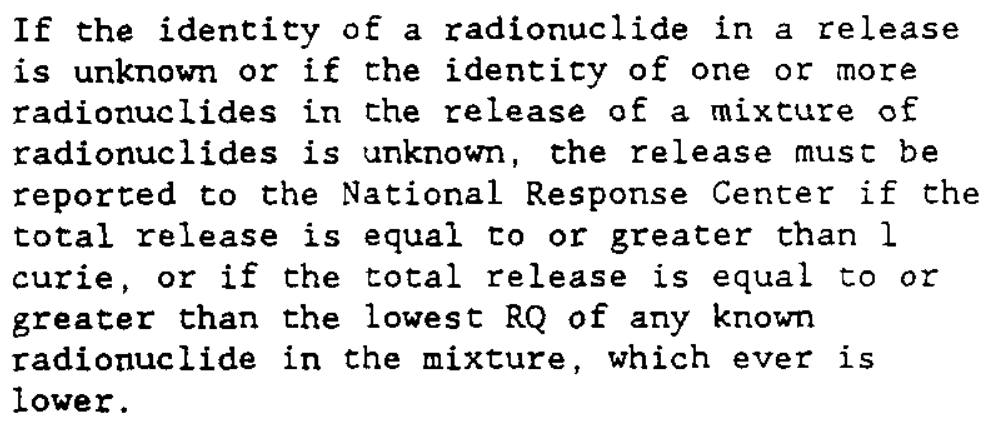

Establishing an RQ of 1 curie for a release in which the identity of the radionuclide or radionuclides involved is unkown is consistent with the 1 curie $R Q$ for the class of radionuclides for which insufficient data exist to extablish individual RQs. The mixture rule requires reporting if the release equals or exceeds 1 curie, or, if some component of the mixture is known and its $R Q$ is less than 1 curie, then the total release must be reported if it equals or exceeds the RQ of the known component.

\subsubsection{Conson Radionuclide Mixtures}

RQs have been developed for four common radionuclide mixtures: radium-226 in equilibrium with its daughters, natural uranium not in secular equilibrium with its daughters, natural uranium in secular equilibrium with 
its daughters, and natural thorium in secular equilibrium with its daughters. Mixed fission products are also recognized by the Agency as an important and common radionuclide mixture. However, the Agency is presenting RQs currently only for the individual radionuclide components within this latter mixture because an RQ for mixed fission products would be time dependent. That is, at different time intervals, the concentration of the different components of this mixture will be different. In addition, the components of the mixed fission product will differ, depending on the type of reactor involved in their production. Therefore, several different mixed fission product RQs. would need to be presented.

Radium-226 has a half life of about 1600 years, substantially greater than the half lives of its eleven daughters. After a sufficient period of time, however, a state of equilibrium is established in the mixture (known as secular equilibrium), such that the activity present for each daughter product and the parent radium is equal. For example, if one curie of radium-226 is released, when equilibrium is reached, the activity level of the mixture will be 12 curies. When radium and its daughters reach this state of equilibrium, its $R Q$ is 0.053 curie. 18

Natural uranium is composed of the isotopes $U .238$ (99.27 percent by weight), U-234 (0.0057 percent by weight), and U-235 ( 0.72 percent by weight). Because the composition by weight of natural uranium is known, we can derive the activity levels of each of its components. The rule results in an RQ for natural uranium, derived through the mixture rule, of 0.1 curie, if the natural uranium is not in equilibrium with its daughters. If the natural uranium is in secular equilibrium with its daughters, the RQ derived through the mixture rule is 0.052 curie.

Natural thorium consists of 100 percent Th-232. When in secular equilibrium with its daughters, the $R Q$ for natural thorium is calculated using the mixture rule to be 0.011 curie.

\subsection{REPORTING REQUIREMGENTS FOR COMIPOUNDS AND MUXIURES OF RADIONUCLIDES AND OTHER HAZARDOUS SUBSTANCES}

The final RQs are for radionuclides, which are species of atoms defined by their atomic number and mass. These RQs are applicable to all chemical and physical forms in which the radionuclides may exist. EPA recognizes that because the radionuclide $R Q s$ are applicable to all chemical forms, some

18Kaplan, I., Nuclear Physics, Addison-Wesley Publishing Company, Reading, Massachusetts, 1958, p. 202. Using the mixture rule, the RQ for radium in equilibrium with its daughters was calculated from the following formula:

where:

$$
\frac{1}{\mathrm{RQ}_{\operatorname{mix}}}-\frac{1}{12} \sum_{i=1}^{12} \frac{1}{\mathrm{RQ}_{\mathrm{i}}}
$$

$R Q_{i}$ is the reportable quantity of radium or the daughter of concern. 
substances containing radionuclides will have two applicable RQs, one based on radiation hazard and the other based on chemical toxicity. In such situations, the lowest applicable RQ for a substance governs when the owner or operator must report the release to the National Response Center. In this way, the RQs reflect the relative chemical toxicity and radiation hazard of a substance.

For example, naturally occurring cadmium consists of roughly 12 percent cadmium-113, a radioactive isotope, and several other isotopes of cadmium that are not radioactive. The $R Q$ for cadmium has been finalized at 10 pounds and the RQ for cadmium-113, just one component of naturally occurring cadmium, is $0.1 \mathrm{Ci}$. A releaser of cadmium metal is required to report if either 10 pounds of the metal (if the diameters of the particles of the released metal are less than or equal to 100 micrometers) or $0.1 \mathrm{Ci}$ of cadmium-113 (regardless of the particle size of the cadmium-113) is released. In this case, the RQ based on chemical toxicity is much more limiting than the RQ based on radiotoxicity (a release of 10 pounds of cadmium metal or 10 pounds of cadmium-113 constitutes far less than $0.1 \mathrm{Ci}$ ). For other materials, however, the RQ based on radiotoxicity is more 1 imiting than the one based on chemical toxicity. In both situations, the lowest RQ applicable to the substance released would be the reporting trigger.

Uranyl acetate and uranyl nitrate are additional examples of substances. with two applicable RQs, one based on chemical toxicity and the other based on radiation hazard. Both substances are specifically listed as CERCLA hazardous substances because they are included under section 311 of the CWA; however, they both consist of about 60 percent uranium-238, a radionuclide. Based on their chemical toxicity, uranyl acetate and uranyl nitrate have a final adjusted RQ of 100 pounds ( 51 ER 34534, September 29, 1986). The final RQ for uranium-238, based upon radiological hazard, is $0.1 \mathrm{Ci}$, which is equivalent to roughly 660 pounds of uranium-238. Both the $0.1 \mathrm{Ci} R Q$ for uranium-238 and the 100 pound $R Q$ are applicable to releases of uranyl acetate and uranyl nitrate, but the 100-pound $R Q$ will always trigger reporting first because it is the lower, more protective level. The RQ of 100 pounds will assure timely reporting of releases of uranyl acetate and uranyl nitrate from both a radiological hazard and chemical toxicity standpoint. 
APPENDICES

A. a 
This Side Left Blank 


\section{APPENDIX A}

MODELING THE AIRBORNE REIEASE AND INHALATION

OF RADIONUCLIDES

This appendix documents the model used to calculate inhalation release values (RVs) which are a component in the adjustment of radionuclide RQs. The inhalation release values represent the quantity of a radionuclide (in units of curies) that, if released into air under an assumed set of conditions, could result in an exposed individual receiving an effective dose-equivalent of 500 millirem through the inhalation pathway. The inhalation RVs calculated for each radionuclide can be found in Appendix $E$ of this report.

This appendix is divided into three main sections. The first section presents the basic model used to calculate inhalation RVs, defines the input, parameters, and discusses the basic rationale underlying the model. In sections A.2 and A.3, the basis for two key input variables used in the model, the airborne release fraction and the atmospheric relative concentration value, respectively, is presented.

\section{A.1 THE INRATATION MODEL}

Radionuclides can be released into the air in several different ways and at any rate. In order to calculate meaningful release values for the adjustment of RQs, it is necessary to use a model that is realistic (i.e., reflects release and exposure conditions that may actually occur) but conservative enough to yield timely reporting for most release situations. The model selected for this purpose assumes that: (1) radionuclides are released to air from a point source at ground level; (2) the radionuclides disperse in the atmosphere in a gaussian plume; and 
(3) an Individual is exposed at a position 30 meters downwind from the point of release and remains in the plume centerline, the point of maximum concentration, for the entire release period. Under this set of conditions, the size of the release in curies (the release value) necessary to provide a 500 millirem effective dose-equivalent to the exposed individual can be calculated using equation (1):

$$
\begin{aligned}
& \text { Inhalation } \\
& \text { Release Value }=\operatorname{ALI} /\left[(10) *(R) *(X / Q) *(B R) *\left(1 \times 10^{6}\right)\right] \\
& \text { (Ci) }
\end{aligned}
$$

where:

$$
\begin{aligned}
& \text { ALI = } \text { annual } 1 \text { imit of intake for inhalation (microcuries); } \\
& 10 \quad \text { factor to convert the annual limit of intake which is } \\
& \text { based on } 5 \text { rem dose-equivalent to a worker in a } \\
& \text { nuclear facility to } 0.5 \text { rem, the Federal Radiation } \\
& \text { Protection Guideline for exposure to members of the } \\
& \text { general public; } \\
& \mathrm{R}=\text { airborne release fraction; } \\
& \mathrm{X} / \mathrm{Q}= \text { atmospheric relative concentration value at a position } \\
& 30 \text { meters downwind }\left(8.4 \times 10^{-13}\right. \text { day/cubic cm); } \\
& \mathrm{BR}= \text { breathing rate for reference man }\left(2.3 \times 10^{7} \mathrm{cubic}\right. \\
& \text { cm/day); and }
\end{aligned}
$$

$1 \times 10^{6}$ conversion factor between microcuries and curies.

The inhalation AIIs used in the calculations are taken from ICRP's Publication $30^{l}$ after being converted from becquerels to microcuries. Where more than one ALI was given for a particular radionuclide, the lowest value was used for the calculations. This assures that the most hazardous chemical form of a radionuclide is used in the release value calculations.

IInternational Commission on Radiological Protection (ICRP), "Limits for Intakes of Radionuclides by Workers," Publication 30 , Part 2, 1980.

$$
A-2
$$


There are two important points to clarify with respect to equation (1). First, the model ignores the effects of radioactive decay. This is because the pathway model considers exposures to an airborne plume of radionuclide. A short-lived radionuclide could undergo significant decay if the release and exposure periods were as long as one day, but decay would be much less if a time period of a few hours, minutes or seconds was considered. Because it was not possible to establish exact bounds on the range of release and exposure periods (note that the equation does not include a specific time factor for these periods), the Agency conservatively assumed that no decay occurs over these periods. EPA also ignored decay over the period of radionuclide transport to the point of inhalation. This approach was adopted because decay during airborne transport to a receptor 30 meters downwind would be negligible for most of the radionuclides considered.

second, it is recognized that' the point source ground level release assumed in the model is not applicable to all release configurations. Radionuclides are also commonly emitted to the air from areal sources and from raised point sources such as smokestacks. Examples of areal sources include coal ash piles found at coal-fired boiler sites and open pit mining operations, both of which emit radon to the atmosphere. A point source release at ground level was assumed in the model because it most closely resembles an episodic release for which a response might be taken and because it yields more conservative (i.e., lower) release values than other release configurations. In this sense, the release values calculated under these conditions will assure timely reporting for most release situations. Conversely, release values that would have been calculated if an areal or elevated source had been assumed would not necessarily assure timely reporting for releases from a point source at ground level. 


\section{A.2 EVAIUATION OF THE RELEASE FRACTION}

The release fraction, $R$, reflects the fraction of a radionuclide release that could become airborne and be of respirable slze (10 microns in diameter or less). The Nuclear Regulatory Commission has developed release fractions for radionuclides under accident conditions ${ }^{2}$. These release fractions and the rationale behtnd-them-are-summarized below.

Isotopes of the noble gases argon, krypton, radon and xenon have been assigned release fractions of 1.0 because they are always gases at room temperature, remain mixed with air, and do not react chemically to form less volatile compounds. The Nuclear Regulatory Commission has assigned a release fraction of 0.5 to compounds of hydrogen, carbon, phosphorous, sulfur, and iodine. Compounds of these elements would be expected to produce less than 100 percent volatilized and respirable particles or gases for the following reasons: '(1) some compounds of the elements will settle out on surfaces and not be released to the atmosphere, and (2) some particles in the release may not be respirable.

Compounds of the elements selenium, mercury, cesium, polonium, tellurium, and ruthenium, among others are only semivolatile and have been assigned release fractions of 0.01 .

Release fractions for non-volatile metals such as uranium, plutonium, tantalum, thorium, and americium, among others, have been set at 0.001 . For these metals or compounds of these metals, the release pathway is not volatilization but entrainment of particles in an air stream. Even finely ground powders will

2McGuire, S.A., "A Regulatory Analysis on Emergency Preparedness for Fuel Cycle and other Radioactive Material Iicensees," NUREG1140 , June 1985 .

$$
\text { A-4 }
$$


generally contain less than a few percent of the powder in respirable size. The fraction of particles of respirable size is kept small by the dificulty in producing small particles and subsequently by agglomeration and weathering, processes which cause micron-sized particles to stick to surfaces, to larger particles and to themselves.

Release fractions for the various elements may be found in Exhibit A-1. Inhalation release fractions were taken from the Nuclear Regulatory Commission's NUREG-1140. Where release fractions for specific isotopes are shown in NUREG-1140, these were used for all isotopes of the element. Where NUREG-1140 does not show a release fraction for a specific element or isotope, the release fractions were derived by reference to statements at the end of the table recommending a release fraction of 0.01 for "any other beta-gamma emitter" and a release fraction of 0.001 for "any other alpha emitter." 


\section{EXHIBIT A-1}

\section{INRAIATION RELEASE FRACTIONS}

Element

Actinium

Aluminum

Americium

Antimony

Argon

Arsenic

Astatine

Barium

Berkelium

$B k-249 \& B k-250$

Beryllium

Bismuth

Bromine

Cadmium

Calcium

Californium

Carbon

Cerium

Cesium

Chlorine

Chromium

Cobalt

Copper

Curium

Dysprosium

Einsteinium

Es-254m

Erbium

Europium

Fermium
Symbol

AC

A1

Am

Sb

Ar

As

At

Ba

Bk

Be

B1

Br

cd

$\mathrm{Ca}$

ce

C

$\mathrm{Ce}$

$\mathrm{Cs}$

Cl

Cr

Co

cu

CIn

Dy

Es

Ex

Eu

Fin
Release Eraction (R)

0.001

0.01 *

0.001

0.01

1.0

0.01 *

$0.001 *$ *

0.01

$0.001 *$ *

0.01 *

$0.01 *$

0.01

0.01

0.01

0.01

0.001

0.5

0.01

0.01

0.01

0.01

0.001

0.01

0.001

$0.01 *$

$0.001 * *$

0.01 *

$0.01 *$

0.01

$0.001 * *$

A-6 
EXHIBIT A-I (Cont.)

\section{Element}

Fluorine

Francium

Gadolinium

Gal11um

Germanium

Gold

Hafnium

Holmiun

Hydrogen

Indium

Iodine

Iridium

Iron

kryptor

Lanthanum

Lead

Lutetium

Magnesium

Manganese

Mandelevium

Mercury

Molybdenum

Neodymium

Neptunium

Nickel

Niobium

Osmium

Palladium

Phosphorus

Platinum

\section{Symbol}

F

Fr

Gd

Ga

Ge

Au

He

Ho

$\mathrm{H}$

In

I

Ir

Fe

Kr :

Ia

$\mathrm{Pb}$

Lu

Mg

in

yd

$\mathrm{Hg}$

Ho

Nd

Np

N1

Nb

Os

Pd

P

Pt
Release

Fraction (R)

0.01 *

$0.01 *$

0.01

0.01 *

0.01

0.01

0.01

0.01

0.5

0.01

0.5

0.001

0.01

1.0

$0.01 *$

0.01

0.01 *

$0.01 *$

0.01

$0.001 *$ *

0.01

0.01

$0.01 *$

0.001

0.01

0.01

0.01 *

$0.01 *$

0.5

$0.01 *$ 
EXHIBIT A-1 (Cont.)

Element
Plutonium
Polonium
Potassium
Praseodymium
Promethium
Protactinium
Radium
Radon
Rhenium
Rhodium
Rubidium
Ruthenium
Samarium
Scandium
Selenium
Silicon
Silver
Sodium
Strontium
Sulfur
Tantalum
Technetium
Tellurium
Terbium
Thallium
Thorium
Thulium
Tin
Titanium

Symbol

Pu

Po

$\pi$

Pr

Pin

Pa

Ra

$R n$

Re

Rh

$R b$

Ru

Sin

Sc

se

si

Ag

$\mathrm{Na}$

sr

$\mathbf{S}$

Ta

TC

Te

Tb

Tl

Th

Tm

sn

T1
Release Eraction (R)

0.001

0.01

0.01

$0.01 *$

0.01

0.001

0.001

1.0

$0.02 *$

0.01 *

0.01

0.01

0.01

0.01

0.01

0.01 *

0.01

0.01

0.01

0.5

0.001

0.01

0.01

0.01

0.01

0.001

0.01

0.01

0.01 


\section{EXRIBIT A-1 (Cont.)}

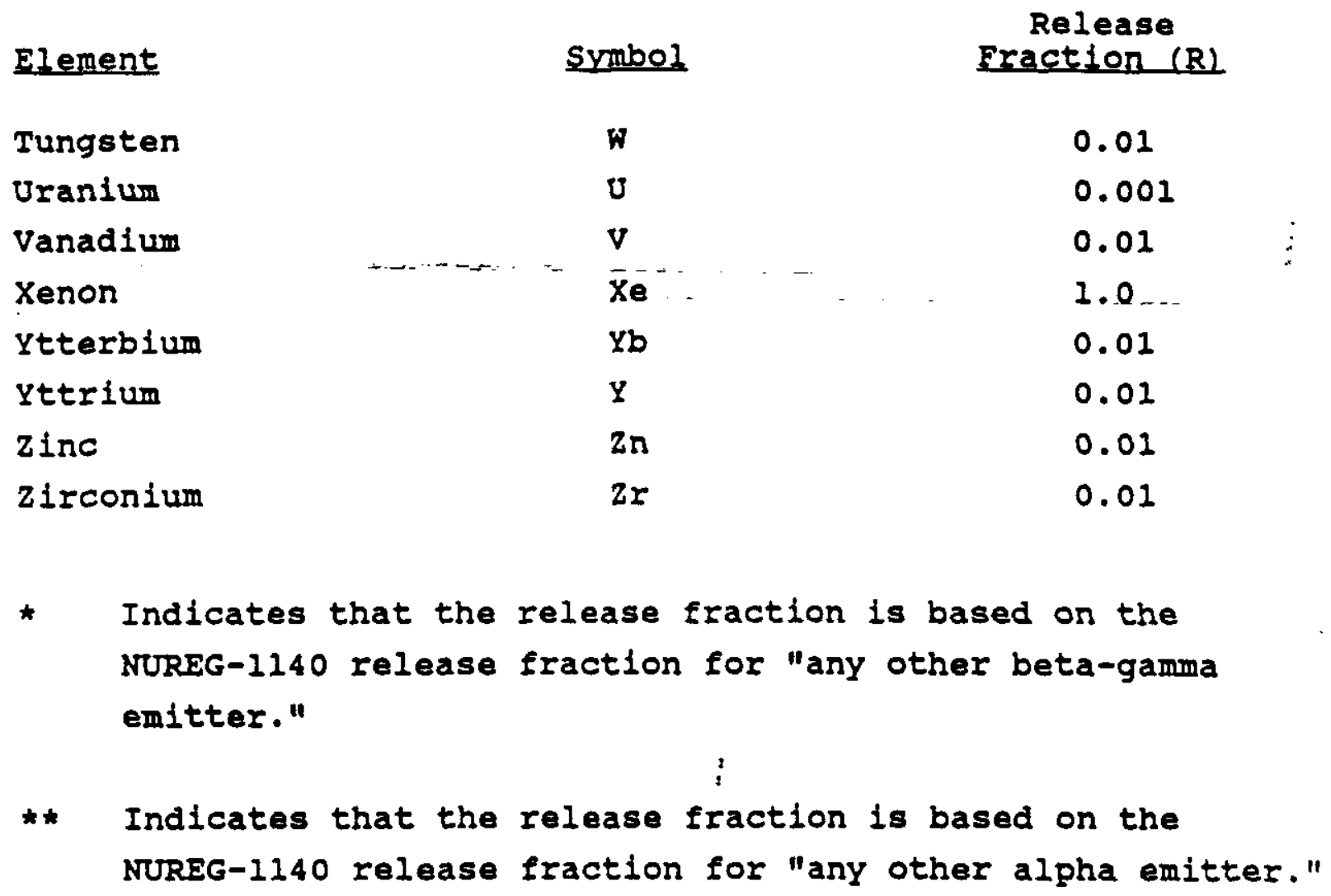

Source: McGuire, S.A., "A Regulatory Analysis on Emergency Preparedness for Fuel Cycle and other Radioactive Material Licensees," NUREG-1140. 


\section{A.3 DERIVATION OF THE ATMOSPFERIC RELATIVE CONCENTRATION VALUE}

In calculating inhalation release values, it is necessary to use atmospherlc dispersion modeling to estimate the fraction of a release which might be encountered by an individual. The atmospheric dispersion parameter needed in equation (1) is the atmospheric relative concentration value, $\operatorname{chl}$ over $Q(X / Q)$. The value used for $X / Q$ was taken erom Exhibit $A-2$, which is an extrapolation of the graph in Exhibit A-3.3 Exhibit A-3 plots $\mathrm{Xu} / \mathrm{Q}$ per square meter versus distance from the source in kilometers for releases varying in height from ground level (the uppermost line in the plot) to a helght of 300 meters. The symbol $u$ in $X u / Q$ stands for wind speed in meters per second. $X u / Q$ is plotted so that a value for $X / Q$ can be derived for any wind speed simply by dividing the value found in the plot by the desired wind speed. In this analysis, a wind speed of 1 meter per second is used, yielding $a / Q^{2}$ in units of seconds per cubic meter.

For the purpose of calculating RQs, some conservative assumptions in deriving $X / Q$ have been made. These assumptions include:

1. The distance from the point source release to the point of exposure is assumed to be 30 meters (about 100 feet). In addition, it is assumed that a gaussian distribution of the released contaminant is established almost immediately within the plume and is fully developed at 30 meters.

3Turner, D. Bruce, "Workbook of Atmospheric Dispersion Estimates," EPA office of Air Programs, 1970.

$$
\text { A-10 }
$$


WHC-SD-GN-HC-20002, REV. 0

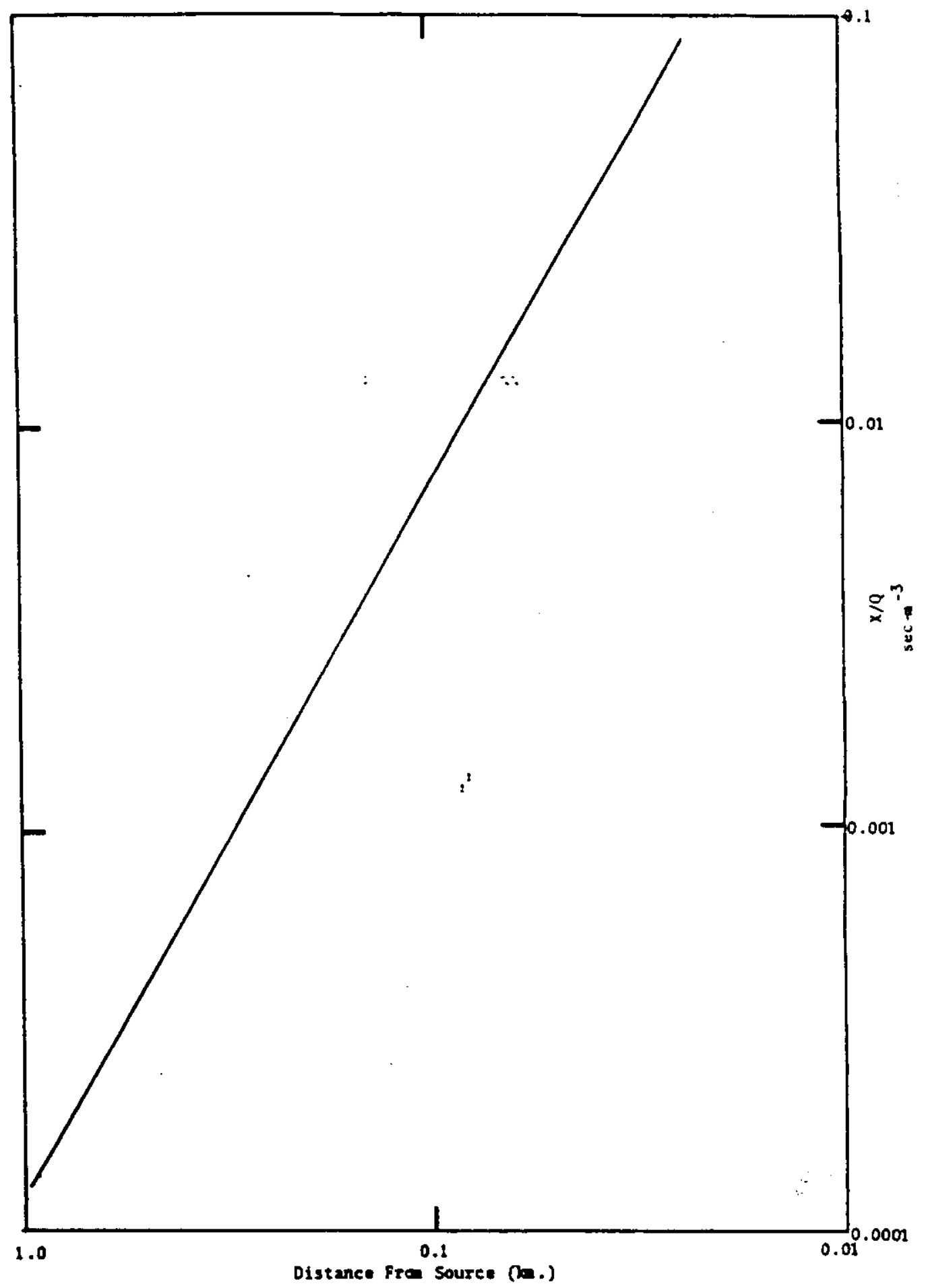

EXHIBIT A-2. X/Q Vs. Distance for a Ground Level Release, Stability Class D.

$$
\text { A-11 }
$$




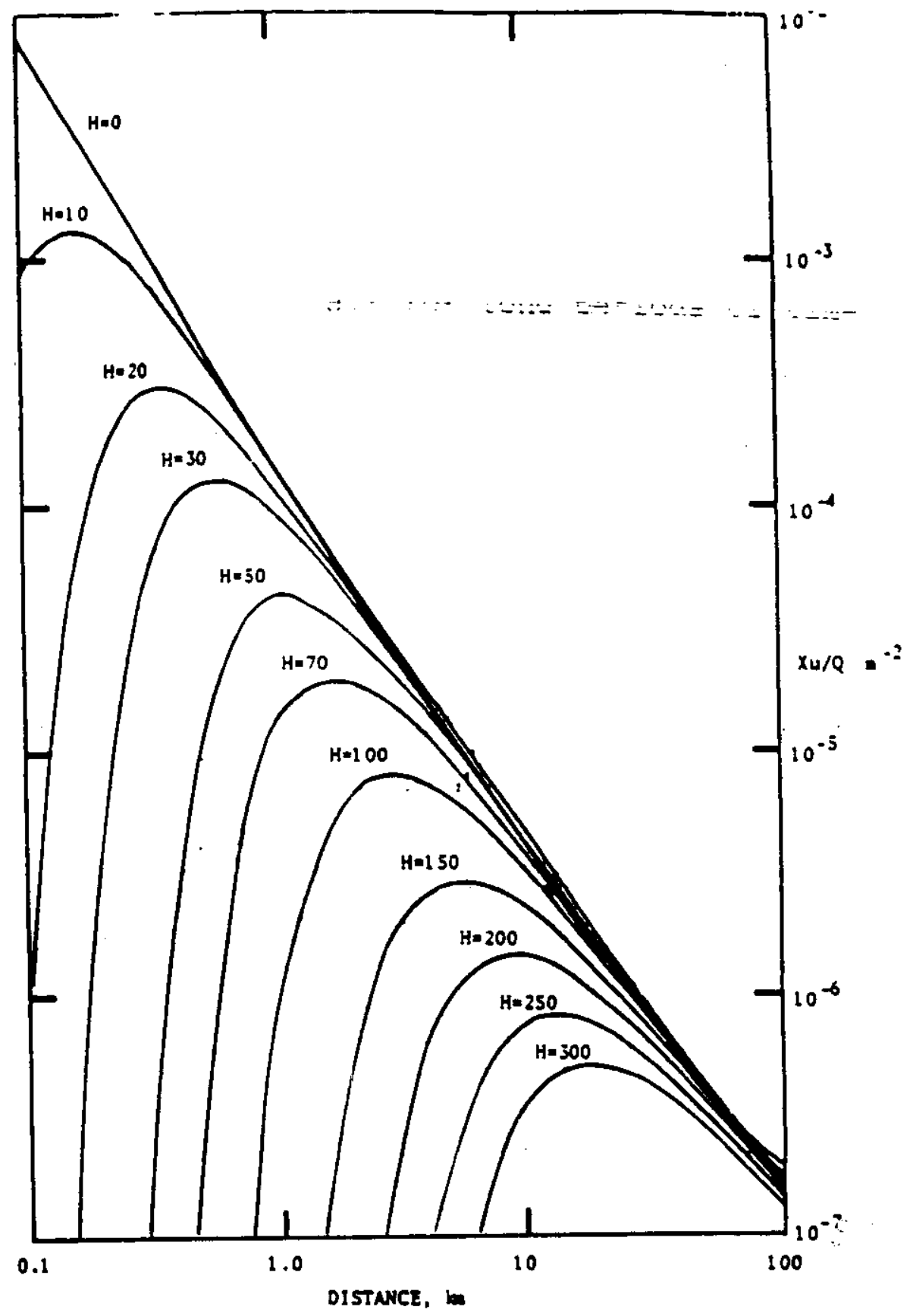

EXHIBIT A-3. Xu/Q Vs. Distance at Various Heights (H) of Release (meters), Stability Class D. 
2.. The release occurs at ground level. This approach gives the highest ground level concentrations and the lowest inhalation RVs.

3. The point of exposure is directly downwind from the release in neutral (Class D) atmospheric conditions and the wind speed (u) is 1 meter per second.

4. The material released is a stable gas or aerosol (less than 20 microns in diameter) which remains suspended in air for long periods of time.

5. The gas or aerosol is continuously emitted from the source or the emission time is equal to or greater than the travel time to the point of exposure. In this case, it is possible to omit from consideration diffusion in the direction of transport. The equations used to produce the graphs in Exhibits $\mathrm{A}-2$ and $\mathrm{A}-3$ are valid only if diffusion in this direction is assumed to be zero. This is a reasonable assumption because the rate of diffusion in this direction would be much smaller than the wind speed of 1 meter per second.

6. None of the material emitted is removed from the plume as it moves downwind and there is complete reflection from the ground.

With these assumptions and referring to Exhibit $A-2$, it is possible to obtain a $X / Q$ of $7.2 \times 10^{-2}$ seconds per cubic meter. Because a breathing rate in units of cubic centimeters per day is being used in equation ( 1 ), it is necessary to convert $x / Q$ to compatible units. This leads to a value of 8.4 4an-13 day per cubic centimeter, the value used in this report.

Most published sources describing gaussian advectiondispersion equations provide graphlcal representations for $x / Q$ at distances from the source as close as 100 meters. The Agency recognizes that extrapolation of these values to shorter distances may introduce an error in subsequent calculations. The extrapolation, however, allows the calculation of conservative release values and, for this application, the error which may be introduced is believed to be inconsequential. Moreover, it is

$$
A-13
$$


recognized that several other assumptions in the atmospheric dispersion model also $Y$ leld a conservative $X / Q$ value. Alternative assumptions would, of course, yield different values for $x / Q$ as discussed below.

If, instead of extrapolating down to 30 meters, the value for a distance of one hundred meters (assuming a ground level release) is chosen, $X / Q$ becomes $9.5 \times 10^{-14}$ day per cubic centimeter. This value is almost an order of magnitude smaller than the 30 meter value and would lead to inhalation RVs nearly a factor of ten higher. Exhlbit A-3 also shows values for plume heights $(H)$ greater than ground level ( $H=10$ to $H=300$ meters). plume heights are not necessarily the same as the stack height and are affected by phenomena such as inversion layers, wind speeds, and the velocity of stack ejecta. In any case, it is clear from Exhibit A-3 that if RVs were to be calculated on the basis of a release from above ground level, they would be much larger. For example, in the case, of a release 20 meters above ground, the calculated $X / Q$ is approximately 1 x 10-17 day per cubic centimeter at one hundred meters, a factor nearly ten thousand times smaller than that for a ground level release. If calculated at 350 meters (the point of maximum concentration according to Exhlbit $A-3$ ) the value would be $3.5 \times 10^{-15}$ day per cubic centimeter, a value more than 200 times smaller than the value used in equation (1).

The graphs shown in Exhiblts $A-2$ and $A-3$ and used for the determination of $X / Q$ are generated from the equations for atmospheric modeling and are intended to simplify the task of determining $X / Q$. The generally accepted expression for the concentration, $X$ (chi), of gas or aerosols at polnt $x ; y, z$ from a continuous source with an effective emission height, $H$, is given in the equation below. The coordinate system referred to can be found in Exhibit A-4. 


$$
x(x, y, z ; H) \cdot \frac{Q}{2 \pi \sigma_{y} \sigma_{z} u} \exp \left[-1\left(\frac{y}{\sigma_{y}}\right)^{2}\right]\left\{\exp \left[-1\left(\frac{z H}{\sigma_{z}}\right)^{2}\right] \cdot \exp \left[-1\left(\frac{z+H}{\sigma_{z}}\right)^{2}\right]\right\}
$$

where:

$$
\begin{aligned}
& \left.x=\text { chi, concentration (curles } / \mathrm{m}^{3}\right) \text {; } \\
& x, y, z=\text { positions in the coordinate systems (see Exhibit: } \\
& \text { A-4): } \quad \therefore-\quad \text { - } \\
& \text { Q } \quad \text { release rate (curles/sec); } \\
& \pi \quad=\text { pl (3.14159, approximately); } \\
& \sigma_{y} \quad=\text { horizontal dispersivity (meters); } \\
& \sigma_{2} \quad=\text { vertical dispersivity (meters); } \\
& \text { u } \quad \text { wind speed (meters per second); } \\
& \exp \quad=\exp (-a / b)=e^{(-a / b)} \text { where e is the base of } \\
& \text { natural logarithms and is approximately equal to } \\
& 2.7183 \text {; and } \\
& \text { H - the effective emission height (meters). }
\end{aligned}
$$

Several assumptions are made concerning the hypothetical release which result in the simplification of Equation (2). These simplifications are shown below.

For concentrations calculated at ground level for a ground level release (1.e., $z=0$ ) the equation simplifies to:

$$
x(x, y, 0 ; H)=\frac{Q}{\pi \sigma_{y} \sigma_{z} u} \exp \left[-\frac{1}{2}\left(\frac{y}{\sigma_{y}}\right)^{2}\right] \exp \left[-\frac{1}{2}\left(\frac{H}{\sigma_{z}}\right)^{2}\right]
$$




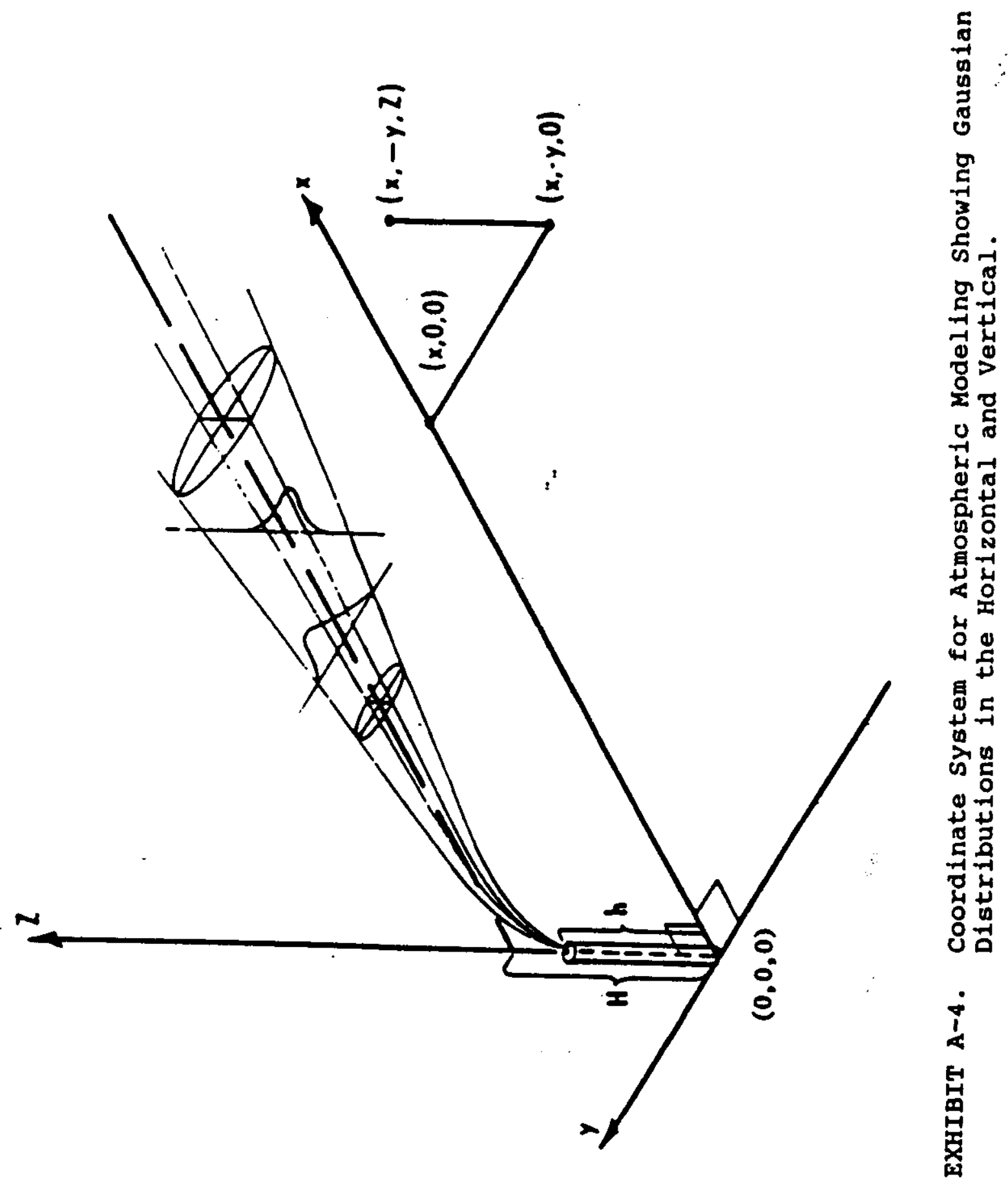


Where the concentration is to be calculated along the centerline of the plume giving the maximum concentration (i.e., $Y=0):$

$$
X(x, 0,0 ; H)=\frac{Q}{\pi \sigma_{y}^{\sigma} \sigma_{z}} \exp \left[-\frac{1}{2}\left(\frac{H}{\sigma_{z}}\right)^{2}\right] .
$$

For a ground level source with no effective plume rise (i.e., $H=0$ ), the equation simplifies even further:

$$
x(x, 0,0 ; 0)=\frac{Q}{\pi \sigma_{y} \sigma_{z} u}
$$

The values for dispersion in the $y$ and $z$ directions $\left(\sigma_{y}\right.$ and $\sigma_{z}$ ) vary with the turbulent structure of the atmosphere, height above the surface, surface roughness, sampling time over which the concentration is to be estimated, wind speed, and distance from the source. Values for $\sigma_{y}$ and $\sigma_{z}$ are estimated for each atmospheric stability class, which'include an estimated wind speed. Stability class $D$, used here, assumes a light wind in overcast conditions during either day or night. Using stability Class $D$ results in higher concentrations and lower RQs than would more turbulent stability classifications. The estimates for horizontal and vertical dispersion coefficients can be found in the Workbook of Atmospheric Dispersion Estimates. 4 Rearranging Equation (5), above, as shown, and applying values for $\sigma_{Y}$ and $\sigma_{z}$ from the graph in Exhibit A-5 yields:

$$
X u / Q=\frac{1}{\pi \sigma_{y} \sigma_{z}}=\frac{1}{\pi(2.6)(1.65)}=7.5 \times 10^{-2} \mathrm{~m}^{-2} .
$$

4Turner, D. Bruce, "Workbook of Atmospheric Dispersion Estimates," EPA office of Air Programs, 1970. 


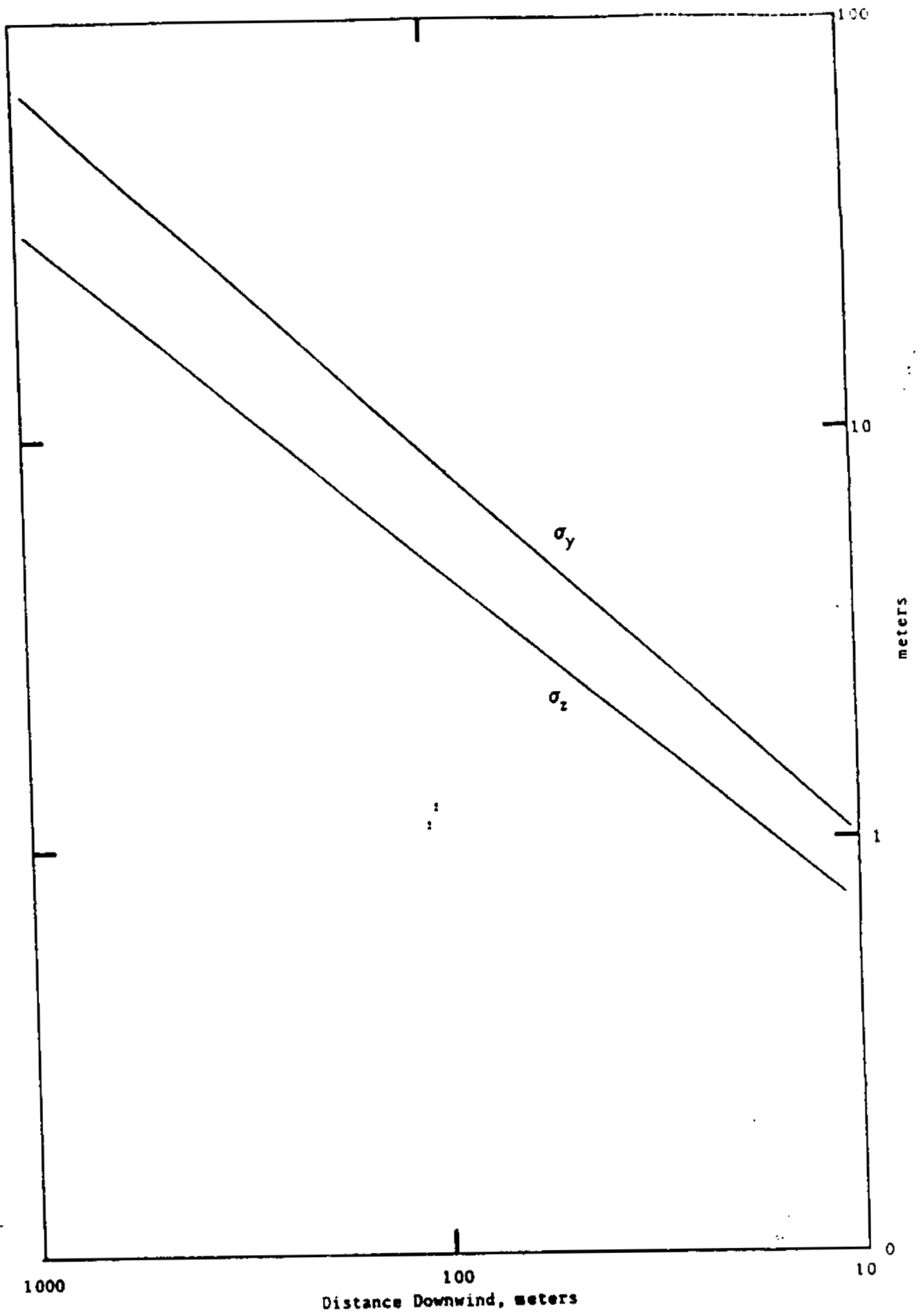

EXHIBIT A-5. Horizontal and Vertical Dispersion Coefficient as a Function of Downwind Distance From the source.

$$
A-18
$$


Division of both sides of the equation by a wind speed, $u$, of 1 meter per second gives:

$$
X / Q=7.5 \times 10^{-2} \sec \mathrm{m}^{-3}
$$

Considering the possibilities for error introduced in extrapolation, this value agrees very well with the value found by reference to Exhibit $A-2\left(7.2 \times 10^{-2} \mathrm{sec} \mathrm{m}^{-3}\right)$. 
This Side Left Blank : 


\section{APPENDIX B \\ MODEIING THE INGESTION OF CONTAYINATED \\ DRINKING WATER}

Drinking water in the United states is usually obtained from one of two sources: wells drilled into subsurface aquifers or surface sources such as reservoirs, lakes or rivers. Any of: these drinking water sources can become contaminated from a release of radionuclides. The Agency has calculated ingestion release values for both subsurface aquifers and for, rivers in order to determine which might provide the more critical pathway for consumption of contaminated water. EPA believes that reservoirs and lakes provide such large dilution factors for releases of radionuclides that modeling these potential sources of contaminated water will provide release values much larger than those produced by modeling of ground water or river water and, therefore, is not necessary.

Point sources of release are assumed in both the groundwater model and surface-water model. This assumption is made because such a source better represents a sudden, episodic release or spill as opposed to a chronic release from a waste site or other impoundment. section B.l provides the general equation the Agency used to calculate release values for the consumption of contaminated drinking water while section $\mathrm{B} .2$ reviews a number of ground-water models examined by the Agency and describes in detail the advection-dispersion model chosen for calculation of a dilution factor to be used in the equation for calculation of release values based on water consumption.

Section B.3 describes a surface water model for contamination of rivers from point source releases of radionuclides and explains the Agency's reasons for not using this model for determination of dilution factors and calculation of release values. 


\section{B. 1 CALCULATION OF REIEASE VALUES FOR THE CONSUMPTION OF CONTAMINATED DRINKING WATER}

The release value calculated for the consumption of contaminated drinking water (DW) is directly proportional to the ingestion ALI and inversely proportional to the dilution factor, contact time, and water consumption rate of reference man. The method which the Agency has adopted for the calculation of release values based on the consumption of contaminated drinking water is summarized in equation ( 1 ).

$D W$ Release Value $=\operatorname{ALI} /\left[(10) *(D F) *(C T) *(W C) *\left(1 \times 10^{6}\right)\right]$

where:

ALI = annual limits if intake for ingestion (microcuries);

10 factor to convert the annual limit of intake which is based on 5 rem dose-equivalent to a worker in a nuclear facility to the more conservative 0.5 rem for exposure to the general public;

$D F=$ dilution factor (liter $\left.{ }^{-1}\right)$;

CT $=$ contact time (days);

WC = water consumption rate of reference man (2 liters per day); and

$1 \times 10^{6}$ conversion factor between microcuries and curies.

The ingestion ALIs used in the calculation are taken from ICRP's Publication $30^{1}$ after conversion from becquerels to microcuries. Where more than one ALI was given for a particular radionuclide, the lowest value was used in the calculations.

International Commission on Radiological protection (ICRP), "Limits for Intakes of Radionuclides by Worker," Publication 30 , Part 2, 1980. 
The dilution factor (DF) and contact time (CT) terms used in equation (l) for calculation of a drinking water release value based on the consumption of contaminated ground water are derived and more fully explained in section B.2 while section B. 3 explains the derivation of a dilution factor for contaminated river water. As described in section B.2, the dilution factor for ground-water consumption takes radioactive decay into account for the period of transport from the point of release to the point of exposure and the contact time term in equation (1) is modified for radioactive decay over the period of consumption. In determination of a dilution factor for consumption of contaminated river water, however, radioactive decay is not considered because the time of transport from the point of release to the point of consumption is very short. Additionaliy, in this case, radioactive decay during the period of consumption is ignored because this period is not well defined as it is in the scenario for consumption of contaminated ground water.

\section{B.2 GROUND-WATER TRANSPORT OF RADIONUCIIDES}

Two ground-water models for the purpose of calculating a dilution factor in equation (1), the advection-dispersion model and the simple dilution model, were examined in some detall by the Agency. Also, four other models developed for specialized purposes within the Resource Conservation and Recovery Act (RCRA) program were reviewed and compared to the selected advectiondispersion model. These models are described below.

\section{B.2.1 The Advection-Dispersion Model.}

The calculation of a dilution factor for a radionuclide release to ground water can be accomplished by assuming a release scenario that is reasonably conservative. In this calculation, it is assumed that the release is directly to ground water, which 
is a conservative assumption because it neglects migration through the unsaturated zone. The following assumptions are also made:

- Llow is uniform and steady (ground-water velocity $=0.5$ meter/day);

- the aquifer is homogeneous and isotropic;

- the release is an instantaneous point source to the saturated zone;

- at time zero, the concentration of radionuclide in the aquifer is zero;

- the aquifer is of finite thickness and infinite extent (there are no boundaries close enough to affect the transport); and

- the drinking water well is located 30 meters down gradient from the point of release.

For an instantaneous point source located on the $z$ axis in uniform steady flow (Exhibit B-1); the analytical solution of the transport equation $1 \mathrm{~s}^{2}$ :

$$
C=\frac{M}{(4 \pi t)^{3 / 2}\left(E_{X} E_{y} E_{z}\right)^{1 / 2} R_{Q^{n}}} \exp -\left[\frac{(x-U t)^{2}}{4 E_{x} t}+\frac{y^{2}}{4 E_{Y} t}+\frac{z^{2}}{4 E_{z} t}+\lambda t\right](2)
$$

where: $M$ magnitude of the instantaneous release ( 1 Ci);

$R_{d}=$ retardation factor;

n effective porosity (0.1);

$\lambda \quad=$ radioactive decay constant $\left(0.693 / t_{1 / 2}\right)$

$t$ - time of travel from source to well $\left(t=30 /\left(V_{x} /\left(n R_{d}\right)\right)\right.$;

$t_{1 / 2}=$ radionuclide half-life in days;

${ }^{2}$ Carlsaw, H., Jaeger, J., "Conduction of Heat in Solids," Oxford University Press, London, 1959.

$$
\text { B- } 4
$$


Scenario for Calculation of Ground-Water Transport
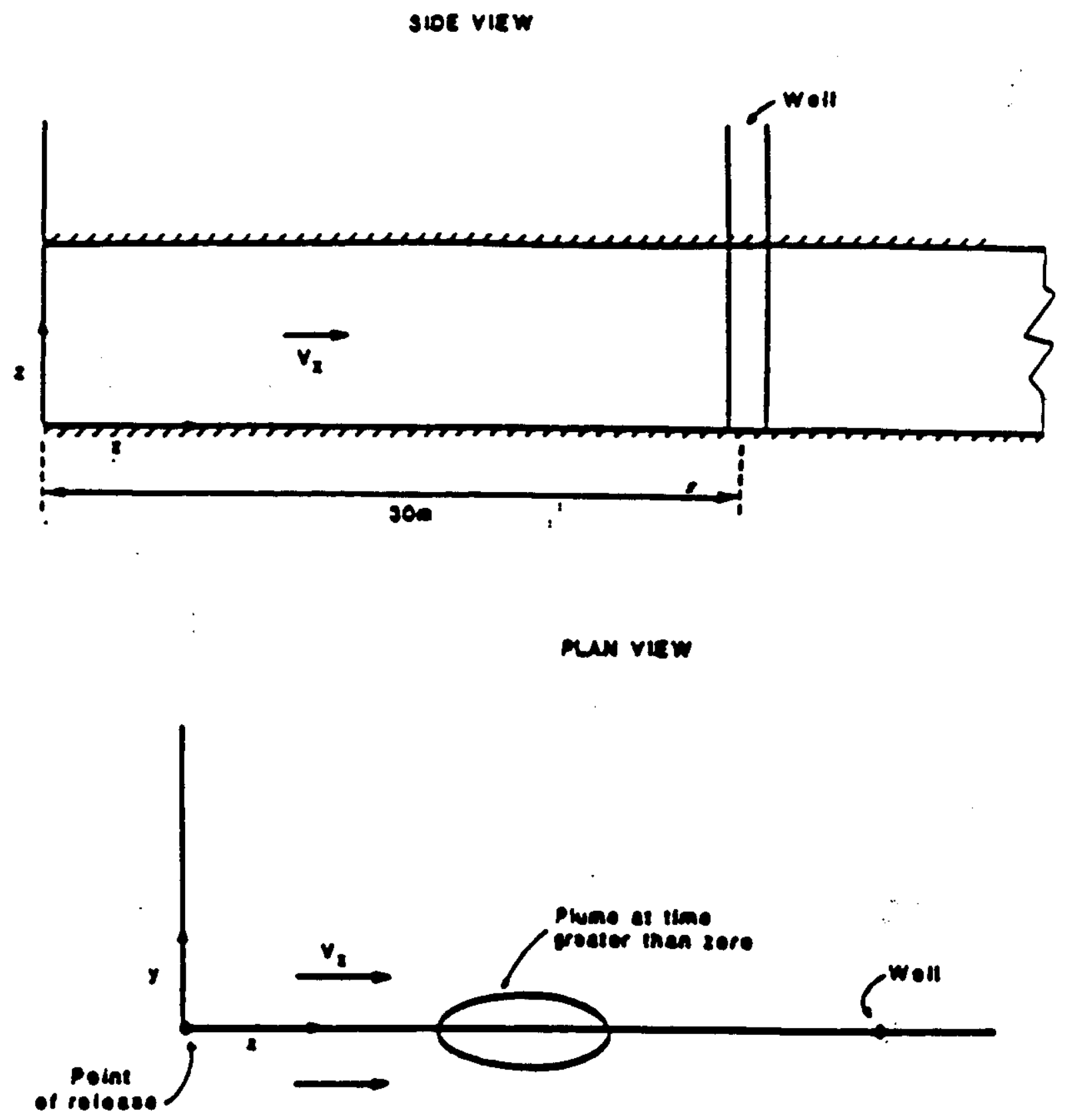

B-5 
c = maximum radionuclide concentration;

and $E_{X}, E_{Y}, E_{z}, R_{d}$, and $U$ are defined as:

$$
\begin{aligned}
E_{x} & =D_{x x} / R_{d} ; E_{y}=D_{y y} / R_{d} ; E_{z}=D_{z z} / R_{d} ; \\
U & =V_{x} / n R_{d} ; R_{d}=1+\left(P_{b}\right) \star\left(K_{d} / n\right) ;
\end{aligned}
$$

where:

$D_{x x}=$ longitudinal coeficient of dispersion;

$D_{y y}=D_{z z}=$ transverse coefficients of dispersion;

$P_{b}=$ bulk density of the aquifer $\left(1.5 \mathrm{gm} / \mathrm{cm}^{3}\right)$;

$v_{\mathbf{X}}=$ flow of the aquifer ( 0.5 meters per day). This value was chosen as a conservative flow rate for sand-containing aquifers by comparison to Table 8-2 in the report referenced ${ }^{3}$. This table lists 45 different saturated zone layers that contain sand and various other earth materials in different proportions. The smallest flow listed is 0.7 meters/year, while the largest is greater than 10,000 meters/year. The average flow is 625 meters/year or abut 1.7 meter/day. A value of 0.5 meters/day is conservative in that it prolongs contact time and leads to a lower (more conservative) Release Value; and

$k_{d}=$ the sorption coefficient in $\mathrm{cm}^{3} / \mathrm{g}$ (see Exhibit B-2 for a compilation of values used).

Dispersion coefficients are defined by the following equations :

where:

$$
D_{X X}=\left(a_{1}\right) *\left(v_{X} / n\right) ; D_{Y Y}=D_{z 2}=\left(a_{t}\right) *\left(v_{X} / n\right) ;
$$

$a_{1}=$ longitudinal dispersivity (20 meters);
$a_{t}=$ transverse dispersivity ( 4 meters).

3"Liner Location Risk and Cost Analysis model," Draft Report under contract No. 68-01-6621, Office of Solid Waste, EPA, January, 1985. 


\section{EXHIBIT B-2 \\ SORPTION COEFFICIENT VAIUES}

\section{EIEMENT}

$$
\text { Actinium }
$$

Aluminum

Americium

Antimony

Argon

Arsenic

Astatine

Barium

Berkelium

Beryllium

Bismuth

Bromine

Cadmium

Calcium

californium

Carbon

Cerium

Cesium

Chlorine

Chromium

cobalt

copper

curium

Dysprosium

Einsteinium

Erbium
Ac

A1

Am

Sb

Ar

As

At

$\mathrm{Ba}$

BK

Be

B1

Br

ca

$\mathrm{Ca}$

ce

C

Ce

Cs

Cl

Cr

co

cu

Cm

Dy

Es

Ex

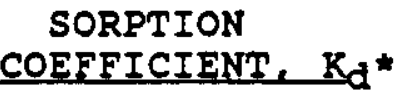

1000

0

1000

1

0

0

0

100

700

75

10

0

50-100 :

15

0

0

2000

2000

0

0

2000

0

500

0

0

0

\section{SOURCE}

EPA 520/4-79-007C

Assumption* *

Hajek (1966), Knoll (1965)

(1969)

EPA 520/6-78-007

EPA 520/4-79-007C

Assumption**

EPA 520/4-79-007C

Analogous to Sr (PNWL $8 / 2 / 86$ )

EPA 520/4-79-007C

EPA 520/4-79-007C

EPA 520-4-79-007C

Assumption**

Estimate (PNWL 8/18/86)

EPA 520/4-79-007C

Assumption* *

Estimate (PNWL, 8/18/86)

Rhodes (1957) Benson (1960)

Letter Report RJS-ARCHO

EPA 520/4-79-007C

Assumption**

EPA 520/6-78-007

Assumption* *

EPA 520/6-78-007, Sheppard (1976)

Assumption * *

Assumption**

Assumption* * 


\section{ELEMENT}

\begin{tabular}{|c|c|c|c|c|}
\hline Europium & Eu & 500 & & Serne Rai (1976) \\
\hline Fermium & Fm & 0 & & Assumption** \\
\hline Fluorine & $\mathbf{F}$ & 0 & & Assumption** \\
\hline Francium & Fr & 200 & & EPA $520 / 4-79-007 C$ \\
\hline Gadolinium & Gd & $500-1000$ & & $\begin{array}{l}\text { Chemical Analogy to Rare Earth } \\
\text { (PNWL } 8 / 28 / 86 \text { ) }\end{array}$ \\
\hline Gallium & $\mathbf{G a}$ & 0 & & Assumption** \\
\hline Germanium & Ge & 0 & & Assumpt Ion** \\
\hline Gold & $\mathrm{Au}$ & 0 & & Assumption** \\
\hline Hafnium & Hf & 0 & & Assumption* * \\
\hline Holmium & Ho & 600 & & EPA $520 / 4-79-007 C$ \\
\hline Hydrogen & H & 0 & & EPA $520 / 6-78-007$ \\
\hline Indium & In & 0 & & Assumption** \\
\hline Iodine & I & 3 & & Shallow Land Burial Program \\
\hline Iridium & Ir & 0 & & Assumption** \\
\hline Iron & Fe & 150 & $\therefore$ & EPA $520 / 4-79-007 C$ \\
\hline Krypton & $\mathrm{Kr}$ & 0 & & Inert Gas (PNWL $8 / 18 / 86$ ) \\
\hline Lanthanum & La & 0 & & Assumption** \\
\hline Lead & $\mathrm{Pb}$ & 4000 & & EPA $520 / 4-79-007 C$ \\
\hline Lutetium & Lu & 0 & & Assumption* * \\
\hline Magnesium & $\mathrm{Mg}$ & 0 & & Assumption** \\
\hline Manganese & Mn & 0 & & Assumption** \\
\hline Mendelevium & Md & 0 & . & Assumption** \\
\hline Mercury & $\mathrm{Hg}$ & 0 & & Assumption $\star *$ \\
\hline Molybdenum & Mo & 5 & & EPA $520 / 4-79-007 C$ \\
\hline Neodymium & Nd & 500 & & $\begin{array}{l}\text { Chemical Analog to Rare Earth } \\
\text { (PNWL } 8 / 18 / 86)\end{array}$ \\
\hline Neptunium & Np & 10 & & $\begin{array}{l}\text { Routson et al 1975, 76, } \\
\text { Sheppard }(1976)\end{array}$ \\
\hline Nickel & Ni & 100 & & Estimate (PNWL $8 / 18 / 86$ ) \\
\hline Niobium & $\mathbf{N B}$ & 2000 & & EPA $520 / 4-79-007 C$ \\
\hline Osmium & Os & 0 & & Assumption** \\
\hline Palladium & Pd & $50-100$ & & Estimate (PNWL $8 / 18 / 86$ ) \\
\hline
\end{tabular}

SORPTION

COEFFICIENT， $\mathrm{k}_{\mathrm{d}}$ *

SOURCE 
EIEMENT.

Phosphorus

$$
\text { platinum }
$$

plutonium

Polonium

Potassium

Praseodymium

Promethium

Protactinium

Radium

Radon

Rhenium

Rhodium

Rubidium

Ruthenium

Samarium

scandium

selenium

silicon

silver

sodium

strontium

sulfur

Tantalum

Technetium

Tellurium

Terbium

Thallium

Thorium
P

Pt

Pu

Po

K

Pr

Pm

$\mathrm{Pa}$

Ra

Rn

Re

Rh

Rb

Ru

sm

sc

se

51

Ag

Na

sr

s

Ta

TC

Ie

Tb

T1

Th
SORPTION

COEFFICIENT, $K_{d}{ }^{*}$

$$
\begin{array}{r}
0 \\
0 \\
100-10000 \\
25 \\
35 \\
500-1000 \\
1000-10000 \\
4000 \\
100-10000 \\
0 \\
0 \\
0 \\
500
\end{array}
$$

$0-500$

500-1000

0

10

0

50-100

10

100

0

0

0

50-100

500-1000

2

1000-10000
SOURCE

Assumption * *

Assumption * *

EPA 520/6-78-007, A shallow Land Burial Program

EPA 520/4-79-007C

EPA 520/4-79-007C

Chemical Analogy to Rare Earth (PNWL 8/18/86)

Benson (1960) Rare Earth

EPA 520/4-79-007C

EPA 520/6-78-007

EPA 520/4-79-007C

Assumption* *

Assumption* *

Chemical Analogy to Cs (PNWL 8/18/86)

Rhodes (1957)

Chemical Analogy to Rare Earth (PNWL 8/18/86).

Assumption * *

Shallow Land Burial Program

Assumption**

Estimate (PNWL 8/18/86)

EPA 520/4-79-007C

Shallow Iand Burial Program

Letter Report RJS-ARCHO

Assumption* *

Assumption* *

Shall Land Burial Program

Estimate (PNWL 8/18/86)

Chemical Analogy to Rare Earth (PNWL $8 / 18 / 86$ )

EPA 520/4-79-007C

EPA 5520-6-78-007 


\section{ELEMENT}

$$
\text { Thulium }
$$

Tin

Titanium

Tungsten

Uranium

Vanadium

Xenon

ytterbium

yttrium

$z$ ine

zirconium
SORPTION

COEFFICIENT， $K_{d}$ *

0

$50-100$

Ti

W

U

$\mathrm{v}$

$\mathrm{Xe}$

Yb

$Y$

$\mathrm{Zn}$

Zr
SOURCE

Assumption**

Estimate (PNWL $8 / 18 / 86$ )

Assumption**

Assumption * *

Est1mate (PNWL $8 / 18 / 86$ )

Assumption * *

Inert Gas (PNWL 8/18/86)

Assumption* *

Estimate (PNWL 8/18/86)

Assumption**

Rhodes (1957)

For sorption coeficient values that are given in ranges, the lowest sorption coefficient was chosen for the ingestion Release value calculation.

** For these elements no $K_{d}$ value has been obtained and a sorption coefficient of zero $\left(K_{d}=0\right)$ was assumed (no retardation).

\section{SOURCES}

Bensen, D.w. 1960. Review of Soll Chemistry Research at Hanford. HW-67201.

Environmental Protection Agency Rep. EPA 520/6-78-007. Ames, L. I. and Dhanpat RaI, "Radionuclide Interactions with Soll and Rock Medla."

Environmental Protection Agency Rep. EPA 520/4-79-007C. "Technical Support of Standards for High Level Radioactive Waste Management," Vol. C, Migration Pathways, 1979.

Hajek, B. F. 1966. "Plutonium and Americium Mobility in Soils." BNWL-CC-925.

Knoll, K. C. 1965. "Reaction of High Salt Aqueous Plus Organic Waste with Soll." BNWL-CC-313.

$$
\text { B-10 }
$$


Knoll, K. C. 1969. "Reactions of Organic Wastes in Soils. BNWL-860."

Letter Report R. J. Serne - ARCHO 6/5/75, a letter written to Atlantic Richlield Hanford Company by $w$. Martin reporting some, at that time, new laboratory data.

PNWL $8 / 18 / 86$, Letter from Martin, w. to EMSI $8 / 18 / 86$, reporting estimates of $k_{d}$ for a Generic Sandy sediment.

Rhodes, D. W. 1957. "The Effect of $\mathrm{pH}$ on the Uptake of Radioactive Isotopes from Solution by a Soll." Soll Science Soclety of America Proceedings, 21:389-392.

Routson 33 . C., G. Jansen, and A. V. Robinson. 1976. " $99 \mathrm{TC}$ " 237 No and 241 Am Sorption on Two Subsoils from Differing Weathering Intensity Areas." BNWL-2000. Pt. 2, pp. 50-52.

Serne, R. J. and Dhanpat Rai. 1976. "AdsorptionPrecipltation Behavior of Eu in Soils and Standard Clays." Agronomy Abstracts. p. 132.

Shallow Land Burial Program - as yet unpublished results obtained on an ongoing DOE sponsored program.

Sheppard, J. C., J. A. Kittrick, T. L. Hart. 1976. "Determination of Distribution Ratios and Diffusion Coefficients of Neptunium, Americium, and curium in soilAquatic Environments," RIO-221-T-12-2. 
For this calculation, the aquifer is assumed to be thick enough so that the upper and lower boundarles do not significantly affect the vertical component of transverse dispersion as the contaminant migrates to the well. In view of the range of values presented by codell and Duguid4, EPA belives these values for transverse and longitudinal dispersivity are reasonably conservative and approprlate for the adfustment of: RQs. 5

The well is assumed to lie on the centerline of the plume $(y=z=0)$ and the maximum concentration at the well is given by:

$$
C=\frac{M}{(4 \pi t)^{3 / 2}\left(E_{x} E_{y} E_{z}\right)^{1 / 2} R_{d} \mathbb{a}} \exp (-\lambda t) \text {. }
$$

Substituting the relationships for $E_{x}, E_{y}, E_{z}$, and $t$ into Equation (3) gives:

$$
C=\frac{1}{\left(\frac{4 \pi(30) n R_{d}}{V_{x}}\right)^{3 / 2}\left[\left(\frac{100}{R_{d}}\right)\left(\frac{20}{R_{d}}\right)\left(\frac{20}{R_{d}}\right)\right]^{1 / 2} R_{d} n} \exp \left[\left(-0.693 / t_{1 / 2}\right)(6)\right]
$$

simplification yields :

$$
c=\frac{y}{(120 \pi)^{3 / 2} a_{t}{ }^{1 / 2} a_{1} n R_{d}} \exp \left(-4.2 R_{d} / t_{1 / 2}\right)
$$

4T111, J.E. Meyer, H.R. (Editors), MRadiological Assessment. A Textbook on Environmental Analys18," NUREG/CR-3332, U.S. Nuclear Regulatory Commission, 1983.

5values for longitudinal and transverse dispersivity used for ground-water models developed for Resource Conservation and Recovery Act (RCRN) purposes are generally smaller because the equations were developed to evaluate risk while equations for $R Q$ purposes are not directly risk related. Further discussion of these RCRA models can be found in this appendix. 
For $a_{t}=20$ meters, $a_{1}=4$ meters, $n=0.1, M=1$ curie, and introducing a conversion fractor from cubic meters to liters ( $1 \mathrm{x}$ $10^{3}$ ), the maximum concentration at the well is calculated as:

$$
\begin{aligned}
& C=\frac{1}{(120 \pi)^{3 / 2}(20) 1 / 2(4)(0.1)\left(R_{d}\right)\left(1 \times 10^{3}\right)} \exp \left(-4.2 R_{d} / t_{1 / 2}\right) \\
& C=7.6 \times 10^{-8} \exp \left(-4.2 R_{d} / t_{1 / 2}\right) 11 \text { ters }^{-1} .
\end{aligned}
$$

Equation (7) gives the amount of dilution for a one curie release into an aquifer. The dilution factor (DF) for the aquifer is, therefore, defined as:

$$
D F=7.6 \times 10^{-8} \exp \left(-4.2 R_{d} / t_{1 / 2}\right) 1 \text { ters }^{-1} \text {. }
$$

The value of the retardation factor will affect not only the maximum concentration of the radionuclides found in the plume developed by the release but also the time required for the plume to reach and pass the well. When the sorption coefficient, $k_{d}$, is equal to zero, the retardation factor is equal to one. When the sorption coefflcient becomes larger, however, the retardation factor increases rapldily (e.g., when $k_{d}=1, R_{d}=16$ ). As $k_{d}$ increases, then, a longer period of time is required for the radionuclide to reach and pass the well. When radioactive decay is considered in this equation and the retardation factor is greater than one, it has the effect of "removing" a large portion of the radionuclides before they can be ingested. As a result, the calculated release value, when the retardation factor is greater than one, is significantly larger than the release value when the retardation factor is equal to one and, in fact, becomes much larger in comparison with the other release values calculated for the other exposure pathways. It is recognized, therefore, that the ground-water ingestion release value 
calculated when the retardation factor is greater than one will never be the smallest of the release values and provide the basis for an RQ. For this reason, the Agency did not develop separate ground-water ingestion equations for situations where the retardation factor is greater than one.

For radionuclides with a sorption coefficient of zero ( $k_{d}=$ o) and a retardation factor of one $\left(R_{d}=1\right)$, the concentration in the plume varies as a gaussian distribution along all three axes (two horizontal, one vertical) of the ellipsoidal plume. The total quantity of radionuclide assumed to be released in the plume is 1 curie (which was the amount of the instantaneous release). For radionuclides with very long half-lives the concentration in the well will increase from zero to a maximum of $7.6 \times 10^{-8}$ curies per liter then decrease to zero again as the plume passes. The time that it takes for the plume to pass the well can be estimated in two ways. First, we can conclude that the maximum amount of time necessary for the plume to pass the well is twelve days (assuming that the eirst arrival of the plume was instantaneous, 6 days to reach the centroid and another 6 days to reach the trailing edge). 6 The second, and more accurate approach, is to use the ratio of dispersivities whlch must be the same as the ratio of the axes of the ellipsoldal plume. Assuming constant concentration in the plume and using the expression for the volume of an ellipsoid, it follows that:

$$
1 C 1=(4 / 3) *(\pi) *(a) *(b) *(c) *\left(7.6 \times 10^{-5}\right)
$$

where: $a, b$ and $c$ are the major and minor axes of the ellipsoid and are related in the same ratio as the dispersivities:

6 Where $t=6$ days is calculated with the expression $t=30\left(V_{x} / n R_{d}\right)$.

$$
\text { B-14 }
$$




$$
a / b=a / c=a_{1} / a_{t}=20 / 4=5 \text {. }
$$

Therefore,

$$
b=a / 5, c=a / 5,
$$

and

$$
1=(4 / 3) *(\pi) *\left(a^{3} / 25\right) *\left(7.6 \times 10^{-5}\right) .
$$

Solving for a gives:

$a=43$ meters,

and the time required for the ellipsoldal plume to pass the well is given by:

$$
\text { Contact Time }(C T)=a /\left(V_{x} / n\right)=9 \text { days. }
$$

Because the time available for conisumption of contaminated water is the same as the period of time the contamination is in contact with the well, the contact time (CT) is 9 days.

In order to consider decay over the period of ingestion, it is recognized that an individual will ingest smaller quantities of radioactivity at times that are succesively more distant from the time that the radionuclide irst arrives at the point of exposure, the drinking water well. Accordingly, radioactive decay over the period of exposure was taken into account by modifying the contact time as follows:

$$
\frac{1-\exp (-\lambda C T)}{\lambda} \text {. }
$$


The Ground-Water Ingestion Release Value is calculated by use of equation ( 1 ) and substituting in the modified expression for contact time as summarized in equation (12) below:

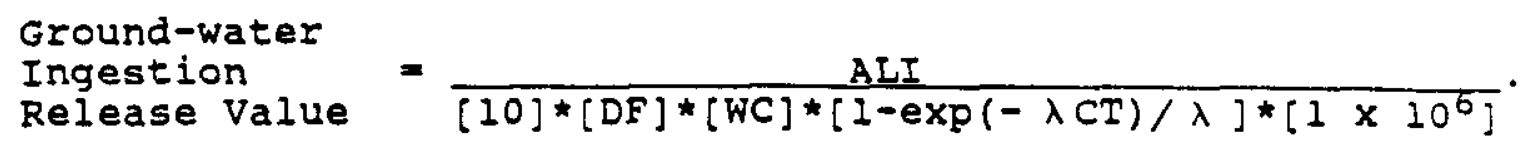

Where:

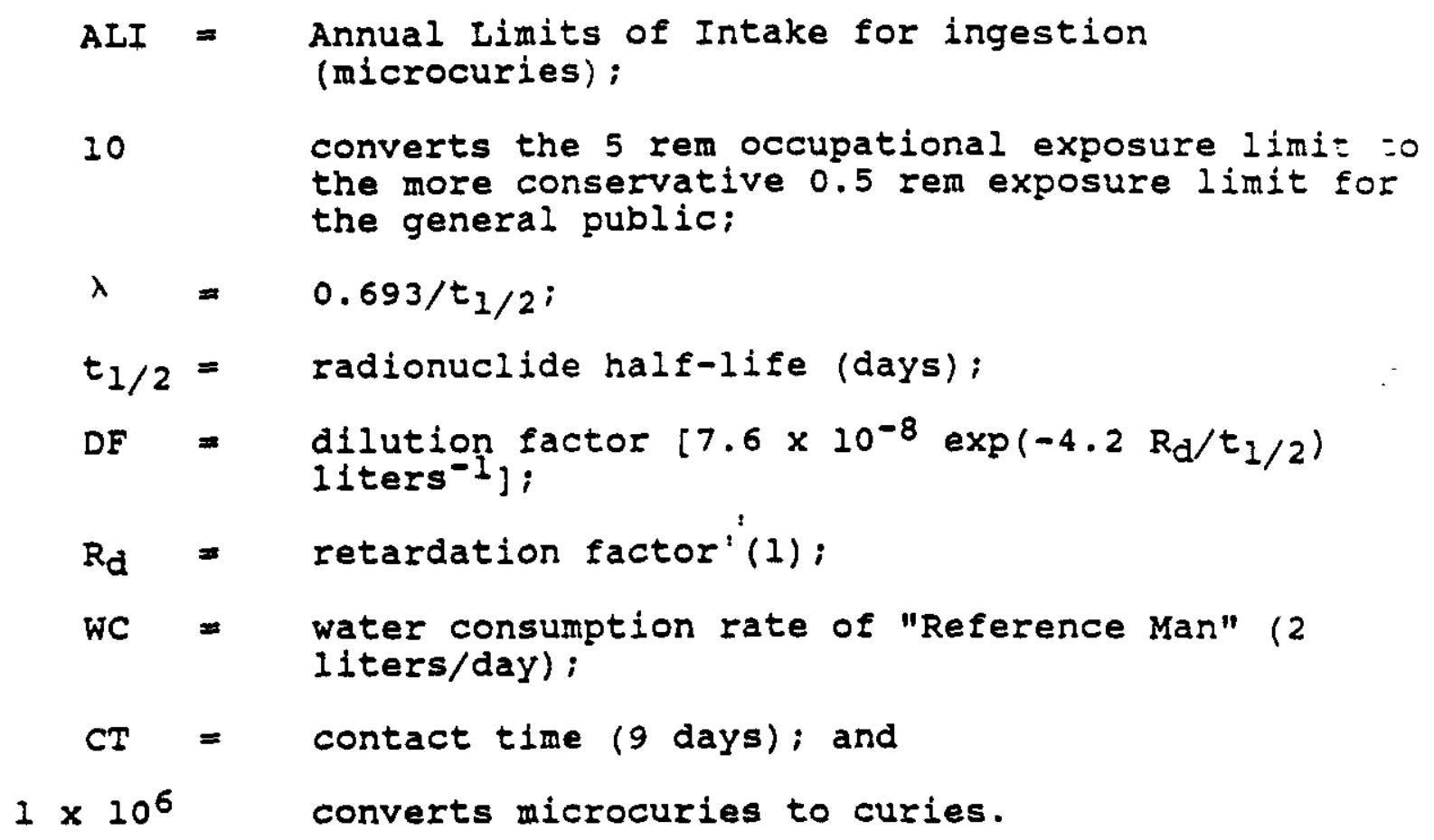

Substituting the values for DF, WC, $R_{d}$, and CT gives the following expression for the ground-water ingestion Release value:

Ground-water Ingestion Release Value $=\frac{A I I}{[2.2] *\left[\exp \left(-4.2 / t_{1 / 2}\right)\right] *\left[t_{1 / 2}-t_{1 / 2} \exp \left(-6.2 / t_{1 / 2}\right)\right]}$. 


\section{B.2.2 The simple Dilution Model.}

The Nuclear Regulatory Commission suggested a simple dilution model for the calculation of Rr.iease Values based on ground-water transport. This model was developed in order to determine the maximum concentrations for on-site disposal of low level nuclear waste and to identify sites suitable for the disposal of such waste. The Commission's goal in both these cases is to minimize the risk to the public for exposure via the ground water to releases of radioactive material. Although this approach may be appropriate for the minimization of risk, it appears inappropriate for the determination of RQs which simply act as triggers for notification of a release of a hazardous substance. Some of the assumptions made by the Nuclear Regulatory commission for their calculations using the simple dilution model are shown below. 7

- Ground-water flow rates:'are between 0.0005 and 0.03 meters/day.

- Longitudinal dispersivities are between 0.05 and 0.1 meter.

- Transverse dispersivities are zero.

- Pumping rates can vary between 7700 cubic meters/year and $2,000,000$ cublc meters/year.

- Water consumption is 2 liters/day for an individual.

Using these assumptions, the aquifer resembles a very slow flowing pipeline between the point of release and the well. The flow occurs at such a rate that the entirety of the release is pumped from the well over a perlod of one year. The contact time (CT) 18, therefore, 365 days. Ignoring radioactive decay and

7Oztunal1, O.I., Roles, C.W., "DeMinimis Waste Impacts Analysis Methodology," NUREG/CR-35 85, February, 1984. 
using a pumping rate of 7700 cublc meters per year as suggested by the Nuclear Regulatory Comission, a dilution factor (DF) can be calculated:

$$
D F=1 / 7700 \mathrm{~m}^{3}=1.3 \times 10^{-4} \mathrm{~m}^{-3}=1.3 \times 10^{-7} 1 \text { iter } \mathrm{t}^{-1}
$$

Using these figures and once again ignoring radioactive decay, a Release value (RV) in curles can be calculated from an AII in microcuries by use of equation (1).

$$
\begin{aligned}
& \operatorname{RV}=\operatorname{ALI} /\left[(10) *\left(\frac{1}{6} \cdot 3 \times 10^{-7} / 1 \text { iter }\right) *(2 \text { iter/day }) *(365 \text { day }) *\right. \\
& \operatorname{RV}=\operatorname{ALI} / 949 .
\end{aligned}
$$

Release Values for ingestion calculated in this way would be about 70 times smaller than those calculated by the advectiondispersion model ignoring radioactive decay and similarly smaller including factors for radioactive decay.

\section{B.2.3 Other Ground-Water Models}

The EPA's Office of solid Waste uses several ground-water models in implementing the Resource Conservation and Recovery Act (RCRA). Although other models are used within the RCRA program, the following four have been analyzed and compared to the groundwater ingestion model:

- The Comparative Risk Assessment Model (CRAM) used to compare the human health risks and costs of various combinations of hazardous waste streams, environmental settings, and waste treatment technologies;

- The IIner-Iocation RIsk and Cost Analysis Model used to estimate the human health risks of land disposal facilities of different designs in different environmental settings; 
- The Threshold Model used in determining the need to ban or restrict hazardous waste from land disposal; and

- The Vertical and Horizontal Spread (VHS) Model used in analyzing ground-water transport issues assoclated with delisting petitions (i.e., petitions to remove a substance from RCRA's hazardous substance list).

The following discussion compares those four RCRA models to the RQ ground-water model in terms of: (1) the basic equations used in each model; and (2) values for the input variables used in the equations.

\section{Comparison of Model Equations}

All simple ground-water transport models -- including the transport models used in the $R Q$ adjustment methodology, the CRAM, the Liner Location Model, the Threshold Model, and the VAS Model -- are based on the same laws of physics and, as such, are based on the same basic transport equation. The only difference in the models' equations is the release scenario used in developing the analytical solution to the transport equation. These release scenarios vary in two respects. First, the configuration of the contaminant source can vary; it can be a point source, a line source, or a plane source. Second, the contaminant that is being modeled can be released in different time frames; it can be released instantaneously, continuously, or at a variable rate. Everything else being equal, all of the ground-water models considered here will give different results only because their equations are based on different source configurations and different contaminant release rates. The source configuration and contaminant release rates assumed in each of the models are shown in Exhibit B-3. 
EXAIBIT $B-3$

SOURCE CONFIGURATIONS AND CONTAYINANT RELEASE RATES ASSUNED IN THE RCRA AND RQ MODEL EQUATIONS

\begin{tabular}{lll}
\hline Model & $\begin{array}{c}\text { Contaminant Source } \\
\text { Conflguration }\end{array}$ & \multicolumn{1}{c}{$\begin{array}{l}\text { Contaminant } \\
\text { Release Rates }\end{array}$} \\
\hline RQ Model & point source & \multicolumn{1}{c}{$\begin{array}{l}\text { instantaneous } \\
\text { release }\end{array}$} \\
CRAM & polnt source & $\begin{array}{l}\text { continuous release } \\
\text { time variable } \\
\text { release } \\
\text { Liner-Location Model }\end{array}$ \\
Threshold Model & plane source & $\begin{array}{l}\text { time variable } \\
\text { release (Gausian) } \\
\text { continuous release }\end{array}$ \\
VHS Model & plane source &
\end{tabular}

Source: ICF Analysis

The selection of instantaneous release for the RQ model was based on the consideration that the highest ground-water concentration will be achleved when the source is released instantaneously rather than continuously or at some variable rate. For example, a well 30 meters downgradient from the point of release would experience a higher concentration of radioactivity if 1 curie was released all at once rather than a little bit at a time over a prolonged period. On the other hand, an instantaneous release versus a prolonged release will result in ground-water contamination that will pass beyond a well more quickly (i.e., the contact time is shorter for an instantaneous release). For a prolonged release, the contamination will be found in smaller concentrations but will persist around a nearby well for a longer period of time. 
In: comparing the different contaminant source conflgurations, neither a point nor a plane source is necessarliy always more conservative than the other. A point source assumes that the entire release, assumed to be 1 cur. - in the RQ groundwater model, is at the outset concentrated into a single point and then allowed to disperse as $1 t$ llows downgradient to the point of exposure. In contrast, a plane source assumes that the total release is distributed throughout a plane of a specified length and width. Whether one is more conservative than the other depends on the dimensions of the plane in relation to the dimensions of the aquifer, and on the distance from the point of release to the point of exposure. A point source is thought to be more appropriate for the purpose of developing an $R Q$ because it besţ represents a sudden, episodic release or spill. A plane source is more: appropriate for modeling chronic releases from a surface impoundment or landflll.

\section{Comparison of values for Input variables}

The primary input variables in the $R Q$ ground-water model are:

- a retardation factor, which takes into account how much a contaminant is retarded (through sorption by soil and other mechanisms) relative to the transporting water mass ;

- ground-water velocity;

- saturated zone thickness;

- porosity, which refers to the amount of openings or holes in a soll or rock;

- longitudinal dispersivity, which reflects the extent of dispersion of a contaminant at right angles to the direction of ground-water flow; and

- the distance to the nearest water supply well. 
The values used for the variables in the $R Q$ ground-water model, as well as the values used in the RCRA ground-water models, are presented in Exhibit B-4. As shown in this exhibit, all but one model (the VHS model) take into account contaminant retardation.

As also shown in Exhibit B-4, the values used for velocity, aquifer thickness, and porosity in the $R Q$ ground-water model are in the range of those commonly used by the RCRA models. However, the values for dispersivity (both longitudinal and transverse) used in the $R Q$ model are significantly higher than those used in the RCRA models.

The values of longltudinal and transverse dispersivity reported in the literature vary widely. Dispersivity values have been obtained for different soll types through fleld measurements, laboratory expertments, and from the calibration of numerical models (1.e., calibration of models to match observed field data). In general, out of these three ways to determine values for dispersivity, values measured in the laboratory are the lowest, fleld measured values are generally intermediate in size, and the model derived values are usually the highest. Laboratory measured values of dispersivity are often so low that they are frequently considered unrealistic; model derived values are considered more realistic than those measured in the laboratory, but not as reallstic as those measured in the field.

Exhibit B-5 presents flelds measured values and model derived values of dispersivity for alluvial aquifers (i.e., deposits composed of particles of gravel, sand, silt, or clay that are not bound or hardened). 


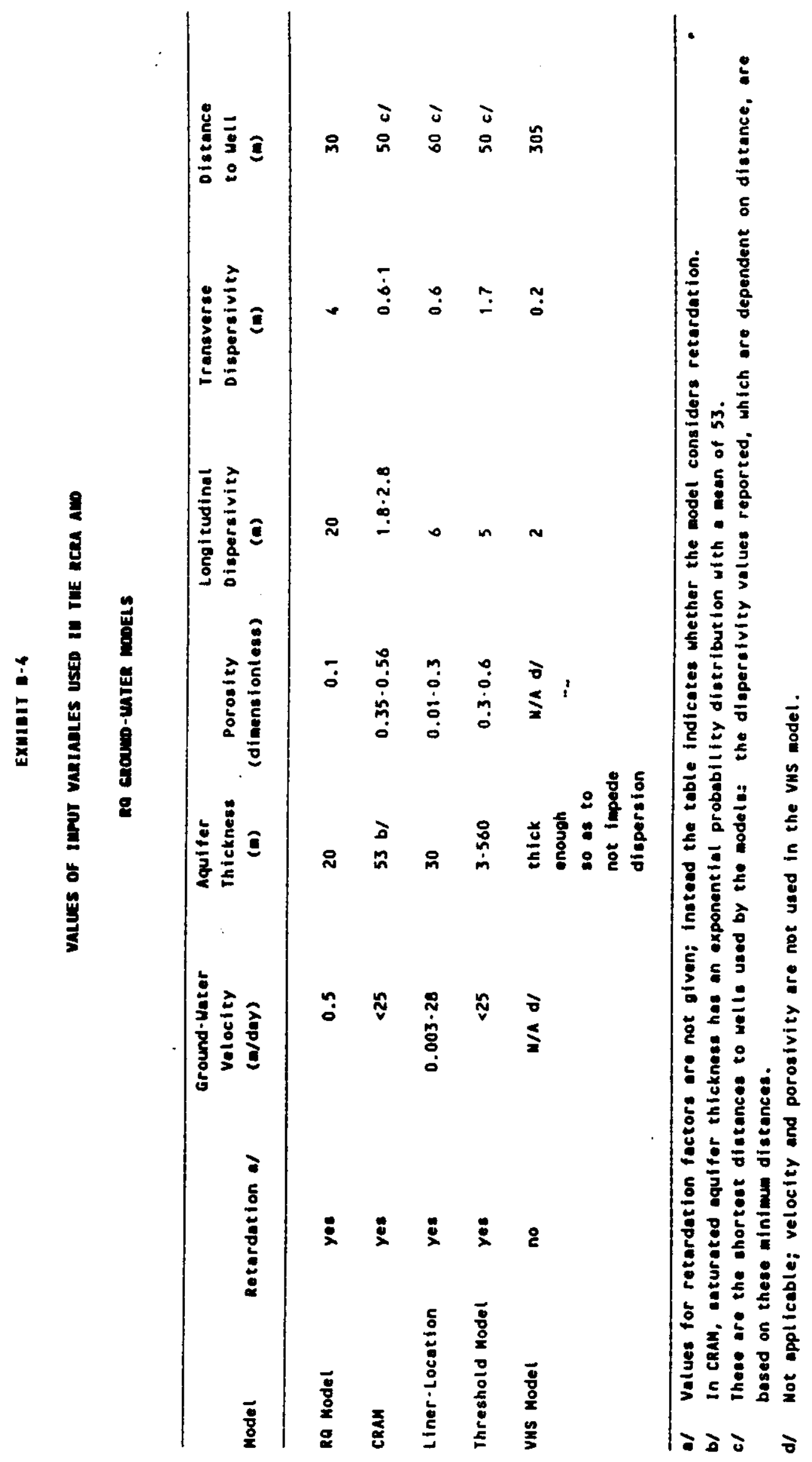

$m$
1
1
$\infty$ 
FIELD YEASUREMERT AND MODEL CALIBRATION VALOES FOR DISPERSIVITY FOR AILUVIAI AQUIFERS

\begin{tabular}{|c|c|c|c|c|}
\hline Setting & $\begin{array}{l}\text { Fleld } \\
\text { Longitudinal } \\
\text { Dispersivity } \\
\text { (m) }\end{array}$ & $\begin{array}{l}\text { surements } \\
\text { Transverse } \\
\text { Dispersivity } \\
\text { (m) }\end{array}$ & $\begin{array}{l}\text { Lodel Callbra } \\
\text { Longitudinal } \\
\text { Dispersivity } \\
\text { (m) }\end{array}$ & $\begin{array}{l}\text { Don values } \\
\text { Transverse } \\
\text { Dispersivity } \\
\text { (I) }\end{array}$ \\
\hline $\begin{array}{l}\text { Chalk River, } \\
\text { Ontario }\end{array}$ & $0.034-0.1$ & & & \\
\hline Lyons, France & $0.1-0.5$ & & & \\
\hline Alsace, France & 12 & 4 & 25 & 1 \\
\hline Barstow, CA & 15.2 & & 61 & 18 \\
\hline $\begin{array}{l}\text { Rocky Mountain } \\
\text { Arsenal }\end{array}$ & & & 30.5 & 30.5 \\
\hline $\begin{array}{l}\text { Arkansas River } \\
\text { Valley }\end{array}$ & & $z$ & 30.5 & 9.1 \\
\hline California & & & 30.5 & 9.1 \\
\hline Sutter Basin, & CA & & $80-200$ & $8-20$ \\
\hline
\end{tabular}

Source: Tables 4.1 and 4.2 in codell, R. and Duigid, J., "Transport of Radionuclides in Groundwater," Chapter 4, Radiological Assessment, Till, J., and Meyer, H., eds., U.S. Nuclear Regulatory Commission, September 1983. 
In comparing the dispersivity values used in the $R Q$ model $=0$ the values in Exhibit B-5, the $R Q$ model's values are on the high side for fleld measured values and on the low slde for model calibration values. EPA considers the dispersivity values used in the $R Q$ model to be realistic for an alluvial aquifer. The dispersivity values used in the RCRA models are generally on the low side of the field measured values, and significantly lower than the values obtained from the model callbrations.

The models developed by the EPA office of solid Waste for application to RCRA are risk based and as such are believed to be more conservative than necessary for development of reportable quantities which act as a trigger for notification of a release of a hazardous substance. For this reason, the Agency has decided to use the advection-dispersion model for determination of Release values based on a ground-water ingestion scenario.

\section{B.3 SURFACE WATER TRANSPORT OF RADIONUCLIDES}

Surface water used for drinking purposes in the United states generally comes from lakes, reservoirs, or rivers. Lakes and reservoirs are similar in that they are generally large bodies of water with relatively low flow rates when compared to rivers. Because of their size, dilution factors for radionuclides in lakes and reservolis are expected to be much larger than those for rivers, and the Agency has chosen to model consumption of contaminated surface water with reference to small rivers in preference to lakes or reservoirs.

\section{B.3.1 Calculation of a Dilution Factor for River Water}

Equation (1) can be used to calculate a drinking water Release value for river water if a dilution factor for this source of water can be determined. Equation (14) has previously 
been recommended by the Agency $^{8}$ for the calculation of ciownstreart concentrations of pollutants after release from a point source.

$$
c_{x}=\{[Q] *[\exp (-\lambda x / u)]\} / F
$$

where:

$$
\begin{aligned}
C_{x}= & \begin{array}{l}
\text { maximum contaminant concentration } 30 \text { meters } \\
\text { downstream (Ci/liter); }
\end{array} \\
Q= & \text { contaminant release rate (Ci/day); } \\
F= & \text { surface water flow rate (liter/day); } \\
\lambda= & \text { radioactive decay constant }\left(0.693 / t_{1} / \text { sec }^{-1}\right. \text {. For } \\
& \text { the reasons discussed above, radioactive decay is } \\
& \text { ignored in this calculation and the radioactive half- } \\
& \text { life, } t_{1 / 2}, \text { is considered to be infinite); } \\
& \text { distance from point of release to point of exposure } \\
& \text { (30 meters); and } \\
u= & \text { mean stream velocity }(0.64 \text { meter/sec). }
\end{aligned}
$$

In applying this equation the following assumptions are made:

- the release is an instantaneous point source and the river is homogeneous and isotropic;

- prior to the moment of release, the concentration of radionuclide in the river is zero;

- contaminant and river water $\mathrm{mix}$ completely and instantaneously and there is no longitudinal dispersion;

- exposure occurs 30 meters downgradient from the point of release;

8U.S. Environmental Protection Agency, Office of Emergency and Remedial Response, "Superfund Exposure Assessment Manual," Final Draft, prepared by Versar, Inc., September 22, 1987. 
- a small river is assumed with a flow rate of $1 \times 10^{9}$ liters per day (about 400 cubic feet per second) and a velocity of about 0.64 meters per second ${ }^{9}$;

- removal of the released radionuclide by other processes (e.g., settling, vaporization) is ignored; and

- radioactive decay during transport is neglected because the transport time to a point 30 meters downstream is short and decay over this short period of time is negligible for all but a handful of radionuclides.

With the radioactive decay constant set to zero (i.e., no decay is considered) equation (14) simplifies to:

$$
C_{\mathbf{x}}=Q / F \text {. }
$$

Using a value of $1 \times 10^{9}$ liters per day for $F$ in equation (15) is reasonably conservative because only about 15 percent of surface water in the United states flows at a rate slower than this valuelo. Because concentration and surface water flow rate are inversely proportional, a higher flow rate would lead to a lower, less conservative concentration. Substituting the source term, $i$ curie, for $Q$ in equation (15) gives:

$$
\begin{aligned}
& c_{x}=(1 \mathrm{ci} / \text { day }) /\left(1 \times 10^{9} \text { 11ter/day }\right) \\
& c_{x}=1 \times 10^{-9} \text { ci/liter. }
\end{aligned}
$$

Equation (17) gives the amount of dilution for a one curle release into a small river. The dilution factor (DF) for use in

${ }^{9}$ U.S. Environmental Protection Agency, Office of Solid Waste, "The RCRA Risk-Cost Analysis Model Phase III Report," prepared by ICF, Inc., March 1, 1984.

10 "Determination of Harmeul Quantities and Rates of Penalty for Hazardous Substances," EPA-440/9-75-005, Volumes a-d, January, 1975. 
calculating surface water release values is, therefore, defined as:

$$
D F=1 \times 10^{-9} \text { ilter }{ }^{-1} \text {. }
$$

Radioactive decay over the period of ingestion is ignored and a 1 day contact time (CT) is used in equation (1). The Agency believes that it is appropriate to lgnore radioactive. decay under these circumstances because, as is the case for radionuclide inhalation, it is not possible to establish exact bounds on the range of exposure periods. An individual could consume a dally quantity of water over a few minutes, allowing little decay for a short-Ilved radionuclide, or over the period of an entire day.

Substituting values for DF, CT, and WC into equation (1) and solving for the drinking water release value based on consumption of contaminated river water gives equation (19):

$$
\begin{aligned}
& \text { River-water } \\
& \text { Ingestion } \\
& \text { Release Value }
\end{aligned}=\frac{\text { AfI }}{0.02} .
$$

Comparison of release values calculated by use of equation (19) and those release values calculated for ground water ingestion, inhalation, consumption of contaminated vegetables, and direct exposure shows that in no case is the river-water ingestion release value the lowest of the calculated release values and no RQs are determined by use of equation (19). For this reason, the Agency used the equation calculating ground-water ingestion release value [equation (13)] to model ingestion of contaminated drinking water. 


\section{APPENDIX C \\ MODELING THE INGESTION OF CONTAMIMATED \\ FOODSTUFFS}

A number of models have been developed to describe the transfer of radionuclides to various foodstuffs and then to man after an atmospheric radioactive release. 1 These models typically begin with an estimate of the radionuclide air concentration above the food crop or pasture and subsequently calculate the radionuclide concentration in and on the food crop or forage. The level of contamination depends upon many factors including the rate at which the radionuclide is deposited, the fraction retained by the plant leaf, the areal density of the crop, and the transfer rate between soil and crop. Equations relating these variables generally include compartments describing mechanisms for removal of radionuclides from crops through weathering and radioactive decay. In addition, models have been developed which describe, the tfansport of radionuclides to man through milk (the so-called air-grass-cow-milk-man pathway), meat, and vegetable crops or forage contaminated by contact with contaminated irrigation water. The Agency has analyzed these pathways for the purpose of calculating RQs and describes the results of these analyses in this Appendix.

EPA has decided to use release values calculated as a result of airborne contamination of leafy vegetables as a component in the determination of reportable quantities for radionuclides. This route was chosen in preference to the irrigation pathway because, as is shown in the discussion of this pathway, the amount of radionuclide provided to man via irrigation of vegetables with ground water will, under the modeling conditions

INair, S., "Models for the Evaluation of Ingestion Doses From the Consumption of Terrestrial Foods Following an Atmospheric Radioactive Release." Central Electricity Generating Board, Berkeley Nuclear Laboratories, England, April, 1984.

$$
c-1
$$


analyzed, always be less than that provided by direct consumption of the contaminated ground water. Milk and/or meat contamination can be an important pathway for radionuclide consumption by man after an airborne or waterborne release of radionuclides. These pathways, however, were not chosen for the calculation of release values because radionuclide concentrations found in meat and $\mathrm{milk}$. are highly dependent upon element specific transfer factors between the forage or water and the animal products. These transfer factors are available for only a few elements and the equations, therefore, can only be used for a fraction of radionuclides.

Section C.l documents the equation used by the Agency to calculate release values for food ingestion. Section C. 2 presents in detail the application of this model to airborne deposition of radionuclides on vegetable crops and discusses the irrigation model investigated by the Agency. Section C. 3 briefly describes the approaches considered by the Agency for evaluation of contaminated meat and milk.

\section{1 THE FOOD INGESTION MODEL}

The size of the release in curies necessary to provide a 500 millirem exposure to a member of the general public through the consumption of contaminated vegetables is the Vegetable Ingestion Release value. This quantity is directly proportional to the annual limit of intake for ingestion and inversely proportional to the concentration on and in the vegetables, the daliy rate of food consumption, the contact time and the release fraction for the radionuclide. This relationship is summarized in equation (1).

\footnotetext{
Vegetable Ingestion Release Value $=\operatorname{ALI} /\left[(10) *(D F) *(F C) *(C T) *(R) *\left(1 \times 10^{6}\right)\right]$ (curies)
} 
where:

ALI = annual limit of intake for ingestion (microcuries);

10 factor to convert the annual limit of intake which is based on 5 rem dose-equivalent to a worker in a nuclear facility to the more conservative 0.5 rem for exposure to the general public;

$D F=$ dilution factor - the concentration of radionuclide in and on the vegetation per curie of radionuclide released to the atmosphere ( $\mathrm{Cl} / \mathrm{kg}$ per $\mathrm{Ci}$ released or $1 / \mathrm{kg}$ - derivation of this term is described in section C. 2 below);

$F C=$ food consumption (i.e., leafy vegetable) of reference $\operatorname{man}(0.175 \mathrm{~kg} /$ day - U.S. Nuclear Regulatory Commission, Regulatory Guide 1.109, October, 1977. Page 40.);

$C T=$ contact time, or the number of days over which the contaminated vegetables are ingested (derivation of this term is described below);

$R$ - airborne release fraction (see Appendix A for a discussion of release fractions); and

$1 \times 10^{6}$ conversion factor betweén microcuries and curies.

The ingestion ALIs used in the calculations are taken from ICRP's Publication $30^{2}$ after conversion from becquerels to microcuries. Where more than one ingestion ALI was given for a particular radionuclide, the lowest value was used in the calculations.

\section{2 DETERMINATION OF THE DILUTION FACTOR}

Two approaches for modeling the concentration of radionuclides in and on vegetable crops after an airborne release were evaluated. The first used an equation published by the Nuclear Regulatory Commission and the second a similar equation

2 International Commission on Radiological protection (ICRP), "Limits for Intakes of Radionuclides by Workers," Publication 30, Part 2, 1980.

$$
c-3
$$


developed by the National Council on Radiation Protection and Measurements (NCRP) and recommended by them to model the effects of continuous or intermittent releases of radioactive material. to the environment.

\section{C.2.1 The Nuclear Regulatory Commission Model ${ }^{3}$}

The Nuclear Regulatory Commission model estimates the concentration of radionuclides on and in vegetation produced by deposition onto the plant foliage from air and by uptake from activity initially deposited on the ground. The model is valid for particulate radionuclides except tritium and carbon-14. The Commission provides values for the model's various input parameters to allow the use of the equation for different purposes such as estimating concentrations in produce consumed by man; in leafy vegetables consumed by man; or in forage consumed by animals and converted to meat or milk consumed by man. The equation contains a term for the deposition rate of a radionuclide $\left(d_{1}\right)$, which is calculated by reference to a second Regulatory Guide 4 and which uses atmospheric dispersion estimates to derive the air concentration at various distances downwind from a release.

EPA used the Nuclear Regulatory Commission's model for the development of proposed RQs for radionuclides; however, after a re-evaluation of the Nuclear Regulatory Commission and NCRP models, EPA decided to use the NCRP model for development of the final RQs. This change was made mainly because it was determined

${ }^{3}$ Nuclear Regulatory Commission, "Calculation of Annual Doses to Man From Routine Releases of Reaction Efeluent for the Purpose of Evaluating Compliance with 10 CFR Part 50, Appendix I." Regulatory Guide 1.109, October, 1977.

${ }^{4}$ Nuclear Regulatory Commission, "Methods for Estimating Atmospheric Transport and Dispersion of Gaseous Effluents in Routine Releases from Light-Water-Cooled Reactors." Regulatory Guide 1.111, July, 1977.

$$
\mathrm{C}-4
$$


that the assumptions and calculational techniques used to develcp the comission's methodology make it unsuitable for application to a distance of 30 meters from an assumed point source. The Commission's approach was developed specifically for consideration at nuclear power plants with particular release characteristics and relatively large distances (i.e., several hundred meters and beyond) to a potentlal receptor of interest. Accordingly, EPA concluded that extrapolation of relative deposition rates presented in Regulatory Guide 1.111 to a distnce of 30 meters would not be accurate.

\section{C.2.2 The NCRP Model 5}

The NCRP model was designed to address continuous or intermittent releases of radloactive material to the environment and aid in the design or redesign of faclilties handing radionuclides so that their projected emissions can be compared with environmental standards. The model is very similar to the Nuclear Regulatory Commission modél, but incorporates a term for the deposition rate of radionuclides from air to crops that is generally believed to be more suitable than the commission's model for the 30-meter distance used in this analysis. The equation allows for the time period that crops are exposed to contamination during the growing season and therefore can be applied to episodic releases. Several assumptions are made in applying this model to the specific circumstances of release considered here, and include:

- the release is an episodic release and all radionuclides which are going to become airborne and be subject to deposition on or near a crop are released in one day or less;

5 "screening Techniques for Determining Compliance with Environmental standards: Releases of Radionuclides to the Atmosphere." NCRP Commentary No. 3, National Council on Radiation Protection and Measurement, March 31, 1986.

$$
c-5
$$


- the exposed vegetable crop is located 30 meters downwind from the point of release and the contaminated food is consumed on a daily basis by an individual for 60 days (the length of the growing season); and

- radioactive decay which may occur between the time of release and the time of deposition on the vegetables is conservatively assumed to be zero (i.e., $\lambda_{i}=0$ ) because the time period of release could be as short as a few seconds or as long as one day, and is undefined.

The NCRP equation along with an explanation of the terms is shown below:

$$
C_{v}=V_{d} C_{a i r}\left[\frac{f_{R}}{Y} \frac{1-\exp \left(-\lambda_{E} t_{e}\right)}{\lambda_{E}}+\frac{B_{v}}{P} \frac{1-\exp \left(-\lambda_{B} t_{b}\right)}{\lambda_{B}}\right]
$$

where:

$c_{v}=$ concentration of radionuclide in and on vegetation $(\mathrm{C} 1 / \mathrm{kg})$;

$C_{\text {air }}=$ concentration of radionuclides in air at the location of growing vegetables $\left(8.4 \times 10^{-7} \mathrm{Ci} /\right.$ meter $\left.^{3}\right)$, where $c_{a i r}=$ (radionuclide release rate) $*(X / Q)$;

$\mathrm{X} / \mathrm{Q}=$ atmospheric relative concentration $\left(8.4 \times 10^{-7}\right.$ day/meter ${ }^{3}$, see Appendix A);

$v_{d}=$ deposition velocity for wet and dry deposition ( 1000 meter/day);

$f_{R}=$ intercept iraction, the fraction of deposited activity intercepted and retained by edible portions of the crop (0.25, dimensionless):

$\lambda_{E}=$ effective decay constant for removal of the radionuclide deposited on vegetation (1/day), where $\lambda_{E}=\lambda_{1}+\lambda_{W} ;$

$\lambda_{1}=$ radioactive decay constant $(1 /$ day $)=0.693 / t_{1 / 2}=0$;

$\lambda_{W}=$ weathering decay constant $(1 /$ day $)=0.693 / t_{W} ;$

$t_{1 / 2}=$ radioactive decay half-life for the individual radionuclide (day, radioactive decay occurring during the period of release and transport to the crop is ignored);

$$
c-6
$$




$$
\begin{aligned}
& t_{w}=\text { weathering half-life (14 days): } \\
& t_{e}=\text { time period of above-ground crop exposure to } \\
& \text { contamination during the growing season (1 day); } \\
& Y \quad=\text { standing crop biomass of edible portion of crop at } \\
& \text { harvest }\left(2 \mathrm{~kg} / \text { meter }^{2}\right) \text {; } \\
& \text { BV = concentration ratio for the transfer of the element } \\
& \text { to the edible portion of a crop from dry soil } \\
& \text { (dimensionless and radionuclide specific, see } \\
& \text { Exhibit c-l for a compilation of these values); } \\
& \lambda_{\mathrm{B}}=\text { the effective rate constant for removal of } \\
& \text { radionuclide from soil (1/day), where } \\
& \bar{\lambda}_{\mathrm{B}}=\bar{\lambda}_{\mathrm{i}}+\bar{\lambda}_{\mathrm{HL}} \text {; }
\end{aligned}
$$

Substituting the appropriate values into equation (2) and solving gives:

$$
C_{v}=\left(1 \times 10^{-4}+3.5 \times 10^{-6} \mathrm{~B}_{v}\right) \mathrm{C} 1 / \mathrm{kg}
$$

This becomes a dilution factor (DF) through division by the source term, 1 curie:

$$
D F=\left(1 \times 10^{-4}+3.5 \times 10^{-6} \mathrm{Bv}_{\mathrm{v}}\right) \mathrm{kg}^{-1}
$$

The dilution factor, used in equation (1) for the calcualtion of vegetable ingestion release values, represents the concentration of radionuclide in and on vegetation per curie of radionuclide release to the atmosphere; it is in units of $\mathrm{Ci} / \mathrm{kg}$ per $\mathrm{cl}$, or $\mathrm{kg}^{-1}$. 
The Agency assumes that the contaminated vegetables are consumed on a daily basis during the growing season and are not stored. The growing season is nominally considered to be 60 days ( $t$ ) and thus would become the contact time (CT) in equation ( 1 ) if one were to ignore radioactive decay and removal of radionuclide from the vegetation by weathering processes. In fact, because radionuclides are removed by both decay and weathering in an exponential fashion, there is an "equivalent" contact time that depends upon the length of the growing and consuming season ( $t$ ) and the rate of loss due to decay and weathering. This equivalent contact time is calculated in the following way:

$$
C T=\frac{1-\exp \left(-\lambda_{E} t\right)}{\lambda_{E}} \text {. }
$$

Substitution for $\lambda_{E}$ gives:

$$
C T=\frac{1-\exp \left[-\left(\lambda_{i}+\lambda_{w}\right) \star t\right]}{\lambda_{i}+\lambda_{w}} \text {. }
$$

Substitution for $\lambda_{i}$ and $\lambda_{w}$ yields:

$$
C T=\frac{1-\exp \left(-\left[\left(0.693 / t_{1 / 2}\right)+\left(0.693 / t_{w}\right)\right] *[t]\right)}{\left(0.693 / t_{1 / 2}\right)+\left(0.693 / t_{w}\right)} \text {. }
$$

Using a value of 60 days for $t$ and a value of 14 days for the weathering half life $\left(t_{w}\right)$, equation ( 7$)$ simplifies to:

$$
C T=\frac{1-\exp -\left[\left(41.6 / t_{1 / 2}\right)+3\right]}{\left(0.693 / t_{1 / 2}\right)+0.0495} \cdot c-8 \text {. }
$$


(1) gives:

Substituting appropriate values for $D F$ and FC into equation

$$
\begin{gathered}
\begin{array}{l}
\text { Vegetable Ingestion } \\
\text { Release Value } \\
\text { (curies) }
\end{array}
\end{gathered}=\frac{\text { ALI (ingestion) }}{\left(175+6.1 \mathrm{~B}_{\mathrm{V}}\right)^{\star}(\mathrm{R})}
$$

where CT is calculated using equation ( 8 ).

Application of this equation to those radionuclides for which ALIs are available produces the food ingestion release values shown in Appendix $E$. 


$$
\text { EXHIBIT } C-I
$$

SOIL TO PLANT CONCENTRATION FACTORS (B,

\begin{tabular}{|c|c|c|}
\hline ELEMENT & SYMBOI & $\underline{B}_{\mathrm{V}}$ \\
\hline Actinium & Ac & 0.0035 \\
\hline Aluminum & Al & 0.0040 \\
\hline Americium & Am & 0.0055 \\
\hline Antimony & $\mathrm{sb}$ & 0.20 \\
\hline Argon* & Ar & 0 \\
\hline Arsenic & As & 0.040 \\
\hline Astatine & At & 1.0 \\
\hline Barium & $\mathrm{Ba}$ & 0.15 \\
\hline Berkelium * * & Bk & 0.001 \\
\hline Beryllium & Be & 0.010 \\
\hline Bismuth & B1 & 0.035 \\
\hline Bromine & Br & 1.5 \\
\hline Cadmium & $\mathrm{cd}$ & 0.55 \\
\hline Calcium & $\mathrm{Ca}:$ & 3.5 \\
\hline Californium** & $c f$ & 0.001 \\
\hline Cerium & $\mathrm{Ce}$ & 0.010 \\
\hline Cesium & Cs & $0.080^{\circ}$ \\
\hline Chlorine & $\mathrm{Cl}$ & 70 \\
\hline Chromium & Cr & 0.0075 \\
\hline cobalt & Co & 0.020 \\
\hline Copper & $\mathrm{Cu}$ & 0.40 \\
\hline Curium & $\mathrm{Cm}$ & 0.00085 \\
\hline Dysprosium & Dy & 0.010 \\
\hline Einsteinium** & Es & 0.001 \\
\hline Erbium & Ex & 0.010 \\
\hline Europium & Eu & 0.010 \\
\hline Fermium** & Fm & 0.001 \\
\hline Fluorine & $\mathbf{F}$ & 0.060 \\
\hline Francium & Fr & 0.030 \\
\hline
\end{tabular}

$c-10$ 
EXHIBIT C-I

SOIL TO PLANT CONCENTRATION FACTORS (BV)

ELEMENT
Gadolinium
Gallium
Germanium
Gold
Hafnium
Helium
Holmium
Indium
Iodine
Iridium
Iron
Krypton*
Lanthanum
Lead
Lutetium
Magnesium
Manganese
Mendelevium**
Mercury
Molybdenum
Neodymium
Neptunium
Nickel
Niobium
Osmium
Palladium
Phosphorus
Platinum
Plutonium

\begin{tabular}{|c|c|}
\hline SYMBOI & $\underline{B}_{v}$ \\
\hline Gd & 0.010 \\
\hline Ga & 0.0040 \\
\hline Ge & 0.40 \\
\hline $\mathrm{Au}$ & 0.40 \\
\hline HI & 0.0035 \\
\hline $\mathrm{He}$ & 0.010 \\
\hline Ho & 0.010 \\
\hline In & 0.0040 \\
\hline I & 0.15 \\
\hline Ir & 0.055 \\
\hline $\mathrm{Fe}$ & 0.0040 \\
\hline $\mathrm{Kr}$ & 0 \\
\hline La : & 0.010 \\
\hline $\mathrm{Pb}$ & 0.045 \\
\hline Iu & 0.010 \\
\hline $\mathrm{Mg}$ & 1.0 \\
\hline $\mathrm{Mn}$ & 0.25 \\
\hline Md & 0.0010 \\
\hline $\mathrm{Hg}$ & 0.90 \\
\hline Mo & 0.25 \\
\hline Nd & 0.010 \\
\hline $\mathrm{Np}$ & 0.10 \\
\hline Ni & 0.060 \\
\hline $\mathrm{Nb}$ & 0.020 \\
\hline os & 0.015 \\
\hline$P d$ & 0.15 \\
\hline $\mathbf{P}$ & 3.5 \\
\hline Pt & 0.095 \\
\hline Pu & 0.00045 \\
\hline
\end{tabular}

$c-11$ 
EXHIBIT $C-1$

SOIL TO PLANT CONCENTRATION FACTORS (BV)

ELEMENT
Polonium
Potassium
Praseodymium
Promethium
Protactinium
Radium
Radon*
Rhenium
Rhodium
Rubidium
Ruthenium
Samarium
Scandium
Selenium
Silicon
Silver
Sodium
Strontium
Sulfur
Tantalum
Technetium
Tellurium
Terbium
Thallium
Thorium
Thulium
Tin

\begin{tabular}{|c|c|}
\hline SYMBOL & $B_{v}$ \\
\hline Po & 0.0025 \\
\hline $\mathrm{k}$ & 1.0 \\
\hline Pr & 0.010 \\
\hline Pm & 0.010 \\
\hline $\mathrm{Pa}$ & 0.0025 \\
\hline Ra & 0.015 \\
\hline $\mathrm{Rn}$ & 0 \\
\hline Re & 1.5 \\
\hline $\mathrm{Rh}$ & 0.15 \\
\hline$R b$ & 0.15 \\
\hline $\mathrm{Ru}$ & 0.075 \\
\hline $\operatorname{sm}$ & 0.010 \\
\hline sc" & 0.0060 \\
\hline se & 0.025 \\
\hline si & 0.35 \\
\hline Ag & 0.40 \\
\hline $\mathrm{Na}$ & 0.075 \\
\hline sr & 2.5 \\
\hline s & 2.5 \\
\hline Ta & 0.010 \\
\hline TC & 9.5 \\
\hline $\mathrm{Te}$ & 0.025 \\
\hline $\mathrm{Tb}$ & 0.010 \\
\hline TI & 0.0040 \\
\hline Th & 0.00085 \\
\hline $\operatorname{Tm}$ & 0.010 \\
\hline $\mathrm{sn}$ & 0.030 \\
\hline
\end{tabular}




\section{EXHIBIT C-1}

SOIL TO PLANT CONCENTRATION FACTORS (Bv)

EIEMENT
Titanium
Tungsten
Uranium
Vanadium
Xenon*
Ytterbium
Yttrium
Zinc
Zirconium

SYMBOL

Ti

พ

U

$\mathrm{V}$

$\mathrm{Xe}$

$\mathrm{Yb}$

$Y$

Zn

zr
Bv

0.0055

0.045

0.0085

0.0055

0

0.010

0.015

1.5

0.0020

* Assumption for noble gases.

* * EMSI Estimate

Source: C.F. Baes III, R.D. Sharp, A.I. Sjoreen, R.W. Shor, "A Review and Analysis of Parameters for Assessing Transport of Environmentally Released Radionuclides Through Agriculture," ORNL-5786, September, 1984. 


\section{C.2.3 The Irrigation Kodel}

In addition to the contamination of vegetable crops through airborne deposition of radionuclides, crops can be contaminated through irrigation with contaminated water. The model presented in section $C . l$ can be used to calculate a release value for contamination through irrigation if the release fraction ( $R$ ), developed for airborne release of radionuclide, is set equal to one. All other variables in the equation have the same definition and the equation becomes:

$$
\begin{aligned}
& \text { Irrigation } \\
& \text { Release Value }=A I I /\left[(10) *(D F) *(F C) *(C T) *\left(1 \times 10^{6}\right)\right] \\
& (\text { curies })
\end{aligned}
$$

The radionuclide that contacts the vegetable crop is contained in the irrigation water rather than in an airborne plume, and the following assumptiops are made:

- the contaminated water is pumped from a well 30 meters downgradient from the radionuclide release and the concentration in the contaminated water is the same as that calculated in the ground-water ingestion model found in Appendix B;

- the crop is watered daily during the 60 day growing season, 51 days with uncontaminated water and 9 days with contaminated water (see Appendix B); and

- the leafy vegetables are eaten as harvested and not stored.

The Nuclear Regulatory Commission provides equation (11) 6 for calculation of radionuclide concentration in vegetation due to irrigation with contaminated water.

6U.S. Nuclear Regulatory Comission, "Calculation of Annual Doses to Man From Routine Releases of Reaction Effluent for the purpose of Evaluating Compliance with 10 CFR Part 50, Appendix I." Regulatory Guide 1.109, October, 1977. 


$$
C_{v}=C_{w} I\left[\frac{r\left[1-\exp \left(-\lambda_{E} t_{e}\right)\right]}{Y_{v} \lambda_{E}}+\frac{f_{I} B_{v}\left[1-\exp \left(-\lambda_{i} t_{b}\right)\right]}{P \lambda_{i}}\right] \exp \left(-\lambda_{i} t_{h}\right)
$$

where:

$$
\begin{aligned}
& c_{v}=\text { concentration of radionuclide in the edible portion of } \\
& \text { the crop }(\mathrm{C} 1 / \mathrm{kg}) \text {; } \\
& C_{w}=\text { concentration of radionuclide in irrigation water } \\
& \left(7.6 \times 10^{-8} / R_{d} C i / 1 \text { iter, see Appendix } B\right) \text {; } \\
& I=\text { average irrigation rate during the growing season }(2.5 \\
& \text { liters per square meter-day, liter } / \mathrm{m}^{2} \text {-day); } \\
& r=\text { fraction of deposited activity retained on crops } \\
& (0.25) \text {; } \\
& \lambda_{E}=\lambda_{i}+\lambda_{w} \\
& \lambda_{i}=0.693 / t_{1 / 2} \text {; } \\
& \lambda_{W}=0.693 / t_{w} ; \\
& t_{1 / 2}=\text { radionuclide half life; } i \\
& t_{w}=\text { weathering half life (14 day); } \\
& t_{e}=\text { time period crops are exposed to contamination during } \\
& \text { the growing season ( } 9 \text { day); } \\
& \mathrm{Y}_{\mathrm{V}}=\text { agricultural yield }\left(2 \mathrm{~kg} / \mathrm{m}^{2}\right) \text {; } \\
& f_{I}=\text { fraction of year crops are irrigated with contaminated } \\
& \text { water }(9 / 365) \text {; } \\
& B_{\mathrm{V}}=\text { concentration factor for soll uptake; } \\
& t_{b}=\begin{array}{c}
\text { period of time soll is exposed to contaminated water ( } 9 \\
\text { day); }
\end{array} \\
& P=\text { effective surface density of soll }\left(240 \mathrm{~kg} / \mathrm{m}^{2}\right) \text {; and } \\
& t_{h}=\text { time between harvest and consumption ( } 0 \text { day). }
\end{aligned}
$$

$$
\text { C-15 }
$$


and dividing by the source term, 1 curie, to yield a dilution factor (DF) gives:

$$
D F=\left[1.7 \times 10^{-7}+\left(1.9 \times 10^{-11}\right) *\left(B_{v}\right)\right] / \mathrm{kg} .
$$

The second term in equation (12) is approximately one tenthousandth $(1 / 10,000)$ of the first term and can be ignored on. substitution into equation (10) to yield equation (13).

$$
\begin{aligned}
& \text { Irrigation } \\
& \text { Release Value }=\operatorname{ALI} /[(0.3) *(C T)] \\
& \text { (curies) }
\end{aligned}
$$

Under the same conditions, the drinking water release value obtained in Appendix $B$ is:

$$
\text { DW Release Value }=A L I /[(1.5) *(C T)] \text {. }
$$

Equation (14) will always yield a release value about 5 times smaller than that given by equation (13). For this reason, it is not necessary to further consider the irrigation route for calculation of release values.

\section{3 INGESTION OF CONTAMINATED MEAT OR MILR}

Radionuclides when released to air can contaminate animal forage or, if released to water, can contaminate animal drinking water. In either case, radionuclides can be consumed by animals. After consumption by domestic animals such as milk producing cows or beef cattle, radionuclides can be found in the milk and meat and provide a route for the exposure of man. The ingestion model found in section C.1 [equation (1)] can be used to calculate a release value for the meat or milk route after an airborne radionuclide release if the appropriate dilution factor (DF) can be derived. Similarly, equation (1) in section $B .1$ can be used

$$
c-16
$$


to calculate a release value for the meat or milk: route after a release to drinking water.

The Nuclear Regulatory Commission provides equation (15) for calculating the concentration of radionuclide in meat or milk. 7 This equation contains compartments for calculating the concentration in forage and the concentration in water and can be split to provide two equations, (16) and (17), separating airborne from waterborne releases.

$$
\begin{aligned}
& c_{i A}=F_{\perp A}\left(c_{i F} Q_{F}+c_{1 A W Q_{A W}}\right) \\
& c_{i A} \text { (airborne) }=F_{1 A} c_{I F} Q_{F} \\
& c_{i A} \text { (waterborne) }=F_{i A} c_{i A W Q_{A W}}
\end{aligned}
$$

where:

$$
\begin{aligned}
& c_{i A}=\text { concentration of radionuclide in animal product } \\
& \text { (Ci/liter for milk or Ci/kg for meat); } \\
& F_{\text {iA }}=\text { transfer coefficient of radionuclide, the fraction } \\
& \text { of the daily intake that is transferred to milk } \\
& \text { (day/liter) or meat (day/kg) - this value is element } \\
& \text { dependent: } \\
& c_{i F}=\text { concentration of radionuclide in forage }(\mathrm{Ci} / \mathrm{kg}) \text {; } \\
& Q_{F}=\text { feed consumed daily by animal (kg/day); } \\
& C_{\text {iAw }}=\begin{array}{l}
\text { concentration of radionuclide in water } \\
\text { and }
\end{array} \\
& Q_{\text {AW }}=\text { water consumed daily by animal (liter/day). }
\end{aligned}
$$

Equations (15), (16) and (17) can be divided by the source term, 1 curie, to produce a dilution factor (DF) in liters-1 or $\mathrm{kg}^{-1}$. A value for $C_{i F}$ can be found through application of equation (2)

\footnotetext{
7U.S. Nuclear Regulatory Commission, "Calculation of Annual Doses to Man From Routine Releases of Reactor Effluents for the Purpose of Evaluating Compliance with 10 CFR Part 50, Appendix I." Regulatory Guide 1.109, October, 1977.
} 
in this Appendix and a value for $C_{i A w}$ can be fourd through application of equation ( 7 ) in Appendix $B$.

These equations are valid for all radionuclides except tritium and carbon-14. Values for $F_{\text {iA }}$, the radionuclide transfer coefficient, are compiled by the Nuclear Regulatory Commission in Regulatory Guide 1.109 (reference 7). Values for this variable are experimentally derived and available for only a few elements. For this reason, if ingestion release values for radionuclides were based on the meat or milk ingestion route, they could not be calculated for many of the 757 radionuclides without estimating transfer coefficients. The Agency believes that it is better to model ingestion of radionuclides based on consumption of leafy vegetables where soil to vegetable matter transfer coefficients $\left(B_{v}\right)$ are better understood and are a minor component in the calculation. 


\section{APPENDIX D. \\ MODELING OF DIRECT EXPOSURE TO RADIONUCLIDES}

In order for an exposure to an individual to occur after a release of radionuclide, it is not necessary for that individual to ingest or inhale the radionuclide. Because radionuclides produce radiation that can be propagated through air, it is possible for an exposure to occur if an individual is physically in the vicinity of the released radionuclide. This type of exposure is termed direst exposure. Because alpha particles, even very energetic alpha particles, have a very short range in air, it is unnecessary to include exposure to alpha particles in the model. Beta particles have a longer range in air than alpha particles, but only very high energy beta particles which are produced only by a very few radionuclides have ranges in air approaching 30 meters, the distance assumed in the model. For this reason, the Agency has chosen to model only direct exposure to gamma rays.

Some uranium isotopes and a few isotopes of some transuranic elements decay by spontaneous fission producing neutrons which have ranges in air exceeding 30 meters. Because direct exposure to neutrons in these few cases could deliver significant radiation doses, the Agency also modeled this route and found that, in every case of spontaneous fission, release values calculated for inhalation were considerably lower than those calculated for direct exposure to gamma rays or neutrons.

Section D.I discusses exposure to fixed point sources of radiation while section $D .2$ develops the equation used by the Agency for calculation of direct exposure release values for argon, krypton and xenon based on submersion in an airborne cloud of these noble gases. 


\section{1 FIXED POINT SOURCES}

The Agency believes that development of a direct exposure model based on exposure to a point source of solid or liquid radionuclide, as opposed to a line or areal source, best represerts a sudden, episodic release of radionuclide. As is the case with the inhalation model and the ingestion model used to calculate release values for radionuclides, the exposure is assumed to occur at a distance of 30 meters from the point of release. The equation developed in section $D .1 .1$ is that used to calculate the release values based on direct exposure to such a point source of gamma radiation, while the equation developed in section $D .1 .2$ was used by the Agency for evaluation of exposure to neutrons from spontaneous fission.

\section{D.I.1 Radionuclides Which Emit Gamma Rays}

The Radlological Health Handbookl provides the following equations for determining gamma ray exposure and gamma ray absorption from a fixed point source of radiation.

$$
\begin{aligned}
& I_{0}=0.156 n_{1} E\left(10^{5} u_{a}\right) \\
& I=I_{0} e^{-100 u_{a} S} \\
& R / h r=\left(\begin{array}{ll}
n_{2} & I
\end{array}\right) / s^{2}
\end{aligned}
$$

where:

$\begin{array}{ll}\text { Io } & =\quad \begin{array}{l}\text { unshielded exposure rate at } 1 \text { meter from a one } \\ \text { curie point source (R/hr-Ci at } 1 \text { meter); }\end{array} \\ I & =\text { attenuated radiation exposure rate (R/hr); } \\ n_{1} & =\text { gamma quanta per disintegration; }\end{array}$

I"The Health Physics and Radiological Health Handbook," Nucleon Lectern Associates, OIney, MD, 1984 , pages 41 and 45 .

$$
\mathrm{D}-2
$$




\begin{tabular}{|c|c|c|}
\hline$u_{a}$ & $=$ & $\begin{array}{l}\text { linear energy absorption coefficient for gamma } \\
\text { rays in air (at standard temperature }\left(23^{\circ} \mathrm{C}\right) \text { and } \\
\text { pressure (l atm)) in } \mathrm{cm}^{-1} \text {; }\end{array}$ \\
\hline$\Omega_{2}$ & $=$ & number of curies; \\
\hline $\mathbf{s}$ & $=$ & distance in meters; and \\
\hline $\mathrm{R} / \mathrm{hr}-\mathrm{Cl}$ & $=$ & $\begin{array}{l}\text { exposure rate in Roentgen per hour per curie } \\
\text { of release. }\end{array}$ \\
\hline
\end{tabular}

When combined, these three equations become:

$$
R / h r-C i=\left[\left(1.56 \times 10^{4}\right) *\left(n_{1}\right) *(E) *\left(u_{a}\right) *\left(n_{2}\right) *\left(e^{-100 u_{a} s}\right)\right] / s^{2}
$$

The value for $u_{a}$ is found in the Radiological Health Handbook to be $3.7 \times 10^{-5} \mathrm{~cm}^{-1}$ for gamma rays with an energy of $1 \mathrm{MeV}$. The value varies with the energy of the gamma ray involved but is approximately correct $( \pm 15 \%)$ for gamma rays with energies ranging from about $0.07 \mathrm{MeV}$ to about $2 \mathrm{MeV}$. Therefore, recognizing the relatively small error, this single value for $u_{a}$ is used for all radionuclides for the sake of simplicity. The distance, $s$, used for other exposure routes is 30 meters and is used here. Photon attenuation in air between the source and receptor is represented by $e^{-100 u_{a} s}$. Incorporation of a term for photon attenuation in the equation results in a slight increase in the direct exposure Release value since approximately 10 percent of the photons emitted from the source will be absorbed in 30 meters of air between the source and the receptor. A 24 hour exposure duration (T) was chosen because RQs are applicable for releases that occur over a maximum of 24 hours. Although it is recognized that it is unlikely that an individual actually would remain 30 meters away for a full 24 hours, EPA could not conclude that it is impossible and, therefore, used a 24-hour exposure period to assure timely reporting in such an event. A shorter time period might raise the 
release value to such an extent that notification might not be given of a release that would be harmful if an individual were to be exposed for 24 hours or other extended periods close to 24 hours. Multiplying by $T$ to convert Roentgen per hour per curie to Roentgen per curie, the equation becomes:

$$
R / C i=\left[\left(1.56 \times 10^{4}\right) *\left(n_{1}\right) *(E) *\left(u_{a}\right) *\left(n_{2}\right) *(T) *\left(e^{-u_{a} S}\right)\right] / S^{2} .
$$

Roentgen is approximately equal to rem for gamma rays:

1 Roentgen $=95$ ergs/gram of soft tissue;

$1 \mathrm{rad}=100 \mathrm{ergs} / \mathrm{gram} ;$ and

1 rem $=1$ rad (for gamma rays).

Therefore, 1 rem is approximately equal to I Roentgen for gamma rays.

Substituting rem per curie of release (Dn) for Roentgen per curie ( $R / C 1$ ) and rearranging equation (4) to solve for $n_{2}$ gives:

$n_{2}=\left[\left(6.41 \times 10^{-5}\right) *(D n) *\left(S^{2}\right)\right] /\left[\left(n_{1}\right) *(E) *\left(u_{a}\right) *(T) *\left(e^{-100 u_{a} s}\right)\right]$.

In this application, the value for $\mathrm{n}_{2}$ is the direct exposure release value, representing the number of curies in a point source yielding a specified dose-equivalent (Dn).

As noted previously, the terms $\mathrm{n}_{1}$ and $E$ are the gamma ray fraction and the gamma ray energy, respectively. Many: radionucildes emit more than one gamma ray per disintegration or they emit gamma rays of varying energies. Often each of these gamma rays are emitted only for a specific fraction of. disintegration events. In order to account for this, the product of the energy of each gamma ray emitted $\left(E_{i}\right)$ and the fraction of time it is emitted $\left(n_{1}\right)$ is summed to produce a value, $E_{1}$, which reflects the total gamna ray energy produced by each radionuclide. The method used for this calculation is shown in equation (7).

$$
D-4
$$




$$
E_{1}=\sum_{i}\left[\left(n_{i}\right) *\left(E_{i}\right)\right]
$$

Some radionuclides emit positively charged electrons (positrons) which, when they strike negatively charged electrons, annihilate one another and produce two gamma rays with an energy of $0.511 \mathrm{MeV}$ each. Both annihilation gamma rays are considered in the calculations for those radionuclides which decay by positron emission. Substituting $E_{1}$ for the product of $n_{1}$ and $E$ and using "Direct Exposure (DE) Release Value (RV)" for $\mathrm{n}_{2}$ yields:

$$
D E R V=\left[\left(6.41 \times 10^{-5}\right) *(D n) *\left(S^{2}\right)\right] /\left[\left(E_{1}\right) *\left(u_{a}\right) *(T) *\left(e^{-100 u_{a} S}\right)\right]
$$

Equation (8) can be used for the calculation of direct exposure release values when radioactive decay is not considered. In order to account for radioactive decay during the period of exposure ${ }^{2}$, this period [ $T$ in equation (8)], must be modified to reflect decreasing exposure at times that are successively more distant from the time that the radionuclide was released (an instantaneous release is assumed). The equation used for this purpose is shown below:

$$
T=\frac{[24] *[1-\exp (-\lambda t)]}{\lambda}
$$

${ }^{2}$ Radioactive decay occurring during the period of release is ignored because this period could be as short as a few seconds or as long as one day and is undefined. similarly, because it is impossible to define the time necessary for an individual to come into contact with the released radioactive material, the Agency conservatively assumed that no decay occurs over this" "transport time". 
where:

$$
\begin{aligned}
t & =\text { period of exposure in days }(1 \text { day); } \\
\lambda & =\text { radioactive decay constant }\left(0.693 / t_{1 / 2}\right) ; \\
t_{1 / 2} & =\text { radioactive half-life in days; and } \\
24 & \text { conversion factor between days and hours. }
\end{aligned}
$$

Combining equation (8) with equation (9) yields equation (10).

$$
D E R V=\frac{\left(6.41 \times 10^{-5}\right) *(D n) *\left(s^{2}\right)}{\left[E_{1}\right] *\left[u_{a}\right] *\left[\exp -\left(100 u_{a} s\right)\right] *[24] *([1-\exp (-\lambda t)] / \lambda)}
$$

Substituting values in for Dn $(0.5$ rem), $S$. (30 meters), $t$ ( 1 day), $u_{a}\left(3.7 \times 10^{-5}\right.$ centimeters $)$, and $\lambda\left(0.693 / t_{1 / 2}\right)$, the equation reduces to:

DE RV $=$

$$
\frac{25.1}{\left[E_{1}\right] *\left[t_{1 / 2}-t_{1 / 2} \exp \left(-0.693 / t_{1 / 2}\right)\right]}
$$

This equation is ldentical to that shown in the body of this report and, except for those cases calculated on the basis of submersion in a cloud of radioactive noble gas, was used to calculate the direct exposure release values shown in Appendix $E$.

D.1.2 Radionuclides Which Decay by Spontaneous Fission and Emit
Neutrons

Included in the ICRP Publication 30 list of 757 radionuclides are 24 radionuclides whtch decay, at least part of the time, by spontaneous fission. These radionuclides are all either uranium 
1sotopes or 1sotopes of transurantc elements ${ }^{3}$. The usual node $0:$ decay for these isotopes is through the emission of alpha particles. Though alpha particles are not penetrating, they have a high quality factor 4 and when radionuclides emitting alpha particles are ingested or inhaled and deposited in tissues, the damage done can be enormous. It is not surprising, then, that for: these alpha emitting uranium isotopes and transuranics, the exposure pathway among the four evaluated (inhalation, ingestion of contaminated drinking water, ingestion of contaminated foodstuffs, and direct exposure) that gives the lowest calculated release value is inhalation. Exhibit D-1 presents a list of radionuclides which decay by spontaneous fission and appear in the ICRP Publication 30 list. Exhibit D-1 also provides the fraction of decays that occur by spontaneous fission, the inhalation release value and the calculated neutron exposure release value for each radionuclide. The method used by the Agency for determining a release value based on exposure to neutrons for isotopes which undergo spontaneous fission is despribed below.

Equation (12) is commonly used for calculation of the neutron dose rate from an isotropic point source 5 .

$$
I=Q /\left[(4) *(p i) *\left(r^{2}\right) *(8000)\right]
$$

3 Transuranic elements are those with higher atomic numbers than uranium and appear beyond uranium in the periodic chart of the elements.

4The quality factor is a measure of the relative amount of damage done to tissues by different types of radiation. Alpha particles have been assigned a quality factor of 20 as compared to 10 for neutrons and are believed to be twice as damaging to tissues than neutrons.

5 "The Health Physics and Radiological Health Handbook," Nucleon Lectern Assoclates, page 38, 1984. 


\section{EXPIBIT D-1}

RADIONOCLIDES INCLUDED IN ICRP PUBLICATION 30 WHICH DECAY BY SPONTANEOUS FISSION

\begin{tabular}{|c|c|c|c|}
\hline Radionuclide & $\begin{array}{c}\text { Spontaneous } \\
\text { Fission } \\
\text { Fraction* } \\
\text { (SFF) }\end{array}$ & $\begin{array}{c}\text { Inhalation } \\
\text { Release Value } \\
\text { (C1) }\end{array}$ & $\begin{array}{c}\text { Neutron Exposure } \\
\text { Release Valide** } \\
\text { (Ci) }\end{array}$ \\
\hline Uranium-232 & $9 \times 10^{-13}$ & 0.01 & $2.8 \times 10^{11}$ \\
\hline Uranium-235 & $4.2 \times 10^{-10}$ & 0.1 & $5.9 \times 10^{3}$ \\
\hline Uranium-236 & $<3 \times 10^{-1}$ & 0.1 & $>0.83$ \\
\hline Uranium-238 & $5.4 \times 10^{-7}$ & 0.1 & $4.6 \times 10^{5}$ \\
\hline Plutonium -236 & $8.1 \times 10^{-10}$ & 0.1 & $3.1 \times 10^{3}$ \\
\hline Plutonium-238 & $1.8 \times 10^{-9}$ & 0.01 & $1.4 \times 10^{3}$ \\
\hline Plutonium-239 & $4.4 \times 10^{-12}$ & 0.01 & $5.7 \times 10^{10}$ \\
\hline Plutonium-240 & $4.9 \times 10^{-8}$ & 0.01 & $5.1 \times 10^{5}$ \\
\hline Plutonium-244 & $1.2 \times 10^{-3}$ & 0.01 & 200 \\
\hline Curium-238 & $<1.5 \times 10^{-4}$ & 1000 & $>1700$ \\
\hline Curium-242 & $6.8 \times 10^{-8}$ & 1 & $3.7 \times 10^{6}$ \\
\hline Curium-244 & $1.3 \times 10^{-6}$ & 0.01 & $1.8 \times 10^{5}$ \\
\hline Curium-246 & $2.6 \times 10^{-4}$ & 0.01 & 960 \\
\hline Curium-248 & $8.3 \times 10^{-2}$ & 0.001 & 3 \\
\hline Berkelium-249 & $4.7 \times 10^{-10}$ & 1 & $5.3 \times 10^{3}$ \\
\hline Californium-246 & $>0.001$ & 10 & $<250$ \\
\hline Californium-248 & $2.9 \times 10^{-5}$ & 0.1 & 8600 \\
\hline Californium -249 & $5.2 \times 10^{-9}$ & 0.01 & $\because \quad 4.8 \times 10^{7}$ \\
\hline Californium-250 & $7.7 \times 10^{-4}$ & 0.01 & 320 \\
\hline Californium-252 & $3.1 \times 10^{-2}$ & 0.1 & 8.0 \\
\hline Californium-254 & $9.9 \times 10^{-1}$ & 0.1 & 0.25 \\
\hline
\end{tabular}




\section{EXHIBIT D-1 - (Continued)}

RADIONOCLIDES INCLUDED IN ICRP PUBLICATION 30

WHICH DECAY BY SPONTANEOUS PISSION

\begin{tabular}{lccc}
\hline Radionuclide & $\begin{array}{c}\text { Spontaneous } \\
\text { Fission } \\
\text { Fraction* } \\
\text { (SFF) }\end{array}$ & $\begin{array}{c}\text { Inhalation } \\
\text { Release Value } \\
\text { (Ci) }\end{array}$ & $\begin{array}{c}\text { Neutron Exposure } \\
\text { Release Value* } \\
\text { (Ci) }\end{array}$ \\
Einsteinium-253 & $8.7 \times 10^{-8}$ & 10 & $2.9 \times 10^{6}$ \\
Einsteinium-254m & $<0.001$ & 1 & $>250$ \\
Fermium-254 & $5.9 \times 10^{-4}$ & 100 & 420 \\
\hline
\end{tabular}

- "Handbook of Chemistry and Physics," 63rd Edition, CRC Press, 1982.

Kocher, David C. "Radioactive Decay Data Tables," Technical

Information Center, U.S. Department of Energy, 1981.

** The phenomenon of "inscattering" might reduce these values by as much as 30 percent. The conclusions, however, remain unchanged. 
where:

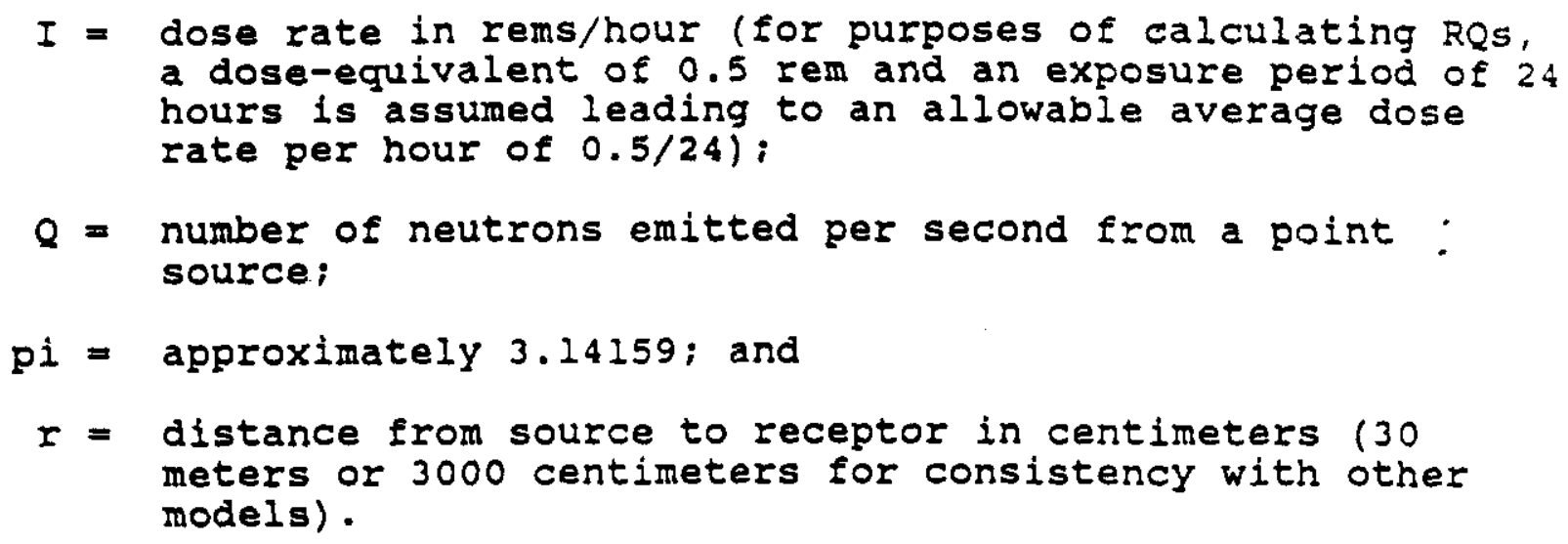

Rearranging equation (12) to solve for Q gives:

$$
Q=(I) *(4) *(p i) *\left(r^{2}\right) *(8000)
$$

substituting in values for $I, p i$, and $r$ yields:

$$
Q=1.88 \times 10^{10} \text { neutrons/second. }
$$

on the average, each fission yields two neutrons, therefore the total number of fissions per second (F) is:

$$
F=9.4 \times 10^{9} \text { fissions/sec. }
$$

One curie is equivalent to $3.7 \times 10^{10}$ disintegrations per second but only a fraction of the total disintegrations, the spontaneous fission eraction (SFF) shown in Exhibit D-1, occur by spontaneous fission. Division of equation (14) by the number of disintegrations per second equal to one curie and the spontaneous fission fraction for each radionuclide gives equation (15) which provides a release value based on direct exposure to neutrons.

$$
\text { D-10 }
$$




\author{
Neutron \\ Exposure $=0.25 /$ SFF. \\ Release Value
}

(Ci)

In this calculation, radioactive decay over the period of exposure is ignored. Inclusion of this factor would, for relatively short-lived radionuclides, increase the release values calculated on the basis of exposure to neutrons. Without consideration of this factor, release values calculated in this way are the lowest they could be but are still uniformly higher than release values calculated on the basis of inhalation as shown in the final two columns of Exhibit D-1. For this reason, the Agency chose to calculate direct exposure release values for all radionuclides on the basis of gamma ray exposure as described in section D.1.1, or if the radionuclides exist as a noble gas, on the basis of submersion in an airborne cloud as described in section D.2.

D. 2 SUBMERSION IN A CLOUD OF NOBLE GAS. 6

The noble gases argon, krypton, and xenon are very resistant to combination with other elements to form solid or liquid derivatives. The radioactive forms of these elements are not

\footnotetext{
6The noble gases helium and neon do not form isotopes with halflives longer than a few seconds. None of these isotopes are listed in ICRP Publication 30 and no release values or proposed RQs have been calculated for them. The noble gas radon has two isotopes (radon-220 and radon-222) listed in ICRP Publication 30 with inhalation ALIs calculated with and without daughters present. Due to the fact that Radon-220 and Radon-222 emit alpha particles and some of the daughters produced by their decay emit alpha particles, inhalation becomes the critical exposure pathway, and submersion in an airborne cloud is not addressed by the ICRP for either isotope. The lowest of the AIIs in each case was used in the usual manner to calculate inhalation release values and, since submersion in an airborne cloud is not addressed by the ICRP for either radon isotope, direct exposure release values were calculated by use of equation (11).
} 
likely to be found in compounds or in solid or liquid ingestible form. In addition, these gases have very low solubility in blocd and are easily displaced from blood by the more common gases found in air such as oxygen and nitrogen. For these reasons, neither ingestion nor inhalation comprise a route of significant exposure for argon, krypton or xenon and ALIs for isotopes of these elements are not found in ICRP Publication 30 . The one route of potential exposure considered signiflcant for radioactive forms of these elements is through direct exposure from submersion in an airborne cloud (known as "cloudshine"). The equation used for calculation of the Direct Exposure (DE)'Release Value (RV) based on submersion in such an airborne cloud is shown below ${ }^{7}$ :

$$
D E \quad \operatorname{RV}=[(83) *(D A C) *(T)] /\left[(10) *(X / Q) *\left(1 \times 10^{6}\right)\right]
$$

Where:

$$
\begin{aligned}
& \text { DAC = derived air concentration (uci/cubic centimeter) } \\
& T=\text { time of exposure ( } 1^{2} \text { day); } \\
& \mathrm{x} / \mathrm{Q}=\text { atmospheric relative concentration value }(8.4 \mathrm{x}
\end{aligned}
$$

83 conversion factor to adjust airborne concentrations from a 2000 hour work year ( 50 weeks times 40 hours per week) to a 24 hour exposure period $(2000 / 24)$; and

$1 \times 10^{6} \quad$ conversion factor from microcurie (uci) to curie.

The DAC is the airborne concentration to which an individual must be exposed for one work year (2000 hours) in order to receive an occupational dose-equivalent of 5 rem. The factor of 10 converts this occupational dose-equivalent to the $0.5 \mathrm{rem} / \mathrm{yr} \mathrm{limit}$ applicable to the general public. For consistency with other

7 Annals of the ICRP, Publication 30, Part 1, Vol. 2, No. 3/4, 1979, Pergammon Press, pages 10 and 47. 
exposure pathways the atmospheric relative concentration value $(X / Q)$ is derived for exposure 30 meters from the release under stability class $D$ conditions (see Appendix A). In order to convert the duration of exposure from a 2000 hour work year to 24 hours ( 1 day), the DAC must be multiplied by a factor of 83 (2000 hours/24 hours). This is the airborne concentration that will deliver a 5 rem dose-equivalent in 24 hours. The exposure time, $T$ ( 1 day), is Included in the equation because RQs are applicable to releases that occur over a maximum exposure time of 24 hours. EPA recognizes that it is unlikely that an individual would actually be exposed to an airborne cloud for a full day 30 meters from the release, but can not conclude that it is impossible and, therefore, uses a 24-hour exposure period in the model. Additionally, because the factor 83 is, as described above, derived by division of the 2000 hour work year by the exposure time, in this case 24 hours, any change in exposure time, $T$, will be exactly compensated by a change in the factor of 83. For example, if a one-half day exposure time were chosen, $T$ in equation (16) would become one half, while the numerical factor 83 would become 166 (2000/12).

Substitution of time $(T)^{8}$ and the atmospheric relative concentration value $(X / Q)$ into equation (16) leads to equation which was used for calculation of the direct exposure release values for isotopes of the noble gases, where appropriate.

$$
\text { DE Release value }=(D A C) /\left(1.0 \times 10^{-7}\right)
$$

\footnotetext{
${ }^{8}$ This pathway assumes an exposure to an airborne plume of radionuclide. Because it is not possible to establish exact bounds on the range of release and exposure periods, the Agency assumes conservatively that no decay occurs over these periods and the time period (T) is not adjusted for decay in this scenario.
} 
WHC-5D-GN-4C-20002, EV.

This Side Left Blank

y

D-14 


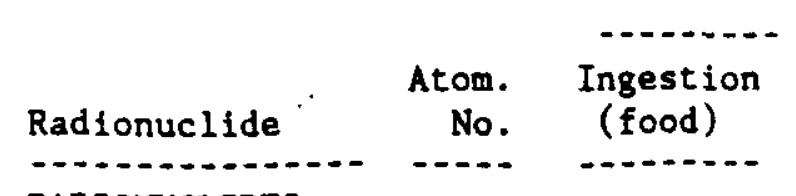

RADIONUCLIDES

Actinium-224

Actinium-225

Actinium-226

Actinium-227

Actinium-228

Aluminum-26

Americium-237

Americium-238

Americium-239

Americium-240

Americium-241

Americium-242m

Americium-242

Americium-243

Americium-244m

Americium-244

Americium-245

Americium-246m

Americium-246

Antimony-115

Ant imony-116m

Antimony-116

Antimony-117

Ant imony-118m

\section{Release Values \\ Ingestion \\ (water) \\ -...-...}

89

$6.6 \mathrm{E} 4$

89

3. $4 \mathrm{E} 1$

89

3.6E 2

6.OE-2

89

3. $2 \mathrm{E} 4$

13

1. $2 \mathrm{E} 1^{\star}$

95

$6.3 \mathrm{E} 6$

95

$2.3 \mathrm{E} 6$

95

95

95

95

95

95

95

95

95

4.1 E 4

$4.3 \mathrm{E} 3$

3. $0 \mathrm{E}-1$

$3.0 \mathrm{E}-1$

$3.1 \mathrm{E} 4$

3. $0 \mathrm{E}-1$

1.3E 7

$2.9 \mathrm{E} 4$

$1.4 \mathrm{E} 6$

95

95

51

51

51

51

51

v. 18 .

v.1g.

v.1g.

v.18.
(Ci)

Inha-

lation

Direct

Exposure

$-\cdots-c--$

-.-.-...

1. $6 \mathrm{E} \mathrm{2*}$

$1.7 \mathrm{E} 3$

$1.6 \mathrm{E} \mathrm{0*}$

1. 3E 3

$1.6 \mathrm{E} 1 * 3.4 \mathrm{E} 2$

$2.1 E-3 *$

$5.4 \mathrm{E} 5$

4.7E 1*

$1.4 \mathrm{E} 2$

2. OE 1

$2.13^{*}$

$1.6 \mathrm{E} 6$

$1.6 \mathrm{E} 4$

5.3 2* $^{\star}$

$5.2 \mathrm{E} 4$

8.0 2* $^{\star}$

$1.6 \mathrm{E} 4$

4. $5 \mathrm{E} 1 *$

$2.6 \mathrm{E}-2^{\star} *$

$2.6 \mathrm{E}-2 \star$

3. 2E 5

$4.1 \mathrm{E} 2$ *

$2.6 \mathrm{E}-2$

$2.1 \mathrm{E} 4$ *

$7.9 \mathrm{E} 2$

$1.0 \mathrm{E} 3$

$9.5 \mathrm{E} \mathrm{1*}$

4.185

$1.7 \mathrm{E} 4$

1. $0 \mathrm{E} 6$

1. 7E 3 *

$5.2 \mathrm{E} 5$

$1.5 E^{3}$

1.OE 5

$2.2 \mathrm{E} 3 *$

$3.6 \mathrm{E} 4$

2. 1 E 2* $^{\text {* }}$

$1.6 \mathrm{E} 5$

1. 3E 3*

1. OE 5

$1.5 \mathrm{E} \mathrm{3}^{\mathrm{x}}$

1. $0 \mathrm{E} 4$

4. 9: 1*

Firial

$\mathrm{RQ} \mathrm{(} \mathrm{Ci})$

].

100

$$
1
$$

.10

0.001

10

10

1000

100

100

10

0.01

0.01

100

0.01

1000

10

1000

1000

1000

1000

100

1000

1000

10 


\begin{tabular}{|c|c|c|c|c|c|c|}
\hline Radionuclide & $\begin{array}{r}\text { Atom. } \\
\text { No. }\end{array}$ & $\begin{array}{l}\text { Ingestion } \\
\text { (food) }\end{array}$ & $\begin{array}{l}\text { Release Values } \\
\text { Ingestion } \\
\text { (water) }\end{array}$ & $\begin{array}{l}(\mathrm{Ci}) \\
\text { Inha- } \\
\text { lation }\end{array}$ & $\begin{array}{l}\text { Direct } \\
\text { Exposure }\end{array}$ & $\begin{array}{r}\text { Firal } \\
R Q(C i \\
\hdashline-\ldots .\end{array}$ \\
\hline Antimony-119 & 51 & $2.9 E 3^{*}$ & v.18. & 1.684 & -- & 1000 \\
\hline $\begin{array}{l}\text { Antimony- } 120 \\
(16 \mathrm{~min})\end{array}$ & 51 & $3.6 \mathrm{E} 6$ & $v .18$. & $2.1 \pm 5$ & $1.15^{*}$ & 1000 \\
\hline $\begin{array}{c}\text { Antimony- } 120 \\
(5.76 \text { day })\end{array}$ & 51 & $8.7 \mathrm{E} 1$ & v.18. & $5.2 \mathrm{E} 2$ & $1.6 \mathrm{E} 1^{*}$ & $\therefore 10$ \\
\hline Antimony- 122 & 51 & $1.2 \mathrm{E} 2$ & v. 18 . & $5.2 \mathrm{~B} 2$ & $9.3 \mathrm{E} 1^{*}$ & 10 \\
\hline Antimony $-124 \mathrm{~m}$ & 51 & $5.6 \mathrm{E} 6$ & v.1g. & $3.1 \mathrm{E} 5^{*}$ & -- & 1000 \\
\hline Antimony -124 & 51 & $1.8 \mathrm{E} 1^{\star}$ & v. 18 . & 1.082 & $2.0 \mathrm{E} 1$ & 10 \\
\hline Antimony -125 & 51 & $6.0 \mathrm{E} 1^{*}$ & v. 18 . & $2.6 \mathrm{E} 2$ & $8.9 \mathrm{E} 1$ & 10 \\
\hline Ant imony $-126 m$ & 51 & $1.5 \mathrm{E} 6$ & v. 18 & $1.0 \mathrm{E} 5$ & $1.2 E^{3 *}$ & 1000 \\
\hline Antimony-126 & 51 & $3.0 \mathrm{E} 1$ & $v .18$. & $2.6 \mathrm{E} 2$ & $1.4 \mathrm{E} 1 *$ & 10 \\
\hline Antimony -127 & 51 & $9.1 \mathrm{E} 1$ & v. $1_{B_{0}}$ & $4.7 \mathrm{E} 2$ & $6.6 \mathrm{E} 1^{*}$ & 10 \\
\hline $\begin{array}{l}\text { Antimony }-128 \\
(10.4 \mathrm{~min})\end{array}$ & 51 & $4.5 \mathrm{E} 6$ & v. 18 . & $2.1 \mathrm{E} 5$ & $1.9 \mathrm{E} 3 *$ & 1000 \\
\hline $\begin{array}{c}\text { Antimony-128 } \\
(9.01 \mathrm{hr})\end{array}$ & 51 & $1.1 E 3$ & v.18. & $1.6 \mathrm{E} 3$ & $2.8 \mathrm{E} 1 *$ & 10 \\
\hline Antimony -129 & 51 & $6.5 \mathrm{E} 3$ & v.18. & $4.7 \mathrm{E} 3$ & $1.1 \mathrm{E} \mathrm{2*}$ & 100 \\
\hline Ant imony -130 & 51 & $3.0 \mathrm{E} 5$ & v. 18 . & $3.1 \mathrm{E} 4$ & $3.4 \mathrm{E} \mathrm{2*}$ & 100 \\
\hline Antimony-131 & 51 & $2.5 \mathrm{E} 5$ & $v .18$ & $1.0 \mathrm{E} 4$ & $1.2 \mathrm{E} 3^{\star}$ & 1000 \\
\hline Argon-39 & 18 & na & na & na & $2.0 \mathrm{E}^{*+}$ & 1000 \\
\hline Argon- 41 & 18 & na & na & na & $3.0 \mathrm{E} 1^{*+}$ & 10 \\
\hline Arsenic -69 & 33 & $1.1 \mathrm{E} 6$ & $>\mathrm{E} 9$ & $5.2 \mathrm{E} 4^{\star}$ & $1.0 E 5$ & 1000 \\
\hline Arsenic -70 & 33 & $1.1 \mathrm{E} 5$ & $>\mathrm{E} 9$ & $2.6 \mathrm{E} 4$ & $2.9 \mathrm{~B} 2^{\star}$ & 100 \\
\hline Arsenic-71 & 33 & $7.3 \mathrm{E} 2$ & $3.9 \mathrm{E} 3$ & $2.6 \mathrm{E} 3$ & $1.9 \mathrm{~B} 2^{\star}$ & 100 \\
\hline Arsenic -72 & 33 & $3.5 \mathrm{E} 2$ & $1.8 \mathrm{E} 4$ & $5.2 \mathrm{E} 2$ & $5.6 \mathrm{E} 1^{\star}$ & 10 \\
\hline Arsenic -73 & 33 & $2.7 \mathrm{E} 2^{\star}$ & $6.4 \mathrm{E} 2$ & $1.0 \mathrm{E} 3$ & - & 100 \\
\hline
\end{tabular}




\begin{tabular}{|c|c|c|c|c|c|c|}
\hline \multirow[b]{2}{*}{ Radionuclide : } & \multicolumn{4}{|c|}{ APPENDIX $\varepsilon$ (Continued) } & \multicolumn{2}{|c|}{ WHC-SJ-GN-4C-20002, :EV. ? } \\
\hline & $\begin{array}{r}\text { Atom. } \\
\text { No. }\end{array}$ & $\begin{array}{l}\text { Ingestion } \\
\text { (food) }\end{array}$ & $\begin{array}{l}\text { Release Values } \\
\text { Ingestion } \\
\text { (water) }\end{array}$ & $\begin{array}{l}(\mathrm{Ci}) \\
\text { Inha- } \\
\text { lation } \\
\end{array}$ & $\begin{array}{l}\text { Direct } \\
\text { Exposure }\end{array}$ & $\begin{array}{l}\text { Final } \\
\text { RQ (Ci) } \\
-\end{array}$ \\
\hline Arsenic -74 & 33 & $5.1 \mathrm{E} 1^{\star}$ & $1.1 \mathrm{E} 2$ & $4.1 \mathrm{E} 2$ & $8.1 \mathrm{E} 1$ & 10 \\
\hline Arsenic-76 & 33 & $3.9 \mathrm{E} 2$ & $1.9 \mathrm{E} 4$ & $5.2 \mathrm{E} 2$ & $1.3 \mathrm{E} 2 \star$ & 100 \\
\hline Arsenic -77 & 33 & $1.1 \mathrm{E} \mathrm{3*}$ & $1.5 \mathrm{E} 4$ & $2.6 \mathrm{E} 3$ & $6.1 \mathrm{E} 3$ & 1000 \\
\hline Arsenic -78 & $33-$ & $5.0 \mathrm{E} 4$ & $>$ E 9 & $1.0 \mathrm{E} 4$ & $3.9 \mathrm{E} \mathrm{2*}$ & 100 \\
\hline Astatine -207 & 85 & $3.1 \mathrm{E} 5$ & $>E 9 \#$ & $1.0 \mathrm{E} 4$ & $3.7 \mathrm{E} \mathrm{2*}$ & 100 \\
\hline Astatine-211 & 85 & $1.3 E 3$ & $1.6 \mathrm{E} 8 \#$ & $2.6 \mathrm{E} \mathrm{2*}$ & $5.3 E 4$ & 100 \\
\hline Barium-126 & 56 & $3.5 \mathrm{E} 4$ & v. 18 . & $1.0 \mathrm{E} 4$ & $1.0 \mathrm{E} \mathrm{3*}$ & 1000 \\
\hline Barium-128 & 56 & $9.5 \mathrm{E} 1 *$ & v. $l_{g}$. & $1.0 \mathrm{E} 3$ & $1.1 \mathrm{E} 3$ & 10 \\
\hline Barium-131m & 56 & $1.6 \mathrm{E} 7$ & v. 18 & $5.2 \mathrm{E} 5$ & $4.1 \mathrm{E} 4^{*}$ & 1000 \\
\hline Barium-131 & 56 & $1.8 \mathrm{E} 2$ & v.18. & 4.183 & $9.3 \mathrm{E} 1 *$ & 10 \\
\hline Barium-133m & 56 & $5.4 \mathrm{E} \mathrm{2 \star}$ & $v \cdot \lg _{p}$ & $4.7 \mathrm{~B} 3$ & $9.5 \mathrm{E} 2$ & 100 \\
\hline Barium-133 & 56 & $5.9 \mathrm{E} 1^{*}$ & $v .18$. & $3.6 \mathrm{E} 2$ & $1.0 \mathrm{E} 2$ & 10 \\
\hline Barium-135m & 56 & $1 . \operatorname{lE~3*}$ & v.18. & $5.2 \mathrm{E} 3$ & $1.1 \mathrm{E} 3$ & 1000 \\
\hline Barium-139 & 56 & $6.8 \mathrm{E} 4$ & $v \cdot 1 g$. & $1.6 \mathrm{~B} 4$ & $9.9 \mathrm{~B} \mathrm{3*}$ & 1000 \\
\hline Barium-140 & 56 & $3.0 \mathrm{~B} 1 \star$ & v.18. & $5.2 \mathrm{E} 2$ & $2.1 \mathrm{E} 2$ & 10 \\
\hline Barium-141 & 56 & $6.2 \mathrm{E} 5$ & v.18. & $3.6 \mathrm{~B} 4$ & $3.6 \mathrm{E} \mathrm{3*}$ & 1000 \\
\hline Barium-142 & 56 & $2.7 \mathrm{E} 6$ & v.18. & $5.2 \mathrm{E} 4$ & $3.4 \mathrm{E} \mathrm{3*}$ & 1000 \\
\hline Berkelium-245 & 97 & $2.2 \mathrm{E} 3$ & v. Is. & $5.2 \mathrm{E} 3$ & $4.6 \mathrm{E} \mathrm{2*}$ & 100 \\
\hline Berkelium-246 & 97 & $7.5 \mathrm{E} 3$ & v.18. & $1.6 \mathrm{E} 4$ & $6.0 \mathrm{E} 1^{\star}$ & 10 \\
\hline Berkelium-247 & 97 & $3.0 \mathrm{E}-1$ & v.18. & & $3.2 \mathrm{E} 2$ & 0.01 \\
\hline Berkelium-249 & 97 & $1.5 \mathrm{E} 1$ & v.1g. & $1.0 \mathrm{E} 0 *$ & -- & 1 \\
\hline Berkelium-250 & 97 & $3.0 \mathrm{E} 4$ & v.18. & $2.1 \mathrm{~B} 2^{*}$ & $2.1 \mathrm{E} 2$ & 100 \\
\hline Beryllium-7 & 4 & $1.5 \mathrm{E} 3$ & v.18. & $1.0 \mathrm{~B} 4$ & $7.4 \mathrm{E} \mathrm{2*}$ & 100 \\
\hline Beryllium-10 & 4 & $3.0 \mathrm{E} 1$ & v.18. & $5.2 \mathrm{E} 0 *$ & -- & 1 \\
\hline
\end{tabular}


APPENDIX E (Continued)

\begin{tabular}{|c|c|c|c|c|c|c|}
\hline Radionuclide & $\begin{array}{l}\text { Atom. } \\
\text { No. }\end{array}$ & $\begin{array}{l}\text { Ingestion } \\
\text { (food) }\end{array}$ & $\begin{array}{l}\text { Release Values } \\
\text { Ingestion } \\
\text { (water) }\end{array}$ & $\begin{array}{l}\left(\mathrm{C}_{i}\right) \\
\text { Inha- } \\
\text { lation } \\
\end{array}$ & $\begin{array}{l}\text { Direct } \\
\text { Exposure }\end{array}$ & $\begin{array}{l}F i m a l \\
R Q(C i \\
\cdots \cdots\end{array}$ \\
\hline Bismuth -200 & 83 & $4.8 \mathrm{E} 5$ & v.1g. & $4.1 \mathrm{E} 4$ & $4.7 \mathrm{E} \mathrm{2*}$ & 100 \\
\hline Bismuth-201 & 83 & $5.3 E 4$ & v. 18 . & $1.6 \mathrm{E} 4$ & $4.7 \mathrm{E} \mathrm{2*}$ & 100 \\
\hline Bismuth-202 & 83 & $5.5 E 4$ & v. $1_{8}$. & $2.1 E 4$ & $1.0 \mathrm{E} \mathrm{3*}$ & 1000 \\
\hline Bismuth -203 & 83. & $1.7 \mathrm{E} 3$ & $v .1_{8}$. & $3.1 E 3$ & $4.2 \mathrm{E} 1 *$ & 10 \\
\hline Bismuth-205 & 83 & $5.4 \mathrm{E} 1$ & v. 18 . & $5.2 \mathrm{E} 2$ & $4.4 \mathrm{E} 1^{*}$ & 10 \\
\hline Bismuth-206 & 83 & $5.5 \mathrm{E} 1$ & v. 18 . & $4.7 \pm 2$ & $1.2 \mathrm{E} \mathrm{1*}$ & 10 \\
\hline Bismuth-207 & 83 & $3.0 \mathrm{E} 1$ & v. Ig. & $2.1 \pm 2$ & $2.5 E 1^{*}$ & 10 \\
\hline Bismuth-210m & 83 & $1.2 \mathrm{E} \quad 0$ & $v \cdot 1 g$ & $3.6 E-1 *$ & $1.5 \mathrm{E} 2$ & 0.1 \\
\hline Bismuth-210 & 83 & $8.6 \mathrm{E} 1$ & $v \cdot l_{8}$. & $1.6 \mathrm{E} 1^{*}$ & $1.3 \mathrm{E} 8$ & 10 \\
\hline Bismuth-212 & 83 & $4.7 \mathrm{E} 4$ & v. $1_{8}$. & $1.0 E 2 *$ & $5.8 E \quad 3$ & 100 \\
\hline Bismuth-213 & 83 & $8.8 E 4$ & v. $18:$ & $1.6 \mathrm{E} \mathrm{2*}$ & -- & 100 \\
\hline Bismuth-214 & 83 & $5.7 \mathrm{E} 5$ & $v .18$ & $4.1 E 2 *$ & $1.4 \mathrm{E} 3$ & 100 \\
\hline Bromine $-74 m$ & 35 & $1.3 E 5$ & $>E 9 \#$ & $2.0 \mathrm{E} 4$ & $3.2 \mathrm{E} 2 \star$ & 100 \\
\hline Bromine -74 & 35 & $4.3 E 5$ & $>\mathrm{E} 9 \#$ & $3.6 \mathrm{E} 4$ & $9.7 \mathrm{E} \mathrm{2 \star}$ & 100 \\
\hline Bromine-75 & 35 & $1.6 \mathrm{E} 5$ & $>$ E $9 \|$ & $2.6 \mathrm{E} 4$ & $3.3 E 2 *$ & 100 \\
\hline Bromine-76 & 35 & $2.3 \mathrm{E} 3$ & $1.3 \mathrm{E} 6 \#$ & $2.0 \mathrm{E} 3$ & $2.8 \mathrm{E} \mathrm{1*}$ & 10 \\
\hline Bromine -77 & 35 & $3.7 \mathrm{E} 3$ & $2.4 \mathrm{E} 4 \#$ & $1.0 \mathrm{E} 4$ & $1.5 \mathrm{E} \mathrm{2*}$ & 100 \\
\hline Bromine- $80 m$ & 35 & $4.1 \mathrm{E} 4$ & $>\mathrm{E} 9 \|$ & $5.0 \mathrm{E} 3 *$ & $-\cdots$ & 1000 \\
\hline Bromine-80 & 35 & $1.5 \mathrm{E} 6$ & $>$ E $9 \#$ & $1.0 \mathrm{E} 5$ & $4.0 \mathrm{E} 4 *$ & 1000 \\
\hline Bromine-82 & 35 & $8.5 B 2$ & $1.6 \mathrm{E} 4 \|$ & $2.0 \mathrm{E} 3$ & $1.7 \mathrm{E} ! *$ & 10 \\
\hline Bromine -83 & 35 & $1.9 \mathrm{E} 5$ & $>$ E $9 \#$ & $3.1 E 4^{*}$ & $3.5 \mathrm{E} 4$ & 1000 \\
\hline Bromine-84 & 35 & $3.4 \mathrm{E} 5$ & $>\mathrm{E} 9 \#$ & $3.1 E 4$ & $6.9 E 2 *$ & 100 \\
\hline Cadmium- 104 & 48 & $1.9 E 5$ & $v .18$. & $3.6 \mathrm{E} 4$ & $2.7 \mathrm{E} \mathrm{3*}$ & 1000 \\
\hline Cadmium-107 & 48 & $2.9 E 4$ & v. 18 . & $2.6 \mathrm{E} 4$ & $1.6 \mathrm{E} 4^{*}$ & 1000 \\
\hline
\end{tabular}




\begin{tabular}{|c|c|c|c|c|c|c|}
\hline Radionuclide & $\begin{array}{l}\text { Atom. } \\
\text { No. }\end{array}$ & $\begin{array}{l}\text { Ingestion } \\
\text { (food) }\end{array}$ & $\begin{array}{l}\text { Release Values } \\
\text { Ingestion } \\
\text { (water) }\end{array}$ & $\begin{array}{l}\left(C_{i}\right) \\
\text { Inha- } \\
\text { lation }\end{array}$ & $\begin{array}{l}\text { Direct: } \\
\text { Exposure }\end{array}$ & $\begin{array}{l}\text { Final } \\
\text { RQ (Ci) }\end{array}$ \\
\hline Cadmium-109 & 48 & $9.0 E 0^{*}$ & v. 18 . & $2.1 E 1$ & $1.1 \mathrm{E} 4$ & 1. \\
\hline Cadmium-113m & 48 & $5.9 E-1 *$ & v. 18 & $1.0 \mathrm{E} 0$ & $6.9 \mathrm{E} 5$ & 0.1 \\
\hline Cadmium-113 & 48 & $5.8 \mathrm{E}-1 \star$ & v. 18 . & $1.0 \mathrm{E} 0$ & -- & 0.1 \\
\hline Cadmium-115m & 48 & $1.181^{\star}$ & $v .18$. & $2.6 \mathrm{E} 1$ & 1.1 E 3 & $\therefore \quad \therefore 10$ \\
\hline Cadmium-115 & 48 & $1.8 \mathrm{E} 2$ & v. Ig. & $5.2 \mathrm{E} 2$ & $1.1 \mathrm{E} \mathrm{2 \star}$ & 100 \\
\hline Cadmium-117m & 48 & $1.4 \mathrm{E} 4$ & v. 18 . & $5.2 \mathrm{E} 3$ & $7.0 \mathrm{E} 1^{\star}$ & 10 \\
\hline Cadmium-117 & 48 & $1.9 \mathrm{E} 4$ & $v . l_{8}$. & $5.2 \mathrm{E} 3$ & $2.8 \mathrm{E} \mathrm{2*}$ & 100 \\
\hline Calcium- 41 & 20 & $8.0 \mathrm{E} 1^{\star}$ & v. 18 . & $2.1 \mathrm{E} 3$ & - & 10 \\
\hline Calcium -45 & 20 & $5.7 E 1^{*}$ & $v \cdot 18$. & $4.1 \mathrm{E} 2$ & -- & 10 \\
\hline Calcium -47 & 20 & $8.2 \mathrm{E} 1$ & $v . l_{g}$. & $4.7 \mathrm{E} 2$ & $3.5 \mathrm{E} 1^{*}$ & 10 \\
\hline Californium-244 & 98 & $8.8 E 6$ & $>E ? \#$ & $3.1 \mathrm{E} \mathrm{3*}$ & -- & 1000 \\
\hline Californium-246 & 98 & $1.2 \mathrm{E} 3$ & $2.0 \mathrm{E} 3 \#$ & $4.7 \mathrm{E} 1^{\star}$ & $3.4 \mathrm{E} 6$ & 10 \\
\hline Californium-248 & 98 & $6.2 \mathrm{E} 0$ & $1.5 \mathrm{E} 0 \#$ & $4.7 \mathrm{E}-1 *$ & -- & 0.1 \\
\hline Californium-249 & 98 & $3.0 \mathrm{E}-1$ & $7.3 \mathrm{E}-2 \#$ & $2.6 \mathrm{E}-2^{\star}$ & $1.2 \mathrm{E} 2$ & 0.01 \\
\hline Californium-250 & 98 & $9.0 \mathrm{E}-1$ & $2.2 \mathrm{E}-1 \#$ & $5.2 E-2 \star$ & -- & 0.01 \\
\hline Californium-251 & 98 & $3.0 \mathrm{E}-1$ & $7.3 \mathrm{E}-2$ & $2.6 \mathrm{E}-2^{\star}$ & -- & 0.01 \\
\hline Californium- 252 & 98 & $1.8 \mathrm{E} \quad 0$ & $4.4 \mathrm{E}-1 \#$ & $1.6 \mathrm{E}-1 *$ & $3.6 \mathrm{E} 6$ & 0.1 \\
\hline Californium- 253 & 98 & $3.0 \mathrm{E} 2$ & $6.6 \mathrm{E} 1 \#$ & $1.0 \mathrm{E} 1^{\star}$ & - & 10 \\
\hline Californium-254 & 98 & $1.1 \mathrm{E} 0$ & $2.5 E-1 \#$ & $1.0 \mathrm{~B}-1^{*}$ & -- & 0.1 \\
\hline Carbon-11 & 6 & -- & $>E 9$ & $4.1 \mathrm{E} 3$ & $1.8 \mathrm{E} 3^{\star}$ & 1000 \\
\hline Carbon- 14 & 6 & -- & $1.5 \mathrm{E} 2$ & $2.1 E 1 *$ & - & 10 \\
\hline Cerium-134 & 58 & $7.7 \mathrm{E} 1^{\star}$ & v.18. & $3.6 \mathrm{E} 2$ & $1.3 \mathrm{E} 3$ & 10 \\
\hline Cerium-135 & 58 & $1.1 E 3$ & v.18. & $2.1 \mathrm{E} 3$ & $7.9 \mathrm{E} 1^{\star}$ & 10 \\
\hline Cerium-137m & 58 & $6.1 \mathrm{E} 2 \star$ & v.1g. & $2.1 \mathrm{E} 3$ & $1.4 \mathrm{E} 3$ & 100 \\
\hline
\end{tabular}




\begin{tabular}{|c|c|c|c|c|c|c|}
\hline Radionuclide & $\begin{array}{r}\text { Atom. } \\
\text { No. }\end{array}$ & $\begin{array}{l}\text { Ingestion } \\
\text { (food) }\end{array}$ & $\begin{array}{l}\text { Release Values } \\
\text { Ingestion } \\
\text { (water) }\end{array}$ & $\begin{array}{l}\left(\mathrm{C}_{i}\right) \\
\text { Inha- } \\
\text { lation }\end{array}$ & $\begin{array}{l}\text { Direct } \\
\text { Exposure }\end{array}$ & $\begin{array}{l}\text { Einal } \\
\operatorname{RO}(C i) \\
\end{array}$ \\
\hline Cerium- 137 & 58 & $5.4 \mathrm{E} 4$ & v. 18 . & $5.2 \mathrm{E} 4$ & $6.9 \mathrm{E} 3{ }^{k}$ & $\$ 000$ \\
\hline Cerium-139 & 58 & $1.6 \mathrm{E} 2 \star$ & v.18. & $3.6 \mathrm{E} 2$ & $2.7 \mathrm{E} 2$ & 100 \\
\hline Cerium-141 & 58 & $8.2 \mathrm{E} 1$ & v.18. & $3.1 \mathrm{E} 2$ & $5.2 \mathrm{E} 1^{*}$ & .10 \\
\hline Cerium- 143 & 58 & $3.2 \mathrm{E} 2$ & v. 18. & $1: O E^{3} 3$ & $1.9 \mathrm{E} \mathrm{2*}$ & $=100$ \\
\hline Ceriun- 144 & 58 & $6.2 \mathrm{~B} 0$ & v. 18. & $5.2 \mathrm{E} 0 *$ & $2.3 \mathrm{E} 3$ & 1 \\
\hline Cesium-125 & 55 & $6.3 \mathrm{E} 5$ & v. 18 . & $5.2 \mathrm{E} 4$ & $3.1 E 3 *$ & 1000 \\
\hline Cesium- 127 & 55 & $9.3 \mathrm{E} 4$ & v. 18 . & $4.7 E 4$ & $3.3 \mathrm{E} \mathrm{2*}$ & 100 \\
\hline Cesium-129 & 55 & $6.4 \mathrm{E} 3$ & $v .18$. & $1.6 \mathrm{E} 4$ & $1.9 \mathrm{E} \mathrm{2*}$ & 100 \\
\hline Cesium-130 & 55 & $1.2 \mathrm{E} 6$ & v.18. & $1.0 \mathrm{E} 5$ & $3.0 \mathrm{E} 4 *$ & 1000 \\
\hline Cesium-131 & 55 & $1.4 \mathrm{E} \mathrm{3 \star}$ & v.18. & $1.6 \mathrm{E} 4$ & $\cdots$ & 1000 \\
\hline Cesium-132 & 55 & 2.782 & $0.18{ }^{\circ}$ & $2.1 \mathrm{E} 3$ & $5.7 \mathrm{E} 1^{*}$ & 10 \\
\hline Cesium-134m & 55 & $3.3 E 5$ & $v .1_{B}$. & $5.2 \mathrm{E} 4$ & $1.3 \mathrm{E} 4 k$ & 1000 \\
\hline Cesium-134 & 55 & $2.1 \mathrm{E} \mathrm{O*}$ & v. 18 . & $5.2 \mathrm{E} 1$ & $2.4 \mathrm{EI}^{1}$ & 1 \\
\hline Cesium-135m & 55 & $1.1 \mathrm{E} 6$ & v. Ig. & $1.0 \mathrm{E} 5$ & $4.3 E 2 *$ & 100 \\
\hline Cesium-135 & 55 & $2.1 \mathrm{E} 1^{\star}$ & v. 18 . & $5.2 E 2$ & - & 10 \\
\hline Cesium- 136 & 55 & $2.3 \mathrm{E} 1$ & v. $1 \mathrm{~g}$. & $3.6 \mathrm{E} 2$ & $2.0 \mathrm{E} 1^{*}$ & 10 \\
\hline Cesium-137 & 55 & $3.0 \mathrm{E} \mathrm{O \star}$ & v. 18 . & $1.0 \mathrm{E} 2$ & $6.5 \mathrm{E} 1$ & 1 \\
\hline Cesium-138 & 55 & $3.5 B 5$ & v.lg. & $3.1 E 4$ & $5.0 \mathrm{2}$ & 100 \\
\hline Chlorine -36 & 17 & $1.7 \mathrm{~B} 1^{\star}$ & $1.5 \mathrm{E} 2$ & $1.0 \mathrm{E} 2$ & -- & 10 \\
\hline Chlorine- 38 & 17 & $9.0 \mathrm{E} 4$ & $>$ E 9 & $2.0 \mathrm{E} 4$ & $6.9 E 2 *$ & 100 \\
\hline Chlorine-39 & 17 & $6.0 \mathrm{E} 4$ & $>$ E 9 & $2.6 \mathrm{E} 4$ & $4.5 \mathrm{E} \mathrm{2*}$ & 100 \\
\hline Chromium-48 & 24 & $2.8 \mathrm{E} 3$ & $3.1 \mathrm{E} 5 \#$ & $3.6 \mathrm{E} 3$ & $1.3 \mathrm{E} \mathrm{2*}$ & 100 \\
\hline Chromium-49 & 24 & $4.1 \mathrm{E} 5$ & $>$ E $9 \#$ & $4.1 \mathrm{E} 4$ & $9.9 \mathrm{E} \mathrm{3*}$ & 1000 \\
\hline Chromium-51 & 24 & $1.7 \mathrm{E} 3$ & $3.8 \mathrm{E} 3 \|$ & $1.0 \mathrm{E} 4$ & $1.1 \mathrm{E} 3 *$ & 1000 \\
\hline
\end{tabular}




\begin{tabular}{|c|c|c|c|c|c|c|}
\hline $\begin{array}{l}\text { Radionuclide } \\
\end{array}$ & $\begin{array}{l}\text { Atom. } \\
\text { No. }\end{array}$ & $\begin{array}{l}\text { Ingestion } \\
\text { (food) }\end{array}$ & $\begin{array}{l}\text { Release Values } \\
\text { Ingestion } \\
\text { (water) }\end{array}$ & $\begin{array}{l}(\mathrm{Ci}) \\
\text { Inha- } \\
\text { lation }\end{array}$ & $\begin{array}{l}\text { Direct. } \\
\text { Exposure }\end{array}$ & $\begin{array}{l}\text { Final } \\
\operatorname{RQ}(\mathrm{C} i) \\
\end{array}$ \\
\hline Cobalt-55 & 27 & $5.7 \pm 3$ & v. lg. & $1.6 \mathrm{E} 4$ & $4.9 E 1^{\star}$ & 10 \\
\hline Cobalt-56 & 27 & $1.4 \mathrm{~B} 2$ & v. 18 . & $1.0 \mathrm{E} 3$ & $1.1 \mathrm{E} 1^{\star}$ & 10 \\
\hline Cobalt -57 & 27 & $1.2 \mathrm{E} 3$ & v. 18 . & $3.6 \mathrm{E} 3$ & $3.0 \mathrm{E} \mathrm{2*}$ & 100 \\
\hline Cobalt-58m & $27 \cdots$ & $\cdots 6.4 E .5$ & $v .18 . \quad$. & 3.1 E 5* $^{\star}$ & 9.186 & 1000 \\
\hline Cobalt-58 & 27 & $3.5 E 2$ & v.18. & $3.6 \mathrm{E} 3$ & $4.5 \mathrm{E} 1^{*}$ & 10 \\
\hline Cobalt-60m & 27 & $5.4 \mathrm{E} 8$ & v. 18 . & $1.6 \mathrm{E} 7$ & $3.0 \mathrm{E} \mathrm{6*}$ & 1000 \\
\hline Cobalt -60 & 27 & $6.0 \mathrm{E} 1$ & v. $1_{8}$. & $1.6 \mathrm{E} 2$ & $1.5 E 1^{*}$ & 10 \\
\hline Cobalt-61 & 27 & $1.2 \mathrm{E} 6$ & v.lB. & $3.1 \mathrm{E} 5$ & $4.0 \mathrm{E} \mathrm{3*}$ & 1000 \\
\hline Cobalt-62m & 27 & $1.6 \mathrm{E} 7$ & v.lg. & 1.086 & $1.0 \mathrm{E} 3{ }^{x}$ & 1000 \\
\hline Copper-60 & 29 & $7.3 E \quad 5$ & $>$ E $9 \#$ & $4.7 \mathrm{E} 4$ & $9.9 \mathrm{E} \mathrm{2*}$ & 100 \\
\hline Copper-61 & 29 & $2.8 \mathrm{E} 4$ & $>E 9 \#$ & $1.6 \mathrm{E} 4$ & $8.2 \mathrm{E} \mathrm{2*}$ & 100 \\
\hline Copper-64 & 29 & $7.7 \mathrm{E} \mathrm{3 \star}$ & $2.2 \mathrm{E} 7 \#$ & 1.084 & $8.1 E^{3} 3$ & 1000 \\
\hline Copper-67 & 29 & $9.0 \mathrm{E} 2$ & $4.9 \mathrm{E} 3 \|$ & $2.6 \mathrm{E} 3$ & $3.7 \mathrm{E} 22^{\star}$ & 100 \\
\hline Curium-238 & 96 & $8.0 \mathrm{E} 5$ & v.lg. & $5.2 \mathrm{E} \mathrm{3*}$ & -- & 1000 \\
\hline Curium-240 & 96 & $4.3 \mathrm{E} 1$ & v. 18 . & $2.6 \mathrm{E} 0 *$ & -- & 1. \\
\hline Curium-241 & 96 & $4.1 \mathrm{E} 2$ & v. Ig. & $1.0 \mathrm{E} 2$ & $9.6 \mathrm{E} 1^{\star}$ & 10 \\
\hline Curium-242 & 96 & $1.9 \mathrm{E} 1$ & v.18. & $1.6 \mathrm{E} 0 *$ & $1.0 \mathrm{E} 7$ & 1. \\
\hline Curium-243 & 96 & $6.0 \mathrm{E}-1$ & v. lg. & $4.1 \mathrm{E}-2^{\star}$ & $5.0 \mathrm{E} 2$ & 0.01 \\
\hline Curium-244 & 96 & $6.0 \mathrm{E}-1$ & v.18. & $5.2 \mathrm{E}-2^{\star}$ & $1.4 \mathrm{E} 7$ & 0.01 \\
\hline Curium-245 & 96 & $3.0 \mathrm{E}-1$ & v.1g. & $2.6 \mathrm{E}-2^{\star}$ & 1.783 & 0.01 \\
\hline Curium-246 & 96 & $3.0 \mathrm{~B}-1$ & v.1g. & $2.6 \mathrm{E}-2^{\star}$ & -- & 0.01 \\
\hline Curium-247 & 96 & $3.0 \mathrm{E}-1$ & v.lg. & $3.1 \mathrm{E}-2^{\star}$ & $1.2 \mathrm{E} 2$ & 0.01 \\
\hline Curium-248 & 96 & $1.2 \mathrm{E}-1$ & v.1g. & $5.2 E-3 \star$ & $\cdots$ & 0.001 \\
\hline Curium-249 & 96 & $4.5 \mathrm{E} 6$ & v. $l_{\mathrm{g}}$. & $1.0 \mathrm{E} 5$ & $3.184^{*}$ & 1000 \\
\hline
\end{tabular}




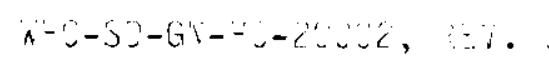

APPENDIX E (Continued)

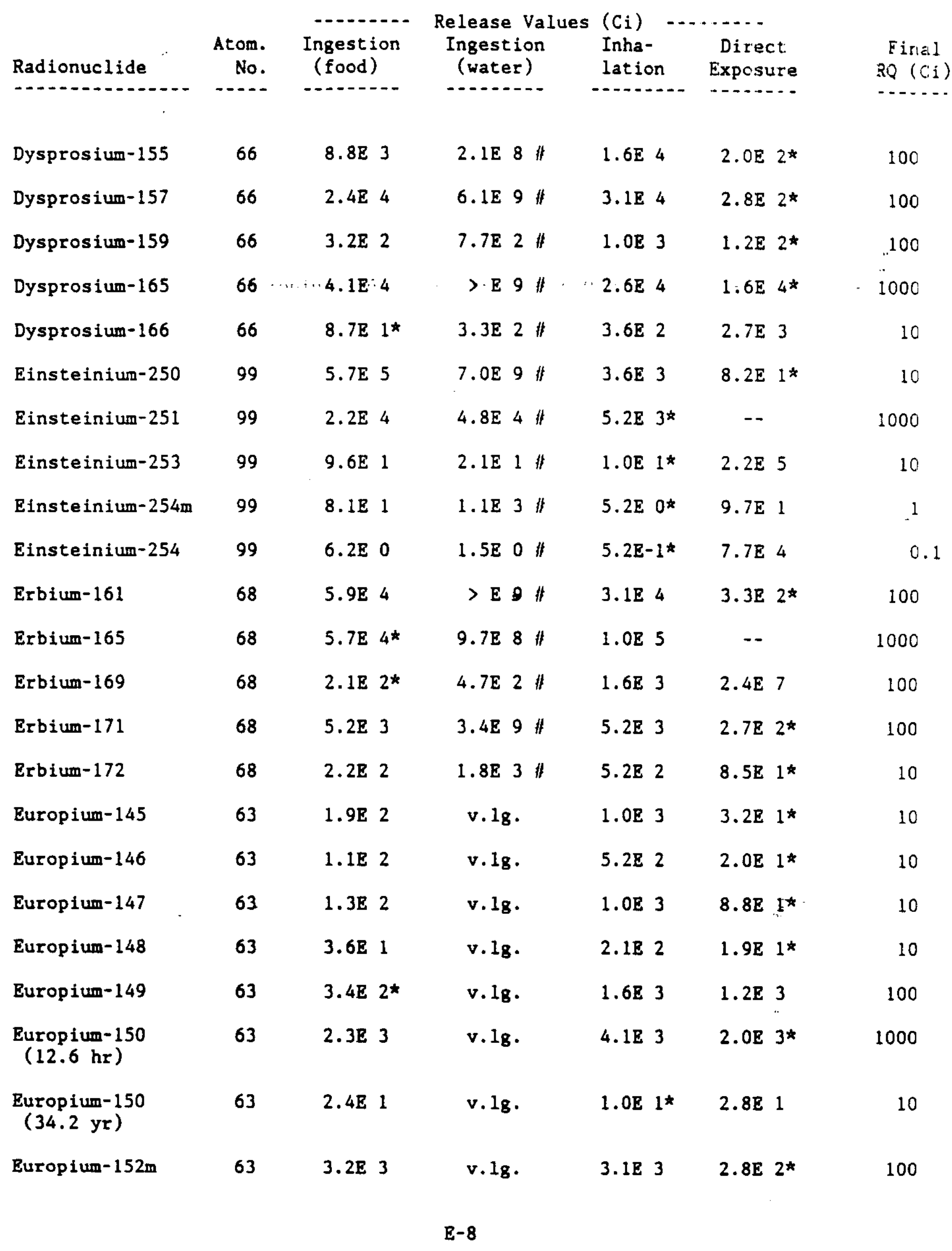




\begin{tabular}{|c|c|c|c|c|c|c|}
\hline Radionuclide & $\begin{array}{r}\text { Atom. } \\
\text { No. }\end{array}$ & $\begin{array}{c}\text { Ingestion } \\
\text { (food) }\end{array}$ & $\begin{array}{l}\text { Release Values } \\
\text { Ingestion } \\
\text { (water) }\end{array}$ & $\begin{array}{l}(\mathrm{C} i) \\
\text { Inha- } \\
\text { lation }\end{array}$ & $\begin{array}{l}\text { Direct } \\
\text { Exposure }\end{array}$ & \begin{tabular}{l} 
Firal \\
$R Q(C i)$ \\
\hdashline$\ldots \ldots$
\end{tabular} \\
\hline Europiun-152 & 63 & $2.4 \mathrm{E} 1$ & v. 18 . & $1.0 E 1 *$ & $3.5 \mathrm{E} 1$ & 10 \\
\hline Europium- 154 & 63 & $1.5 \mathrm{E} 1$ & v. lg. & $1.0 \mathrm{E} 1^{*}$ & $4.2 \mathrm{E} 1$ & 10 \\
\hline Europium-155 & 63 & $1.2 \mathrm{E} 2$ & v. 18 . & $4.7 \mathrm{E} 1 *$ & $7.0 \mathrm{E} 2$ & 10 \\
\hline Europium-156 & 63. & $3.3 E 1$ & v. 18 . & $2.6 \mathrm{E} 2$ & $2.3 \mathrm{E} 1^{*}$ & 10 \\
\hline Europium- 157 & 63 & $1.3 \mathrm{E} 3$ & v.18. & $2.6 \mathrm{E} 3$ & $4.9 E 1^{*}$ & 10 \\
\hline Europium-158 & 63 & $2.2 \mathrm{E} 5$ & v.18. & $3.1 E 4$ & $1.0 \mathrm{E} \mathrm{3*}$ & 1000 \\
\hline Fermium-252 & 100 & $2.0 \mathrm{E} 3$ & $1.1 \mathrm{E} 4 \#$ & $5.2 \mathrm{E} 1 *$ & -- & 10 \\
\hline Fermium-253 & 100 & $1.6 \mathrm{E} 3$ & $7.0 \mathrm{E} 2 \#$ & $5.2 \mathrm{E} 1^{*}$ & $5.5 \mathrm{E} 3$ & 10 \\
\hline Fermium-254 & 100 & $8.9 E 4$ & $>\mathrm{E} 9 \|$ & $5.2 \mathrm{E} \mathrm{2*}$ & -- & 100 \\
\hline Fermium-255 & 100 & $2.5 E 3$ & $3.9 \mathrm{E} 4 \#$ & $1.0 \mathrm{E} 2 *$ & -- & 100 \\
\hline Fermium-257 & 100 & $1.7 \mathrm{E} 1$ & $3.9 \mathrm{E} O \#$ & $1.0 \mathrm{E} 0 *$ & $8.7 \mathrm{E} 2$ & 1. \\
\hline Fluorine-18 & 9 & $2.6 E 5$ & $>E 9 \#$ & $3.6 \mathrm{E} 4^{*}$ & -- & 1000 \\
\hline Francium-222 & 87 & $7.9 \mathrm{E} 4$ & v. 18 . & $2.6 \mathrm{E} \mathrm{2*}$ & -- & 100 \\
\hline Francium- 223 & 87 & $1.6 \mathrm{E} 4$ & v.lg. & $4.1 \mathrm{E} 2 \star$ & $5.5 \mathrm{E} 4$ & 100 \\
\hline Gadolinium-145 & 64 & $1.2 \mathrm{E} 6$ & v.18. & $1.0 E 5$ & $8.3 E 2^{\star}$ & 100 \\
\hline Gadolinium-146 & 64 & $3.7 \mathrm{E} 1 *$ & v.18. & $5.2 \mathrm{E} 1$ & $2.1 \mathrm{E} 2$ & 10 \\
\hline Gadolinium-147 & 64 & $5.6 \mathrm{E} 2$ & v. $1_{8}$. & $2.1 E 3$ & $4.3 E 1 *$ & 10 \\
\hline Gadolinium- 148 & 64 & $3.0 \mathrm{E}-1$ & v.18. & $4 \cdot 1 E-3 *$ & $--\therefore$ & 0.001 \\
\hline Gadolinium-149 & 64 & $2.1 \mathrm{E} 2$ & v. g. $_{\text {. }}$ & $1.0 \mathrm{E} 3$ & $1.1 \mathrm{E} \mathrm{2*}$ & 100 \\
\hline Gadolinium-151 & 64 & $2.0 \mathrm{E} \mathrm{2 \star}$ & $v .18$ & $2.1 \mathrm{E} 2$ & $1.4 \mathrm{E} 3$ & 100 \\
\hline Gadolinium-152 & 64 & $6.0 E-1$ & v.18. & $5.2 E-3^{\star}$ & -- & 0.001 \\
\hline Gadolinium-153 & 64 & $1.6 \mathrm{E} 2$ & v. 18 . & $5.2 \mathrm{E} 1 *$ & $7.0 \mathrm{E} 2$ & 10 \\
\hline Gadolinium-159 & 64 & $1.6 \mathrm{E} 3$ & v. Ig. & $3.1 E 3$ & $1.4 \mathrm{E} \mathrm{3*}$ & 1000 \\
\hline Gallium-65 & 31 & $1.9 \mathrm{E} 6$ & $>$ E $9 \#$ & $1.0 \mathrm{E} 5$ & $5.7 \mathrm{E} 3^{\star}$ & 1000 \\
\hline
\end{tabular}




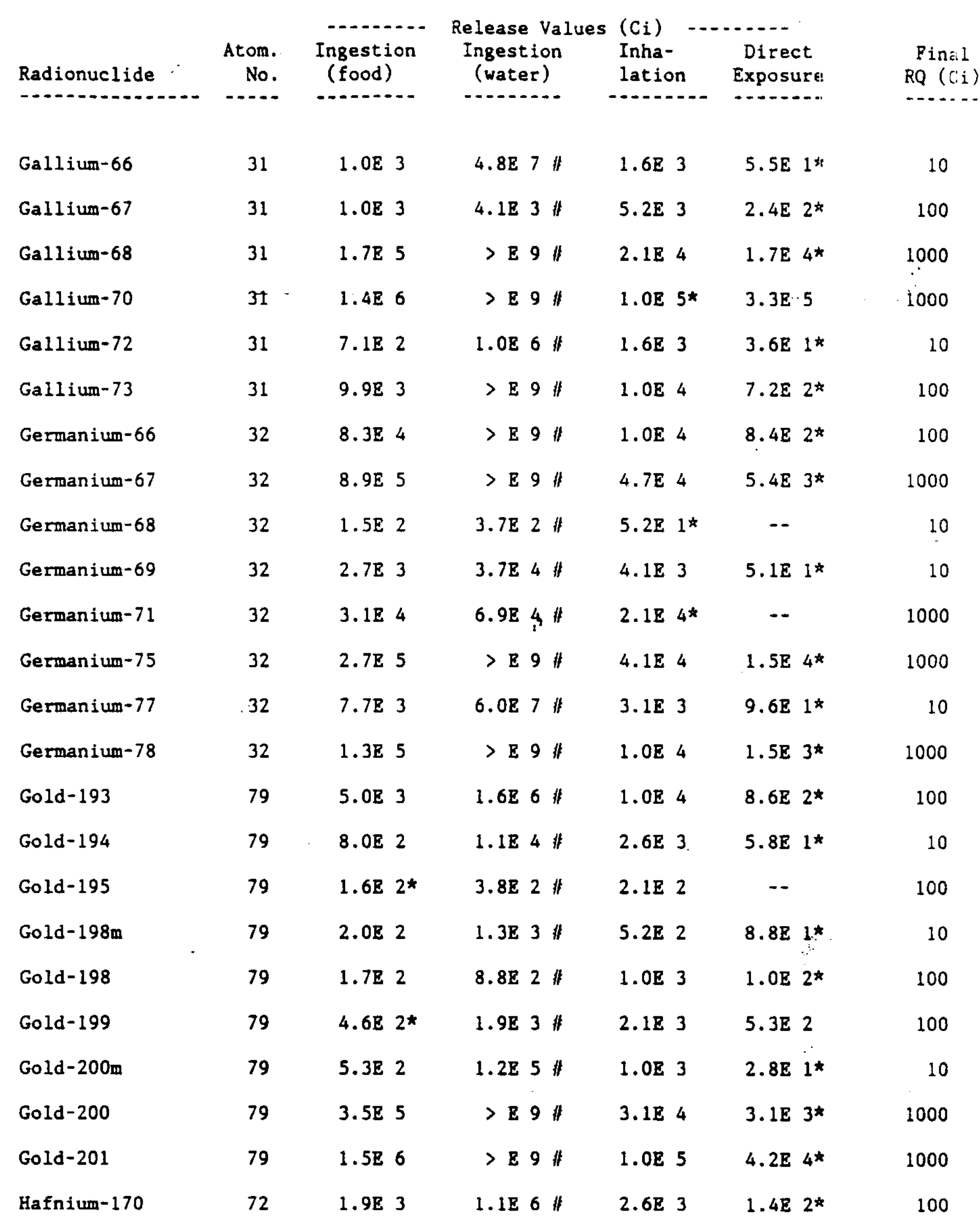




\begin{tabular}{|c|c|c|c|c|c|c|}
\hline Radionuclide" & $\begin{array}{l}\text { Atom. } \\
\text { No. }\end{array}$ & $\begin{array}{l}\text { Ingestion } \\
\text { (food) }\end{array}$ & $\begin{array}{l}\text { Release Values } \\
\text { Ingestion" } \\
\text { (water) }\end{array}$ & $\begin{array}{l}\text { ( } \mathrm{Ci} \text { ) } \\
\text { Inha- } \\
\text { lation }\end{array}$ & $\begin{array}{l}\text { Direct } \\
\text { Exposure }\end{array}$ & $\begin{array}{c}\text { Firnal } \\
\text { RQ (Ci) }\end{array}$ \\
\hline Hafnium-172 & 72 & $3.0 \mathrm{E} 1$ & $7.4 \mathrm{E} 1 \|$ & $4.7 \mathrm{E} \mathrm{O*}$ & $1.5 \mathrm{E} 3$ & 1 \\
\hline Hafnium-173 & 72 & $2.2 \mathrm{E} 3$ & $1.6 \mathrm{E} 5 \#$ & $5.2 \mathrm{E} 3$ & $1.6 \mathrm{E} \cdot 2^{\star}$ & 100 \\
\hline Hafnium- 175 & 72 & $1.0 \mathrm{E} \mathrm{2*}$ & $2.4 \mathrm{E} 2 \#$ & $4.7 \mathrm{E} 2$ & $1.2 \mathrm{E} 2$ & 100 \\
\hline Hafnium-177m & 72 & $6.2 E 8$ & $>\mathrm{B} 9 \#$ & $3.1 \mathrm{E} \mathrm{4*}$ & 2.186 & 1000 \\
\hline Hafnium-178m & 72 & $2.6 \mathrm{E} 6$ & $>\mathrm{E} 9 \#$ & $5.2 \mathrm{E}-1 \star$ & $5.7 \mathrm{E} 5$ & $\mathrm{C} .1$ \\
\hline Hafnium-179m & 72 & $1.8 \mathrm{E} 6$ & $>\mathrm{E} 9 \#$ & $1.6 \mathrm{E} \mathrm{2 \star}$ & $5.6 \mathrm{E} 5$ & 100 \\
\hline Hafnium-180m & 72 & $1.2 E 4$ & $>\mathrm{E} 9 \#$ & $1.0 \mathrm{E} 4$ & $1.2 \mathrm{E} 2^{\star}$ & 100 \\
\hline Hafnium-181 & 72 & $3.8 \mathrm{E} 1^{\star}$ & $8.7 \mathrm{E} 1 \#$ & $1.0 \mathrm{E} 2$ & $7.4 E^{2} 1$ & 10 \\
\hline Hafnium-182m & 72 & $3.7 \mathrm{E} 5$ & $>E 9 \#$ & $4.7 \mathrm{E} 4$ & $6.7 \mathrm{E} 2^{\star}$ & 100 \\
\hline Hafnium- 182 & 72 & $6.0 \mathrm{E} 0$ & $1.5 \mathrm{E} 1 \#$ & $4 \cdot 1 \mathrm{E}-1 *$ & $1.6 \mathrm{E} 2$ & 0.1 \\
\hline Hafnium-183 & 72 & $1.8 \mathrm{E} 5$ & $>\mathrm{E}_{19} 9 \|$ & $2.6 \mathrm{E} 4$ & $7.9 \mathrm{E} \mathrm{2*}$ & 100 \\
\hline Hafnium-184 & 72 & $4.7 \mathrm{E} 3$ & $>\mathrm{E} 9 \#$ & $3.1 \mathrm{E} 3$ & $6.7 \mathrm{E} \mathrm{2*}$ & 100 \\
\hline Holmium- 155 & 67 & $4.8 E 5$ & $v .18$. & $1.0 \mathrm{E} 5$ & $7.8 \mathrm{E} \mathrm{3*}$ & 1000 \\
\hline Holmium- 157 & 67 & $1.4 \mathrm{E} 7$ & v.lg. & $5.2 \mathrm{E} 5$ & $9.2 \mathrm{E} \mathrm{3*}$ & 1000 \\
\hline Holmium-159 & 67 & $3.5 \mathrm{E} 6$ & $v .18$. & $5.2 \mathrm{E} 5$ & $5.4 \mathrm{E} 3 *$ & 1000 \\
\hline Holmium-161 : & 67 & $3.8 \mathrm{E} 5$ & v. 18 . & $2.1 E 5$ & $4.5 \mathrm{E} 4^{*}$ & 1000 \\
\hline Holmium-162m & 67 & $4.2 B 5$ & v. Ig. & $1.6 \mathrm{E} 5$ & $1.1 \mathrm{E} 3^{\star}$ & 1000 \\
\hline Holmium-162 & 67 & $1.9 E 7$ & v.18. & $1.0 \mathrm{E} 6$ & $3.7 \mathrm{E} 4^{\mathrm{k}}$ & 1000 \\
\hline Holmium-164m & 67 & $1.5 \mathrm{~B} 6$ & $v .18$. & $1.6 \mathrm{E} 5^{\star}$ & $6.9 \mathrm{E} 6$ & 1000 \\
\hline Holmium-164 & 67 & $3.9 E 6$ & v. $1_{8}$. & $3.1 \mathrm{E} 5 *$ & $3.5 \mathrm{E} 5$ & 1000 \\
\hline Holmium-166m & 67 & $1.8 \mathrm{E} 1$ & v.1g. & $3.6 \mathrm{E} 0 *$ & $2.2 \mathrm{E} 1$ & 1 \\
\hline Holmium-166 & 67 & $3.4 \mathrm{E} \mathrm{2*}$ & $v .18$ & $1.0 \mathrm{E} 3$ & $2.2 \mathrm{E} 3$ & 100 \\
\hline Holmium-167 & 67 & $6.2 \mathrm{E} 4$ & v.18. & $3.1 \mathrm{E} 4$ & $6.1 E 2^{\star}$ & 100 \\
\hline Hydrogen-3 & 1 & -- & $5.9 \mathrm{E} 3$ & $8.3 \mathrm{E} 2 \star$ & -- & 100 \\
\hline
\end{tabular}




\begin{tabular}{|c|c|c|c|c|c|c|}
\hline Radionuclide & $\begin{array}{l}\text { Atom. } \\
\text { No. }\end{array}$ & $\begin{array}{l}\text { Ingestion } \\
\text { (food) }\end{array}$ & $\begin{array}{l}\text { Release Values } \\
\text { Ingestion } \\
\text { (water) }\end{array}$ & $\begin{array}{l}\text { (Ci) } \\
\text { Inha- } \\
\text { lation }\end{array}$ & $\begin{array}{l}\text { Direst. } \\
\text { Exposure }\end{array}$ & \begin{tabular}{l} 
Firlai \\
RQ $(C i)$ \\
\hdashline$\ldots$
\end{tabular} \\
\hline Indium-109 & 49 & $4.6 \mathrm{E} 4$ & $>$ E $9 \#$ & $2.1 \mathrm{E} 4$ & $4.5 \mathrm{E} 2 \star$ & 100 \\
\hline $\begin{array}{l}\text { Indium-110 } \\
(69.1 \mathrm{~min})\end{array}$ & 49 & $1.7 \mathrm{E} 5$ & $>$ E $9 \#$ & $2.1 \mathrm{E} 4$ & $6.8 \mathrm{E} \mathrm{2*}$ & 100 \\
\hline $\begin{array}{l}\text { Indium-110 } \\
(4.9 \mathrm{hr})\end{array}$ & 49 & $9.8 \mathrm{E} 3$ & $>\mathrm{E} 9 \|$ & $\begin{array}{l}1.084 \\
\therefore\end{array}$ & $\begin{array}{l}4.5 \mathrm{E} \mathrm{1*} \\
\therefore\end{array}$ & $\therefore 10$ \\
\hline Indium-111 & 49 & $6.8 \mathrm{E} 2$ & $3.2 \mathrm{E} 3 \|$ & $3.1 \mathrm{E} 3$ & $1.1 \mathrm{E} 2 \star$ & 100 \\
\hline Indium- 112 & 49 & $\therefore 9 \mathrm{E} 6$ & $>$ E $9 \#$ & $3.1 \mathrm{E} 5$ & $6.0 \mathrm{~B} 4 *$ & 1000 \\
\hline Indium-113m & 49 & $2.9 \mathrm{E} 5$ & $>\mathrm{E} 9 \|$ & $5.2 \mathrm{E} 4$ & $1.5 \mathrm{E} \mathrm{3*}$ & 1000 \\
\hline Indium-114m & 49 & $1.1 \mathrm{E} 1 *$ & $2.5 \mathrm{E} \perp \#$ & 3.181 & $4.8 \mathrm{E} 2$ & 10 \\
\hline Indium-115m & 49 & 2.184 & $>\mathrm{E} 9 \#$ & 2.184 & $8.9 \mathrm{E} \mathrm{2*}$ & 100 \\
\hline Indium-115 & 49 & $1.2 \mathrm{E} 0$ & $>\mathrm{E} 9 \|$ & $5.2 \mathrm{E}-1^{\star}$ & -- & 0.1 \\
\hline Indium-116m & 49 & 2.185 & $>E q \|$ & $4.1 \mathrm{E} 4$ & $3.3 \mathrm{E} \mathrm{2*}$ & 100 \\
\hline Indium-117m & 49 & $4.9 \mathrm{E} 4$ & $>$ E $9 \#$ & $1.6 \mathrm{E} 4$ & $5.2 \mathrm{E} \mathrm{2*}$ & 100 \\
\hline Indium-117 & 49 & $8.0 \mathrm{R} 5$ & $>\mathrm{E} 9 \#$ & $1.0 \mathrm{E} 5$ & $1.2 \mathrm{E} \mathrm{3*}$ & 1000 \\
\hline Indium-119m & 49 & $1.3 \mathrm{E} 6$ & $>$ E $9 \#$ & $5.2 \mathrm{E} 4^{\star}$ & $9.1 \mathrm{E} 4$ & 1000 \\
\hline Iodine-120m & 53 & $2.1 \mathrm{E} 3$ & $v .1 g$. & $2.1 \mathrm{E} \mathrm{2 \star}$ & $2.4 \mathrm{~B} 2$ & 100 \\
\hline Iodine-120 & 53 & $5.6 \mathrm{~B} 2$ & v.lg. & $9.3 \mathrm{~B} 1 \star$ & $4.9 \mathrm{E} 2$ & 10 \\
\hline Iodine-121 & 53 & $1.1 E^{3} 3$ & v. lg $_{8}$. & $2.1 \mathrm{E} \mathrm{2*}$ & $1.5 \mathrm{E} 3$ & 100 \\
\hline Iodine-123 & 53 & $4.5 \mathrm{E} 1 *$ & $v \cdot l_{8}$. & $6.2 \mathrm{E} 1$ & $4.5 \mathrm{E} 2$ & 10 \\
\hline Iodine-124 & 53 & $1.2 \mathrm{E}-1^{*}$ & v.18. & $8 \cdot 3 E-1$ & $5.3 \mathrm{E} 1$ & 0.1 \\
\hline Iodine- 125 & 53 & $2.8 \mathrm{E}-2 \star$ & v. $\mathbf{l g}_{\mathbf{B}}$. & $6.2 \mathrm{E}-1$ & -- & 0.01 \\
\hline Iodine-126 & 53 & $2.3 \mathrm{E}-2 \star$ & $v .18$. & $4.1 \mathrm{E}-1$ & $1.0 \mathrm{E} 2$ & 0.01 \\
\hline Iodine-128 & 53 & $1.8 \mathrm{E} 4$ & v.lg. & $1.0 \mathrm{E} 3 *$ & $1.7 \mathrm{E} 4$ & 1000 \\
\hline Iodine-129 & 53 & $3.0 \mathrm{E}-3 \star$ & v.18. & $9.3 \mathrm{E}-2$ & -- & 0.001 \\
\hline Iodine -130 & 53 & $6.3 \mathrm{E} 0 *$ & v. 18 . & $7.2 \mathrm{E} 0$ & $3.2 \mathrm{E} 1$ & 1 \\
\hline
\end{tabular}




\begin{tabular}{|c|c|c|c|c|c|c|}
\hline Radionuclide & $\begin{array}{r}\text { Atom. } \\
\text { No. }\end{array}$ & $\begin{array}{l}\text { Ingestion } \\
\text { (food) }\end{array}$ & $\begin{array}{l}\text { Release Values } \\
\text { Ingestion } \\
\text { (water) }\end{array}$ & $\begin{array}{l}\left(C_{i}\right) \\
\text { Inha- } \\
\text { lation }\end{array}$ & $\begin{array}{l}\text { Direct } \\
\text { Exposure }\end{array}$ & $\begin{array}{l}\text { Final } \\
\text { RQ (Ci) }\end{array}$ \\
\hline Iodine -131 & 53 & $4.6 \mathrm{E}-2^{\star}$ & v.18. & $5.2 E-1$ & $1.0 \mathrm{E} 2$ & 0.01 \\
\hline Iodine-132m & 53 & $5.5 \mathrm{E} 2$ & v. 18 . & $8.3 \mathrm{E} \mathrm{1*}$ & $2.1 \times 2$ & 10 \\
\hline Iodine-132 & 53 & $3.2 \mathrm{E} 2$ & v. 18 . & $8.3 \mathrm{E} 1^{\star}$ & $1.5 E^{3} 3$ &. .10 \\
\hline Iodine-133 & $: 53 \ldots$ & . - $9.7 \mathrm{E}-1^{\star}$ & v. 18 . & $3.1 \mathrm{E} 0$ & $5.6 \mathrm{E} 1$ & 0.1 \\
\hline Iodine-134 & 53 & $4.3 E 3$ & v.lg. & $5.2 \mathrm{E} 2$ & $2.9 \mathrm{E} 2^{\star}$ & 100 \\
\hline Iodine-135 & 53 & $2.3 \mathrm{E} 1$ & v.18. & $2.1 \mathrm{E}^{\prime} 1^{\star}$ & $6.6 \mathrm{E} \quad 1$ & 10 \\
\hline Iridium-182 & 77 & $1.5 \mathrm{E} 7$ & $>\mathrm{E} 9 \|$ & $5.2 \mathrm{E} 5$ & $4.8 \mathrm{E} \mathrm{3*}$ & 1000 \\
\hline Iridium-184 & 77 & $2.6 \mathrm{E} 5$ & $>E 9 \#$ & $1.0 \mathrm{E} 5$ & $1.6 \mathrm{E} \mathrm{2*}$ & 100 \\
\hline Iridium-185 & 77 & $3.5 \mathrm{E} 4$ & $4.986 \#$ & $5.2 \mathrm{E} 4$ & $1.3 E 2^{*}$ & 100 \\
\hline Iridium-186 & 77 & $1.3 \mathrm{E} 4$ & $8.185 \#$ & $3.1 \mathrm{E} 4$ & $5.4 \mathrm{E} 1^{*}$ & 10 \\
\hline Iridium- 187 & 77 & $9.3 \mathrm{E} 4$ & $1.4 \mathrm{E} 8 \#$ & $1.6 \mathrm{E} 5$ & $3.7 \mathrm{E} \mathrm{2*}$ & 100 \\
\hline Iridium-188 & 77 & $5.1 \mathrm{E} 3$ & $6.1 \mathrm{E} 3 \#$ & $1.6 \mathrm{E} 4$ & $2.7 \mathrm{E} 1^{\star}$ & 10 \\
\hline Iridium-189 & 77 & $2.9 \mathrm{E} 3$ & $6.3 \mathrm{E} 2^{\star} \#$ & $2.1 \mathrm{E} 4$ & $1.8 \mathrm{E} 3$ & 100 \\
\hline Iridium-190m & 77 & $1.6 \mathrm{E} 7$ & $>B 9 \#$ & $1.0 \mathrm{E} 6 *$ & -- & 1000 \\
\hline Iridium-190 & 77. & $6.2 \mathrm{E} 2$ & $1.3 \mathrm{E} 2 \#$ & $4.7 \mathrm{E} 3$ & $3.4 \mathrm{E} 1^{\star}$ & 10 \\
\hline Iridium-192m & 77 & $1.2 \mathrm{E} 7$ & $>$ E $9 \|$ & $1.0 \mathrm{~B} 2 \star$ & $6.7 \mathrm{E} 8$ & 100 \\
\hline Iridium-192 & 77 & $3.1 \mathrm{E} 2$ & $7.3 \mathrm{E} 1 \#$ & $1.0 \mathrm{E} 3$ & $4.8 \mathrm{E} 1^{*}$ & 10 \\
\hline Iridium-194m & 77 & 1.982 & $4.6 \mathrm{E} 1 \#$ & $4.7 \mathrm{E} 2$ & $1.6 \mathrm{E} 1^{*}$ & 10 \\
\hline Iridium-194 & 77 & $5.2 \mathrm{E} \quad 3$ & $1.0 \mathrm{E} 5 \#$ & $1.0 \mathrm{E} 4$ & $7.1 \mathrm{E} \mathrm{2 \star}$ & 100 \\
\hline Iridium-195m & 77 & $2.0 \mathrm{E} 5$ & $>E 9 \#$ & $1.0 \mathrm{E} 5$ & $5.6 \mathrm{E} \mathrm{2*}$ & 100 \\
\hline Iridium-195 & 77 & $3.4 \mathrm{E} 5$ & $>$ E $9 \#$ & $2.1 E 5$ & $1.5 \mathrm{E} 4^{*}$ & 1000 \\
\hline Iron-52 & 26 & $1.1 \mathrm{E} 3$ & v. 18 . & $1.0 \mathrm{~B} 3$ & $5.1 \mathrm{E} \mathrm{2*}$ & 100 \\
\hline Iron-55 & 26 & $2.7 \mathrm{E} 2 \star$ & v. 18 . & $1.0 \mathrm{~B} 3$ & -- & 100 \\
\hline Iron-59 & 26 & $3.0 \mathrm{E} 1 *$ & v.18. & $1.6 \mathrm{E} 2$ & $3.1 \mathrm{E} 1$ & 10 \\
\hline
\end{tabular}




\begin{tabular}{|c|c|c|c|c|c|c|}
\hline Radionuclide : & $\begin{array}{l}\text { Atom. } \\
\text { No. }\end{array}$ & $\begin{array}{l}\text { Ingestion } \\
\text { (food) }\end{array}$ & $\begin{array}{l}\text { Release Values } \\
\text { Ingestion } \\
\text { (water) }\end{array}$ & $\begin{array}{l}(\mathrm{C} i) \\
\text { Inha- } \\
\text { lation }\end{array}$ & $\begin{array}{c}\text { Direct. } \\
\text { Exposure }\end{array}$ & $\begin{array}{r}\text { Final } \\
\text { RQ (Ci })\end{array}$ \\
\hline 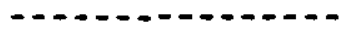 & $\cdots-$ & $\cdots-----\infty$ & $\cdots$ & $\cdots$ & $\cdots+\cdots$ & $\cdots+\cdots$ \\
\hline Iron -60 & 26 & $8.9 E-1 *$ & v. 18 . & $3.1 \mathrm{E} 0$ & $6.2 \mathrm{E} 2$ & 0.1 \\
\hline Krypton -74 & 36 & na & na & na & $3.0 \mathrm{E} 1^{*}+$ & 10 \\
\hline Krypton-76 & 36 & na & na & na & $9.0 \mathrm{E} 1 *+$ & 10 \\
\hline Krypton -77 & $36 \cdots-$ & na & na & na & $4.0 \mathrm{E} 1^{*+}$ & 10 \\
\hline Krypton-79 & 36 & na & na & na & $2.0 \mathrm{E} 22^{*}$ & 100 \\
\hline Krypton-81 & 36 & na & na & na & $7.0 \mathrm{E} \mathrm{3*+}$ & 1000 \\
\hline Krypton-83m & 36 & na & na & na & $1.0 \mathrm{E} 5^{*}+$ & 1000 \\
\hline Krypton $-85 m$ & 36 & na & na & na & $2.0 \mathrm{E} \mathrm{2*+}$ & 100 \\
\hline Krypton -85 & 36 & na & na & na & $1.0 \mathrm{E} 3^{*}+$ & 1000 \\
\hline Krypton-87 & 36 & na & na & na & $5.0 \mathrm{E} 1^{*+}$ & 10 \\
\hline Krypton-88 & 36 & na & na: & na & $2.0 \mathrm{E} 1^{*}+$ & 10 \\
\hline Lanthanum-131 & 57 & $4.8 \mathrm{E} 5$ & $>$ E $9 \|$ & $5.2 \mathrm{E} 4$ & $2.5 E 3^{*}$ & 1000 \\
\hline Lanthanum-132 & 57 & $6.0 \mathrm{E} 3$ & $>E 9 \#$ & $5.2 \mathrm{E} 3$ & $1.0 \mathrm{E} \mathrm{2*}$ & 100 \\
\hline Lanthanum-135 & 57 & $2.1 E 4$ & $3.8 \mathrm{E} 6 \#$ & $4.7 \mathrm{E} 4$ & $5.8 \mathrm{E} \mathrm{3*}$ & 1000 \\
\hline Lanthanum- 137 & 57 & $3.0 \mathrm{~B} 2$ & $7.3 \mathrm{E} 2 \#$ & $3.1 \mathrm{E} 1^{\star}$ & $\cdots$ & 10 \\
\hline Lanthanum-138 & 57 & $2.7 \mathrm{E} \quad 1$ & $6.6 \mathrm{E} 1 \#$ & $2.1 \mathrm{E} \mathrm{O*}$ & $>\mathrm{E} 9$ & 1 \\
\hline Lanthanum-140 & 57 & $1.6 \mathrm{E} 2$ & $2.0 \mathrm{E} 3 \#$ & $5.2 \mathrm{E} 2$ & $2.0 \mathrm{E} 1 *$ & 10 \\
\hline Lanthanum-141 & 57 & $9.8 \mathrm{E} 3$ & $>\mathrm{E} 9 \#$ & $4.7 \mathrm{E} \mathrm{3 \star}$ & $6.6 \mathrm{E} 3$ & 1000 \\
\hline Lanthanum-142 & 57 & $5.0 \mathrm{E} 4$ & $>B 9 \#$ & $1.0 \mathrm{~B} 4$ & $2.3 E 2^{\star}$ & 100 \\
\hline Lanthanum-143 & 57 & $1.6 \mathrm{E} 6$ & $>\mathrm{E} 9 \#$ & $4.7 \mathrm{E} 4^{\star}$ & $4.7 \mathrm{E} 4$ & 1000 \\
\hline Lead-195m & 82 & $2.3 \mathrm{E} 6$ & v.18. & $1.0 \mathrm{E} 5$ & $2.2 \mathrm{E} \mathrm{3 \star}$ & 1000 \\
\hline Lead-198 & 82 & $1.2 \mathrm{E} 5$ & v.1g. & $3.1 \mathrm{E} 4$ & $7.3 \mathrm{~B} 2^{\star}$ & 100 \\
\hline Lead-199 & 82 & $1.3 \mathrm{E} 5$ & v. 18 . & $3.6 \mathrm{~B} 4$ & $5.3 \mathrm{E} \mathrm{2*}$ & 100 \\
\hline Lead-200 & 82 & $1.4 \mathrm{E} 3$ & v.18. & $3.1 \mathrm{E} 3$ & $4.7 \mathrm{E} \mathrm{2*}$ & 100 \\
\hline
\end{tabular}




\begin{tabular}{|c|c|c|c|c|c|c|}
\hline $\begin{array}{l}\text { Radionuclide } \\
\end{array}$ & $\begin{array}{c}\text { Atom. } \\
\text { No. } \\
-\end{array}$ & $\begin{array}{c}\text { Ingest : } \\
\text { (food) } \\
\ldots \ldots\end{array}$ & $\begin{array}{c}\text { Release Va..ues } \\
\text { Ingestion } \\
\text { (water) } \\
\end{array}$ & $\begin{array}{l}\left(C_{i}\right) \\
\text { lnha- } \\
\text { lation } \\
\ldots\end{array}$ & $\begin{array}{c}\text { Direct: } \\
\text { Exposure }\end{array}$ & $\begin{array}{l}\text { Final } \\
\text { RQ }\left(C_{i}\right) \\
-\end{array}$ \\
\hline Lead-201 & 82 & $7.3 \mathrm{E} 3$ & 0.18. & 1.084 & $1.4 \mathrm{E} 2 \star$ & 100 \\
\hline Lead-202m & 82 & $2.4 E 4$ & v.lg. & $1.6 \mathrm{E} 4$ & $8.7 \mathrm{E} 1 *$ & 10 \\
\hline Lead-202 & 82 & $3.0 \mathrm{~B} \quad 0^{*}$ & v.18. & $2.6 \mathrm{E} 1$ & - & 1 \\
\hline Lead-203 & 82 & 1.183 & v.18. & .4 .783 & $1.8 \mathrm{E} 2 *$ & 100 \\
\hline Lead -205 & 82 & $1.2 \mathrm{E} \mathrm{2*}$ & v.1g. & $5.2 \mathrm{E} 2$ & - & 100 \\
\hline Lead-209 & 82 & $5.9 \mathrm{E} 4$ & $v .18$. & $3.1 \mathrm{E} 4^{*}$ & - & 1000 \\
\hline Lead -210 & 82 & $1.8 \mathrm{E}-2^{\star}$ & v.18. & $1.0 \mathrm{E}-1$ & -- & 0.01 \\
\hline Lead-211 & 82 & $1.6 \mathrm{E} 5$ & v.18. & $3.1 \mathrm{E} \mathrm{2*}$ & $1.9 \mathrm{E} 4$ & 100 \\
\hline Lead-212 & 82 & $7.4 \mathrm{E} 1$ & v.1g. & $1.6 \mathrm{E} 1^{*}$ & $6.3 \mathrm{E} 2$ & 10 \\
\hline Lead -214 & 82 & $1.9 \mathrm{E} 5$ & v.18. & $4.1 \mathrm{E} \mathrm{2*}$ & $6.3 \mathrm{E} 3$ & 100 \\
\hline Lutetium-169 & 71 & 9.282 & $1.8 \mathrm{E} 4 \#$ & $2.1 \mathrm{E} 3$ & $7.7 \mathrm{E} 1^{*}$ & 10 \\
\hline Lutetium-170 & 71 & $2.3 \mathrm{E} 2$ & $1.9 \mathrm{E} 3 \#$ & $1.0 \mathrm{E} 3$ & $2.5 \mathrm{E} 1 *$ & 10 \\
\hline Lutetium-171 & 71 & $1.5 \mathrm{E} 2$ & $3.5 \mathrm{E} 2 \#$ & $1.0 \mathrm{E} 3$ & $7.0 \mathrm{E} \mathrm{1*}$ & 10 \\
\hline Lutetium-172 & 71 & $8.7 \mathrm{E} 1$ & $2.1 \mathrm{E} 2 \#$ & $5.2 \mathrm{E} 2$ & $2.4 \mathrm{E} 1 *$ & 10 \\
\hline Lutetium- 173 & 71 & $1.5 \mathrm{E} \mathrm{2 \star}$ & $3.7 \mathrm{E} 2 \#$ & $1.6 \mathrm{E} 2$ & $6.8 \mathrm{E} 2$ & 100 \\
\hline Lutetium-174m & 71 & $6.5 \mathrm{E} 1^{*}$ & $1.5 \mathrm{E} 2 \#$ & $1.0 \mathrm{E} 2$ & 4.383 & 10 \\
\hline Lutetium-174 & 71 & $1.5 \mathrm{E} 2$ & $3.7 \mathrm{E} 2 \#$ & $5.2 \mathrm{E} 1^{\star}$ & $4.3 \mathrm{E} 2$ & 10 \\
\hline Lutetium-176m & 71 & 2.184 & $>\mathrm{E} 9 \|$ & $1.0 \mathrm{E} 4^{*}$ & 2.184 & 1000 \\
\hline Lutetium-176 & 71 & 2.181 & $5.1 \mathrm{E} 1 \#$ & $2.6 \mathrm{E} 0 *$ & $>\mathrm{E} g$ & 1 \\
\hline Lutetium-177m & 71 & $2.2 \mathrm{E} 1^{*}$ & $5.4 \mathrm{E} 1 \#$ & $4.1 \mathrm{E} 1$ & $4.1 \mathrm{E} 1$ & 10 \\
\hline Lutetium-177 & 71 & $1.7 \mathrm{E} \mathrm{2 \star}$ & $4.2 \mathrm{E} 2 \#$ & $1.0 \mathrm{E} 3$ & $1.3 \mathrm{E} 3$ & 100 \\
\hline Lutetium-178m & 71 & $1.2 \mathrm{E} 6$ & $>\mathrm{E} 9 \#$ & $1.0 \mathrm{E} 5$ & $3.6 \mathrm{E} 4^{*}$ & 1000 \\
\hline Lutetium-178 & 71 & $8.0 \mathrm{E} 5$ & $>\mathrm{E} 9 \#$ & $5.2 \mathrm{E} 4$ & $1.3 \mathrm{E} 4^{*}$ & 1000 \\
\hline Lutetium-179 & 71 & $1.3 \mathrm{E} 4$ & $>\mathrm{B} 9 \|$ & $1.0 \mathrm{E} 4$ & $5.1 \mathrm{E} 3 *$ & 1000 \\
\hline
\end{tabular}




\begin{tabular}{|c|c|c|c|c|c|c|}
\hline Radionuclide & $\begin{array}{r}\text { Atom. } \\
\text { No. }\end{array}$ & $\begin{array}{l}\text { Ingestion } \\
\text { (food) }\end{array}$ & $\begin{array}{l}\text { Release Values } \\
\text { Ingestion } \\
\text { (water) }\end{array}$ & $\begin{array}{l}(\mathrm{C} i) \\
\text { Inha- } \\
\text { lation }\end{array}$ & $\begin{array}{c}\text { Direct } \\
\text { Exposure }\end{array}$ & $\begin{array}{l}\text { Final } \\
R Q(C i)\end{array}$ \\
\hline Magnesium-28 & 12 & $3.3 E 2$ & $4.2 \mathrm{E} 4 \#$ & $5.2 \mathrm{E} 2$ & $3.7 \mathrm{E} l^{*}$ & 10 \\
\hline Manganese -51 & 25 & $2.5 E 5$ & $>E 9 \#$ & $2.6 \mathrm{E} 4 *$ & $1.5 \mathrm{E} 5$ & 1000 \\
\hline Manganese $-52 m$ & 25 & $8.0 \mathrm{E} 5$ & $>E 9 \#$ & $4.7 \mathrm{E} 4$ & $1.2 \mathrm{E} 3 *$ & 1000 \\
\hline Manganese -52 & 25 & $6.9 \mathrm{E} 1$ & $1.8 E 2 \#$ & $4.7 \mathrm{E} 2$ & $1.7 \mathrm{E} 1 *$ & 10 \\
\hline Manganese -53 & 25 & $1.5 \mathrm{E} \mathrm{3*}$ & $3.7 \mathrm{E} 3 \#$ & $5.2 \mathrm{E} 3$ & -- & 1000 \\
\hline Manganese -54 & 25 & $6.1 \mathrm{E} 1$ & $1.5 E 2 \#$ & $4.1 \mathrm{E} 2$ & $4.4 \mathrm{E} 1^{\star}$ & 10 \\
\hline Manganese -56 & 25 & $1.8 \mathrm{E} 4$ & $>E 9 \|$ & $1.0 \mathrm{E} 4$ & $1.4 \mathrm{E} 2 *$ & 100 \\
\hline Mendelevium-257 & 101 & $1.7 \mathrm{E} 5$ & $>\mathrm{E} 9 \#$ & $5.2 \mathrm{E} 2 \star$ & -- & 100 \\
\hline Mendelevium-258 & 101 . & $2.5 \mathrm{E} 1$ & $5.8 \mathrm{E} O \|$ & $1.6 \mathrm{E} 0^{*}$ & -- & 1 \\
\hline Mercury-193m & 80 & $2.4 \mathrm{E} 3$ & $1.3 \mathrm{E} 7 \|$ & $4.1 \mathrm{E} 3$ & $5.4 \mathrm{E} 1^{\star}$ & 10 \\
\hline Mercury-193 & 80 & $4.9 \mathrm{E} 4$ & $>E$ I & $1.6 \mathrm{E} 4$ & $2.3 \mathrm{E} \mathrm{2 \star}$ & 100 \\
\hline Mercury- 194 & 80 & $5.8 E-1 \star$ & $1.5 \mathrm{E} 0 \#$ & $1.6 \mathrm{E} 1$ & -- & 0.1 \\
\hline Mercury-195m & 80 & $5.2 \mathrm{E} 2$ & $6.8 \mathrm{E} 3 \#$ & $2.1 \mathrm{E} 3$ & $2.5 \mathrm{E} \mathrm{2*}$ & 100 \\
\hline Mercury-195 & 80 & $9.9 \mathrm{E} 3$ & $4.2 \mathrm{E} 8 \#$ & $1.6 \mathrm{E} 4$ & $6.4 \mathrm{E} \mathrm{2*}$ & 100 \\
\hline Mercury-197m & 80 & 1.283 & $9.2 \mathrm{E} 4 \#$ & $2.6 \mathrm{E} 3$ & $1.1 \mathrm{E} \mathrm{3*}$ & 1000 \\
\hline Mercury- 197 & 80 & $1.0 E^{3 x}$ & $5.4 \mathrm{E} 3 \#$ & $4.1 \mathrm{E} 3$ & $2.8 \mathrm{E} 3$ & 1000 \\
\hline Mercury-199m & 80 & $7.8 \mathrm{E} 5$ & $>89 \|$ & $4.1 E 4$ & $6.3 \mathrm{E} \mathrm{3*}$ & 1000 \\
\hline Mercury-203 & 80 & $1.8 \mathrm{E} 1^{*}$ & $4.381 \|$ & $4.1 E 2$ & $1.6 \mathrm{E} 2$ & 10 \\
\hline Molybdenum-90 & 42 & $3.4 E 3$ & v. 18 . & $2.6 \mathrm{E} 3$ & $1.5 \mathrm{E} \mathrm{2 \star}$ & 100 \\
\hline Molybdenum-93m & 42 & $5.6 \mathrm{~B} 3$ & v.18. & $5.2 \mathrm{E} 3$ & $4.2 \mathrm{E} 1^{*}$ & 10 \\
\hline Molybdenum-93 & 42 & $1.2 \mathrm{E} 2$ & v.18. & $1.0 \mathrm{E} \mathrm{2*}$ & -- & 100 \\
\hline Molybdenum-99 & 42 & $1.7 \mathrm{E} \mathrm{2 \star}$ & v. 18 . & $5.2 \mathrm{E} 2$ & $1.7 \mathrm{E} 2$ & 100 \\
\hline Molybdenum-101 & 42 & $1.6 \mathrm{E} 6$ & v.18. & $5.2 \mathrm{E} 4$ & $4.5 E \quad 3 *$ & 1000 \\
\hline Neodymium- 136 & 60 & 1.185 & $v .18$. & $2.6 \mathrm{E} 4$ & $5.1 \mathrm{E} 3 \star$ & 1000 \\
\hline
\end{tabular}




\begin{tabular}{|c|c|c|c|c|c|c|}
\hline Radionuclide & $\begin{array}{l}\text { Atom. } \\
\text { No. }\end{array}$ & $\begin{array}{l}\text { Ingestion } \\
\text { (food) }\end{array}$ & $\begin{array}{l}\text { Release Values } \\
\text { Ingestion } \\
\text { (water) }\end{array}$ & $\begin{array}{l}(\mathrm{Ci}) \\
\text { Inha- } \\
\text { lation }\end{array}$ & $\begin{array}{l}\text { Direct } \\
\text { Exposure }\end{array}$ & $\begin{array}{c}\text { Pinal } \\
\operatorname{RQ}(C i)\end{array}$ \\
\hline - - & $\cdots-$ & $\ldots$ & $\cdots+\cdots$ & - n. & $\cdots$ & $\ldots+\ldots$ \\
\hline Neodymium-138 & 60 & $5.2 \mathrm{~B} 4$ & v. 18 . & $2.6 \mathrm{E} \mathrm{3*}$ & $1.5 \mathrm{E} 5$ & 1000 \\
\hline Neodymium-139m & 60 & $9.5 \mathrm{E} 3$ & v.1g. & $5.2 \mathrm{E} 3$ & $1.1 \mathrm{E} 2^{\star}$ & 1010 \\
\hline Neodymium-139 & 60 & $1.7 \mathrm{E} 6$ & v. 18 . & $1.6 \mathrm{E} 5$ & $1.3 \mathrm{E} 4^{*}$ & 1000 \\
\hline Neodymium-141 & 60 & $7.7 \mathrm{E} 5$ & v.18. & $3.1 E 5$ & $1.2 \mathrm{E} 4^{\star}$ & 1000 \\
\hline Neodymium-147 & 60 & $6.4 \mathrm{E} 1^{\star}$ & v. 18 . & $4.1 \mathrm{E} 2$ & $3.1 \mathrm{E} 2$ & 10 \\
\hline Neodymium-149 & 60 & $5.5 \mathrm{E} 4$ & v. 18 . & $1.0 \mathrm{E} 4$ & $7.8 \mathrm{E} \mathrm{2*}$ & 100 \\
\hline Neodymium-151 & 60 & $3.2 \mathrm{E} 6$ & v.lg. & $1.0 \mathrm{E} 5$ & $4.7 \mathrm{E} \mathrm{3*}$ & 1000 \\
\hline Neptunium-232 & 93 & $1.2 \mathrm{E} 7$ & v. Ig. & $1.0 \mathrm{E} 4$ & $2.5 \mathrm{E} \mathrm{3 \star}$ & 1000 \\
\hline Neptunium-233 & 93 & $1.3 E 8$ & v. $1_{8}$. & $1.6 \mathrm{E} 7$ & $1.5 \mathrm{E} 5 *$ & 1000 \\
\hline Neptunium-234 & 93 & $2.4 \mathrm{E} 3$ & v.18. & $1.6 \mathrm{E} 4$ & $3.9 \mathrm{E} 1^{\star}$ & 10 \\
\hline Neptunium-235 & 93 & $3.1 \mathrm{E} \mathrm{3*}$ & v.1 1 ? & $5.2 \mathrm{E} 3$ & -- & 1000 \\
\hline $\begin{array}{r}\text { Neptunium-236 } \\
(1.2 \mathrm{E} 5 \mathrm{yr})\end{array}$ & 93 & $1.2 \mathrm{E}-1^{\star}$ & $v \cdot l_{g}$. & $1.6 \mathrm{E}-1$ & $6.9 \mathrm{E} 2$ & 0.1 \\
\hline $\begin{array}{l}\text { Neptunium-236 } \\
(22.5 \mathrm{hr})\end{array}$ & 93 & $2.2 \mathrm{E} 3$ & $v \cdot l_{8}$. & $2.1 \mathrm{E} \mathrm{2*}$ & $6.9 \mathrm{E} 3$ & 100 \\
\hline Neptunium-237 & 93 & $2.1 \mathrm{E}-2 \star$ & v.18. & $3.1 \mathrm{E}-2$ & $2.6 \mathrm{E} 3$ & 0.01 \\
\hline Neptunium-238 & 93 & $1.7 \mathrm{E} 3$ & v.18. & $4.7 \mathrm{E} 2$ & $6.9 \mathrm{E} 1^{\star}$ & 10 \\
\hline Neptunium-239 & 93 & $3.9 \mathrm{E} 3$ & v.18. & $1.0 \mathrm{E} 4$ & $3.9 \mathrm{E} \mathrm{2*}$ & 100 \\
\hline Neptunium-240 & 93 & $1.8 \mathrm{~B} 6$ & v.18. & $4.1 \mathrm{E} 5$ & $5.4 \mathrm{E} \mathrm{2*}$ & 100 \\
\hline Nickel-56 & 28 & $9.3 \mathrm{E} 1$ & v.18. & $5.2 \mathrm{E} 2$ & $2.3 \mathrm{E} 1^{\star}$ & 10 \\
\hline Nicke1-57 & 28 & $5.8 \mathrm{E} 2$ & v.18. & $1.6 \mathrm{E} 3$ & $3.0 \mathrm{~B} 1 *$ & 10 \\
\hline Nickel-59 & 28 & $5.9 \mathrm{E} \mathrm{2*}$ & $v .18$. & $2.1 \mathrm{E} 3$ & -- & 100 \\
\hline Nickel-63 & 28 & $2.7 \mathrm{E} \mathrm{2 \star}$ & v.18. & $1.0 \mathrm{E} 3$ & -- & 100 \\
\hline Nickel-65 & 28 & $3.0 \mathrm{~B} 4$ & v.18. & $1.0 \mathrm{E} 4$ & $4.5 E 2^{\star}$ & 100 \\
\hline Nickel-66 & 28 & $8.1 \mathrm{E} 1 *$ & v.1g. & $3.1 \mathrm{E} 2$ & -- & 10 \\
\hline
\end{tabular}




\begin{tabular}{|c|c|c|c|c|c|c|}
\hline Radionuclide & $\begin{array}{r}\text { Atom. } \\
\text { No. } \\
-\end{array}$ & $\begin{array}{l}\text { Ingestion } \\
\text { (food) }\end{array}$ & $\begin{array}{l}\text { Release Values } \\
\text { Ingestion } \\
\text { (water) }\end{array}$ & $\begin{array}{l}\text { (Ci) } \\
\text { Inha- } \\
\text { lation }\end{array}$ & $\begin{array}{l}\text { Direct: } \\
\text { Exposure }\end{array}$ & $\begin{array}{r}\text { Final } \\
\mathrm{RQ}(\mathrm{Ci}\end{array}$ \\
\hline Niobium-88 & 41 & $2.0 \mathrm{E} 6$ & v. Ig. & $1.0 \mathrm{E} 5$ & $7.9 \mathrm{E} \mathrm{2*}$ & 100 \\
\hline $\begin{array}{l}\text { Niobium-89 } \\
\text { (66 min) }\end{array}$ & 41 & $8.7 \mathrm{E} 4$ & v. 18 . & $2.1 \mathrm{E} 4$ & $3.0 \mathrm{E} 2^{\star}$ & 100 \\
\hline $\begin{array}{r}\text { Niobium }-89 \\
(122 \mathrm{~min})\end{array}$ & 41 & $2.4 \mathrm{E} 4$ & v. 18 . & $1.0 \mathrm{~B} 4$ & $8.1 \mathrm{E} \mathrm{2*}$ & 100 \\
\hline Niobium-90 & 41 & $6.8 \mathrm{~B} 2$ & v. $l_{\mathbf{g}}$. & $1.0 \mathrm{E} 3$ & $1.5 \mathrm{E} 1^{\star}$ & 10 \\
\hline Niobium-93m & 41 & $2.7 \mathrm{E} 2$ & v. $l_{g}$. & $1.0 \mathrm{E} \mathrm{2*}$ & -- & 100 \\
\hline Niobium-94 & 41 & $2.7 \mathrm{E} \quad 1$ & v. $1 \mathrm{~g}$. & $1.0 \mathrm{~B} 1 *$ & $2.3 \mathrm{E} 1$ & 10 \\
\hline Niobium-95m & 41 & $2.8 \mathrm{E} \mathrm{2 \star}$ & v.1g. & $1.0 \mathrm{E} 3$ & $6.1 \mathrm{E} 2$ & 100 \\
\hline Niobium-95 & 41 & $8.0 \mathrm{E} 1$ & v. 18 . & $5.2 \mathrm{E} 2$ & $4.8 \mathrm{~B} 1^{\star}$ & 10 \\
\hline Niobium-96 & 41 & 4.382 & v. 18 . & $1.0 \mathrm{E} 3$ & $2.2 \mathrm{~B} 1 *$ & 10 \\
\hline Niobium-97 & 41 & $1.6 \mathrm{E} 5$ & v.182 & $3.6 \mathrm{E} 4$ & $7.4 \mathrm{E} \mathrm{2 \star}$ & 100 \\
\hline Niobium-98 & 41 & $1.2 \mathrm{E} 8$ & v. 18 . & $2.6 \mathrm{E} 4 *$ & $1.2 \mathrm{E} 7$ & 1000 \\
\hline Osmium-180 & 76 & $2.6 \mathrm{E} 6$ & $>\mathrm{E} 9 \|$ & $2.1 \mathrm{E} 5 *$ & -- & 1000 \\
\hline Osmium-181 & 76 & $5.5 \mathrm{E} 4$ & $>\mathrm{E} 9 \|$ & $2.1 E 4$ & $4.4 \mathrm{~B} \mathrm{2*}$ & 100 \\
\hline Osmium-182 & 76 & $9.4 \mathrm{E} 2$ & $1.1 \mathrm{E} 5 \#$ & $2.1 \mathrm{E} 3$ & $1.4 \mathrm{E} \mathrm{2 \star}$ & 100 \\
\hline Osmium-185 & 76 & $6.7 \mathrm{~B} 1$ & $1.6 \mathrm{E} 2 \#$ & $2.6 \mathrm{E} 2$ & $5.5 \mathrm{E} \mathrm{1 \star}$ & 10 \\
\hline Osmium-189m & 76 & $1.3 \mathrm{E} 5$ & $>$ E $9 \#$ & $1.0 \mathrm{E} \mathrm{5*}$ & - & 1000 \\
\hline Osmium-191m & 76 & $7.5 \mathrm{E} \mathrm{3*}$ & $1.7 \mathrm{E} 7 \|$ & $1.0 \mathrm{E} 4$ & $1.2 \mathrm{E} 6$ & 1000 \\
\hline Osmium-191 & 76 & $1.1 \mathrm{E} 2^{\star}$ & $2.3 \mathrm{E} 2 \#$ & $5.2 \mathrm{E} 2$ & $1.1 \mathrm{E} 3$ & 100 \\
\hline Osmium-193 & 76 & $6.7 \mathrm{E} 2^{\star}$ & $1.8 \mathrm{E} 4 \#$ & $1.6 \mathrm{E} 3$ & $1.1 \mathrm{E} 3$ & 100 \\
\hline Osmium-194 & 76 & $1.2 \mathrm{E} \mathrm{I}$ & $2.9 \mathrm{E} 1 \#$ & $4.1 \mathrm{E} \mathrm{O \star}$ & -- & 1 \\
\hline Palladium-100 & 46 & $1.4 \mathrm{E} 2 \star$ & v.18. & $5.2 \mathrm{~B} 2$ & $2.3 \mathrm{E} 2$ & 100 \\
\hline Palladium-101 & 46 & $1.2 \mathrm{E} 4$ & v. 18 . & $1.6 \mathrm{E} 4$ & $3.7 \mathrm{E} 2 \star$ & 100 \\
\hline Palladium-103 & 46 & $3.1 \mathrm{E} 2^{\star}$ & $v .18$. & $2.1 \mathrm{E} 3$ & $4.1 \mathrm{E} 5$ & 100 \\
\hline
\end{tabular}




\begin{tabular}{|c|c|c|c|c|c|c|}
\hline $\begin{array}{l}\text { Radionuclide } \\
\text { R }\end{array}$ & $\begin{array}{r}\text { Atom. } \\
\text { No. }\end{array}$ & $\begin{array}{l}\text { Ingestion } \\
\text { (food) }\end{array}$ & $\begin{array}{l}\text { Release Values } \\
\text { Ingestion } \\
\text { (water) }\end{array}$ & $\begin{array}{l}(\mathrm{Ci}) \\
\text { Inha- } \\
\text { lation } \\
\end{array}$ & $\begin{array}{c}\text { Dizect } \\
\text { Exposure }\end{array}$ & $\begin{array}{c}\text { Final } \\
\text { RQ }(C i) \\
-\ldots . . .\end{array}$ \\
\hline Palladium-107 & 46 & $8.9 \pm 2$ & v. 18 . & $2.1 \mathrm{E} \mathrm{2*}$ & - & 100 \\
\hline Palladium-109 & 46 & $1.5 \mathrm{E} \mathrm{3*}$ & $v .18$. & $2.6 \mathrm{E} 3$ & $1.6 \mathrm{E} 4$ & 1000 \\
\hline Phosphorus- 32 & 15 & $6.0 \mathrm{E}-1^{*}$ & $7.2 \mathrm{E} 1 \#$ & $4.1 E 0$ & $\cdots$ & $\therefore 0.1$ \\
\hline Phosphorus-33 & $15::$ & $::-4.7 \mathrm{E} \mathrm{0*}$ & $5.8 \mathrm{E} 2 \|$ & $3.1 E 1$ & $\cdots-$ & 1 \\
\hline Platinum- 186 & 78 & $4.8 \mathrm{E} 4$ & $>$ E $9 \|$ & $2.1 \mathrm{E} 4$ & $4.0 \mathrm{E} \mathrm{2*}$ & 100 \\
\hline Plat inum- 188 & 78 & $1.3 \mathrm{E} \mathrm{2 \star}$ & $2.9 \mathrm{E} 2 \|$ & 1.053 & $3.1 \mathrm{E} 2$ & 100 \\
\hline Platinum-189 & 78 & $9.0 E 3$ & $9.5 \mathrm{E} 7 \|$ & $1.6 \mathrm{E} 4$ & $4.4 \mathrm{E} \mathrm{2*}$ & 100 \\
\hline Platinum-191 & 78 & $6.5 \mathrm{E} 2$ & $2.9 E 3 \#$ & $4.1 E 3$ & $2.2 \mathrm{E} \mathrm{2*}$ & 100 \\
\hline Platinum-193m & 78 & $3.6 \mathrm{E} \mathrm{2 \star}$ & $1.1 \mathrm{E} 3 \|$ & $3.1 \mathrm{E} 3$ & $2.6 \mathrm{E} 5$ & 100 \\
\hline Plat inum- 193 & 78 & $1.2 \mathrm{E} 3^{\star}$ & $2.9 \mathrm{E} 3 \mathrm{H}$ & $1.0 \mathrm{E} 4$ & -- & 1000 \\
\hline Platinum-195m & 78 & $2.5 \mathrm{E} \mathrm{2 \star}$ & $8.1 \mathrm{E} ? \#$ & $2.1 \mathrm{E} 3$ & $2.7 \mathrm{E} 3$ & 100 \\
\hline Platinum-197m & 78 & $1.2 \mathrm{E} 5$ & $>\mathrm{E} 9 \#$ & $2.1 E 4$ & $9.9 \mathrm{E} \mathrm{3*}$ & 1000 \\
\hline Platinum- 197 & 78 & $1.6 \mathrm{E} \mathrm{3*}$ & $4.2 \mathrm{E} 5 \#$ & $4.7 \mathrm{E} 3$ & $7.3 \mathrm{E} 3$ & 1000 \\
\hline Platinum-199 & 78 & $9.2 \mathrm{E} 5$ & $>\mathrm{E} 9 \|$ & $5.2 \mathrm{E} 4$ & $6.7 \mathrm{E} \mathrm{3*}$ & 1000 \\
\hline Platinum-200 & 78 & $7.9 \mathrm{E} \mathrm{2*}$ & $2.6 \mathrm{E} 6 \#$ & $1.6 \mathrm{E} 3$ & $3.4 \mathrm{E} 3$ & 100 \\
\hline Plutonium-234 & 94 & $9.9 \mathrm{~B} 4$ & v.18. & $1.0 \mathrm{E} \mathrm{3*}$ & -- & 1000 \\
\hline Plutonium-235 & 94 & $2.0 \mathrm{E} 8$ & v.1. . & $1.6 \mathrm{E} \mathrm{7*}$ & -- & 1000 \\
\hline Plutonium-236 & 94 & $6.0 \mathrm{E} 0$ & v. $1_{8}$. & $1.0 \mathrm{E}-1^{*}$ & $-\quad \therefore$ & 0.1 \\
\hline Plutonium-237 & 94 & $3.8 \mathrm{E} \mathrm{3 \star}$ & v.18. & $1.6 \mathrm{E} 4$ & -- & 1000 \\
\hline Plutonium-238 & 94 & $2.1 E 0$ & v. 18 . & $3.1 \mathrm{E}-2 *$ & $\cdots$ & 0.01 \\
\hline Plutonium-239 & 94 & $1.8 \mathrm{E} 0$ & v. $1_{8}$. & $2.6 \mathrm{E}-2^{*}$ & $1.7 \mathrm{E} 6$ & 0.01 \\
\hline Plutonium-240 & 94 & $1.8 \mathrm{E} \quad 0$ & v.18. & $2.6 \mathrm{E}-2 \star$ & $5.0 \mathrm{E} 6$ & 0.01 \\
\hline Plutonium-241 & 94 & $9.0 \mathrm{E} 1$ & v. 18 . & $1.6 \mathrm{E} 0 *$ & $1.4 \mathrm{E} 8$ & 1 \\
\hline Plutonium-242 & 94 & 2.180 & v. 18 . & $3.1 E-2 \star$ & $4.1 E 6$ & 0.01 \\
\hline
\end{tabular}




\begin{tabular}{|c|c|c|c|c|c|c|}
\hline Radionuclide & $\begin{array}{r}\text { Atom. } \\
\text { No. }\end{array}$ & $\begin{array}{l}\text { Ingestion } \\
\text { (food) }\end{array}$ & $\begin{array}{l}\text { Release Values } \\
\text { Ingestion } \\
\text { (water) }\end{array}$ & $\begin{array}{l}(\mathrm{Ci}) \\
\text { Inha- } \\
\text { lation }\end{array}$ & $\begin{array}{l}\text { Direct } \\
\text { Exposure }\end{array}$ & $\begin{array}{c}\text { Final } \\
R Q \text { (ci) }\end{array}$ \\
\hline 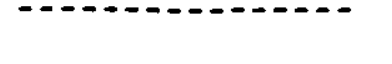 & 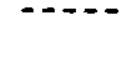 & $---n+--\infty$ & 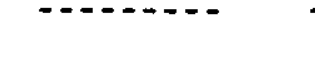 & 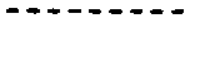 & $\cdots+\cdots$ & $\cdots-1$ \\
\hline Plutonium-243 & 94 & $3.9 \mathrm{E} 5$ & v.18. & $2.1 \mathrm{E} 5$ & $5.7 \mathrm{E} 3 *$ & 1000 \\
\hline Plutonium-244 & 94 & $2.1 \mathrm{E} 0$ & v. 18 . & $3.1 \mathrm{E}-2^{\star}$ & - & 0.01 \\
\hline Plutonium-245 & 94 & $1.9 \mathrm{E} 4$ & v.18. & $2.1 \mathrm{E} 4$ & $3.1 \mathrm{E} 2 *$ & .100 \\
\hline Polonium-203 & 84 & $4.9 \mathrm{E} 5$ & v.18. & $3.1 \mathrm{E} 4$ & $8.8 \mathrm{E} 2 *$ & 100 \\
\hline Polonium-205 & 84 & $1.1 \mathrm{E} 5$ & v.18. & $2.1 E 4$ & $2.7 \mathrm{E} \mathrm{2 \star}$ & 100 \\
\hline Polonium-207 & 84 & $1.3 E 4$ & v. 18 . & $1.6 \mathrm{E} 4$ & $9.4 \mathrm{E} 1^{*}$ & 10 \\
\hline Polonium-210 & 84 & $9.7 \mathrm{E}-2 *$ & v.18. & $3.1 E-1$ & $4.5 E 6$ & 0.01 \\
\hline Potassium- 40 & 19 & $8.6 \mathrm{E} \mathrm{O*}$ & v.lg. & $2.1 E 2$ & $2.4 \mathrm{E} 2$ & 1 \\
\hline Potassium -42 & 19 & $3.9 E 3$ & v.18. & $2.6 \mathrm{E} 3$ & $2.3 \mathrm{E} 2 *$ & 100 \\
\hline Potassium-43 & 19 & $2.6 \mathrm{E} 3$ & v.18. & $4.7 \mathrm{E} 3$ & $5.9 \mathrm{E} 1 *$ & 10 \\
\hline Potassium- 44 & 19 & $5.0 \mathrm{E} 5$ & v. $18 *$ & $3.6 \mathrm{E} 4$ & $6.8 \mathrm{E} \mathrm{2 \star}$ & 100 \\
\hline Potassium-45 & 19 & $9.6 \mathrm{E} 5$ & v. 18 . & $5.2 \mathrm{E} 4$ & $1.2 \mathrm{E} \mathrm{3*}$ & 1000 \\
\hline Praseodymium-136 & 59 & $2.2 \mathrm{E} 6$ & v. 18 . & $1.0 \mathrm{E} 5$ & $2.3 \mathrm{E} \mathrm{3*}$ & 1000 \\
\hline Praseodymium-137 & 59 & $3.0 E 5$ & v. $1 \mathrm{~g}$. & $5.2 \mathrm{E} 4$ & $1.5 \mathrm{E} 4 *$ & 1000 \\
\hline Praseodymium-138m & 59 & $4.6 \mathrm{E} 4$ & v.lg. & $2.1 \mathrm{E} 4$ & $1.4 \mathrm{E} \mathrm{2*}$ & 100 \\
\hline Praseodymium-139 & 59 & $8.7 \mathrm{E} 4$ & v.18. & $5.2 \mathrm{E} 4$ & $1.5 \mathrm{E} \mathrm{3*}$ & 1000 \\
\hline Praseodymium-142m & 59 & $3.1 \mathrm{E} 6$ & v.1g. & $5.2 \mathrm{E} 4 *$ & $\cdots$ & 1000 \\
\hline Praseodymium-142 & 59 & $5.3 \mathrm{E} \mathrm{2*}$ & v.18. & $1.0 \mathrm{E} 3$ & $9.3 \mathrm{~B} 2$ & 100 \\
\hline Praseodymium-143 & 59 & $5.2 \mathrm{E} 1^{\star}$ & v.1g. & $3.6 \mathrm{~B} 2$ & $5.0 \mathrm{E} 8$ & 10 \\
\hline Praseodymium- 144 & 59 & $9.9 \mathrm{E} 5$ & v. $1_{8}$. & $5.2 \mathrm{E} 4^{\star}$ & $7.4 \mathrm{E} 4$ & 1000 \\
\hline Praseodymium-145 & 59 & 4.983 & $v .18$. & $4.1 \mathrm{~B} \mathrm{3*}$ & $9.2 \mathrm{E} 3$ & 1000 \\
\hline Praseodymium- 147 & 59 & 2.186 & v.18. & $1.0 \mathrm{E} 5$ & $4.6 \mathrm{E} \mathrm{3*}$ & 1000 \\
\hline Promethium-141 & 61 & $1.4 \mathrm{E} 6$ & v.18. & 1.085 & $2.7 \mathrm{E} 3 *$ & 1000 \\
\hline Promethium-143 & 61 & $1.6 \mathrm{E} 2$ & v. Ig. & $3.1 \mathrm{E} 2$ & $1.3 \mathrm{E} 2 \star$ & 100 \\
\hline
\end{tabular}




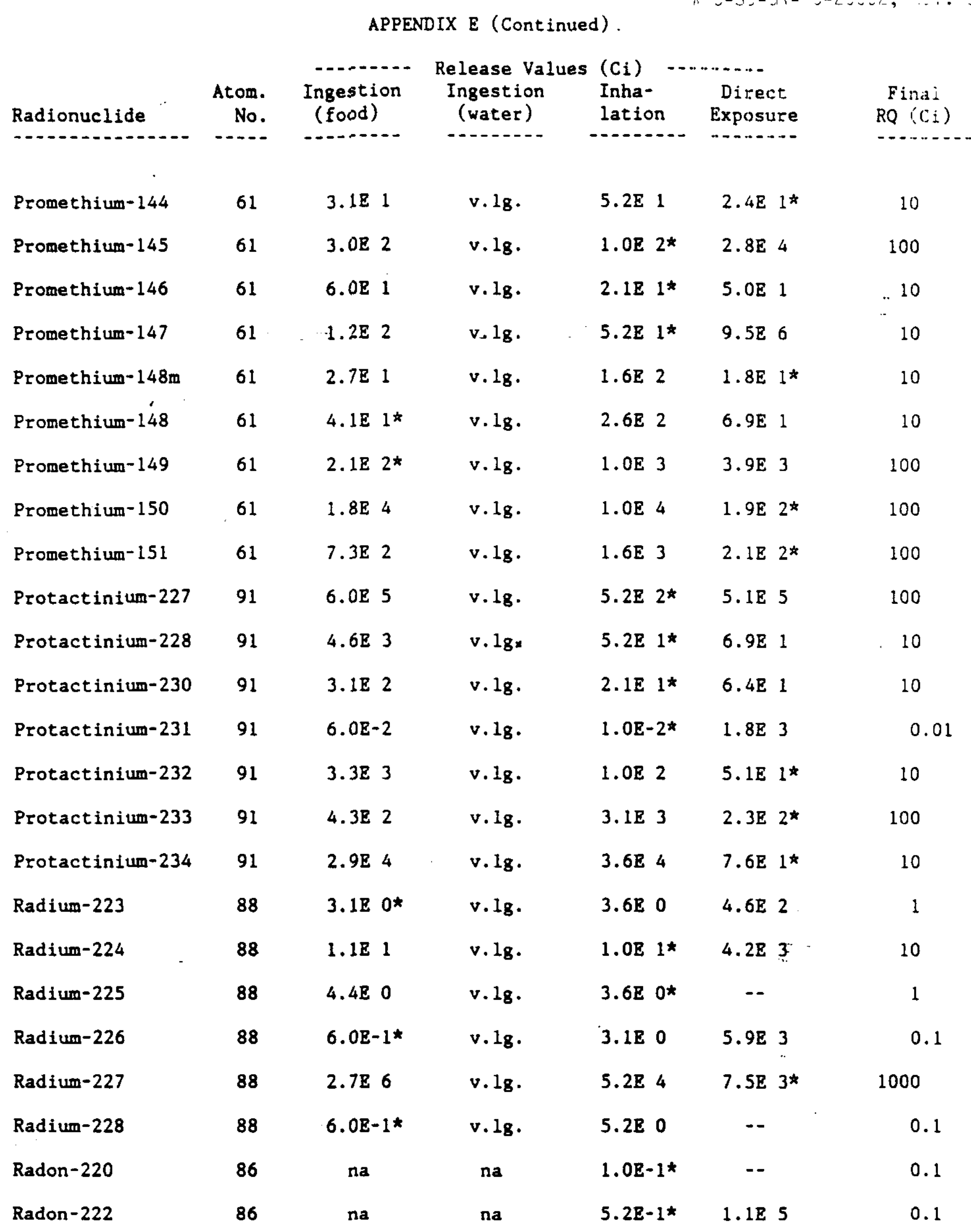


APPENDIX E (Continued)

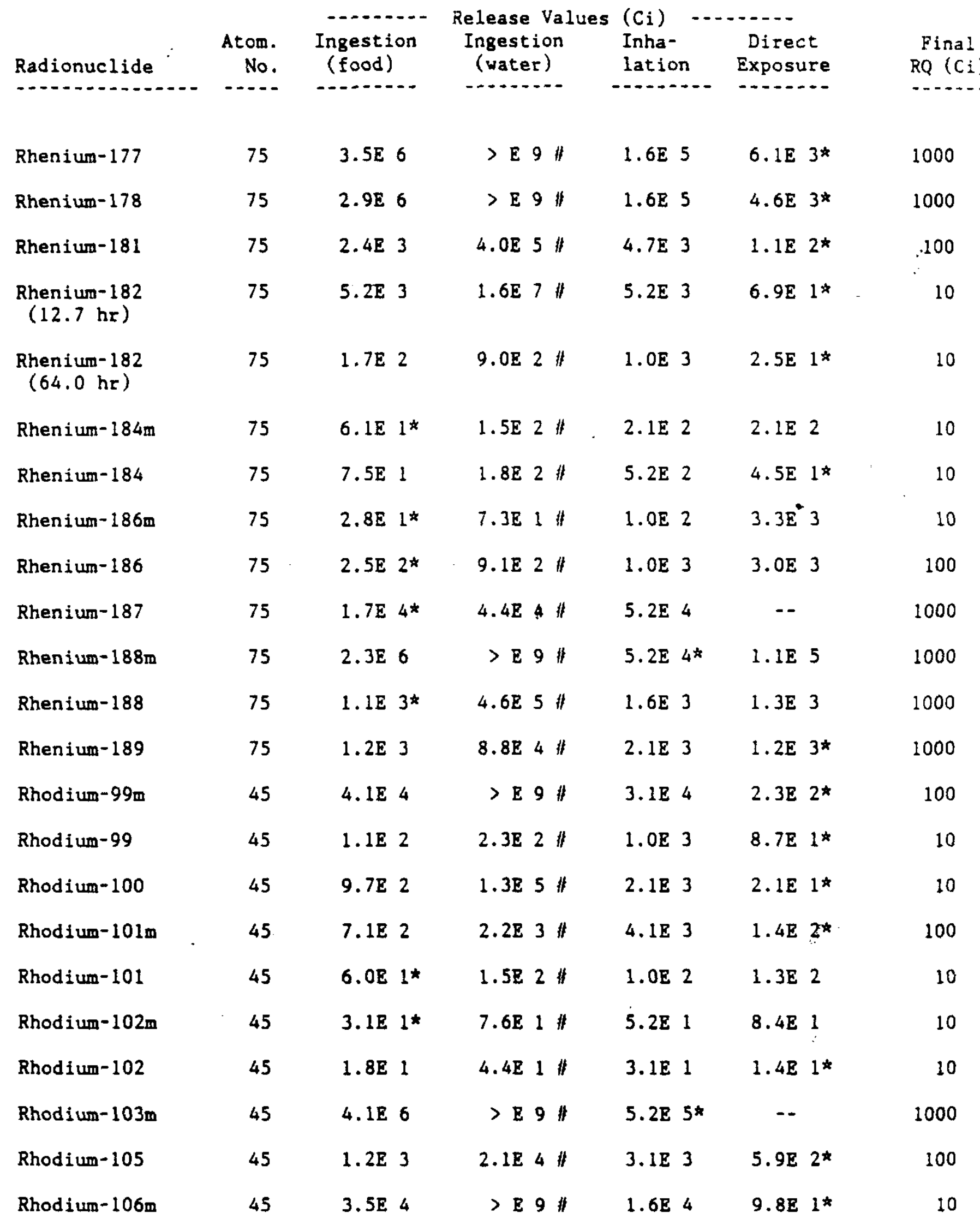




\begin{tabular}{|c|c|c|c|c|c|c|c|}
\hline \multirow[b]{2}{*}{ Radionuclide } & \multicolumn{4}{|c|}{ APPENDIX E (Continued) } & \multicolumn{3}{|c|}{ WHC-SD-GN-HC-2000?, Z:V. C } \\
\hline & $\begin{array}{l}\text { Atom. } \\
\text { No. }\end{array}$ & $\begin{array}{l}\text { Ingestion } \\
\text { (food) }\end{array}$ & $\begin{array}{l}\text { Release Values } \\
\text { Ingestion } \\
\text { (water) }\end{array}$ & $\begin{array}{l}\text { ( } \mathrm{Ci}) \\
\text { Inha- } \\
\text { latior }\end{array}$ & $n^{-\cdots}$ & $\begin{array}{l}\text { Direct } \\
\text { Exposure }\end{array}$ & $\begin{array}{l}\text { Final } \\
\operatorname{RQ}(C i)\end{array}$ \\
\hline Rhodium- 107 & 45 & $1.8 E 6$ & $>$ E $9 \#$ & $1.0 \mathrm{~B}$ & 5 & $5.6 \mathrm{E} 3 *$ & 1000 \\
\hline Rubidium-79 & 37 & $9.9 \mathrm{E} 5$ & v.18. & $5.2 \mathrm{E}$ & 4 & $1.2 \mathrm{E} 3 *$ & 1000 \\
\hline Rubidium-81m & 37 & $3.6 \mathrm{~B} 6$ & v.18. & $1.6 \mathrm{E}$ & 5 & $4.8 \mathrm{~B} 3^{\star}$ & 1000 \\
\hline Rubidium-81 & $37 \ldots$ & $-8.4 \mathrm{E} 4$ & v.18. & $2.6 \mathrm{E}$ & $4-$ & $2.9 \mathrm{E} \mathrm{2 \star}$ & 100 \\
\hline Rubidium-82m & 37 & $1.5 \mathrm{E} 4$ & v.18. & $1.0 \mathrm{E}$ & 4 & $3.9 \mathrm{E} 1 *$ & 10 \\
\hline Rubidium-83 & 37 & $2.0 \mathrm{~B} 1^{*}$ & v.lg. & $5.2 E$ & 2 & $7.3 \mathrm{E} 1$ & 10 \\
\hline Rubidium-84 & 37 & $2.0 \mathrm{~B} 1 *$ & v.18. & $4.1 \mathrm{E}$ & 2 & $5.4 \mathrm{E} 1$ & 10 \\
\hline Rubidium-86 & 37 & $2.5 \mathrm{E} 1^{*}$ & v.1g. & 4.18 & 2 & $3.9 \mathrm{E} 2$ & 10 \\
\hline Rubidium-88 & 37 & $6.4 \mathrm{E} 5$ & v.18. & $3.1 \mathrm{E}$ & 4 & $2.9 \mathrm{E} \mathrm{3*}$ & 1000 \\
\hline Rubidium-89 & 37 & $1.5 \mathrm{E} 6$ & v. $1 \mathrm{~g}$. & $5.2 \mathrm{E}$ & 4 & $1.3 \mathrm{E} \mathrm{3*}$ & 1000 \\
\hline Rubidium-87 & 37 & $3.0 \mathrm{~B} 1 *$ & v. lgs & $1.0 \mathrm{~B}$ & 3 & $\cdots$ & 10 \\
\hline Ruthenium-94 & 44 & $2.2 \mathrm{E} 5$ & $>$ E 9 & $2.1 \mathrm{E}$ & 4 & $1.4 \mathrm{E} \mathrm{3*}$ & 1000 \\
\hline Ruthenium-97 & 44 & $1.3 \mathrm{E} 3$ & $6.0 \mathrm{E} 3$ & $5.2 \mathrm{E}$ & 3 & $1.2 \mathrm{E} 2 *$ & 100 \\
\hline Ruthenium-103 & 44 & $7.8 \mathrm{E} 1^{\star}$ & $1.8 \mathrm{E} 2$ & $3.1 \mathrm{E}$ & 2 & $7.9 \mathrm{E} 1$ & 10 \\
\hline Ruthenium-105 & 44 & $1.1 \mathrm{E} 4$ & $>$ E 9 & $5.2 \mathrm{E}$ & 3 & $2.0 \mathrm{E} \mathrm{2 \star}$ & 100 \\
\hline Ruthenium-106 & 44 & $6.1 \mathrm{BO}$ & $1.5 \mathrm{E} 1$ & $5.2 \mathrm{E}$ & $0 *$ & -- & 1 \\
\hline Samarium-141m & 62 & $7.6 \mathrm{~B} 5$ & v.18. & 5.28 & 4 & $1.0 \mathrm{E} \mathrm{3*}$ & 1000 \\
\hline Samarium-141 & 62 & $2.8 \mathrm{E} 6$ & v.18. & $1.0 \mathrm{E}$ & 5 & $3.4 \mathrm{E} \mathrm{3*}$ & 1000 \\
\hline Samarium-142 & 62 & $6.3 \mathrm{~B} 4$ & v.18. & $1.6 \mathrm{~B}$ & 4 & $8.2 \mathrm{E} \mathrm{3*}$ & 1000 \\
\hline Samarium-145 & 62 & $1.8 \mathrm{E} \mathrm{2*}$ & v.18. & $2.6 \mathrm{~B}$ & 2 & $2.5 \mathrm{E} 6$ & 100 \\
\hline Samarium-146 & 62 & $3.0 \mathrm{E}-1$ & v.1g. & $2.1 \mathrm{E}-$ & $-2 *$ & -- & 0.01 \\
\hline Samarium-147 & 62 & $6.0 \mathrm{~B}-1$ & v.18. & $2.1 \mathrm{E}-2$ & $-2 *$ & -- & 0.01 \\
\hline Samarium-151 & 62 & $3.0 \mathrm{~B} 2$ & v.18. & $5.2 \mathrm{E}$ & $1 *$ & -- & 10 \\
\hline Samarium-153 & 62 & $4.6 \mathrm{~B} \mathrm{2*}$ & v.lg. & $1.6 \mathrm{E}:$ & 3 & $1.3 \mathrm{E} 3$ & 100 \\
\hline
\end{tabular}




\begin{tabular}{|c|c|c|c|c|c|c|}
\hline \multirow[b]{2}{*}{ Radionuclide } & \multicolumn{5}{|c|}{ APPENDIX E (Continued) } & \multirow[b]{2}{*}{$\begin{array}{c}\text { Fina.. } \\
\text { RQ (c:) }\end{array}$} \\
\hline & $\begin{array}{r}\text { Atom. } \\
\text { No. }\end{array}$ & $\begin{array}{l}\text { Ingestion } \\
(\text { food })\end{array}$ & $\begin{array}{l}\text { Release Values } \\
\text { Ingestion } \\
\text { (water) }\end{array}$ & $\begin{array}{l}\text { (Ci) } \\
\text { Inha- } \\
\text { lation }\end{array}$ & $\begin{array}{l}\text { Direct: } \\
\text { Exposure }\end{array}$ & \\
\hline Samarium-155 & 62 & $1.5 \mathrm{E} 6$ & v.18. & $1.0 \mathrm{E} 5$ & $1.8 \mathrm{E} 4 *$ & 1000 \\
\hline Samarium-156 & 62 & $5.2 \mathrm{E} 3$ & v.lg. & $4.7 \mathrm{E} 3$ & $7.0 \mathrm{E} \mathrm{2*}$ & 100 \\
\hline Scandium-43 & 21 & $1.7 \mathrm{E} 4$ & $>$ E $9 \#$ & $1.0 \mathrm{E} 4$ & $1.9 \mathrm{E} 3 \star$ & $\begin{array}{l}1000 \\
\therefore\end{array}$ \\
\hline Scandium-44m & 21 & $9.5 E 1^{*}$ & $5.6 \mathrm{E} 2 \#$ & $3.6 \mathrm{E} 2$ & $1.3 \mathrm{E} 2$ & 10 \\
\hline Scandium- 44 & 21 & $9.8 \mathrm{E} 3$ & $>$ E $9 \#$ & $5.2 \mathrm{E} 3$ & $1.3 \mathrm{E} 2^{\star}$ & 100 \\
\hline Scandium-46 & 21 & $3.1 \mathrm{E} 1$ & $7.2 \mathrm{E} 1 \#$ & $1.0 \mathrm{E} 2$ & $1.8 \mathrm{E} 1^{\star}$ & 10 \\
\hline Scandium- 47 & 21 & $2.9 \mathrm{E} \mathrm{2 \star}$ & $1.1 \mathrm{E} 3 \#$ & $1.6 \mathrm{E} 3$ & $3.7 \mathrm{E} 2$ & 100 \\
\hline Scandium-48 & 21 & $2.0 \mathrm{E} 2$ & $2.0 \mathrm{E} 3 \#$ & $5.2 \mathrm{E} 2$ & $1.3 \mathrm{E} 1^{\star}$ & 10 \\
\hline Scandium-49 & 21 & $2.0 \mathrm{E} 5$ & $>\mathrm{E} 9 \#$ & $2.6 \mathrm{E} 4 \star$ & $7.2 \mathrm{E} 5$ & 1000 \\
\hline Selenium-70 & 34 & $1.4 \mathrm{E} 5$ & v.18. & $2.1 \mathrm{E} 4$ & $4.6 \mathrm{E} \mathrm{3 \star}$ & 1000 \\
\hline Selenium-73m & 34 & $2.3 \mathrm{E} 3$ & v. $1 g^{t}$ & $5.2 \mathrm{E} 4$ & $1.7 \mathrm{E} \mathrm{2 \star}$ & 100 \\
\hline Selenium-73 & 34 & $4.1 \mathrm{E} 3$ & v.18. & $5.2 \mathrm{E} 3$ & $9.5 \mathrm{E} \mathrm{1*}$ & 10 \\
\hline Selenium-75 & 34 & $1.6 \mathrm{E} 1^{\star}$ & v.lg. & $3.1 \mathrm{E} 2$ & $1.0 \mathrm{E} 2$ & 10 \\
\hline Selenium-79 & 34 & $1.8 \mathrm{E} 1^{\star}$ & v.18. & $3.1 \mathrm{E} 2$ & -- & 10 \\
\hline Selenium-81m & 34 & $2.0 \mathrm{E} 5$ & v.lg. & $3.6 \mathrm{E} 4^{*}$ & $6.1 \mathrm{E} 4$ & 1000 \\
\hline Selenium-81 & 34 & $1.9 \mathrm{E} 6$ & v.lg. & $1.0 \mathrm{E} 5^{*}$ & $1.8 \mathrm{E} 5$ & 1000 \\
\hline Selenium-83 & 34 & $7.7 \mathrm{E} 5$ & v.18. & $5.2 \mathrm{E} 4$ & $1.0 \mathrm{E} 3^{*}$ & 1000 \\
\hline Silicon-31 & 14 & $3.3 \mathrm{E} 4$ & $>\mathrm{B} 9 \|$ & $1.6 \mathrm{E} 4 *$ & $2.6 \mathrm{E} 5$ & 1000 \\
\hline Silicon-32 & 14 & $5.9 \mathrm{E} 1$ & $1.5 \mathrm{E} 2 \#$ & $2.6 \mathrm{E} 0 *$ & -- & 1 \\
\hline Silver-102 & 47 & $2.2 \mathrm{E} 6$ & v.lg. & $1.0 \mathrm{E} 5$ & $8.8 \mathrm{E} 2 \star$ & 100 \\
\hline Silver-103 & 47 & $3.4 \mathrm{E} 5$ & $v .18$. & $5.2 \mathrm{E} 4$ & $1.5 \mathrm{E} \mathrm{3 \star}$ & 1000 \\
\hline Silver-104m & 47 & $5.1 \mathrm{E} 5$ & v.18. & $4.7 \mathrm{E} 4$ & $1.183^{*}$ & 1000 \\
\hline Silver-104 & 47 & $1.6 \mathrm{E} 5$ & v.lg. & $3.6 \mathrm{E} 4$ & $2.9 \mathrm{E} \mathrm{3*}$ & 1000 \\
\hline Silver-105 & 47 & $1.1 \mathrm{E} 2$ & $v .18$. & $5.2 \mathrm{E} 2$ & $8.2 \mathrm{E} 1^{\star}$ & 10 \\
\hline
\end{tabular}




\begin{tabular}{|c|c|c|c|c|c|c|}
\hline Radionuclide & $\begin{array}{r}\text { Atom. } \\
\text { No. }\end{array}$ & $\begin{array}{l}\text { Ingestion } \\
\text { (food) }\end{array}$ & $\begin{array}{l}\text { Release Values } \\
\text { Ingestion } \\
\text { (water) }\end{array}$ & $\begin{array}{l}\text { (Ci) } \\
\text { Inha- } \\
\text { lation }\end{array}$ & $\begin{array}{l}\text { Direct } \\
\text { Exposure }\end{array}$ & $\begin{array}{l}\text { Final } \\
R Q(C i) \\
-\end{array}$ \\
\hline Silver-106m & 47 & $5.9 \mathrm{E} 1$ & v. 18 . & $3.6 \mathrm{E} 2$ & $1.4 \mathrm{E} 1^{*}$ & 10 \\
\hline Silver-106 & 47 & $1.4 \mathrm{E} 6$ & v. 18 . & $1.0 \mathrm{E} 5$ & $2.1 \mathrm{E} 3 *$ & 1000 \\
\hline Silver-108m & 47 & $1.8 \mathrm{E} 1$ & v. 18 . & $1.0 \mathrm{E} 1^{\star}$ & $2.2 \mathrm{E} 1$ & 10 \\
\hline Silver-110m & 47 & $1.5 \mathrm{E} 1$ & v. 18 . & $4.7 \mathrm{E} 1$ & $1.3 \mathrm{~B} 1^{\star}$ & 10 \\
\hline Silver-111 & 47 & $7.2 \mathrm{~B} 1^{*}$ & v.18. & $4.7 \mathrm{E} 2$ & $1.5 E 3$ & 10 \\
\hline Silver-112 & 47 & $9.0 \mathrm{E} 3$ & $v \cdot 1_{8}$. & $4.1 E^{3}$ & $3.8 \mathrm{E} \mathrm{2*}$ & 100 \\
\hline Silver-115 & 47 & $8.4 E 5$ & v. 18 . & $4.1 \mathrm{E} 4$ & $7.1 \mathrm{E} \mathrm{3*}$ & 1000 \\
\hline Sodium-22 & 11 & $1.2 \mathrm{E} 1^{\star}$ & v. 18 . & $3.1 \mathrm{E} 2$ & -- & 10 \\
\hline Sodium-24 & 11 & $2.6 \mathrm{E} 3$ & v. 18 . & $2.6 \mathrm{E} 3$ & $1.5 \mathrm{E} 1^{*}$ & 10 \\
\hline Strontium-80 & 38 & $2.0 \mathrm{E} 4$ & v. 18 . & $5.2 \mathrm{E} 3$ & $4.1 \mathrm{E} \mathrm{2*}$ & 100 \\
\hline Strontium-81 & 38 & $4.7 \mathrm{E} 5$ & v. I $_{g}$ & $4.1 E 4$ & $1.3 \mathrm{E} \mathrm{3*}$ & 1000 \\
\hline Strontium-83 & 38 & 5.982 & v. 18 . & $2.1 E .3$ & $1.3 \mathrm{E} \mathrm{2*}$ & 100 \\
\hline Strontium-85m & 38 & $1.6 \mathrm{E} 6$ & v. Ig. & $3.1 \mathrm{E} 5$ & $2.7 \mathrm{E} 3^{\star}$ & 1000 \\
\hline Strontium-85 & 38 & $9.7 \mathrm{E} 1$ & v. 18. & $1.0 \mathrm{E} 3$ & $7.2 \mathrm{E} 1^{*}$ & 10 \\
\hline Strontium-87m & 38 & $1.3 \mathrm{E} 5$ & v.lg. & $5.2 \mathrm{E} 4$ & $6.8 \mathrm{E} \mathrm{2 \star}$ & 100 \\
\hline Strontium-89 & 38 & $1.7 \mathrm{E} 1 *$ & v. 18 . & $5.2 \mathrm{E} 1$ & $4.5 E 6$ & 10 \\
\hline Strontium-90 & 38 & $8.2 E-1 \star$ & v.lg. & $2.1 \mathrm{E} 0$ & -- & 0.1 \\
\hline Strontium-91 & 38 & $1.9 \mathrm{E} 3$ & v.lg. & $2.1 \mathrm{E} 3$ & $7.9 \mathrm{E} 1^{\star *}$ & 10 \\
\hline Strontium-92 & 38 & $9.8 \mathrm{E} 3$ & v.18. & $3.6 \mathrm{E} 3$ & $1.7 \mathrm{E} \mathrm{2 \star}$ & 100 \\
\hline Sulfur -35 & 16 & $3.9 \mathrm{E} 0 *$ & $4.8 \mathrm{E} 2 \#$ & $2.1 \mathrm{E} 1$ & $\cdots$ & 1 \\
\hline Tantalum- 172 & 73 & $6.2 \mathrm{E} 6$ & $>E 9 \#$ & $5.2 \mathrm{E} 5$ & $8.0 \mathrm{~B} \mathrm{2*}$ & 100 \\
\hline Tantalum- 173 & 73 & $1.8 \mathrm{E} 5$ & $>$ E $9 \#$ & $1.0 \mathrm{E} 5$ & $4.9 \mathrm{E} \mathrm{2*}$ & 100 \\
\hline Tantalum- 174 & 73 & $2.4 \mathrm{E} 6$ & $>$ E $9 \#$ & $4.7 \mathrm{E} 5$ & $9.6 \mathrm{E} \mathrm{2*}$ & 100 \\
\hline Tantalum-175 & 73 & $5.6 \mathrm{E} 4$ & $8.4 \mathrm{E} 7 \#$ & $5.2 \mathrm{E} 4$ & $1.9 \mathrm{E} \mathrm{2*}$ & 100 \\
\hline
\end{tabular}


APPENDIX E (Continued)

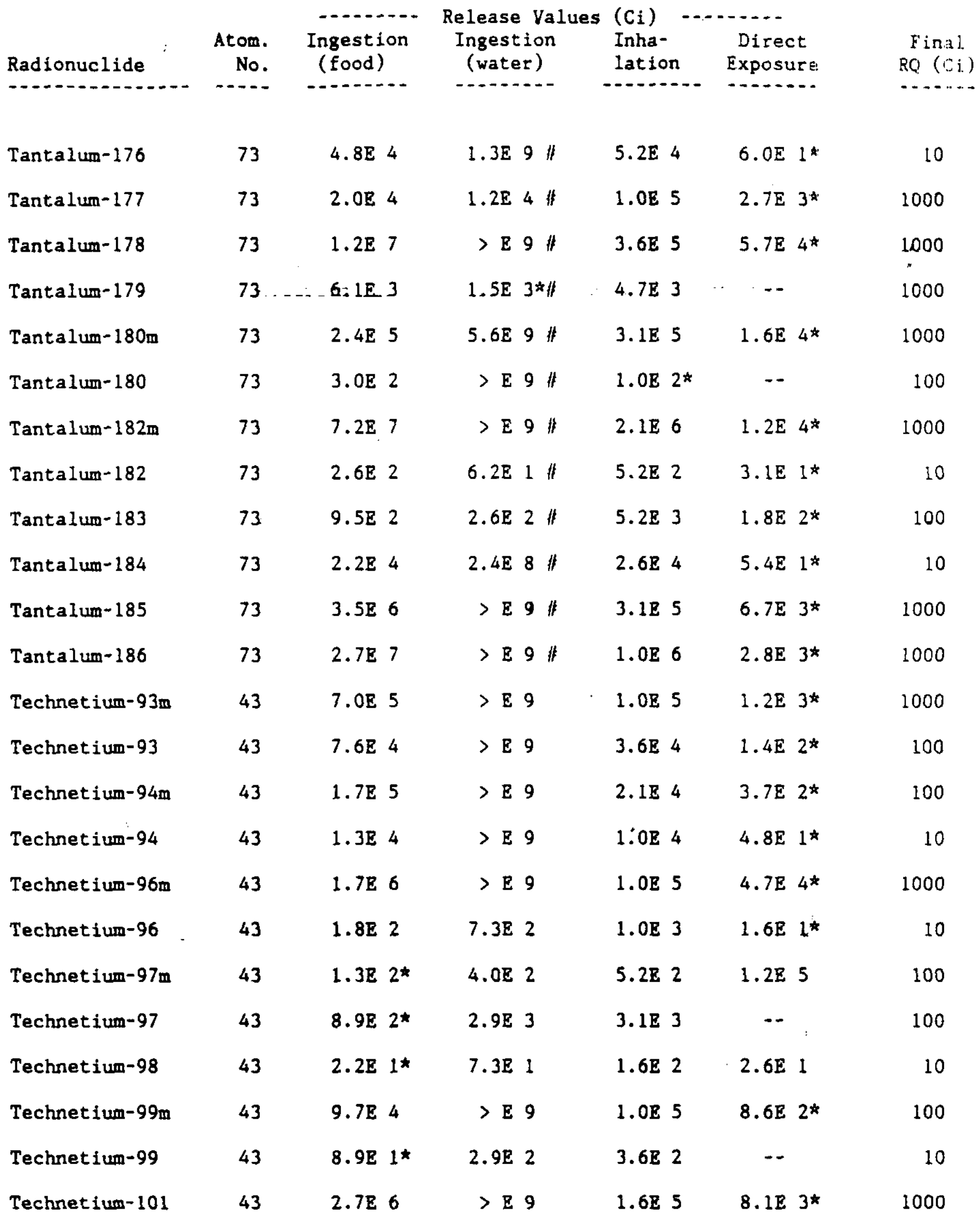




\begin{tabular}{|c|c|c|c|c|c|c|}
\hline Radionuclide & $\begin{array}{l}\text { Atom. } \\
\text { No. }\end{array}$ & $\begin{array}{l}\text { Ingestion } \\
\text { (food) }\end{array}$ & $\begin{array}{l}\text { Release Values } \\
\text { Ingestion } \\
\text { (water) }\end{array}$ & $\begin{array}{l}(\mathrm{Ci})-- \\
\text { Inha- } \\
\text { lation }\end{array}$ & $\begin{array}{l}\text { Direct. } \\
\text { Exposure }\end{array}$ & $\begin{array}{c}\text { Final } \\
R Q\left(D_{i}\right)\end{array}$ \\
\hline Technetium-104 & 43 & $4.7 \mathrm{E} 5$ & $>E 9$ & $3.6 \mathrm{E} 4$ & $1.3 \mathrm{E} 3 \mathrm{H}$ & 1000 \\
\hline Tellurium-116 & 52 & $3.1 \mathrm{E} 4$ & v. 1 g. & $1.0 \mathrm{E} 4$ & $4 \cdot 1$ E $3 *$ & 1000 \\
\hline Tellurium-121m & 52 & $1.6 \mathrm{E} 1^{\star}$ & v. $l_{8}$. & $1.0 \mathrm{E} 2$ & $1.8 \mathrm{E} 2$ & 10 \\
\hline Tellurium-121 & 52 & $1.6 \mathrm{E} 2$ & v. 18 . & $1.6 \mathrm{E} 3$ & $6.7 \mathrm{E} 1^{*}$ & 10 \\
\hline Tellurium-123m & 52 & $2.081^{\star}$ & v.lg. & $1.0 \mathrm{E} 2$ & $2.7 \mathrm{E} 2$ & 10 \\
\hline Tellurium-123 & 52 & $1.5 E 1^{\star}$ & v. 18 . & $1.0 E 2$ & -- & 10 \\
\hline Tellurium-125m & 52 & $3.6 \mathrm{E} 1^{\star}$ & v.lg. & $2.1 \mathrm{E} 2$ & $1.1 \mathrm{E} 5$ & 10 \\
\hline Tellurium-127m & 52 & $2.0 \mathrm{E} 1^{*}$ & v.lg. & $1.6 \mathrm{E} 2$ & $5.2 \mathrm{E} 5$ & 10 \\
\hline Tellurium-127 & 52 & $7.2 \mathrm{E} \mathrm{3*}$ & v. Ig. & $1.0 \mathrm{E} 4$ & $2.1 \mathrm{E} 5$ & 1000 \\
\hline Tellurium-129m & 52 & $2.0 \mathrm{E} 1^{*}$ & v. 18 . & $1.0 \mathrm{E} 2$ & $7.9 \mathrm{E} 2$ & 10 \\
\hline Tellurium-129 & 52 & $2.5 \mathrm{E} 5$ & v. 18 , & $3.1 \mathrm{E} 4$ & $1.1 \mathrm{E} 4^{\star}$ & 1000 \\
\hline Tellurium-131m & 52 & $9.6 \mathrm{E} 1$ & v. 18 . & $2.1 \mathrm{E2}$ & $4.0 \mathrm{E} 1 *$ & 10 \\
\hline Tellurium-131 & 52 & $6.8 \mathrm{E} 4$ & v. 18 . & $2.6 \mathrm{E} \mathrm{3*}$ & $4.1 \mathrm{E} 3$ & 1000 \\
\hline Tellurium-132 & 52 & $3.0 \mathrm{E} 1^{*}$ & v. $1 \mathrm{~g}$. & $1.0 \mathrm{E} 2$ & $2.0 \mathrm{E} 2$ & 10 \\
\hline Tellurium-133m & 52 & $3.1 \mathrm{E} 4$ & v.1g. & $2.6 \mathrm{E} \mathrm{3*}$ & $6.5 E 3$ & 1000 \\
\hline Tellurium-133 & 52 & $4.6 \mathrm{~B} 5$ & v. 18 . & $1.0 \mathrm{E} 4$ & $3.4 \mathrm{E} \mathrm{3*}$ & 1000 \\
\hline Tellurium-134 & 52 & 2.785 & v. 18 . & $1.0 \mathrm{E} 4$ & $1.0 \mathrm{E} \mathrm{3 \star}$ & 1000 \\
\hline Terbium-147 & 65 & $4.8 \mathrm{E} 4$ & v. g. $_{\text {. }}$ & $1.6 \mathrm{E} 4$ & $1.9 \mathrm{E} 2^{*}$ & 100 \\
\hline Terbium-149 & 65 & $1.2 \mathrm{E} 4$ & v. 18 . & $3.6 \mathrm{E} 2$ & $1.7 \mathrm{E} \mathrm{2 \star}$ & 100 \\
\hline Terbium-150 & 65 & $1.5 B 4$ & v. 18 . & $1.0 \mathrm{E} 4$ & $2.2 \mathrm{E} \mathrm{2*}$ & 100 \\
\hline Terbium-151 & 65 & 2.383 & v.18. & $4.7 \mathrm{E} 3$ & $8.5 E 1^{\star}$ & 10 \\
\hline Terbium-153 & 65 & $9.9 \mathrm{E} 2$ & v. 18 . & $3.6 \mathrm{E} 3$ & $3.0 \mathrm{E} \mathrm{2*}$ & 100 \\
\hline Terbium-154 & 65 & 9.282 & v. 18 . & $2.1 \mathrm{E} 3$ & $3.2 \mathrm{E} 1^{\star}$ & 10 \\
\hline Terbium-155 & 65 & $6.2 \mathrm{E} 2$ & v. 18 . & $4.1 \mathrm{E} 3$ & $4.4 \mathrm{E} \mathrm{2*}$ & 100 \\
\hline
\end{tabular}




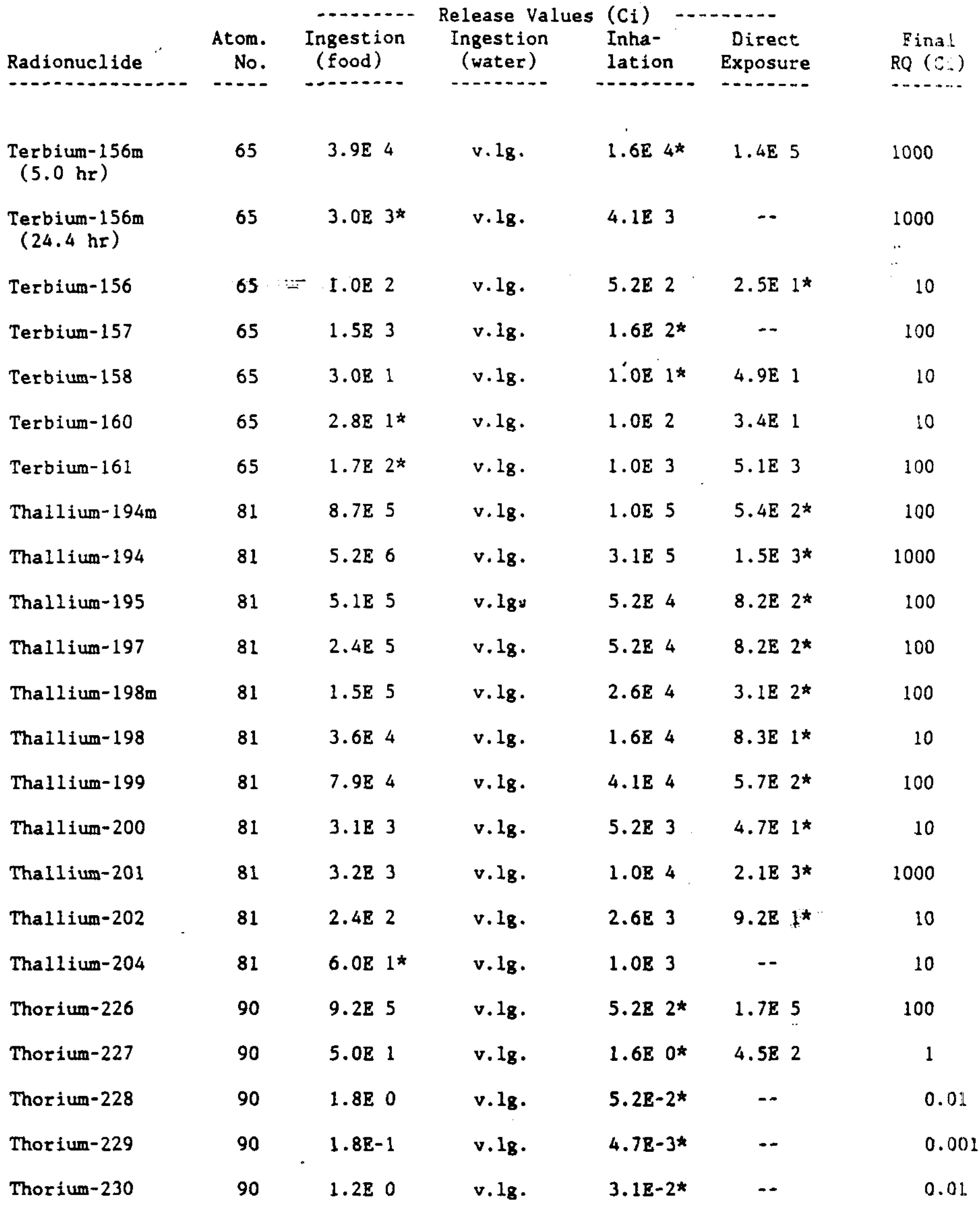




\begin{tabular}{|c|c|c|c|c|c|c|c|}
\hline Radionuclide & $\begin{array}{l}\text { Atom. } \\
\text { No. }\end{array}$ & $\begin{array}{l}\text { Ingestion } \\
\text { (food) }\end{array}$ & $\begin{array}{l}\text { Release Values } \\
\text { Ingestion } \\
\text { (water) }\end{array}$ & $\begin{array}{l}\left(\mathrm{C}_{i}\right) \\
\text { Inha- } \\
\text { lation }\end{array}$ & $\begin{array}{l}\text { Direct } \\
\text { Exposure }\end{array}$ & & $\begin{array}{c}F, \text { nal } \\
R Q(C i)\end{array}$ \\
\hline Thorium-231 & 90 & $1.6 \mathrm{E} \quad 4$ & v.lg. & $3.1 \mathrm{E} 4$ & $6.0 \mathrm{E} 2 *$ & & 100 \\
\hline Thorium-232 & 90 & $2.1 \mathrm{E}-1$ & v. 18 . & $5.2 \mathrm{E}-3 \star$ & $7.3 \mathrm{E} 5$ & & 0.001 \\
\hline Thorium-234 & 90 & $1.4 \mathrm{E} \mathrm{2 \star}$ & v. 18 . & $1.0 \mathrm{E} 3$ & $7.0 \mathrm{E} 3$ & & 100 \\
\hline Thulium-162 & 69 & $-5.8 \mathrm{~B} \quad 6$ & $>E 9 \#$ & $1.6 \mathrm{E} 5$ & $2.1 \mathrm{E} \mathrm{3*}$ & - & 1000 \\
\hline Thulium-166 & 69 & $5.1 \mathrm{E} 3$ & $2.4 \mathrm{E} 9 \#$ & $5.2 \mathrm{E} 3$ & $4.6 \mathrm{~B} 1^{\star}$ & & 10 \\
\hline Thulium-167 & 69 & $1.4 \mathrm{E} \mathrm{2*}$ & $3.2 \mathrm{E} 2 \#$ & $1.0 \mathrm{E} 3$ & $4.0 \mathrm{E} 2$ & & 100 \\
\hline Thulium-170 & 69 & $2.6 \mathrm{E} 1^{*}$ & $6.2 \mathrm{E} 1 \#$ & $1.0 \mathrm{E} 2$ & $1.3 \mathrm{E} 4$ & & 10 \\
\hline Thulium-171 & 69 & $3.0 \mathrm{E} 2$ & $7.4 \mathrm{E} 2 \#$ & $1.6 \mathrm{E} \mathrm{2*}$ & - & & 100 \\
\hline Thulium-172 & 69 & $1.2 \mathrm{~B} 2$ & $6.4 \mathrm{E} 2 \#$ & $5.2 \mathrm{E} 2$ & $1.2 \mathrm{E} 2^{\star}$ & & 100 \\
\hline Thulium- 173 & 69 & $4.7 \mathrm{E} 3$ & $9.7 \mathrm{E} 8 \|$ & $5.2 \mathrm{E} 3$ & $2.2 \mathrm{E} \mathrm{2 \star}$ & & 100 \\
\hline Thulium-175 & 69 & $2.6 \mathrm{~B} 6$ & $>E, 9 \#$ & $1.6 \mathrm{E} 5$ & $2.9 E 3^{\star}$ & & 1000 \\
\hline Tin-110 & 50 & $9.6 \mathrm{E} 3$ & v. 18 . & $5.2 \mathrm{E} 3$ & $5.6 \mathrm{E} 2 *$ & & 100 \\
\hline Tin-111 & 50 & $1.1 \mathrm{E} 6$ & v. 18 . & $1.0 \mathrm{E} 5$ & $8.5 E 3^{*}$ & & 1000 \\
\hline $\operatorname{Tin}-113$ & 50 & $6.6 \mathrm{E} \mathrm{1*}$ & v. 18 . & $2.6 \mathrm{E} 2$ & $1.4 \mathrm{E} 2$ & & 10 \\
\hline $\operatorname{Tin}-117 m$ & 50 & $1.182^{\star}$ & v.18. & $5.2 \mathrm{E} 2$ & $2.7 \mathrm{E} 2$ & & 100 \\
\hline Tin-119m & 50 & $9.3 \mathrm{E} 1 \star$ & v. $1 \mathrm{~g}$. & $5.2 \mathrm{E} 2$ & -- & & 10 \\
\hline $\operatorname{Tin}-121 \mathrm{~m}$ & 50 & $8.9 \mathrm{~B} 1^{\star}$ & v. 18 . & $2.6 \mathrm{E} 2$ & $\cdots$ & & 10 \\
\hline Tin-121 & 50 & $2.3 \mathrm{E} \mathrm{3*}$ & v. $1 \mathrm{~g}$. & $5.2 \mathrm{E} \quad 3$ & -- & & 1000 \\
\hline Tin-123m & 50 & $7.1 \mathrm{~B} 5$ & v. 18 . & $5.2 \mathrm{E} 4$ & $6.6 \mathrm{E} \mathrm{3*}$ & & 1000 \\
\hline Tin-123 & 50 & $1.6 \mathrm{E} 1^{\star}$ & v. $l_{8}$. & $1.0 \mathrm{OE} 2$ & $5.3 \mathrm{E} 3$ & & 10 \\
\hline Tin-125 & 50 & $2.8 \mathrm{E} \mathrm{1*}$ & v.18. & $2.1 \mathrm{E} 2$ & $1.4 \mathrm{E} 2$ & & 10 \\
\hline Tin-126 & 50 & $8.9 \mathrm{E} \mathrm{O*}$ & v. 18 . & $3.1 \mathrm{~B} 1$ & $2.0 \mathrm{E} 1$ & & 1 \\
\hline Tin- 127 & 50 & $3.2 \mathrm{E} 4$ & v. $1_{8}$. & $1.0 \mathrm{E} 4$ & $2.0 \mathrm{~B} \mathrm{2*}$ & & 100 \\
\hline $\operatorname{Tin}-128$ & 50 & $8.7 \mathrm{E} 4$ & v. 18 . & $1.6 \mathrm{~B} 4$ & $1.183^{*}$ & & 1000 \\
\hline
\end{tabular}




\begin{tabular}{|c|c|c|c|c|c|c|}
\hline Radionuclide & $\begin{array}{l}\text { Atom. } \\
\text { No. }\end{array}$ & $\begin{array}{c}\text { Ingestion } \\
\text { (food) }\end{array}$ & $\begin{array}{l}\text { Release Values } \\
\text { Ingestion } \\
\text { (water) }\end{array}$ & $\begin{array}{l}\text { (Ci) } \\
\text { Inha- } \\
\text { lation } \\
\end{array}$ & $\begin{array}{l}\text { Direct } \\
\text { Exposure }\end{array}$ & $\begin{array}{c}F i n a l \\
R Q(C i)\end{array}$ \\
\hline Titanium-44 & 22 & $8.9 \mathrm{E} 0$ & $2.2 \mathrm{E} 1 \|$ & $3.1 \mathrm{E} 0 *$ & $2.7 \mathrm{E} 2$ & 1 \\
\hline Titanium-45 & 22 & $2.8 \mathrm{~B} 4$ & $>\mathrm{E} 9 \|$ & $1.6 \mathrm{~B} 4 \star$ & -- & 1000 \\
\hline Tungsten-176 & 74 & $3.8 \mathrm{~B} 4$ & $>$ E $9 \#$ & 2.684 & $2.1 \mathrm{E} 3 *$ & 1000 \\
\hline Tungsten-177 & 74 & $8.6 \mathrm{~B} 4$ & $>\mathrm{BS} \|$ & $4.7 \mathrm{E} 4$ & $5.7 \mathrm{E} 2 \star$ & 100 \\
\hline Tungsten-178 & 74 & $2.3 \mathrm{E} \mathrm{2 \star}$ & $5.182 \#$ & $1.0 \mathrm{E} 4$ & $\cdots$ & 100 \\
\hline Tungsten-179 & 74 & $7.6 \mathrm{E} 6$ & $>$ E $9 \#$ & $1.0 \mathrm{E} 6 *$ & -- & 1000 \\
\hline Tungsten-181 & 74 & $6.5 \mathrm{E} \mathrm{2*}$ & $1.6 \mathrm{~B} 3 \#$ & $1.6 \mathrm{E} 4$ & $2.2 \mathrm{E} 5$ & 100 \\
\hline Tungsten-185 & 74 & $6.9 \mathrm{E} 1 \star$ & $1.6 \mathrm{E} 2 \#$ & $3.6 \mathrm{E} 3$ & $1.5 \mathrm{~B} 6$ & 10 \\
\hline Tungsten -187 & 74 & $8.5 E^{2} 2$ & $6.0 \mathrm{E} 4 \#$ & $4.7 \mathrm{E} 3$ & $1.1 \mathrm{E} 2 *$ & 100 \\
\hline Tungsten-188 & 74 & $1.4 \mathrm{~B} 1^{\star}$ & $3.2 \mathrm{~B} 1 \#$ & $5.2 \mathrm{E} 2$ & $2.3 B 4$ & 10 \\
\hline Uranium-230 & 92 & $1.9 \mathrm{~B} 0$ & v. 18. & $1.6 \mathrm{~B} 0 *$ & $4.1 \mathrm{E} 4$ & 1 \\
\hline Uranium-231 & 92 & $4.9 \mathrm{E} 3 *$ & v. $1 \mathrm{~g}$. & $2.6 \mathrm{E} 4$ & $5.3 \mathrm{E} 3$ & 1000 \\
\hline Uranium-232 & 92 & $6.0 \mathrm{E}-1$ & v.18. & 4. $1 E-2 \star$ & $\cdots$ & 0.01 \\
\hline Uranium -233 & 92 & $3.0 \mathrm{~B} 0$ & v.18. & $2.1 \mathrm{E}-1^{\star}$ & $1.9 \mathrm{E} 6$ & 0.1 \\
\hline Uranfum- 234 & 92 & $3.0 \mathrm{EO}$ & v.18. & $2.1 E-1 *$ & $7.5 E^{5}$ & 0.1 \\
\hline Uranium-235 & 92 & $3.0 \mathrm{~B} 0$ & v.18. & $2.1 \mathrm{E}-1^{*}$ & $2.7 \mathrm{~B} 2$ & 0.1 \\
\hline Uranium-236 & 92 & 3.080 & v.1g. & $2.1 E-1^{\star}$ & $1.6 \mathrm{E} 6$ & 0.1 \\
\hline Uranium- 237 & 92 & 1.783 & v.18. & $5.2 \mathrm{E} 3$ & $7.2 \mathrm{E} 2 \star$ & 100 \\
\hline Uranium-238 & 92 & $3.0 \mathrm{~B} 0$ & v.18. & $2.1 \mathrm{E}-1^{*}$ & -- & $0.1 \varepsilon$ \\
\hline Uranium-239 & 92 & $1.7 \mathrm{E} 7$ & v. 18 . & $1.0 \mathrm{E} 6$ & $3.5 B 5 *$ & 1000 \\
\hline Uranium-240 & 92 & $7.083 \star$ & v.18. & i. $0 \mathrm{E} 4$ & -- & 1000 \\
\hline Vanadium -47 & 23 & $5.5 B 5$ & $>$ E 9 & $4.1 \mathrm{E} 4^{\star}$ & $3.4 \mathrm{~B} 5$ & 1000 \\
\hline Vanadium-48 & 23 & $3.2 \mathrm{E} 1 *$ & $6.9 \mathrm{E} 1$ & $3.1 \mathrm{E} 2$ & 3.581 & 10 \\
\hline Vanadium-49 & 23 & $2.2 \mathrm{E} 3^{\star}$ & $5.2 \mathrm{E} 3 \#$ & $1.0 \mathrm{~B} 4$ & - & 1000 \\
\hline
\end{tabular}




\begin{tabular}{|c|c|c|c|c|c|c|}
\hline Radionuclide & $\begin{array}{l}\text { Atom. } \\
\text { No. }\end{array}$ & $\begin{array}{l}\text { Ingestion } \\
\text { (food) }\end{array}$ & $\begin{array}{l}\text { Release Values } \\
\text { Ingestion } \\
\text { (water) }\end{array}$ & $\begin{array}{l}\left(\mathrm{C}_{i}\right) \\
\text { Inha- } \\
\text { lation }\end{array}$ & $\begin{array}{l}\text { Direct: } \\
\text { Exposure }\end{array}$ & $\begin{array}{c}\text { Final } \\
R Q(C i)\end{array}$ \\
\hline$\cdots+-+-\infty+\infty+\infty$ & $\cdots$ & $---\cdots--$ & $-\infty---\infty$ & $-\infty+-\infty-\infty$ & - & $\rightarrow-\cdots+-\cdots$ \\
\hline Xenon-120 & 54 & na & na & na & $1.0 \mathrm{E} 2 *+^{*}$ & 100 \\
\hline Xenon-121 & 54 & na & na & na & $2.0 \mathrm{E}^{*}+$ & 10 \\
\hline Xenon-122 & 54 & na & na & na & $7.0 \mathrm{E} 2 *+$ & 100 \\
\hline Xenon-123 & 54 & na & na & na & $6.0 \mathrm{E} 1^{*+}+$ & 10 \\
\hline Xenon-125 & 54 & na & na & na & $2.0 \mathrm{E} \mathrm{2*+}$ & 100 \\
\hline Xenon-127 & 54 & na & na & na & $1.0 \mathrm{E} \mathrm{2*+}$ & 100 \\
\hline Xenon-129m & 54 & na & na & na & $2.0 \mathrm{E} 3 *+$ & 1000 \\
\hline Xenon-131m & 54 & na & na & na & $4.0 \mathrm{E} 3 *+$ & 1000 \\
\hline Xenon-133m & 54 & na & na & na & $1.0 \mathrm{E}^{\frac{*}{*}+}$ & 1000 \\
\hline Xenon-133 & 54 & na & na & na & $1.0 \mathrm{E} 3 x^{+}$ & 1000 \\
\hline Xenon-135m & 54 & na & na : & na & $9.0 \mathrm{E} 1^{*}+$ & 10 \\
\hline Xenon-135 & 54 & na & na & na & $1.0 \mathrm{E} \mathrm{2*+}$ & 100 \\
\hline Xenon-138 & 54 & na & na & na & $4.0 \mathrm{E} 1 *+$ & 10 \\
\hline Ytterbium-162 & 70 & $2.1 \mathrm{E} 6$ & $>\mathrm{E} 9 \|$ & $1.6 \mathrm{~B} 5$ & $2.2 \mathrm{E} 4^{\star}$ & 1000 \\
\hline Ytterbium-166 & 70 & $2.0 \mathrm{~B} 2$ & $1.2 \mathrm{E} 3 \#$ & $1.0 \mathrm{E} 3$ & $4.2 \mathrm{E} 1^{*}$ & 10 \\
\hline Ytterbium-167 & 70 & $9.8 \mathrm{E} 6$ & $>\mathrm{E} 9 \|$ & $3.6 \mathrm{~B} 5$ & $1.5 \mathrm{E} 4^{\star}$ & 1000 \\
\hline Ytterbium-169 & 70 & $8.2 \mathrm{E} 1^{\star}$ & $1.8 \mathrm{E} 2 \#$ & $3.6 \mathrm{E} 2$ & $1.9 \mathrm{E} 2$ & 10 \\
\hline Ytterbium-175 & 70 & $3.7 \mathrm{E} \mathrm{2*}$ & $1.1 \mathrm{E} 3 \#$ & $1.6 \mathrm{~B} 3$ & $1.1 \mathrm{E} 3$ & 100 \\
\hline Ytterbium-177 & 70 & $1.0 \mathrm{E} 5$ & $>\mathrm{Bg}$ & $2.6 \mathrm{E} 4$ & $2.2 \mathrm{E} \mathrm{3*}$ & 1000 \\
\hline Ytterbium-178 & 70 & $7.8 \mathrm{E} 4$ & $>$ B $9 \#$ & $2.1 \mathrm{E} \mathrm{4*}$ & - & 1000 \\
\hline Yttrium-86m & 39 & $2.4 \mathrm{E} 5$ & v.18. & $2.6 \mathrm{~B} 4$ & $3.9 \mathrm{E} \mathrm{3*}$ & 1000 \\
\hline Yttrium-86 & 39 & $6.7 \mathrm{E} 2$ & v. 18 . & 1.683 & $2.3 \mathrm{E} 1^{*}$ & 10 \\
\hline Yttrium-87 & 39 & $2.9 \mathrm{E} 2$ & v.18. & $1.6 \mathrm{E} 3$ & $5.1 \mathrm{E} 1^{*}$ & 10 \\
\hline Yttrium-88 & 39 & $3.3 \mathrm{E} 1$ & v. 18 . & $1.0 \mathrm{E} 2$ & $1.4 \mathrm{E} 1 *$ & 10 \\
\hline
\end{tabular}




\begin{tabular}{|c|c|c|c|c|c|c|}
\hline Radionuclide : & $\begin{array}{r}\text { Atom. } \\
\text { No. }\end{array}$ & $\begin{array}{l}\text { Ingestion } \\
\text { (food) }\end{array}$ & $\begin{array}{l}\text { Release Values } \\
\text { Ingestion } \\
\text { (water) }\end{array}$ & $\begin{array}{l}(\mathrm{Ci}) \\
\text { Inha- } \\
\text { lation }\end{array}$ & $\begin{array}{l}\text { Direct } \\
\text { Exposure }\end{array}$ & $\begin{array}{c}\text { Final } \\
R Q(C i) \\
-\end{array}$ \\
\hline Yttrium-90m & 39 & $2.4 E 4$ & v. 18 . & $5.2 \mathrm{E} 3$ & $3.0 \mathrm{E} 2 *$ & 100 \\
\hline Yttrium-90 & 39 & $7.1 \mathrm{E} 1^{*}$ & v. 18 . & $3.1 \mathrm{E} 2$ & $-\cdots$ & 10 \\
\hline Yttrium-91m & 39 & $1.1 \mathrm{E} 6$ & v. 18 . & $1.0 \mathrm{E} 5$ & $1.4 \mathrm{E} 3 \mathrm{k}$ & 1000 \\
\hline Yttrium-91 & 39 & $1.8 \mathrm{E} 1^{*}$ & v. 18 . & $5.2 \mathrm{E} 1$ & $1.0 \mathrm{E} 4$ & 10 \\
\hline Yttrium-92 & 39 & $8.1 \mathrm{E} 3^{3}$ & v. $l_{8}$. & $4.1 \mathrm{E} 3$ & $7.0 E 2 *$ & 100 \\
\hline Yttrium-93 & 39 & $9.6 \mathrm{E} 2$ & v. 18 . & $1.0 \mathrm{E} 3$ & $8.8 \mathrm{E} \mathrm{2*}$ & 100 \\
\hline Yttrium-94 & 39 & $6.1 \mathrm{E} 5$ & $v .18$. & $4.1 \mathrm{E} 4$ & $1.4 E 3 x$ & 1000 \\
\hline Yttrium-95 & 39 & $2.2 \mathrm{E} 6$ & v. 18 . & $5.2 \mathrm{E} 4$ & $3.1 \mathrm{E} \mathrm{3*}$ & 1000 \\
\hline Zinc -62 & 30 & $1.0 \mathrm{E} 3$ & $5.7 \mathrm{E} 7 \#$ & $1.6 \mathrm{E} 3$ & $2.6 \mathrm{E} \mathrm{2*}$ & 100 \\
\hline Zinc-63 & 30 & $2.9 \mathrm{E} 5$ & $>$ E $9 \|$ & $3.6 \mathrm{E} 4$ & $7.1 \mathrm{E} \mathrm{3 \star}$ & 1000 \\
\hline Zinc- 65 & 30 & $1.2 \mathrm{E} I^{\star}$ & $3.0 E\}$ & $1.6 E 2$ & $6.4 \mathrm{E} 1$ & 10 \\
\hline Zinc-69m & 30 & $2.7 \mathrm{E} 3$ & $4.4 \mathrm{E} 6 \#$ & $3.6 \mathrm{E}^{3}$ & $1.5 \mathrm{E} \mathrm{2*}$ & 100 \\
\hline Zinc -69 & 30 & $5.7 \mathrm{E} 5$ & $>\mathrm{E} 9 \|$ & $5.2 E 4^{*}$ & $2.0 \mathrm{E} 8$ & 1000 \\
\hline Zinc-71m & 30 & $1.4 \mathrm{E} 4$ & $>$ E 9 & $1.0 \mathrm{E} 4$ & $1.1 \mathrm{E} \mathrm{2 \star}$ & 100 \\
\hline Zinc-72 & 30 & $2.3 \mathrm{E} \mathrm{2*}$ & $2.5 \mathrm{E} 3 \|$ & $5.2 \mathrm{E} 2$ & $3.1 \mathrm{E} 2$ & 100 \\
\hline Zirconium-86 & 40 & $6.0 \mathrm{E} 2$ & v.lg. & $1.0 \mathrm{E} 3$ & $2.2 \mathrm{E} \mathrm{2*}$ & 100 \\
\hline Zirconium-88 & 40 & $1.4 \mathrm{E} 2$ & v. 18 . & $1.0 \mathrm{E} 2$ & $9.6 \mathrm{E} 1^{*}$ & 10 \\
\hline Zirconium-89 & 40 & $3.0 \mathrm{E} 2$ & v.lg. & $1.0 \mathrm{E} 3$ & $1.6 \mathrm{E} \mathrm{2*}$ & 100 \\
\hline Zirconium-93 & 40 & $3.0 \mathrm{E} 1$ & v.1g. & $3.1 \mathrm{E} 0 *$ & - & 1 \\
\hline Zirconium-95 & 40 & $3.5 \mathrm{~B} \mathrm{1*}$ & v. 18 . & $5.2 \mathrm{E} 1$ & $5.0 E 1$ & 10 \\
\hline Zirconium-97 & 40 & $3.6 \mathrm{E} 2$ & v.18. & $5.2 \mathrm{E} 2$ & $6.9 \mathrm{E} 1^{*}$ & 10 \\
\hline
\end{tabular}


\& The adfusted $R Q$ of one curie applies to all radionuclides not otherwise 1 isted. Whenever the RQs found in 40 CFR Part 302.4 and this appendix are in conflict, the lowest RQ shall apply. For example, uranyl acetate and uranyl nitrate have adjusted RQs shown in $40 \mathrm{CFR}$ Part 302.4 of 100 pounds, equivalent to about onetenth of the RQ level for uranium-238 listed in this appendix.

E Exponent to the base 10. For example, $1.3 \mathrm{E} 2$ is equal to 130 while $1.3 \mathrm{E} 3$ is equal to 1300 .

* Indicates the lowest release value for the specific radionuclide; this value is used to determine the proposed RQ group.

v.lg. Indicates that the sorption coefficient is greater than zero and the release value is much greater than that for other pathways.

\# A value for the sorption coefficient of this radionuclide was unavailable and the value is conservatively assumed to be equal to zero.

-. No gamma rays are emitted or the gamma rays which are emitted have gamma ray energies of less than $0.07 \mathrm{MeV}$ and are strongly attenuated in air. No release value for the direct exposure pathway was calculated.

m Signifies a nuclear isomer which is a radionuclide in a higher energy metastable: state relative to the parent isotope. :

$+\quad$ The release value was calculated assuming submersion in an airborne cloud. The derived air concentration (DAC) is used to estimate the release value for the specific radionuclide.

na An annual limit of intake (ALI) for either ingestion or inhalation (or both) was unavailable for this radionuclide.

>E9 The calculated release value for this pathway is greater than one billion curies.

NOTE

In order to determine the final RQ for a radionuclide in units of becquerel, multiply the number of curies by $3.7 \mathrm{E} 10$ ( 1 curie is equal to $3.7 \mathrm{E} 10$ becquerel). 
This page intentionally left blank.

$E-34$ 


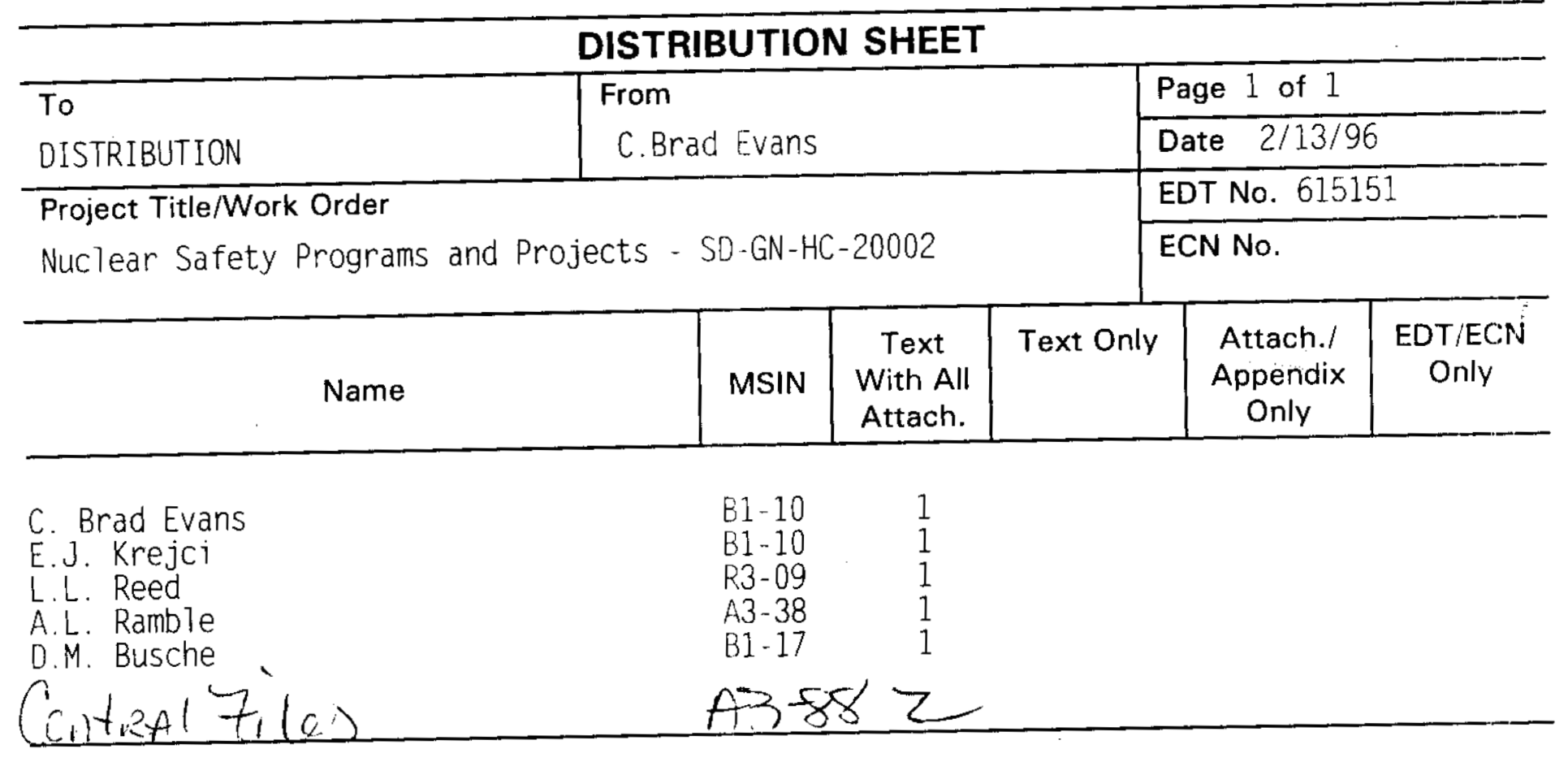

